



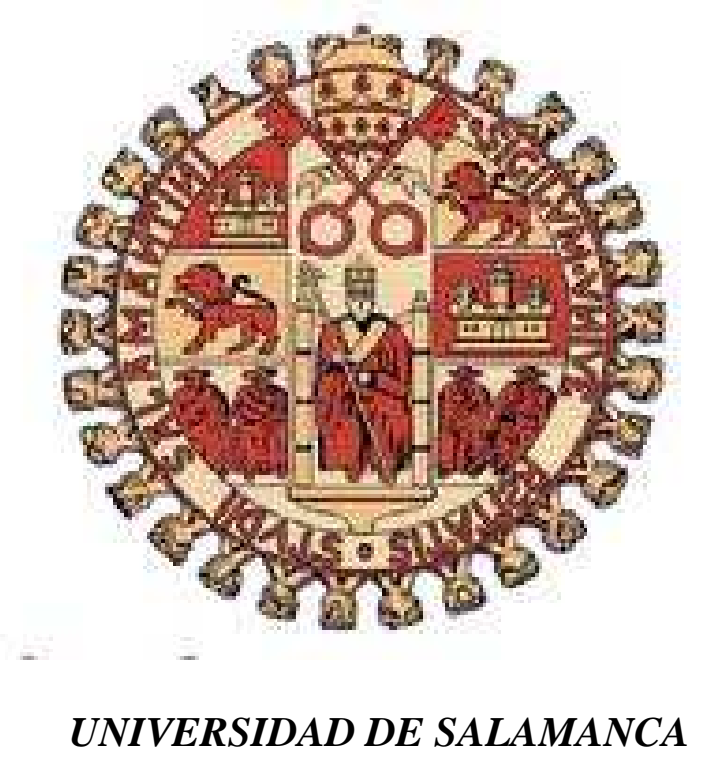

EL ARCHIVO QUE PERDÍA LOS PAPELES

EL ARCHIVO DE LA GUERRA CIVIL SEGÚN EL FONDO DOCUMENTAL DE LA DELEGACIÓN NACIONAL DE SERVICIOS DOCUMENTALES

TESIS DOCTORAL

JOSÉ TOMÁS VELASCO SÁNCHEZ

MMXVII 

EL ARCHIVO QUE PERDÍA LOS PAPELES

\section{EL ARCHIVO DE LA GUERRA CIVIL SEGÚN EL FONDO DOCUMENTAL DE LA DELEGACIÓN NACIONAL DE SERVICIOS DOCUMENTALES}

TESIS DOCTORAL DIRIGIDA POR LUIS HERNÁNDEZ OLIVERA

PROGRAMADE DOCTORADO EN INFORMACIÓN Y DOCUMENTACIÓN 

Los dioses no han revelado cada cosa desde el primer momento sino que el hombre con su paciente investigación lo descubre.

JENÓFANES 



\section{ÍNDICE GENERAL}

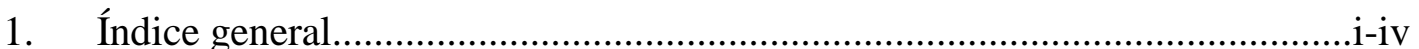

2. Índice de figuras y tablas..................................................................

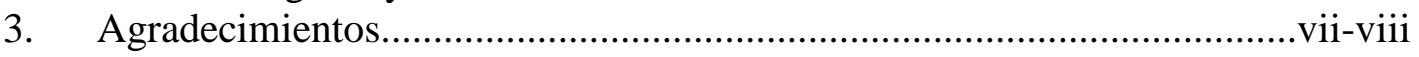

\section{Capítulo 0}

Introducción

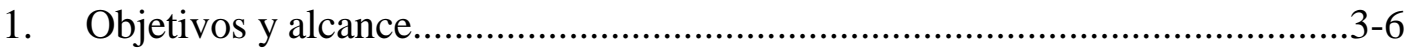

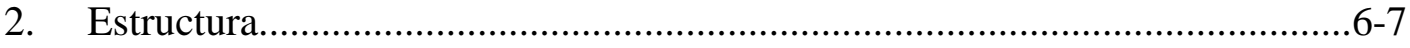

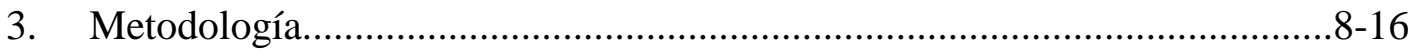

3.1. Búsqueda e inventario de los materiales utilizados...........................8-15

3.1.1. Fuentes archivísticas........................................................9-15

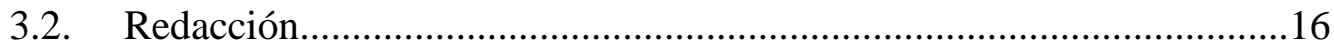

3.3. Cuestiones formales.......................................................................16

4. Estado de la cuestión...........................................................................17-19

\section{Capítulo 1}

La organización franquista: las instituciones encargadas de la recuperación de documentos........................................................................................................21-37

1. Organización del Estado provisional franquista.......................................25-27

2. Organización para la recuperación de documentos del enemigo..................27-32

2.1. La Oficina de Investigación y Propaganda Anticomunista.............27-30

2.2. La Delegación Nacional de Asuntos Especiales..............................31-32

3. La Administración del Estado posbélico: la reforma de 1938.....................32-36

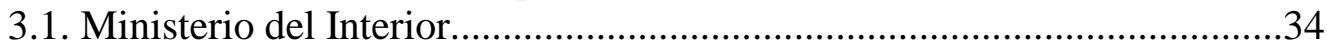

3.2. La Delegación del Estado para Recuperación de Documentos..............35-36

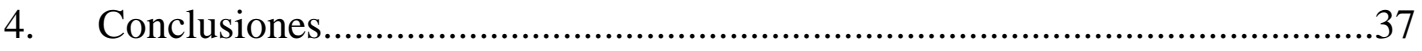




\section{Capítulo 2}

1. La Dirección del Archivo: Marcelino de Ulibarri y Eguílaz, primer Director

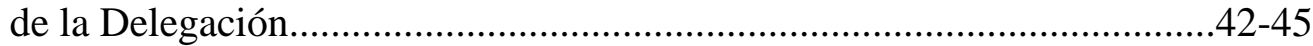

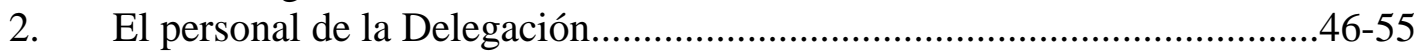

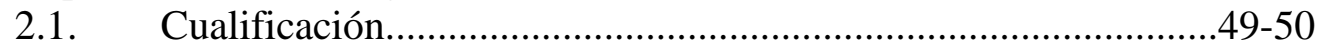

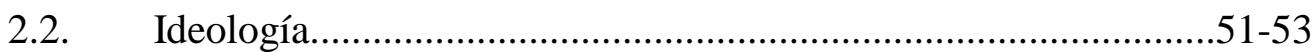

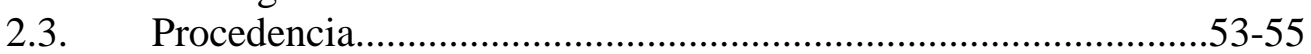

3. Servicios a los trabajadores: el alojamiento del personal de la Delegación.........................................................................................56-58

4. El perfil del archivero que trabajó en la Delegación......................................59

\section{Capítulo 3}

La sede de la Delegación. El edificio de San Estanislao de Kostka......................61-77

1. El edificio: El noviciado de San Estanislao de Kostka.............................65-70

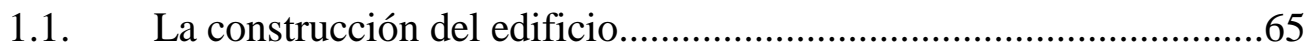

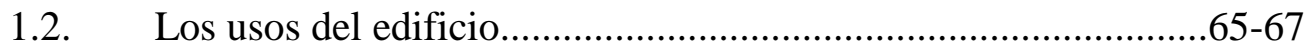

1.3. La instalación del archivo en el edificio...................................67-69

1.4. Ventajas que presentaba el edificio para la instalación del

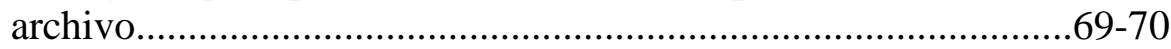

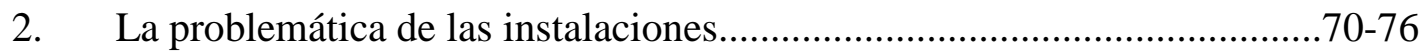

2.1. El sistema de desagüe..............................................................70-71

2.2. La instalación eléctrica............................................................ 71

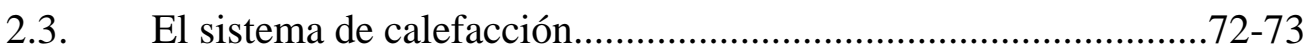

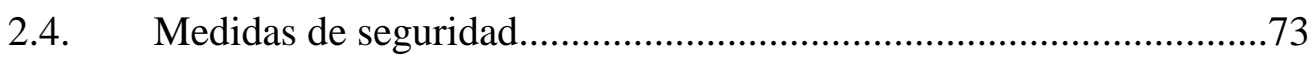

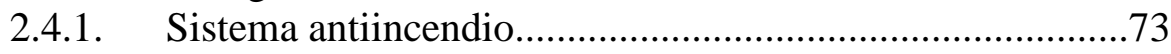

2.4.2. El sistema de vigilancia.........................................74-76

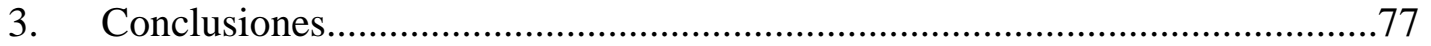

\section{Capítulo 4}

La metodología archivística de la Delegación.

1. La requisición de documentos.

1.1. Metodología de las requisiciones de documentos. Consideraciones generales

1.2. Un aspecto esencial en la requisición de documentos: las

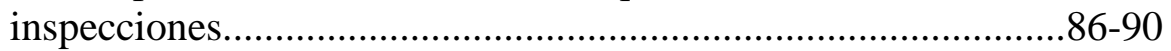

1.2.1. Algunas disfunciones producidas en las inspecciones....89-90

1.3. El transporte de la documentación...........................................90-92

1.3.1. Medios de transporte....................................................91-92

1.3.1.1 Por ferrocarril.......................................................91

1.3.1.2 Por carretera...................................................91-92

1.3.1.3 Enlaces de la Guardia Civil..................................92

1.4. Las organizaciones a las que se incautó la documentación...........92-95 
2. El coordinador de las incautaciones.

95-97

3. Los equipos de recuperación de documentos

3.1. Requisitos para formar parte de los equipos de recuperación de documentos.... .98

3.2. Operativa de los equipos de recuperación de documentos...........98-99

3.3. Aportación de ayuda local a los equipos de recuperación de documentos.

4. La red de archivos de la Delegación.

99-107

5. La clasificación documental llevada a cabo en la Delegación.

$108-112$

6. Instalación de la documentación en la Delegación. El instrumento clave: el legajo y expediente personal.

7. Finalidad última: la creación del fichero general de la Delegación.....113-122

7.1. Sobre la ficha. 113-115

7.2. Sobre los ficheros antropométricos: el ejemplo del fichero central del gabinete antropométrico de la prisión celular de Madrid...115-117

7.3. La explotación de la información: el fichero general de la Delegación......

117-122

8. La Delegación y su relación con las autoridades archivísticas 122-124

9. Balance de los trabajos de la Delegación desde su creación en abril de 1938.

124-126

10. Conclusiones

126-127

\section{Capítulo 5}

Las agrupaciones documentales de la Delegación............................................129-196

1. Las requisiciones

132-189

1.1. La requisición en Alicante: PS-Alicante.

$132-134$

1.2. Las formación de PS-Aragón

1.3. La requisición en Cataluña.

1.3.1. PS-Barcelona.

140-146

1.3.2. PS-Barcelona Generalidad.

$146-147$

1.3.3. PS-Israelita "Agudad Ahim" de Barcelona.

1.4. La formación de PS-Bilbao $149-150$

1.5. La requisición en Cádiz: PS-Cádiz.

1.6. La formación de PS-Cartagena.

$152-153$

1.7. La requisición en Castellón: PS- Castellón

$.154-160$

1.8. La formación de PS- Extremadura 160-168

1.9. La requisición en Gijón: PS-Gijón................................................169

1.10. La formación de PS-Jaén...........................................................170-171

1.11. La requisición en Lérida: PS-Lérida..........................................171-177

1.12. La formación de PS-Madrid.....................................................177-180

1.13. La requisición en Santander: PS-Santander...............................180-181

1.14. La formación de PS-Valencia..............................................181-186

1.15. La requisición en Vinaroz: PS-Vinaroz....................................186-189

2. La requisición realizada por los militares: PS-Militar o Serie Militar...189-192

3. Conclusiones.

192-196 
Fuentes

$205-216$

Fuentes archivísticas... $205-208$

Fuentes jurídicas

$208-210$

Fuentes hemerográficas.

.211

Referencias bibliográficas. $.211-216$ 


\section{Índice de figuras y tablas}

0.1. Denominación de los fondos del Archivo General de la Guerra Civil Española, según su actual árbol de peticiones $.12-14$

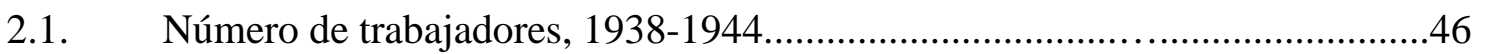

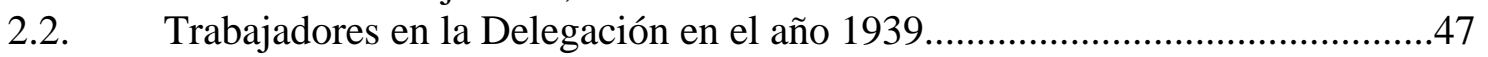

2.3. Grado de temporalidad de la relación laboral...............................................48

2.4. Formación del personal de la Delegación.....................................................49

2.5. Tipos de estudios superiores realizados por el personal de la Delegación........50

2.6. Ideología política del personal de la Delegación............................................51

2.7. Partidos políticos en los que militaron los trabajadores de la Delegación.......52

2.8. Procedencia del personal de la Delegación..................................................53

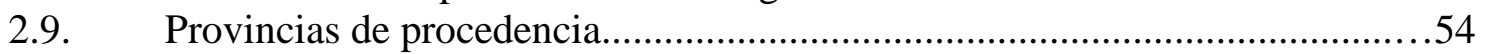

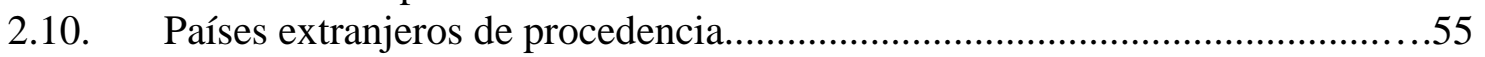

3.1. Delegación del Estado para Recuperación de Documentos o Archivo central de Salamanca. Edificio de San Estanislado de Kostka. Paseo de San Antonio, s/n.

4.1. Sedes de la Delegación y depósitos documentales.

4.2. Delegación del Estado para Recuperación de Documentos o Archivo central de Salamanca. Edificio de San Estanislado de Kostka. Paseo de San Antonio, s/n.

4.3. Delegación en Barcelona. Calle Montaner, núm. 264....................................102

4.4. Delegación en Bilbao. Edificio de la Bolsa. Calle Pelota, núm. 10..............102

4.5. Castellón. Depósito documental. Plaza de la Paz, núm. 8...............................103

4.6. Delegación en Don Benito (Badajoz). Edificio de la antigua Escuela de Artes y Oficios y de la Escuela Elemental de Trabajo. Calle Torres Isunza, núm.

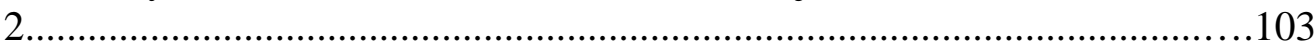

4.7. Lérida. Depósito documental. Plaza de Cervantes, núm. 15...........................104

4.8. Delegación en Madrid. Calle Manuel Silvela, núm. 4..................................104

4.9. Madrid. Depósito documental. Calle Santa Engracia, núm. 7.......................105

4.10. Delegación en Valencia. Calle Luis Vives, núm. 3 .....................................105

4.11. Valencia. Depósito documental. Gobierno militar. Calle del Justicia, número

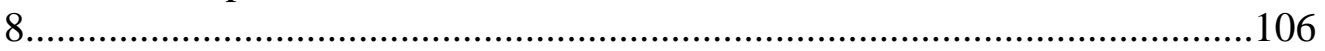

4.12. Valencia. Depósito documental. Casa de la Misericordia (edificio derribado en 1949). Antigua plaza de San Miguel, número 4.........................................106

4.13. Sevilla. Cuartel General del general Queipo de Llano. Plaza de Gavidia,

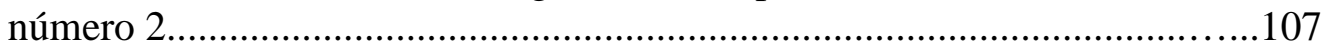

4.14. Fichero General. Ficheros de madera y de metal............................................119

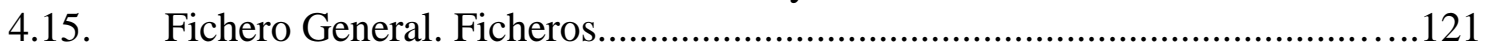


5.1. 16.02.1938. Expedición requisitoria. Itinerario Daroca-Argente-VisiedoPerales de Alfambra-Alfambra................................................................136

5.2. 23, 24 y 25 de febrero de 1938. Expediciones requisitorias. Equipo de Queralt. Itinerario Teruel-Tortajada-Villalba Baja-Celadas......................................137

5.3. 23, 24 y 25 de febrero de 1938. Expediciones requisitorias. Equipo de Martín Sastre. Itinerario Teruel-Cella-Villarquemado-Santa Eulalia del CampoCaminreal-Vivel del Río Martín.

5.4. Municipios barceloneses que enviaron documentación a la Delegación.143-44

5.5. Municipios gerundenses que enviaron documentación a la Delegación........145

5.6. Municipios tarraconenses que enviaron documentación a la Delegación.....146

5.7. Ingreso de la documentación la Generalidad de Cataluña en la Delegación..147

5.8. Junio de 1938. Expediciones requisitorias. Itinerario Castellón-GraoVillarreal-Nules-Benicasin-Sierra Egarcerán...........................................156

5.9. 22.07.1938. Expedición requisitoria. Equipo de Fuentes. Itinerario CastellónHigueras-Benafer.

5.10. 4.07.1938. Expediciones requisitorias. Itinerario Castellón-Fanzara-VallatLudiente-Zucaina.................................................................................158

5.11. 30.07.1938. Expedición requisitoria. Equipo de Aizcorbe. Itinerario Don Benito-Villanueva de la Serena-Medellín-La Haba......................................161

5.12. Del 28.07.1938 al 07.08.1938. Expediciones requisitorias. Localidades pacenses donde fueron realizados registros...............................................162

5.13. Documentación requisada en los municipios de la provincia de Badajoz.....163

5.14. 19.08.1938. Expediciones requisitorias. Itinerario Don Benito-Helechal-La

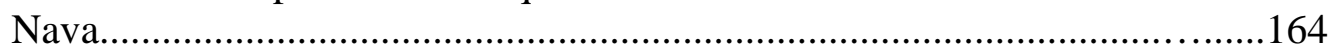

5.15. 20.08.1938. Expediciones requisitorias. Itinerario Don Benito-BelalcázarPuebla de Alcocer-Casas de Don Pedro........................................................165

5.16. 21.08.1938. Expediciones requisitorias. Itinerario Don Benito-Cabeza de Buey-Almorchón..................................................................................165

5.17. 07.06.1938. Expedición requisitoria. Equipo de Salinas. Itinerario AltorricónAlbelda-Alcarrás-Alguerri-Balaguer.. 172

5.18. 08.06.1938. Expedición requisitoria. Equipo de Salinas. Itinerario AltorricónVillanueva de Alpicat -Torrefarrera-Roselló-Alguaire-Almenar. 173

5.19. Expedición requisitoria. Equipo de Salinas. Itinerario Altorricón -Vilanova de Segriá-Torregrosa-Benavet-Portella-Albesa. 174

5.20. 13.06.1938. Expedición requisitoria. Equipo de Salinas. Itinerario AltorricónOs de Balaguer-Avellanes-Ager-Tremp.

5.21. 16.05.1939. Expediciones requisitorias. Itinerario Valencia-BenifayóVillanueva de Castellón-Puebla del Duc-Oliva-Bocairente -Godella-DomeñoZarra. 182

5.22. 16.05.1939. Expediciones requisitorias. Itinerario Valencia-Dos AguasBuñol 183

5.23. 31.05.1938. Expedición requisitoria. Equipo de Salinas. Itinerario VinarozAres del Mestre-Benasal-Culla.....................................................................188

5.24. Equipos de recuperación de documento y sus áreas de actuación..................193

5.25. Envío de la documentación a la Delegación.................................................195 


\section{AGRADECIMIENTOS}

En primer lugar, quiero mostrar mis más profundo y sincero agradecimiento a mis padres, mi principal apoyo: gracias por estar siempre ahí.

En segundo lugar, en este apartado de agradecimientos, deseo expresar mi agradecimiento a Luis HERNÁNDEZ OLIVERA, director de esta tesis doctoral por sus orientaciones y apoyo hasta el final.

En este apartado, no me quiero olvidar, tampoco, de la también profesora del Departamento de Biblioteconomía y Documentación de la Universidad de Salamanca, Rosa López Alonso, que me facilitó la consulta de la primera edición del Manuel d'Archivistique. Théorie et practique des Archives publiques en France (Paris, S.E.V.P.E.N. Imprimiere Nationale, 1970.

Asimismo, a través de estas breves líneas, quiero expresar mi agradecimiento a todos los directores de los diferentes archivos y centros de documentación, cuyos fondos, para la realización de esta tesis doctoral, he consultado.

A Manuel Melgar Camarzana, director, desde 2011, del Archivo General de la Guerra Civil Española del Centro Documental de la Memoria Histórica; a partir de septiembre de ese mismo año 2011, director en funciones, también, simultaneándolo con su puesto de director del Archivo, del Centro Documental de la Memoria Histórica; y, desde junio de 2013, actual y únicamente director del Centro Documental de la Memoria Histórica. Y, a través del mismo, mi agradecimiento a todo el personal del Centro. 
También, deseo manifestar mi agradecimiento a Miguel Ángel JARAMILLO GUERREIRA, director del Archivo de la Universidad de Salamanca y ex-director del Archivo General de la Guerra Civil Española, y a Carmen Rosell García, jefa del Archivo Central de la Universidad de Salamanca, por la consulta de los fondos de los mismos. Y, finalmente y en este mismo sentido, deseo manifestar mi agradecimiento a Ana BLANCO ENCINAS, directora de la Hemeroteca de la Universidad de Salamanca, ubicada en la Biblioteca de Santa María de los Ángeles, por su amabilidad mostrada durante la consulta de los fondos de la Hemeroteca. 
Capítulo 0

Introducción 
El Archivo que perdía los papeles. El Archivo de la Guerra Civil según el fondo documental de la DNSD 


\section{Objetivos y alcance.}

El presente trabajo tiene como objetivo general presentar la historia de la Delegación del Estado para Recuperación de Documentos, de abril de 1938 a septiembre de 1944. Se trata, por tanto, de un trabajo de la historia de un archivo en sus orígenes, el conocido como Archivo de Salamanca. No es, en ningún caso, un trabajo académico dedicado a la Guerra Civil, el franquismo y la memoria histórica, aunque la Guerra Civil y el franquismo constituyan el contexto histórico-político de los orígenes del Archivo.

Para definir el tema de forma más precisa se fijaron los siguientes objetivos específicos:

$1^{\text {o }}$. Presentar los antecedentes históricos de los órganos que precedieron a la Delegación del Estado para Recuperación de Documentos, la Oficina de Investigación y Propaganda Anticomunista y la Delegación Nacional de Asuntos Especiales. Y, conocer, con exactitud, la fundación de la Delegación del Estado para Recuperación de Documentos, origen del actual Archivo General de la Guerra Civil Española, y su ubicación en el organigrama de la Administración General del recién nacido nuevo Estado franquista.

$2^{\circ}$. Ofrecer el tratamiento archivístico aplicado a la documentación de la Delegación, desde su ingreso, las incautaciones, hasta la elaboración de fichas personales, operación con la que culminaba el proceso de tratamiento, pasando por la 
valoración, clasificación y ordenación de la documentación enviada a él por diferentes vías.

$3^{\circ}$. Descubrir cómo se conformaron todos los fondos originarios del Archivo, los fondos de la actual Sección Político-Social del mismo.

$4^{\circ}$. Estudiar los recursos humanos con los que contó el Archivo, el personal de la Delegación, centrándonos en su nivel de cualificación, que llevó a cabo la aplicación del tratamiento archivístico.

$5^{\circ}$. Describir el edificio donde se instaló la Delegación en el que se custodió la documentación requisada y se realizaron trabajos archivísticos.

Se desea, con esta tesis doctoral, contribuir al desarrollo de los estudios dedicados a la historia de los centros o archivos, pertenecientes, dentro del sistema archivístico español, al sistema archivístico estatal, gestionados por el Ministerio de Cultura (o la Secretaría de Estado de Cultura del Ministerio de Educación, Cultura y Deporte). Hasta la fecha, no se ha escrito ninguna monografía, o libro, dedicado a la historia del Archivo General de la Guerra Civil Española en su periodo fundacional, de 1938 a 1944.

Se pretende que esta tesis sea de utilidad para los numerosos investigadores que, con leal periodicidad anual, sobre todo en periodo estival, acuden a Salamanca, para iniciar o continuar con sus investigaciones, y que, pueda explicar cómo se han realizado, en el Archivo, muchas de las citadas investigaciones, dedicadas, prioritariamente, a la Guerra Civil, el franquismo y la memoria histórica.

En este sentido, se aspira a que este estudio sirva para dar a conocer, no sólo entre los investigadores sino entre la ciudadanía, la riqueza documental custodiada en el Archivo, compatible con la política de difusión realizada por la Subdirección General de Archivos Estatales, a través de las exposiciones realizadas por la misma. En definitiva, acercar a la población, salmantina o no, al Archivo.

Además, este estudio, al que se debe la primera parte del título, puede aportar algo de luz al caos informativo provocado por la polémica conocida como los papeles de Salamanca, puesto que sólo el conocimiento del pasado puede servir para entender el presente. Como suele decirse, los orígenes, los principios, son la mitad de una historia. 
Finalmente, se desea que esta tesis doctoral contribuya a disponer de una historia, a las víctimas del franquismo, que les permita conocer que la represión y depuración franquistas estuvieron intrínsecamente ligadas al tratamiento archivístico de la documentación, y la información contenida en ella, que llegó al Archivo de Salamanca.

Los objetivos formulados con anterioridad se han visto limitados por los problemas que implica un estudio de carácter histórico. Por consiguiente, en este momento del discurso, es necesario apuntar las dificultades que se presentaron durante el periodo de investigación:

A. El propio tema, su elección y acotación del mismo. En un principio, se planteó la posibilidad de realizar una tesis doctoral dedicada a toda la historia del Archivo General de la Guerra Civil Española, desde su fundación hasta el presente, que incluyera la historia del Archivo en el periodo democrático, desde 1979 hasta 2011. Después, nos propusimos enfocar la tesis a la realización de una historia del Archivo, ceñida estrictamente al periodo franquista, y en relación con la historia de España de la época, la Guerra Civil y el franquismo, como marco de la misma. Esto último, el estudio de ese periodo de la historia de España, nos hubiera desviado de lo importante: el estudio de la historia del propio Archivo. Finalmente, el tema estudiado quedó limitado a la historia de los orígenes del Archivo.

B. El trabajo de investigación. La documentación consultada, para reconstruir sólo los seis primeros años de historia del Archivo, y para cumplir, con ello, con los objetivos específicos propuestos, se caracteriza por:

B1. Ser enorme. Se han tenido que consultar 723 cajas y, por consiguiente, una cantidad innumerable de legajos y expedientes.

B2. Su falta de interés. Muchos de los documentos leídos, incorporados a los citados legajos, no tenían absolutamente nada que ver con el tema de la tesis, pero su lectura resultaba obligada, para poder encontrar información de interés para la misma. 
B3. Ser de difícil consulta. Aunque la mayor parte de la documentación consultada tiene sólo unos 70 años de antigüedad, el mal estado de conservación en el que se encontraba, el papel, la tinta, etc., hacía difícil, en algún caso, su lectura.

C. El carácter novedoso del estudio. Respecto a la historia de los orígenes del Archivo, escasean los estudios previos, careciéndose de trabajos sobre el mismo -no se ha escrito ninguna monografía- exceptuándose algunos artículos dedicados al Archivo de manera geneneralista.

A pesar de estas limitaciones, se ha podido, en la tesis, reconstruir la historia de la Oficina de Investigación y Propaganda Anticomunista, de la Delegación Nacional de Asuntos Especiales, de los fondos de la Sección Polítco-Social y el tratamiento archivístico al que fueron sometidos, el personal que trabajó en el Archivo, la historia de su sede, en definitiva, la historia de la Delegación Especial para Recuperación de Documentos en sus primeros seis años.

En conclusión, las limitaciones que se han encontrado para la consecución de los objetivos formulados son los propios de toda investigación realizada en el ámbito de conocimiento de las ciencias sociales y humanas, en general, y de la especialidad histórica en particular, que, en el caso de esta tesis, se basa prioritariamente en fuentes primarias o de archivo.

\section{Estructura.}

Este trabajo, dedicado a la Delegación para Recuperación de Documentos y, como consecuencia, a la historia de los orígenes del Archivo General de la Guerra Civil, se organiza en cinco capítulos, a los que hay que añadir el capítulo introductorio, las conclusiones, las fuentes y las referencias bibliográficas.

En la introducción, se exponen los objetivos, la estructura y la metodología seguida en la realización de este estudio. También, se desarrolla un estado de la cuestión.

Como ya se ha comentado, esta tesis doctoral se compone de cinco capítulos: 
$1^{\circ}$. El capítulo primero se dedica a los órganos precedentes de la Delegación del Estado para Recuperación de Documentos: la Oficina de Investigación y Propaganda Anticomunista y la Delegación Nacional de Asuntos Especiales, creados, en Salamanca, en el seno del primer Estado provisional franquista.

$2^{\circ}$. En el capítulo segundo, se estudia al personal de la Delegación, que trabajó en la misma, tratando archivísticamente la documentación requisada. También, en este capítulo, se realiza un bosquejo, creemos que bastante definitivo, del primer director de la Delegación del Estado para Recuperación de Documentos, y, por tanto, del Archivo salmantino, Marcelino de Ulibarri y Eguílaz, de 1938 a 1944.

$3^{\circ}$. El capítulo tercero está dedicado al edificio de San Estanislao de Kostka, primera sede de la Delegación del Estado para Recuperación de Documentos, y, por tanto, del Archivo en Salamanca. En este capítulo, se explican las condiciones favorables del edificio, que hicieron posible la instalación de la Delegación en el mismo.

$4^{\text {o }}$. El importante capítulo cuarto se dedica a explicar la no muy compleja, pero eficaz, para la finalidad represora que se perseguía, metodología archivística aplicada en el tratamiento de la documentación incautada, y de la información, que llegaba a la Delegación en Salamanca. Éste es uno de los principales objetivos, y también objeto de estudio, de esta tesis doctoral. Se trata de una archivística aplicada, práctica e inmediata.

$5^{\circ}$. Finalmente, en el capítulo quinto, se estudian los fondos originarios, que constituyen la Sección Político-Social del actual Archivo General de la Guerra Civil de Salamanca.

A pesar de no constituir un objetivo específico inicial, poner en valor y divulgar la riqueza documental del Archivo, y aproximar el conocimiento de esa riqueza documental a la ciudadanía, lo cual realiza muy acertadamente la Subdirección General de Archivos Estatales, a través de sus políticas de adquisición de documentos así como de las exposiciones realizadas por el departamento de difusión del Archivo, impulsaron la redacción de este último capítulo. En definitiva, acercar a la ciudadanía, alejada del conocimiento de los fondos que conforman el Archivo General de la Guerra Civil, es la finalidad de este capítulo.

Finalmente, se presentan las conclusiones a las que se ha llegado en esta tesis doctoral. 


\section{Metodología.}

El proceso de investigación se ha desarrollado conforme a una serie de pautas que se corresponden con los criterios requeridos por la metodología histórica. La investigación se realizó en diferentes fases, de las que señalamos las dos principales. Una primera, de conocimiento del material de estudio, en la que se realizó un vaciado de las fuentes archivísticas, en el propio Archivo General de la Guerra Civil de Salamanca. Y, una segunda fase de estudio y análisis de la escasa bibliografía relacionada con la historia del Archivo para el periodo 1938 a 1944. A su explicación, dedicamos los siguientes apartados.

\subsection{Búsqueda e inventario de los materiales utilizados.}

La actividad desarrollada, en esta fase, consistió en la obtención de las fuentes archivísticas que podían ser de utilidad para la investigación. Este trabajo se ha elaborado utilizando, básicamente, fuentes de archivo, teniendo en consideración la bibliografía relativa a la historia de los orígenes del Archivo existente, cuyas referencias se han obtenido en los respectivos catálogos de las bibliotecas universitarias de Salamanca y Zaragoza.

Para su análisis, se han agrupado los materiales empleados en diversas clases. Las categorías que se establecieron fueron las siguientes: fuentes archivísticas y bibliográficas. Las bibliográficas se dividen en monografías, revistas y actas de congresos. 


\subsubsection{Fuentes archivísticas.}

Al tratarse de una tesis de carácter histórico, ésta se fundamenta, esencialmente, en fuentes archivísticas. Las fuentes archivísticas fueron tratadas caja a caja, procediendo a un vaciado de la información contenida en cada una de ellas, que nos permitiera obtener los datos de interés para nuestra investigación. La consulta de cada una de las cajas resultó dificultosa a causa de la gran cantidad de documentación existente que no aportaba nada a los objetivos que se querían alcanzar. Fueron consultadas un total de 723 cajas.

Para el capítulo primero, dedicado a conocer la breve historia de los organismos que precedieron a la fundación de la Delegación del Estado para Recuperación de Documentos, la Oficina de Investigación y Propaganda Anticomunista y la Delegación Nacional de Asuntos Especiales, como a conocer la propia fundación de la misma, se consultaron las 22 cajas de la serie Secretaría General-Expedientes Secretaría del fondo Delegación Nacional de Servicios Documentales del Archivo. Además, para encuadrar el Archivo en el seno de la nueva Administración General del Estado franquista, se recurrió a la consulta de fuentes jurídicas, los Boletines Oficiales del Estado del periodo 1936-1938.

El capítulo segundo está dedicado al primer director del Archivo y al personal que tuvo bajo su dirección.

La biografía de Marcelino de Uibarri y Eguílaz se ha podido escribir gracias a la consulta de su expediente de procurador en Cortes, en el Archivo del Congreso de los Diputados, y a la búsqueda de noticias sobre su figura, en las fuentes hemerográficas, que dieron como resultado el hallazgo de datos biográficos del mismo en el diario $A B C$, edición sevillana del periódico en la época. Y, la relación de Ulibarri con el Archivo de la Diputación Foral de Navarra se pudo estudiar gracias a la consulta de los fondos del citado Archivo.

Gran parte del capítulo segundo es el resultado de la aplicación de las técnicas estadísticas a la información sistematizada, procedente del vaciado de las 10 cajas de la 
serie Administración-Expedientes del fondo Delegación Nacional de Servicios Documentales del Archivo General de la Guerra Civil Española.

Las técnicas estadísticas aplicadas están tomadas de la obra de Daniel PEÑA y Juan Romo, Introducción a la Estadística para las Ciencias Sociales (Madrid, McGraw-Hill, 1997), utilizado en el Máster en Análisis Económico del Derecho y las Políticas Públicas que se imparte en la Universidad de Salamanca.

Las técnicas estadísticas se pueden aplicar a todas las ciencias sociales, entre las que se cuentan la política, la economía, el derecho, la sociología y la historia.

El empleo de las técnicas estadísticas recogidas en el citado manual se justifica debido a que dichas técnicas permiten sintetizar y describir las variables cuantitativas discretas, aquellas que, como en el caso que nos ocupa, pueden:

A. Expresarse numéricamente.

B. Contarse, es decir, son el resultado de contar las diferentes cualidades de la población estudiada, el personal del Archivo.

C. Representarse a través de gráficos, histogramas y diagramas de barras.

D. Y, lo que es más importante, permiten extraer conclusiones.

El estudio de la sede del Archivo, el edificio de San Estanislao de Kostka, al que se dedica el capítulo tercero, se pudo realizar tras la consulta de las 22 cajas de la serie Secretaría General-Expedientes Secretaría y de las 63 cajas de la serie SecretaríaCorrespondencia del fondo Delegación Nacional de Servicios Documentales del Archivo General de la Guerra Civil Española.

Para reconstruir el tratamiento que se daba en el Archivo a la documentación, desde su incautación hasta la generación de fichas, al que se dedica el capítulo cuarto, fueron consultadas las 22 cajas de la serie Secretaría General-Expedientes Secretaría y las 63 cajas de la serie Secretaría-Correspondencia del fondo Delegación Nacional de Servicios Documentales del Archivo General de la Guerra Civil Española.

Asimismo, para comprender y explicar cómo fueron creados los fondos en aquella época se consultó el Manuel d'Archivistique del Ministère des Affaires Culturelles. Y, 
también, para entender la utilización de la ficha con fines archivísticos, y la historia y el uso de la ficha en distintas áreas de conocimiento, se consultó la más importante obra existente sobre este tema, la obra de Markus KRAJWESKI, Paper Machines. About Cards \& Catalogs, 1548-1929.

El capítulo quinto está dedicado a la requisición de los fondos originarios del Archivo, resultado de las incautaciones. Para realizar la historia de los orígenes de cada uno de los fondos que forman la actual Sección Político-Social del Archivo, fueron consultadas las 10 cajas de la serie Administración-Expedientes, las 22 cajas de la serie Secretaría General-Expedientes Secretaría y las 63 cajas de la serie AdministraciónCorrespondencia del fondo Delegación Nacional de Servicios Documentales del Archivo. Además, se consultaron las 180 cajas de la agrupación documental PSAlicante, las 145 cajas de PS-Aragón, las 6 cajas de PS-Cádiz, las 60 cajas de PSCartagena, las 37 cajas de PS-Extremadura, las 26 cajas del PS-Jaén, las 65 cajas de PSLérida y las 13 cajas de la agrupación documental de PS-Vinaroz, en busca de información sobre los mismos.

Después de comentar cómo se han empleado las fuentes archivísticas y bibliográficas en la redacción de este trabajo, se hace necesario resaltar la falta de normalización a la hora de citar las fuentes del Archivo General de la Guerra Civil Española en las notas a pie de página.

Durante el periodo de vaciado de las fuentes realizado en el Archivo, la petición manual de las cajas a través de fichas de consulta fue sustituida por un nuevo sistema de petición, lo que supuso un gran inconveniente para la investigación, a la hora de realizar las consultas, de pedir las cajas y, como consecuencia, de citar éstas correctamente en este trabajo. Ello se debió a la implantación de un nuevo árbol en el Intrapares del Archivo. Dicho árbol tenía 141 ramas, que se referían a todos los fondos custodiados: el árbol cambió la denominación de los mismos, y, consiguientemente, el modo de citarlos. Las 141 ramas eran las siguientes: 
El Archivo que perdía los papeles. El Archivo de la Guerra Civil según el fondo documental de la DNSD

\begin{tabular}{|c|l|}
\hline $\mathrm{N}^{\circ}$ & \multicolumn{1}{|c|}{ DENOMINACIÓN DE LOS FONDOS (para su cita) } \\
\hline 1 & AHN-SGC \\
\hline 2 & BIBLIOTECA \\
\hline 3 & BRUNO_ALONSO \\
\hline 4 & CORREOS-CUERPO AUXILIAR \\
\hline 5 & CORREOS-CUERPO_CARTEROS \\
\hline 6 & CORREOS-CUERPO_SUBALTERNOS \\
\hline 7 & CORREOS-CUERPO_TÉCNICO \\
\hline 8 & DNSD-CORRESPONDENCIA \\
\hline 9 & DNSD-EXP._ANTECEDENTES \\
\hline 10 & DNSD-EXP__SECRETARIA \\
\hline 11 & DNSD-PRESIDENCIA \\
\hline 12 & ESTADO_MAYOR \\
\hline 13 & FEDIP \\
\hline 14 & FOTOGRAFÍAS-CAPA \\
\hline 15 & FOTOGRAFIAS-DESCHAMPS \\
\hline 16 & FOTOGRAFİAS-HERMANOS MAYO \\
\hline 17 & FOTOGRAFÍAS-KATI_HORNA \\
\hline 18 & FOTOGRAFÍAS-LEGIÓN_CONDOR \\
\hline 19 & FUENTES_ORALES-LINCOLN \\
\hline 20 & FUENTES_ORALES-MEXICO \\
\hline 21 & HEMEROTECA \\
\hline 22 & OFICINA_TERMC-COMUNISTAS \\
\hline 23 & OFICINA_TERMC-MASONES \\
\hline 24 & PS-ALICANTE \\
\hline 25 & PS-ARAGON \\
\hline 26 & PS-BANDERAS \\
\hline 27 & PS-BARCELONA \\
\hline 28 & PS-BARCELONA_GENERALIDAD \\
\hline 29 & PS-BILBAO \\
\hline 30 & PS-CADIZ \\
\hline 31 & PS-CALENDARIOS \\
\hline 32 & PS-CARTAGENA \\
\hline 33 & PS-CARTELES \\
\hline 34 & PS-CASTELLON \\
\hline 35 & PS-COLECCIÓN_FOTOS \\
\hline 36 & PS-DOCUMENTACION_PARTICULAR \\
\hline 37 & PS-EXTREMADURA \\
\hline 38 & PS-FILATELIA \\
\hline 39 & PS-FOTOGRAFIAS \\
\hline 40 & PS-GIJON_AGA \\
\hline 41 & PS-GIJON_F \\
\hline 42 & PS-GION_G \\
\hline 43 & PS-GIJON_H \\
\hline 44 & PS-GIJON_I \\
\hline 45 & PS-GIJON_J \\
\hline & \\
\hline
\end{tabular}




\begin{tabular}{|c|c|}
\hline 46 & PS-GIJON_K \\
\hline 47 & PS-GIJON_TPJA \\
\hline 48 & PS-INSIGNIAS \\
\hline 49 & PS-JAEN \\
\hline 50 & PS-LAMINAS \\
\hline 51 & PS-LERIDA \\
\hline 52 & PS-MADRID \\
\hline 53 & PS-MADRID_ECHEVARRIETA \\
\hline 54 & PS-MAPAS_PLANOS \\
\hline 55 & PS- NUMISMÁTICA \\
\hline 56 & PS-OBJETOS_VARIOS \\
\hline 57 & PS-PANFLETOS \\
\hline 58 & PS-SANTANDER_A \\
\hline 59 & PS-SANTANDER_C \\
\hline 60 & PS-SANTANDER_CU \\
\hline 61 & PS-SANTANDER_D \\
\hline 62 & PS-SANTANDER_E \\
\hline 63 & PS-SANTANDER_HA \\
\hline 64 & PS-SANTANDER_L \\
\hline 65 & PS-SANTANDER_L_C.E.EUZKADI \\
\hline 66 & PS-SANTANDER_L_C.E. SANTANDER \\
\hline 67 & PS-SANTANDER_M \\
\hline 68 & PS-SANTANDER_O \\
\hline 69 & PS-SANTANDER_OIPA \\
\hline 70 & PS-SANTANDER_VD_T. P.EUZKADI \\
\hline 71 & PS-SELLOS_IMPRONTAS \\
\hline 72 & PS-SERIE_MILITAR \\
\hline 73 & PS-SERIE_MILITAR_ESCUELA_P. \\
\hline 74 & PS-SERIE_MILITAR_PSET \\
\hline 75 & PS-SERIE_MILITAR_TRIBUNALES \\
\hline 76 & PS-TARJETAS_POSTALES \\
\hline 77 & PS-VALENCIA \\
\hline 78 & PS-VALENCIA_AUDIENCIA \\
\hline 79 & PS-VARIA_MILITAR \\
\hline 80 & PS-VINAROZ \\
\hline 81 & DNSD-RECUPERACION-BARCELONA \\
\hline 82 & DNSD-RECUPERACION-MADRID \\
\hline 83 & DNSD-RECUPERACION-SECRETARIA \\
\hline 84 & DNSD-RECUPERACION-VALENCIA \\
\hline 85 & SE-BANDAS \\
\hline 86 & SE-CENTRO_ISRAELITA \\
\hline 87 & SE-CLUBS ROTARIOS \\
\hline 88 & SE-ESPADAS \\
\hline 89 & SE-IGLESIA_EVANGELICA \\
\hline 90 & SE-JOYAS \\
\hline 91 & SE-LIGA_DERECHOS_HOMBRE \\
\hline
\end{tabular}




\begin{tabular}{|c|l|}
\hline 92 & SE-MALLETES \\
\hline 93 & SE-MANDILES \\
\hline 94 & SE-MASONERIA_A \\
\hline 95 & SE-MASONERIA_B \\
\hline 96 & SE-OCULTISMO \\
\hline 97 & SE-PENDONES \\
\hline 98 & SE-ROTARISMO \\
\hline 99 & SE-SELLOS \\
\hline 100 & SE-TEOSOFIA \\
\hline 101 & SE-VARIOS \\
\hline 102 & TERMC \\
\hline 103 & DNSD-SERVICIOS_GENERALES \\
\hline 104 & DNSD-SECCION_ESPECIAL \\
\hline 105 & DNSD-SECCION_POLITICO_SOCIAL \\
\hline 106 & FONDOS_INCORPORADOS \\
\hline 107 & DNSD-OFICINA_TERCM \\
\hline 108 & SÁNCHEZ_CRISTOS \\
\hline 109 & CORREOS \\
\hline 110 & LIGA_MUTILADOS \\
\hline 111 & EXILIO-ARGENTINA \\
\hline 112 & SE-TEOSOFIA-FOTOGRAFIAS \\
\hline 113 & HOJAS_PROPAGANDA \\
\hline 114 & OCUPACIÓN \\
\hline 115 & INCORPORADOS \\
\hline 116 & CUERPO_DE_SEGURIDAD \\
\hline 117 & SE-MASONERIA_B-FOTOGRAFIAS \\
\hline 118 & FOTOGRAFIAS-REPUBLICA \\
\hline 119 & CARLOS_ESPLA \\
\hline 120 & COLECCIÓN_ARMERO \\
\hline 121 & DNSD-ADMINISTRACION \\
\hline 122 & GOBIERNO_MILITAR \\
\hline 123 & SE-MASONERIA_A-FOTOGRAFIAS \\
\hline 124 & EXILIO-MEXICO \\
\hline 125 & DIONISIO_RIDRUEJO \\
\hline 126 & MATERIALES_GRAFICOS \\
\hline 127 & PS-PARTICULAR-FOTOS \\
\hline 128 & PS-FOTOGRAFIAS_PGM \\
\hline 129 & COLECCIÓN_GARCIA-CERDENOO \\
\hline 130 & SEMINARIO_FUENTES_ORALES \\
\hline 131 & ZAFRA \\
\hline 132 & MAPAS \\
\hline & \\
\hline
\end{tabular}

Tabla 0.1. Denominación de los fondos del Archivo General de la Guerra Civil Española, según su actual árbol de peticiones 
Según el nuevo sistema de petición de fondos, las cajas se solicitaban a DNSDADMINISTRACION, DNSD-EXP._SECRETARIA, DNSD-CORRESPONDENCIA y DNSD-PRESIDENCIA. Este sistema no distinguía, en el fondo Delegación Nacional de Servicios Documentales (DNSD), las series Administración A y AdministraciónExpedientes, e inducía a la confusión. Por ello, se prefirió citar las series, desarrollando todo su nombre y siendo lo más específico posible, para poder permitir la verificación de cada consulta realizada en los citados fondos. Así, el sistema de cita empleado va del fondo al expediente:

Fondo. Delegación Nacional de Servicios Documentales (DNSD).

Serie. Cinco series:

- Administración A.

- Administración. Expedientes.

- Secretaría General. Expedientes Secretaría (DNSD-EXP._SECRETARIA).

- Secretaría Correspondencia (DNSD-Correspondencia).

- Presidencia (DNSD-Presidencia).

- Además, de las conocidas como series de procedencia geográfica (PS-Alicante, etc.).

Número de caja. En cada serie, cada caja tiene una signatura específica:

- Cajas de la serie Administración A. Signatura: ADMON - A.

- Cajas de la serie Administración. Signatura: ADMON.

- Cajas de la serie Secretaría General. Expedientes Secretaría. Signatura: S.G.

- Cajas de la serie Secretaría. Correspondencia. Carece de signatura.

- Cajas de las serie Presidencia. Carece de signatura.

Número de legajo. Regularmente, cada caja contiene dos legajos.

Número de expediente. Los expedientes se incluyen en los legajos. 


\subsection{Redacción.}

Para la redacción del texto, se ha utilizado el Diccionario de la Lengua Española de la ReAl ACAdEMia EsPañola (Madrid, RAE \& Espasa Calpe, 2014, 23 a edición) y los siguientes diccionarios especializados de terminología archivística: el Dictionary of Archival Terminology. Dictionne de terminologie archivistique. English and French, with equivalents in Dutch, German, Italian, Russian and Spanish del Consejo Internacional de Archivos (New York, London, Paris, München, Peter Walne \& K.G. Saur, 1988); el Diccionario de Terminología Archivística de la Dirección General de Archivos estatales (Madrid, Ministerio de Cultura, 1993); y el diccionario de Ángel RIESCO TERRERO, titulado Vocabulario científico-técnico de Paleografía, Diplomática y Ciencias afines (Madrid, Barrezo \& Acedo Ediciones, 2003).

\subsection{Cuestiones formales.}

Ese trabajo se ha desarrollado respetando los preceptos que se recogen en la doctrina en la que se regulan las cuestiones formales de presentación de trabajos y tesis doctorales de carácter histórico. En concreto, se han seguido las siguientes obras:

ECO, Umberto., Cómo se hace una tesis doctoral. Técnicas y procedimientos de investigación, estudio y escritura. Barcelona, Gedisa, 1998.

Ballard, Brigid.; Clanchy, John., Cómo se hace un trabajo académico. Guía práctica para estudiantes universitarios. Zaragoza, Prensas Universitarias, 2000.

En resumen, la elaboración de esta Tesis doctoral responde a un sistemático y exhaustivo trabajo de vaciado del fondo Delegación Nacional de Servicios Documentales, depositado en el Archivo General de la Guerra Civil, para encontrar información relativa al propio Archivo, que pudiera reconstruir sus primeros años de historia.

Las referencias bibliográficas siguen el sistema tradicional de citas. 


\section{Estado de la cuestión.}

Sobre la historia de los orígenes del Archivo, del periodo 1938 a 1944, que es de lo que trata esta tesis doctoral, y sobre la historia del Archivo en general, se constata una escasez de trabajos sobre esta materia.

Dicha escasez se extiende al estudio de la historia de los archivos de titularidad estatal, gestionados por el Ministerio de Cultura (o, en su caso, la Secretaría de Estado de Cultura), hermanados con el Archivo General de la Guerra Civil Española, que forman parte del sistema archivístico español y a los que se han dedicado pocos trabajos. Entre ellos, cabe destacar la obra de José Luis RoDRíGUEZ DE DIEGO, Director del Archivo General de Simancas de 1998 a 2009, Instrucción para el gobierno del Archivo de Simancas. Año 1588 (Madrid, Ministerio de Cultura, 1989, segunda edición de 1998), un auténtico best seller de la Archivística; y, las obras de Margarita GómEz GómEz, Catedrática de Historia Medieval y Ciencias y Técnicas Historiográficas de la Univesidad de Sevilla, dedicadas al Archivo General de Indias, tituladas Fundación y Ordenanzas del Archivo General de Indias. Su significación en la política archivística española (Sevilla, Universidad de Sevilla, 1993), y su más reciente obra El Sello y Registro de Indias. Imagen y representación (Colonia, Böhlau Verlag Köln Weimar Wien, 2008).

No existe ninguna monografía dedicada a la historia del Archivo General de la Guerra Civil Española en el periodo 1938-1948, si exceptuamos la obra de carácter generalista, del profesor titular de Archivística, del departamento de Biblioteconomía y Documentación de la Universidad Carlos III de Madrid, Diego NAVARRo BonILla, titulada Morir Matando (Sevilla, Espuela de Plata, 2012).

En ella, además de una historia de los servicios de inteligencia y de información de la época (el Servicio de Información de las Fronteras del Norte de España ${ }^{1}$; la Segunda Sección, Información, del Estado Mayor del Ejército Republicano²; los Servicios de

\footnotetext{
${ }^{1}$ NAVARro Bonilla, Diego., Morir Matando. Sevilla, Espuela de Plata, 2012, pp. 79-86.

${ }^{2}$ Op. cit., pp. 107-116.
} 
Información de la Federación Anarquista Internacional ${ }^{3}$ ) y del anarcosindicalismo de la Confederación Nacional del Trabajo en Zaragoza, organización política a la que pertenecieron algunos de sus antepasados fichados en el Archivo ${ }^{4}$, se traza una historia del Archivo y se aportan algunos datos de interés relativos a la biografía de los primeros directores del Archivo, Marcelino de Ulibarri y Eguílaz y su sobrino Pedro Ricardo Ruiz de Ulibarri ${ }^{5}$; las sedes del Archivo en Salamanca ${ }^{6}$; los frustrados intentos de traslado del Archivo ${ }^{7}$; e incluso el intento de sabotaje e incendio del Archivo, en julio de $1946^{8}$. Además, Diego NAVARro Bonilla se preocupa por documentar cuándo y dónde se realizó la primera incautación de documentos que fueron a parar al Archivo ${ }^{9}$, y de explicar los conocimientos archivísticos y de tratamiento de la información, adquiridos por Emilio Mola, al frente de la Dirección General de Seguridad, de febrero de 1930 a abril de 1931, conocimientos que, a través de los servicios de información del carlismo y antes de su muerte en junio de 1937, pudo haber trasmitido a Marcelino de Ulibarri y Eguílaz, y que éste habría aplicado en el tratamiento de la documentación incautada llegada al Archivo ${ }^{10}$.

Desde 1980 hasta nuestros días, casi todos los sucesivos directores que ha tenido el Archivo General de la Guerra Civil Española (de mayo de 1979 a marzo de 1999, Sección Guerra Civil del Archivo Histórico Nacional), han dedicado algún artículo al Archivo. Se alude, aquí, a los artículos de María Teresa DíEz DE LOS Ríos SAN JUAN, titulados "La Sección de la Guerra Civil del Archivo Histórico Nacional (Salamanca)", publicado en la obra colectiva La II República española. Ponencias presentadas al Coloquio Internacional sobre la II República española, celebrado en Zaragoza del 7 al

\footnotetext{
${ }^{3}$ Op. cit., pp. 135-137 y 147-149.

${ }^{4}$ Op. cit., pp. 183-190, 212-251 у 385-457.

${ }^{5}$ Op. cit., pp. 260-266.

${ }^{6}$ Op. cit., pp. 312-314.

${ }^{7}$ Op. cit., pp. 314-319.

${ }^{8}$ Sobre el intento de incendio y sabotaje del Archivo, véase CDMH. AGGCE. DNSD. Presidencia. Caja 115. Expediente 11. Sobre la explicación del mismo, véase op. cit., pp. 371-379.

${ }^{9}$ Op. cit., pp. 335-340.

${ }^{10}$ Op. cit., pp. 258-260.
} 
10 de abril de 1981 (Barcelona, Universidad de Barcelona, 1983), casi con el mismo título, "La Sección Guerra Civil del Archivo Histórico Nacional”, pero publicado, dos años después, en la obra Archivos para la Historia del Movimiento Obrero español. XV Conferencia de la IALHI, celebrada del 25 al 28 de septiembre de 1984 en Madrid (Madrid, Fundación Pablo Iglesias, 1985), y "Estado actual de la Sección Guerra Civil del Archivo Histórico Nacional", publicado, ese mismo año 1985, en la revista Studia Histórica. Historia Contemporánea, $n^{o} 3$, de la Universidad de Salamanca; al artículo, en su día, pionero, y todavía de referencia, de Antonio GonZÁLEZ QuiNTANA, titulado "Fuentes para el estudio de la represión franquista en el Archivo Histórico Nacional, Sección Guerra Civil”, publicado, en 1994, en la revista Espacio, Tiempo y Forma. Serie V. Historia Contemporánea, $n^{o} 7$, de la Universidad Nacional de Educación a Distancia (UNED); y, de las recientes aportaciones de Jesús ESPINOSA ROMERO, en sendos artículos, titulados "El Archivo de Guerra Civil de Salamanca. De la campaña a la Transición", publicado en la obra colectiva Paseo documental por el Madrid de antaño (Madrid, Universidad Complutense de Madrid, 2015), y "La Delegación del Estado para la Recuperación de Documentos en Madrid”, publicado, también, en otra obra colectiva, titulada Madrid, una ciudad en guerra, 1936-1938 (Madrid, Catarata, 2016); y, finalmente, del artículo de Franciso Javier Fito MANTECA, actual Director de la Biblioteca del Centro Documental de la Memoria Histórica, titulado "La documentación anticomunista y el Archivo de Salamanca. El viaje de María de Smeth, el Antikomintern y la Delegación para la Recuperación de Documentos", publicado en el número 101 de la revista Archivamos, boletín de la Asociación de Archiveros de Castilla y León. Por ello, en este sentido, son importantes las aportaciones que se realizan en estos trabajos, que intentan arrojar luz sobre los órganos precedentes a la Delegación del Estado para Recuperación de Documentos, la Oficina de Investigación y Propaganda Anticomunista y la Delegación Nacional de Asuntos Especiales. En todos ellos, se presentan hipótesis sobre la posible influencia en la metodología de trabajo archivístico aplicada en el Archivo y, como consecuencia, en el tratamiento de la información, desde la pre-historia del Archivo, es decir, desde la creación de la Oficina de Investigación y Propaganda Anticomunista, de la policía o los agentes nazis que llegarían, entonces, a la España franquista de la época, a Salamanca (Francisco Javier FITO MANTECA). 
El Archivo que perdía los papeles. El Archivo de la Guerra Civil según el fondo documental de la DNSD $>$ 
Capítulo 1

La organización franquista: las instituciones encargadas de la recuperación de documentos 
Este primer capítulo está dedicado a estudiar, por orden cronológico, los órganos que dieron origen al actual Archivo General de la Guerra Civil Española, y que, por tanto, se pueden considerar antecedentes del mismo: la Oficina de Investigación y Propaganda Anticomunista, la Delegación Nacional de Asuntos Especiales y, finalmente, la Delegación del Estado para Recuperación de Documentos, encargados, desde un primer momento, de la requisición de documentos al enemigo durante la Guerra Civil.

Dichos órganos se estudian contextualizándolos en el organigrama de la Administración General del Estado franquista, con los cambios que sufrió ésta, para conocer, así, su importancia dentro de la misma.

Los objetivos de este primer capítulo son los siguientes:

$1^{\circ}$. Presentar sucintamente la Administración General del Estado franquista y la evolución de la misma.

$2^{\circ}$. Establecer la ubicación en el seno del organigrama de la Administración General del Estado de los órganos encargados de la requisición de documentos al enemigo, y, más concretamente, su dependencia administrativa inmediatamente superior.

$3^{\circ}$. Analizar las normas jurídicas fundacionales, que, respectivamente, dieron lugar a cada uno de los órganos encargados de la requisición de documentos al enemigo, la Oficina de Investigación y Propaganda Anticomunista, la Delegación Nacional de Asuntos Especiales y la Delegación del Estado para Recuperación de Documentos. 
$4^{\circ}$. Conocer las funciones archivísticas que desarrollaron la Oficina de Investigación y Propaganda Anticomunista, la Delegación Nacional de Asuntos Especiales y la Delegación del Estado para Recuperación de Documentos, y, a partir de ellas, resaltar sus similitudes y sus diferencias.

$5^{\circ}$. Y, finalmente, conocer a los máximos responsables de la Oficina de Investigación y Propaganda Anticomunista, la Delegación Nacional de Asuntos Especiales y la Delegación del Estado para Recuperación de Documentos.

Para ello, este primer capítulo se estructura en los cuatro siguientes apartados:

$1^{\circ}$. El primero está dedicado al Estado provisional franquista, creado por Ley, de 1 de octubre de 1936.

$2^{\circ}$. El segundo se divide en dos subapartados, dedicados, cada uno de ellos, a la Oficina de Investigación y Propaganda Anticomunista y a la Delegación Nacional de Asuntos Especiales.

$3^{\circ}$. En el tercer apartado, se trata la organización de la Administración General del Estado franquista, creada por La Ley, de 30 de enero de 1938, y la creación de la Delegación del Estado para Recuperación de Documentos, por Decreto, de 26 de abril de 1938, y su adscripción al Ministerio del Interior.

$4^{\text {o }}$. Finalmente, en el último apartado, se exponen las conclusiones a las que se han llegado en este capítulo.

Los distintos órganos, dedicados a la incautación y gestión de documentos pertenecientes al enemigo, nacieron en un contexto político institucional creado para ganar una guerra.

Y, cabe señalar que -según Javier ESPINOSA ROMERO ${ }^{11}$ - no surgieron de la nada, sino que surgirían de las experiencias previas que dos de los principales militares sublevados tuvieron en la constitución de archivos especializados en la lucha anticomunista:

- El general Mola, al frente de la Dirección General de Seguridad.

- El capitán Jesús Fontán Lobé, adscrito al Cuartel General de Salamanca.

\footnotetext{
${ }^{11}$ ESPINOSA Romero, Jesús.; RodríGUEZ LÓPEZ, Sofía., "El Archivo de la Guerra Civil en Salamanca: de la campaña a la transición", en AA.VV., Paseo documental por el Madrid de antaño. Madrid, Universidad Complutense de Madrid, 2015, pp. 131-155.
} 
Según Javier ESPINOSA ROMERO, el capitán Fontán Lobé propuso una metodología de trabajo ante la caída del Cinturón de Hierro que no varió con el tiempo. Esta metodología consistiría en señalar, en todos los documentos de interés:

- Dónde y cuándo se habían requisado.

- Conservar un número mínimo de folletos, revistas y libros.

- Separar los documentos que requerían un análisis más detenido, como la correspondencia o los libros de actas, de los documentos relativos a las personas, como listas de afiliados, que servirían para crear fichas directamente.

- De todos ellos, se elaborarían tres fichas de referencias por cada persona encontrada en la documentación ${ }^{12}$.

\section{ORGANIZACIÓN DEL ESTADO PROVISIONAL FRANQUISTA}

El Estado provisional franquista fue creado, por la Ley, de 1 de octubre de 1936, por la que se establecía la organización administrativa, a la que había de ajustarse la nueva estructuración del Estado, tras el alzamiento militar de julio de $1936^{13}$. La organización administrativa del Estado estaba formada, según la citada Ley, por cuatro órganos administrativos de carácter provisional:

$1^{a}$. La Junta Técnica del Estado. Fue el principal órgano administrativo, para la administración y el gobierno de la Administración General del Estado. Al frente de la Junta Técnica del Estado se situaría un Presidente, con cuatro principales funciones:

- Presidir las reuniones de todas y cada una de las Comisiones.

- Resolver los distintos asuntos que en las Comisiones se tratara.

\footnotetext{
${ }^{12}$ Espinosa Romero, Jesús.; RodríGuez López, Sofía., "El Archivo de la Guerra Civil en Salamanca: de la campaña a la transición", en AA.VV., Paseo documental por el Madrid de antaño. Madrid, Universidad Complutense de Madrid, 2015, pp. 131-155.

${ }^{13}$ Ley, de 1 de octubre de 1936, estableciendo la Organización administrativa a que ha de ajustarse la nueva estructuración del Estado, en Boletín Oficial del Estado, $n^{\circ} 1$, del 2 de octubre de 1936. La ley fue publicada en el primer ejemplar o número del Boletín Oficial del Estado, que fue impreso en la Imprenta Provincial del Gobierno Civil de Burgos. Destaca, en su cabecera, el escudo de la segunda República.
} 
- Recabar la cooperación de técnicos y, en su caso, destinarlos, previo nombramiento, en función de su especialización, a la comisión correspondiente. También, dichos técnicos podían tener carácter meramente consultivo.

- Someter sus dictámenes a la aprobación del Jefe del Estado, Francisco Franco Bahamonde.

La Junta Técnica del Estado estaba formada, a modo de ministerios con capacidad legislativa, por siete Comisiones:

- Comisión de Hacienda.

- Comisión de Justicia.

- Comisión de Industria, Comercio y Abastos.

- Comisión de Agricultura y Trabajo agrícola.

- Comisión de Trabajo.

- Comisión de Cultura y Enseñanza.

- Comisión de Obras Públicas y Comunicaciones.

2a. El Gobernador General. Jefe y coordinador de los Gobernadores Civiles, a través de ellos y de la intervención de las Diputaciones provinciales y Ayuntamientos, fue el máximo responsable de la Administración provincial y local, tenía como principal función "la organización de la vida ciudadana, [su] abastecimiento, trabajo y [régimen de] beneficencia"14. Para tal fin, el 4 de octubre de 1936, fue nombrado primer Gobernador General, el general de brigada Francisco Fermoso Blanco ${ }^{15}$.

3a. La Secretaría de Relaciones Exteriores. Era la encargada de las relaciones diplomáticas con los demás países ${ }^{16}$. En abril de 1937, el Secretario de Asuntos Exteriores era el diplomático Miguel Ángel de Muguiro y Muguiro, siete años después,

\footnotetext{
${ }^{14}$ Artículo $3^{\circ}$, de cuatro líneas de extensión, de la Ley, de 1 de octubre de 1936, estableciendo la Organización administrativa a que ha de ajustarse la nueva estructuración del Estado, en Boletín Oficial del Estado, $n^{o} 1$, del 2 de octubre de 1936.

${ }^{15}$ Decreto, no 14 , de 4 de octubre de 1936, en Boletín Oficial del Estado, $n^{o} 2$, del 6 de octubre de 1936.

16 Artículo $4^{\circ}$, de tres líneas de extensión, de la Ley, de 1 de octubre de 1936, estableciendo la Organización administrativa a que ha de ajustarse la nueva estructuración del Estado, en Boletín Oficial del Estado, $n^{o} 1$, del 2 de octubre de 1936.
} 
desde 1944, embajador de España en Budapest (Hungría), donde colaboró en la salvación de muchos judíos que huían del holocausto ${ }^{17}$.

4a. La Secretaría General del Estado. Formada por personal de las distintas Comisiones de la Junta Técnica del Estado y por un diplomático de la Secretaría de Relaciones Exteriores, era una especie de Consejo de Ministros. Con sede en Salamanca, al lado del Cuartel General del Generalísimo, Nicolás Franco Bahamonde, hermano mayor de Francisco y también militar, fue nombrado Secretario General del Estado $^{18}$.

La Oficina de Investigación y Propaganda Anticomunista y la Delegación Nacional de Asuntos Especiales, dependientes de la Secretaría General del Estado o del Jefe del Estado, son fruto de este Estado provisional y embrionario.

\section{ORGANIZACIÓN PARA LA RECUPERACIÓN DE DOCUMENTOS DEL ENEMIGO}

Dependiendo de la Secretaría General, el Estado franquista creó dos órganos que se suceden cronológicamente en la recuperación de documentos al enemigo: la Oficina de Investigación y Propaganda Anticomunista y la Delegación Nacional de Asuntos Especiales.

\subsection{LA OFICINA DE INVESTIGACIÓN Y PROPAGANDA ANTICOMUNISTA}

La Oficina de Investigación y Propaganda Anticomunista dependía directamente de la Secretaría General. La Oficina de Investigación y Propaganda Anticomunista fue creada en Salamanca, por Orden interna, el 20 de abril de 1937. El contenido de la Orden se conoce a través de un documento que reúne las siguientes características:

\footnotetext{
${ }^{17}$ Decreto, $\mathrm{n}^{\mathrm{o}}$ 262, de 22 de abril de 1937, en Boletín Oficial del Estado, $n^{o}$ 187, del 25 de abril de 1937.

18 Artículo $5^{\circ}$, de tres líneas de extensión, de la Ley, de 1 de octubre de 1936, estableciendo la Organización administrativa a que ha de ajustarse a la nueva estructuración del Estado, en Boletín Oficial del Estado, $n^{o} 1$, del 2 de octubre de 1936.
} 
- Tiene un formato tamaño cuartilla.

- Se trata de un documento mecanografiado, de cuarenta y dos líneas de extensión.

- No fue publicado en el Boletín Oficial del Estado, para cumplimiento y efectividad exclusiva dentro de la propia Secretaría General, que la dictó, y la Oficina de Investigación y Propaganda Anticomunista, como órgano dependiente de la misma ${ }^{19}$.

- Fue firmada por Nicolás Franco, como Secretario General del Estado.

De la Orden interna de la Oficina de Investigación y Propaganda Anticomunista, se colige que ésta constaba de cuatro artículos.

La Orden interna establecía el objeto y las funciones de la Oficina: "recoger, analizar y catalogar todo el material de propaganda comunista" ${ }^{20}$. No hay una especificación de las tareas y herramientas. Según Francisco Javier FITO MANTECA, los métodos empleados en la Oficina de Investigación y Propaganda Anticomunista fueron los que se utilizaron en el Anti-Komintern ${ }^{21}$.

En la Orden, se nombraba a los máximos responsables de la Oficina. Hubo tres responsables de la misma, que fueron nombrados, directa y simultáneamente, tal y como se cita explícitamente en el texto de la citada Orden, por la Secretaría General: Manuel Maestro Maestro, Juan Fuentes Bertrán y Eduardo Galán Ruiz.

Las instituciones, consideradas marxistas y masónicas, cuya documentación propagandística, incluyéndose el material cinematográfico, debía recoger la Oficina, están fijadas en uno de los artículos de la Orden interna:

\footnotetext{
${ }^{19}$ Centro Documental de la Memoria Histórica (CDMH). Archivo General de la Guerra Civil Española (AGGCE). Delegación Nacional de Servicios Documentales (DNSD). Secretaría General. Expedientes Secretaría. Caja 330-348. Legajo 23. Expediente 330.

${ }^{20}$ CDMH. AGGCE. DNSD. Secretaría General. Expedientes Secretaría. Caja 330-348. Legajo 23. Expediente 330 .

${ }^{21}$ Fito MANTECA, Francisco Javier., "La documentación anticomunista y el Archivo de Salamanca. El viaje de María de Smeth, el Antikomintern y la Delegación para la Recuperación de Documentos", en Archivamos, $n^{\circ}$ 101. Salamanca, ACAL, 2016, pp. 41-47.
} 
- Logias masónicas ${ }^{22}$, los locales donde celebraban los masones sus asambleas, diseminadas por todo el territorio nacional.

- La Liga de los Derechos del Hombre. Se constituyó en Madrid, el 23 de noviembre de 1913. Su principal finalidad fue defender las libertades públicas, sobre todo, la libertad de conciencia. Fue suprimida en 1923, con la llegada al poder del general Miguel Primo de Rivera. Tras la dictadura y durante la segunda República, la Liga de los Derechos del Hombre fue refundada en 1932, siendo presidente Miguel de Unamuno. En 1936, fue definitivamente suprimida ${ }^{23}$.

- El Socorro Rojo Internacional. Era una organización internacional de auxilio social. Durante la Guerra Civil, las principales funciones desarrolladas fueron la creación de comedores sociales y hospitales en la zona republicana. Fue suprimida al terminar la Guerra Civil ${ }^{24}$.

- Los Ateneos libertarios. Se trata de instituciones culturales cuya finalidad era la educación de la clase obrera. Surgieron durante la II República y la Guerra Civil, ligados al sindicato $\mathrm{CNT}^{25}$.

- La Federación de los Trabajadores de la Enseñanza. Creada en abril de 1931, se trata de la sección de los trabajadores de la enseñanza afiliados al sindicato $\mathrm{UGT}^{26}$.

\footnotetext{
${ }^{22}$ Posteriormente a la masonería, por doctrina de la Delegación, se añadieron otras instituciones y confesiones: la teosofía, el rotarismo, el protestantismo, la Iglesia evangélica y el judaísmo.

${ }^{23}$ La documentación sobre la Liga de los Derechos del Hombre puede consultarse en CDMH. AGGCE. DNSD. PS-Madrid. Caja 571. Expedientes 56, 80 y 108; Caja 639, Expediente 334; y, Caja 736, Expediente 54. Sobre la Liga de los Derechos del Hombre, véase AYALA, José Antonio., "Revolución, derechos individuales y masonería. Las ligas españolas de derechos del hombre (1913-1936)", en FERRER BENIMELI, José Antonio (coord.)., Masonería, revolución y reacción. Symposium Internacional de Historia de la Masonería Española. Alicante, Diputación Provincial de Alicante. Instituto Alicantino de Cultura Juan Gil-Albert, 1990, pp. 123-143; y, MARTín MARTíneZ, Luis P., "Un instrumento de democracia: la Liga Española de los Derechos del Hombre, 1913-1936", en Derechos y libertades. Revista del Instituto Bartolomé de las Casas, $n^{\circ}$ 6. Madrid, Universidad Carlos III, 1998, pp. 377-396.

${ }^{24}$ CDMH. AGGCE. DNSD. PS-Madrid. Caja 1465,5 y PS-Carteles. Sobre el Socorro Rojo Internacional, véase BRANCIFORTE, Laura María., "El Socorro Rojo Internacional y su intervención en España", en Congreso La Guerra Civil Española, 1936-1939. Madrid, Sociedad Estatal de Conmemoraciones Culturales, 2006.

${ }^{25}$ La documentación sobre los Ateneos libertarios puede consultarse en CDMH. AGGCE. DNSD. PSMadrid, Cajas 385, 386, 393, 404, 411, 437, 445, 452, 458, 663, 894, 932, 933, 990, 1039 y 1121; y, PSBarcelona, Cajas 140, 828, 1349 y 1857. Sobre los Ateneos libertarios, véase NAVARRO NAVARRO, Francisco Javier., "Los Ateneos. Teoría y práctica en el movimiento libertario", en CHAPUT, MarieClaude.; PÉREZ SERRANO, Julio (coords.)., De l'anarchime aux courants alternatifs XIXe-XXIe siècles. Nanterre, Universidad de París X, 2007, pp. 187-206.
} 
Finalmente, se hace referencia a la "ayuda y cooperación" que, a la Oficina, debían prestar las autoridades civiles y militares ${ }^{27}$. Las autoridades civiles y militares debían de prestar su cooperación a la Oficina de Investigación y Propaganda Anticomunista en la recogida de la propaganda comunista. La creación de la Oficina de Investigación y Propaganda Anticomunista, como sucedería con la Delegación del Estado para Recuperación de Documentos, fue comunicada a los altos mandos militares ${ }^{28}$.

Sólo un mes y nueve días después de su fundación, la Oficina de Investigación y Propaganda Anticomunista fue suprimida, siendo reemplazada por la Delegación Nacional de Asuntos Especiales, dependiente, también, de la Secretaría General ${ }^{29}$. Con la supresión de la Oficina, el nuevo órgano se especializó en la requisición de documentación masónica, de las logias masónicas en general, y no sólo de la propaganda comunista que éstas generaban ${ }^{30}$.

\footnotetext{
${ }^{26}$ Finalmente, la documentación relativa a la Federación de los Trabajadores de la Enseñanza de la Unión General de Trabajadores puede consultarse en diversas cajas de las series PS-Aragón, PSBarcelona, PS-Gijón, PS-Lérida, PS-Madrid y PS-Santander. Sobre la FETE, véase LUIS MARTín, Francisco de., La FETE en la Guerra Civil Española, 1936-1939. Barcelona, Ariel, 2002.
}

${ }^{27}$ CDMH. AGGCE. DNSD. Secretaría General. Expedientes Secretaría. Caja 330-348. Legajo 23. Expediente 330.

${ }^{28}$ De su creación debían ser informados el General del Ejército del Norte, Emilio Mola Vidal (18871937), cuyo Cuartel General se encontraba en Valladolid; el General del Ejército del Sur, Gonzalo Queipo de Llano (1875-1951), cuyo Cuartel General se encontraba en Sevilla; la División reforzada de Madrid, con sede en Navalcarnero, al mando del general Luis Orgaz Yoldi (1881-1946); la $5^{\text {a }}$ División Orgánica de Zaragoza, al mando del general Miguel Cabanellas Ferrer (1872-1938); la 6a División Orgánica de Burgos, al mando del general Domingo Batet Mestres (1872-1937); la $7^{\text {a }}$ División Orgánica de Valladolid, al mando del general Andrés Saliquet Zumeta (1877-1955); la $8^{\text {a }}$ División Orgánica de La Coruña, de cuyo mando había sido responsable el general salmantino Enrique Salcedo Mollinuevo (18711936); el Jefe de las Fuerzas Militares de Baleares (Palma de Mallorca), que había sido Manuel Goded Llopis (1882-1936); el Jefe de las Fuerzas Militares de Canarias (Santa Cruz de Tenerife), que habían dependido directamente del propio Francisco Franco; el Jefe de las Fuerzas Militares de Marruecos (Tetuán), que había sido el comandante Osvaldo Capaz Montes (1894-1936); y, como no, el Presidente de la Junta Técnica del Estado, en Burgos, el general Fidel Dávila Arrondo (1878-1972).

${ }^{29}$ De hecho, toda la documentación referida a sectas secretas y logias masónicas, correspondencia oficial, correspondencia particular y giros, podía ser enviada al apartado de correos de la Delegación Nacional de Servicios Especiales, dependiente de la Secretaría General del Jefe del Estado, en CDMH. AGGCE. DNSD. Secretaría. Correspondencia. Caja 125-200. Legajo 7. Expediente 142. También, podía enviarse a la Secretaría Particular del Cuartel General del Generalísimo, ubicado en el Palacio Episcopal de Salamanca.

${ }^{30}$ Sobre la Oficina de Investigación y Propaganda Anticomunista, véase GONZÁLEZ QUINTANA, Antonio., "Fuentes para el estudio de la represión franquista en el Archivo Histórico Nacional, Sección Guerra Civil", en Espacio, Tiempo y Forma. Serie V. Historia Contemporánea, $n^{o}$ 7. Madrid, Universidad Nacional de Educación a Distancia (UNED), 1994, pp. 479-508 y FiTO MANTECA, Francisco Javier., "La 


\subsection{LA DELEGACIÓN NACIONAL DE ASUNTOS ESPECIALES}

La creación de la Delegación Nacional de Asuntos Especiales se debe a un cambio de objetivos. Los intereses por los que había sido creada la Oficina de Investigación y Propaganda Anticomunista, incluyendo al que debe su denominación, la requisición de propaganda, fueron reemplazados, en un mes, por el único interés por la requisición de la documentación producida por las logias masónicas y la persecución de la masonería en general.

La Delegación Nacional de Asuntos Especiales, también denominada Delegación de Asuntos o Servicios Especiales, fue creada, por Decreto reservado, del 29 de mayo de 1937. El Decreto no se ha conservado ${ }^{31}$. Como Decreto reservado, refleja un acto administrativo, el de creación de la Delegación Nacional de Asuntos Especiales, emanado del poder ejecutivo, de rango jerárquicamente inferior a las leyes, que, debido a su carácter reservado, no fue publicado en el Boletín Oficial del Estado.

La única función, a desempeñar por la Delegación Nacional de Asuntos Especiales, era recuperar la documentación de las logias masónicas, con el objetivo de perseguir y sancionar a los miembros de la masonería. Frente a la Oficina de Investigación y Propaganda Anticomunista, la recién creada Delegación Nacional de Asuntos Especiales se especializaba, así, en recuperar, ordenar y clasificar toda la documentación generada por las sectas o asociaciones secretas, principalmente la masonería, que se reunía en logias masónicas dispersadas por todo el territorio peninsular. La creación de este órgano se debe a la necesidad de reunir pruebas documentales que pudieran demostrar la pertenencia de una persona a la masonería, para su futura sanción penal a través de la Ley para la Represión de la Masonería y el Comunismo, de 1 de marzo de 1940.

\footnotetext{
documentación anticomunista y el Archivo de Salamanca, el Antikomintern y la Delegación del Estado para la Recuperación de Documentos”, en Archivamos núm. 101. Salamanca, ACAL 2016, pp. 40-47.

${ }^{31}$ Sólo se alude a él en otros textos legislativos, todos ellos escuetos, debido a la técnica legislativa de la época, no pudiéndose, por ello, reconstruir la estructura de su articulado.
} 
Para la dirección de la Delegación Nacional de Asuntos Especiales, fue nombrado "[el] caballero cristiano y gran patriota, a quien Dios y España premiarán su magnífica labor", Marcelino de Ulibarri y Eguílaz ${ }^{32}$.

Se desconoce el motivo por el cual -excepto la orden verbal de Franco indicada con anterioridad- se pasó de tener interés por la propaganda comunista, para cuya requisición fue creada la Oficina de Investigación y Propaganda Anticomunista, a tener interés por la documentación masónica, para cuya requisición fue creada la Delegación Nacional de Asuntos Especiales.

La Delegación Nacional de Asuntos Especiales quedó unida, por Decreto reservado, de 30 de septiembre de 1944, a la Delegación del Estado para Recuperación de Documentos, dando lugar a la Delegación Nacional de Servicios Documentales, adscrita a la Presidencia del Gobierno. Desde su creación, y durante el periodo mayo de 1937 a septiembre de 1944, la Delegación Nacional de Asuntos Especiales quedó, en el desarrollo de sus funciones y a efectos de tratamiento archivístico de la documentación, subordinada a la Delegación del Estado para Recuperación de Documentos, que fue la que, a partir de abril de 1938, se ocupó de la requisición de los documentos de carácter masónico $^{33}$.

\section{LA ADMINISTRACIÓN DEL ESTADO POSBÉLICO: LA REFORMA DE 1938}

La Ley, de 30 de enero de 1938, de Administración General del Estado, supuso la derogación de la Ley, de 1 de octubre de 1936, que establecía la organización administrativa a que había de ajustarse la nueva estructuración del Estado, y, como consecuencia, la desaparición de los cuatro órganos, que, hasta ese momento, se habían encargado de la Administración del Estado franquista.

\footnotetext{
32 CDMH. AGGCE. DNSD. Secretaría General. Expedientes Secretaría. Caja 081-115. Legajo 5. Expediente 97.

${ }^{33}$ Sobre la Delegación Nacional de Asuntos Especiales, véase GonZÁLEZ QuINTANA, Antonio., "Fuentes para el estudio de la represión franquista en el Archivo Histórico Nacional, Sección Guerra Civil”, en Espacio, Tiempo y Forma. Serie V. Historia Contemporánea, $n^{o}$ 7. Madrid, Universidad Nacional de Educación a Distancia (UNED), 1994, pp. 479-508.
} 
Dicha derogación, tanto de la Ley, de 1 de octubre de 1936, como de los organismos a que dio lugar, se justifica en el preámbulo de la Ley, de 30 de enero de 1938, de Administración General del Estado. La organización embrionaria y provisional del Estado debía dar paso a otra, debido a:

$1^{\circ}$. Su insuficiencia notoria, tanto en su constitución como en su funcionamiento.

$2^{\circ}$. El volumen y la complejidad crecientes de las funciones de gobierno y de gestión.

$3^{\circ}$. En definitiva, la necesidad de un nuevo sistema administrativo, una vez terminada la guerra, para la cual no había sido diseñado el anterior.

La organización del nuevo sistema administrativo quedaba sujeta a "la constante influencia del Movimiento Nacional"34.

La Ley, de 30 de enero de 1938, disponía que la nueva Administración General del Estado se organizase en once Ministerios, o Departamentos Ministeriales, subordinados a la Presidencia del Gobierno. A saber:

- Ministerio de Asuntos Exteriores.

- Ministerio de Justicia

- Ministerio de Defensa Nacional.

- Ministerio de Orden Público.

- Ministerio de Hacienda.

- $\quad$ Ministerio de Industria y Comercio.

- Ministerio de Agricultura.

- Ministerio de Educación Nacional.

- Ministerio de Obras Públicas.

- Ministerio de Organización y Acción Social. Y, por último,

- El Ministerio del Interior.

\footnotetext{
${ }^{34}$ Ley, de 30 de enero de 1938, de Administración General del Estado, en Boletín Oficial del Estado, $n^{o}$ 467, del 31 de enero de 1938.
} 


\subsection{MINISTERIO DEL INTERIOR}

El Ministerio del Interior tenía como función secundar la acción política en colaboración con el Ministerio de Orden Público ${ }^{35}$.

El Ministerio del Interior comprendía ocho Servicios Nacionales:

- Administración local.

- Regiones devastadas y reparaciones.

- Beneficencia.

- Sanidad.

- Prensa.

- Propaganda. Y, la

- Política Interior.

Además, del Ministerio del Interior, dependían directamente los Delegados de Orden Público, para hacer frente a los problemas específicos de orden público, mientras que la acción política y demás competencias dependían de los respectivos Gobernadores civiles.

La política interior alude a las decisiones internas de un gobierno, en este caso, de seguridad interior, en contraposición a las decisiones de política exterior, en concreto, de seguridad frente a otros países. Dentro de la política interior, la requisición de documentos fue la herramienta utilizada para poder desarrollar la función represora.

Por ello, la Delegación del Estado para Recuperación de Documentos quedó significativamente adscrita al Servicio Nacional de Política Interior del Ministerio del Interior.

\footnotetext{
${ }^{35}$ Ibídem.
} 


\subsection{LA DELEGACIÓN DEL ESTADO PARA RECUPERACIÓN DE DOCUMENTOS}

La Delegación del Estado para Recuperación de Documentos fue creada por el Decreto, de 26 de abril de 1938, publicado en el Boletín Oficial del Estado, $n^{\circ}$ 553, del 27 de abril de $1938^{36}$. El Decreto, de 26 de abril de 1938, de creación de la Delegación del Estado para Recuperación de Documentos, fue firmado por Ramón Serrano Suñer, como Ministro del Interior. Diego NAVARro Bonilla, afirma, en su obra Morir Matando, que "Serrano Suñer [...], como Ministro de Gobernación, acabó por impulsar, desde los principales resortes de la Administración del Régimen, la magna obra documental que se diseñó y ejecutó desde Salamanca"37. Fue adscrita directamente al Ministerio del Interior. El Decreto fue dictado por Franco a propuesta del Ministerio del Interior. El Decreto de creación de la Delegación del Estado para Recuperación de Documentos tenía una extensión de un preámbulo y cuatro artículos.

El objeto principal, por la que fue creada la Delegación fue "suministrar al Estado información referente a la actuación de sus enemigos"38.

Se exponen, en el Decreto, sin desarrollarlas, las tres funciones archivísticas a desempeñar por la Delegación:

- La recogida o recuperación de documentos.

- La custodia de documentos.

- La clasificación de documentos.

Dichos documentos, requisados tanto en la retaguardia como en los frentes, procedentes de archivos y oficinas, debían suministrar información y datos útiles concretos sobre los enemigos del Estado.

\footnotetext{
${ }^{36}$ El nombre oficial, que aparece entrecomillado en el Decreto, es el de "Delegación del Estado para Recuperación de Documentos" [sic], no el de Delegación del Estado para la Recuperación de Documentos.

${ }^{37}$ NAVARro Bonilla, Diego., Morir Mantando. Sevilla, Espuela de Plata, 2012, p. 262.

${ }^{38}$ Artículo primero del Decreto, de 26 de abril de 1938, en Boletín Oficial del Estado, $n^{\circ}$ 553, del 27 de abril de 1938.
} 
La documentación era requisada, no sólo a logias masónicas, sino a personas físicas y jurídicas, particulares, autoridades y organismos oficiales considerados enemigos del Estado franquista.

El Decreto dispone que la dirección de la Delegación recaiga en una persona, nombrada por el Ministro del Interior, persona que tenía que desempeñar, con absoluta dedicación y esmero, tres funciones:

- La dirección de la Delegación, siendo el máximo responsable de la misma.

- La selección del personal de la Delegación en Salamanca y la creación de los equipos de recuperación de documentos, proponiendo y designado a los miembros que formarían los mismos.

- La comunicación, y relación, con las autoridades civiles y militares, para la actuación de los equipos de recuperación de documentos.

En lo relativo a la cooperación de las autoridades civiles y militares, se expone que los equipos de recuperación de documentos actuarían subordinados a las autoridades militares y que, en su caso, contarían con la cooperación y colaboración de las autoridades civiles, funcionarios e incluso particulares.

De acuerdo con los mandos militares, los equipos de recuperación de documentos podrían "cerrar y sellar los locales y oficinas donde [pudieran] encontrarse documentos de interés" ${ }^{, 39}$, que contuvieran información sobre los enemigos del Estado.

Finalmente, se encarga al Ministerio la redacción de las disposiciones reglamentarias.

La Delegación del Estado para Recuperación de Documentos, por Decreto reservado, de 30 de septiembre de 1944, quedó unida a la Delegación Nacional de Asuntos Especiales, dando lugar a la Delegación Nacional de Servicios Documentales, que quedó bajo la dependencia de la Presidencia del Gobierno ${ }^{40}$.

\footnotetext{
${ }^{39}$ Artículo tercero del Decreto, de 26 de abril de 1938, en Boletín Oficial del Estado, $n^{\circ}$ 553, del 27 de abril de 1938.

${ }^{40}$ EsPinOSA ROMERO, Jesús.; RODRÍGUEZ LÓPEZ, Sofía., "El Archivo de la Guerra Civil en Salamanca: de la campaña a la transición", en AA.VV., Paseo documental por el Madrid de antaño. Madrid, Universidad Complutense de Madrid, 2015, pp. 131-155.
} 


\section{CONCLUSIONES}

Tras lo expuesto en los apartados anteriores de este capítulo, se ha llegado a las siguientes conclusiones:

I. Los distintos órganos, dedicados a la incautación de documentos pertenecientes al enemigo, nacieron en un contexto político institucional creado para ganar una guerra. La requisición de documentos fue la herramienta mediante la cual se pudo desarrollar la represión durante la Guerra Civil y la posguerra. Para ello, se crearon la Oficina de Investigación y Propaganda Anticomunista, la Delegación Nacional de Asuntos Especiales y, finalmente, la Delegación del Estado para Recuperación de Documentos.

II. Las funciones de los tres órganos fueron cambiando. En un primer momento, para la Oficina de Investigación y Propaganda Anticomunista, las funciones consistieron en recoger, analizar y catalogar la documentación. Para la Delegación Nacional de Asuntos Especiales, las funciones fueron recuperar, ordenar y clasificar toda la documentación. Finalmente, para la Delegación del Estado para Recuperación de Documentos, las funciones archivísticas a desempeñar fueron la recogida, custodia y clasificación de la documentación.

III. El enemigo al que requisar la documentación se fue ampliando. En un primer momento, el enemigo fue el comunismo, por que la Oficina de Investigación y Propaganda Anticomunista se dedicó a requisar la documentación de aquellas organizaciones que consideraba comunistas como las logias masónicas, la Liga de los Derechos del Hombre, el Socorro Rojo Internacional, los Ateneos libertarios y la Federación de Trabajadores de la Enseñanza. Poco después, la Delegación Nacional de Asuntos Especiales tuvo como objeto específico recuperar la documentación de las logias masónicas, con el objetivo de perseguir y sancionar a los miembros de la masonería. Finalmente, la Delegación del Estado para Recuperación de Documentos tuvo como objetivo la requisición de los documentos de todos los enemigos del Estado franquista, para, también, proceder a su posterior encausamiento. 
El Archivo que perdía los papeles. El Archivo de la Guerra Civil según el fondo documental de la DNSD $>$ 
Capítulo 2

El personal de la Delegación 
Los recursos humanos son importantes para el tratamiento archivístico de la documentación. A ellos, le dedicamos este capítulo.

Los objetivos de este capítulo están, por tanto, relacionados con las características específicas de los recursos humanos con los que contó la Delegación, desde su número hasta su ideología, pasando por su formación académica. En concreto, nos interesa conocer:

1. Cuántas personas trabajaron en el mismo.

2. Su tiempo de permanencia en la Delegación y su red de archivos.

3. Su formación, particularmente, si habían tenido formación archivística o no.

4. Su orientación política, y si ésta había influido a la hora de pasar a formar parte del personal de la Delegación. Y, su

5. Procedencia.

El capítulo se estructura en cuatro apartados:

$1^{\circ}$. El primero está dedicado a la dirección de la Delegación en esta primera etapa originaria del Archivo General de la Guerra Civil Española, de 1938 a 1944.

$2^{\circ}$. En el segundo, estudiamos el personal considerando aspectos como su cualificación, su ideología y la procedencia del personal que trabajó en la Delegación .

$3^{\text {o }}$. En el tercer apartado, tratamos algunos de los servicios que la Delegación puso a disposición de sus empleados, concretamente, su alojamiento. Se exponen las conclusiones a las que se han llegado respecto a los recursos humanos con los que contó la Delegación.

$4^{\circ}$. Finalmente, en el último apartado, se exponen las conclusiones a las que se ha llegado respecto a los recursos humanos con los que contó la Delegación. 


\section{LA DIRECCIÓN DEL ARCHIVO: MARCELINO DE ULIBARRI Y EGUÍLAZ, PRIMER DIRECTOR DE LA DELEGACIÓN}

El 7 de mayo de 1938, Marcelino de Ulibarri y Eguílaz fue nombrado director de la Delegación del Estado para Recuperación de Documentos, creado el 26 de abril del mismo año y dependiente del Ministerio del Interior. Durante los ocho años que estuvo al frente del mismo, de mayo de 1936 a septiembre de 1944, Marcelino de Ulibarri:

$1^{\circ}$. Se preocupó de dirigir la requisición de la documentación al enemigo.

$2^{\circ}$. Realizó, con criterios político-morales y no archivísticos, la selección del personal con la que se formaron los equipos de recuperación de documentos, que fueron coordinados por Manuel Martín Sastre. Y, del personal que trabajó en el Archivo central de Salamanca.

$3^{\circ}$. Dirigió la clasificación de la documentación.

$4^{\circ}$. Y, finalmente, se encargó de la custodia secreta de la documentación ${ }^{41}$.

Según Diego NAVARro Bonilla, los conocimientos archivísticos y de tratamiento de la información adquiridos por el general carlista Emilio Mola, al frente de la Dirección General de Seguridad, de febrero de 1930 a abril de 1931, habrían sido transmitidos, a través de los servicios de información del carlismo y antes de su muerte en junio de 1937, a Marcelino de Ulibarri y Eguílaz, conocimientos que éste habría aplicado en el tratamiento de la documentación incautada llegada al Archivo ${ }^{42}$.

\footnotetext{
${ }^{41}$ En el articulado del Decreto, de 27 de abril de 1938, del Ministerio del Interior, de creación de la Delegación del Estado para Recuperación de Documentos, quedan expuestas las funciones a desempeñar por el director de la Delegación. Una gran parte de los funcionarios de cualquiera de los organismos del Estado, militares y particulares creyeron, en su relación epistolar con Marcelino de Ulibarri y Eguílaz, como Director de la Delegación, que Ulibarri era un militar con el grado de Coronel; y, otros, pensaron que tanto el propio Ulibarri como su sobrino, Pedro Ruiz de Ulibarri, que se encontraban al frente de la Delegación, pertenecían a alguna orden religiosa regular, teniendo Ruiz de Ulibarri que aclarar, sucintamente, que tanto él como su tío, el Director de la Delegación, eran "seglares", en CDMH. AGGCE. DNSD. Secretaría. Correspondencia. Caja 1066-1149. Legajo 58. Expediente 1111; y, Caja 1250-1379. Legajo 62. Expediente 1379. Del nombramiento de Marcelino de Ulibarri y Eguílaz, como Director de la Delegación del Estado para Recuperación de Documentos, se hace eco en la sección "Disposiciones Oficiales", el diario $A B C$, edición de Sevilla, del 13 de mayo de 1938, p. 13.

${ }^{42}$ NaVArro Bonilla, Diego., Morir mantando. Sevilla, Espuela de Plata, 2012, pp. 258-260. Por su parte, Fernando MiKelarena PEÑA sostiene que más que a Mola, Marcelino de Ulibarri estuvo ligado directamente a Franco, al que había conocido y con el que entabló una estrecha amistad en Zaragoza, durante los años en que Franco dirigió la Academia General Militar, en Mikelarena PeÑa, Fernando., "Estructura, cadena de mando y ejecutores de la represión de boina roja en Navarra en 1936", en Historia contemporánea, $n^{\circ}$ 53. Lejona (Vizcaya), Universidad del País Vasco, 2016, pp. 602-604.
} 
Tras el Alzamiento militar y el comienzo de la Guerra Civil, el 20 de julio de 1936, Marcelino de Ulibarri y Eguílaz se puso al frente, como directivo de la misma, y en representación de la merindad de Tafalla, de la Junta Central de Guerra de la Región Navarra del Partido Carlista o Junta Carlista de Guerra de Navarra, que desarrolló un modelo de represión y de la que dependía la Oficina de Prensa y Propaganda Carlista, creada, en Pamplona, en agosto de 1936, órgano similar a la Oficina de Investigación y Propaganda Anticomunista ${ }^{43}$. La Oficina de Prensa y Propaganda Carlista estuvo instalada, de agosto de 1936 a enero de 1937, en el Colegio de los Escolapios y en el Palacio de la Diputación Foral, y, a partir de enero de 1937, en su sede definitiva, el edificio de La Agrícola, una Sociedad de Banca y Seguros, ubicada en la plaza de San Francisco. Se nombró Jefe, o Delegado, de la Oficina a Santiago Fernández Viyella, que tuvo como auxiliar a su hijo Alejandro Fernández Viyella ${ }^{44}$.

Marcelino de Ulibarri y Eguílaz, como directivo de la Junta Carlista de Guerra de Navarra, tuvo conocimiento del funcionamiento de la Oficina de Prensa y Propaganda Carlista, en Pamplona.

El 19 de abril de 1937, en Salamanca, fue promulgado el Decreto de Unificación, por el cual fueron fusionados Falange Española y Comunión Tradicionalista. En ese momento, y dos años y cinco meses después, en septiembre de 1939, Marcelino de Ulibarri y

${ }^{43}$ Según María José TURRIÓn GARCíA, en 1940, la función propagandística de la Oficina de Prensa y Propaganda Anticomunista seguía siendo desarrollada por la Delegación del Estado para Recuperación de Documentos, función cuyo modelo se había tomado de Hungría, en TURRIón GARCíA, María José., "La Biblioteca de la Sección Guerra Civil del Archivo Histórico Nacional (Salamanca)", en Boletín de la $A N A B A D, n^{\circ}$ 2. Madrid, ANABAD, 1997, p. 90.

44 La Oficina de Prensa y Propaganda Carlista, en Pamplona, se encargó de conocer y revisar, diariamente, la prensa extranjera (francesa, belga, suiza, alemana, italiana, inglesa y estadounidense), y la prensa republicana, de las que se obtenían, traducían (en su caso), ordenaban y archivaban artículos y fotografías, a los que sólo podían tener acceso aquellas personas que poseyeran autorización escrita del Delegado; en segundo lugar, de elaborar y publicar, en periódicos, semanarios y folletos, la propaganda carlista; y, finalmente, de organizar y enviar la documentación oficial carlista, y censurar la correspondencia, la prensa y a los periodistas tanto nacionales como extranjeros. Aunque, en septiembre de 1937, la Oficina de Prensa y Propaganda Carlista se disolvió, hacía medio año que, en marzo de 1937, había hecho entrega, a la Oficina de Salamanca, de los documentos gráficos que entonces custodiaba en sus Archivos, en OllanQuindia Aguirre, Ricardo., "La Oficina de Prensa y Propaganda Carlista de Pamplona al comienzo de la Guerra de 1936", en Príncipe de Viana, $n^{o}$ 205. Pamplona, Gobierno de Navarra, 1995, pp. 493-494. OLLAQUINDIA no explica cómo los documentos gráficos custodiados en los Archivos de la Oficina de Prensa y Propaganda Carlista de Pamplona llegaron a Salamanca. Sobre el modelo de represión que desarrolló la Junta Central Carlista de Guerra de Navarra a comienzos de la Guerra Civil, véase Mikelarena PeÑA, Fernando., Sin piedad. Limpieza política en Navarra, 1936. Responsables, colaboradores y ejecutores. Arre (Navarra), Pamiela, 2015. Mikelarena pone el foco en los verdugos, con sus diferentes niveles. 
Eguílaz se mostraba, en una carta enviada al Teniente General Agustín Muñoz Grandes, entonces Ministro Secretario General de FET de las JONS, fervoroso partidario de la Unificación, mostrándole cuál era la situación del partido carlista tras la Unificación, a través de un informe adjunto. En su carta, Ulibarri concluía que, en el citado informe,

elevado a S.E. el Generalísimo, a mediados del año 1938, por mediación del entonces Ministro de Justicia, Conde de Rodezno, los más genuinos representantes del Carlismo en Navarra suscribían la Unificación ${ }^{45}$.

Dos meses después de su carta dirigida a Muñoz Grandes, en septiembre de 1939, Marcelino de Ulibarri y Eguílaz se desplazó a Burgos, para jurar, con total solemnidad, su nombramiento como Consejero Nacional de FET de las $\mathrm{JONS}^{46}$, para el que había sido elegido, nombramiento de una gran trascendencia para su trayectoria personal, pues no sólo le afianzaba al frente de la dirección de la Delegación sino que -y esto es lo importante-, al poco tiempo, le posibilitaría dar comienzo a su trayectoria política en Madrid, lo cual le alejaría, junto a motivos personales relacionados con su salud, progresivamente, de la dirección de la Delegación.

En junio de 1940, Marcelino de Ulibarri y Eguílaz, fue nombrado Presidente del Tribunal Especial para la Represión de la Masonería y el Comunismo, puesto que desempeñó hasta marzo de 1941 y que compatibilizó con la dirección de la Delegación. En junio de ese mismo año 1940, Marcelino de Ulibarri había fijado su residencia, o domicilio particular, definitivamente, en Salamanca, en el número 37 del Paseo de los Carmelitas (entonces Avenida de Alemania), justo al otro de la ciudad respecto al edificio de San Estanislao de Kostka, sede de la Delegación ${ }^{47}$.

\footnotetext{
${ }^{45}$ CDMH. AGGCE. DNSD. Secretaría General. Expedientes Secretaría. Caja S.G. 046-080. Legajo 4. Expediente 73. Por contra, el profesor Julio PONCE AlBERCA sostiene que Marcelino de Ulibarri, de tendencia tradicionalista, mantuvo una escasa sintonía con el sector falangista del régimen, en PONCE ALBERCA, Julio., "Los gobernadores civiles en el primer franquismo", en Hispania. Revista Española de Historia, $n^{\circ}$ 252. Madrid. Consejo Superior de Investigaciones Científicas, 2016, pp. 262-263.

${ }^{46}$ CDMH. AGGCE. DNSD. Administración. Expedientes. Caja ADMON 041-070. Legajo 6. Expediente 67.

${ }^{47}$ CDMH. AGGCE. DNSD. Secretaría. Correspondencia. Caja 830-909. Legajo 52. Expediente 905.
} 
Dos años después, el 17 de julio de 1942, se produjo la apertura de las Cortes franquistas. En su condición de Consejero Nacional de Falange, Marcelino de Ulibarri y Eguílaz fue procurador en Cortes durante tres legislaturas, de marzo de 1943 a febrero de $1951^{48}$.

Durante seis años, desde marzo de 1942 hasta abril de 1948, por motivos de enfermedad, disfrutó de sucesivas y concatenadas licencias para su restablecimiento. La realidad es que Marcelino de Ulibarri y Eguílaz ya no volvería a hacerse cargo de la dirección del Archivo en Salamanca: fijó su residencia en Tafalla, al lado de su mujer Petra, y se dedicó a la vida política, viajando, desde Tafalla a Madrid, para asistir a las sesiones celebradas en las Cortes ${ }^{49}$. El 1 de abril de 1944, el Jefe del Estado, General Franco, concedió a Marcelino de Ulibarri y Eguílaz, la Encomienda, con placa, de la Orden de Cisneros, por sus servicios prestados ${ }^{50}$, y también la Gran Cruz de la Orden del Mérito Civil. En septiembre de 1944, Marcelino de Ulibarri y Eguílaz abandonaba la dirección de la Delegación.

\footnotetext{
${ }^{48}$ ARChivo Del CONGRESO DE los DipuTAdos (ACD), Serie Documentación Electoral, 183, nº 5.

${ }^{49}$ CDMH. AGGCE. DNSD. Administración. Expedientes. Caja ADMON 001-020. Legajo 1. Expediente 1.

50 “El día de la victoria en Sevilla”, en diario $A B C$, edición de Sevilla, del 2 de abril de 1944, p. 19.
} 


\section{EL PERSONAL DE LA DELEGACIÓN}

En la Delegación, trabajaron, en el periodo estudiado, 407 personas, que constituyen nuestra población.

En el periodo 1938-1944, trabajó en la Delegación una media anual de 91 personas. En el gráfico que se expone a continuación, se recoge el número máximo de personas que trabajaron en un determinado mes del año en cuestión en la Delegación:

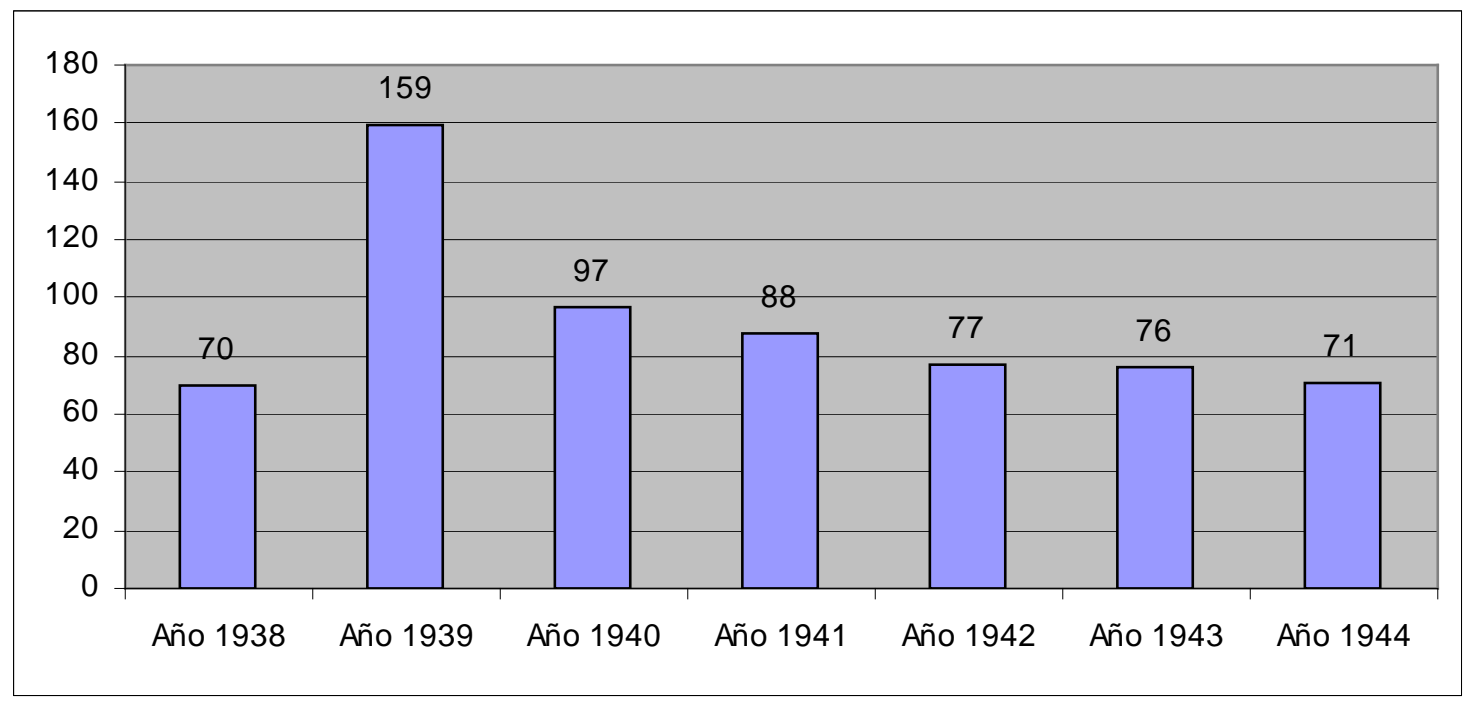

Fig. 2.1. Número de trabajadores, 1938-1944

FUENTES. CDMH. AGGCE. DNSD. Administración. Expedientes. Diez cajas, de la Caja ADMON 001-020 a la Caja ADMON 371-430. Cuadro de elaboración propia.

El número de personas que trabajaron en la Delegación osciló en función de las necesidades requeridas por la propia Delegación, y de las personas que estuvieran dispuestas e interesadas en desarrollar las funciones que requería la Delegación. 
El mes mayo de 1939 fue el momento en el que la Delegación contó con mayor número de recursos humanos:

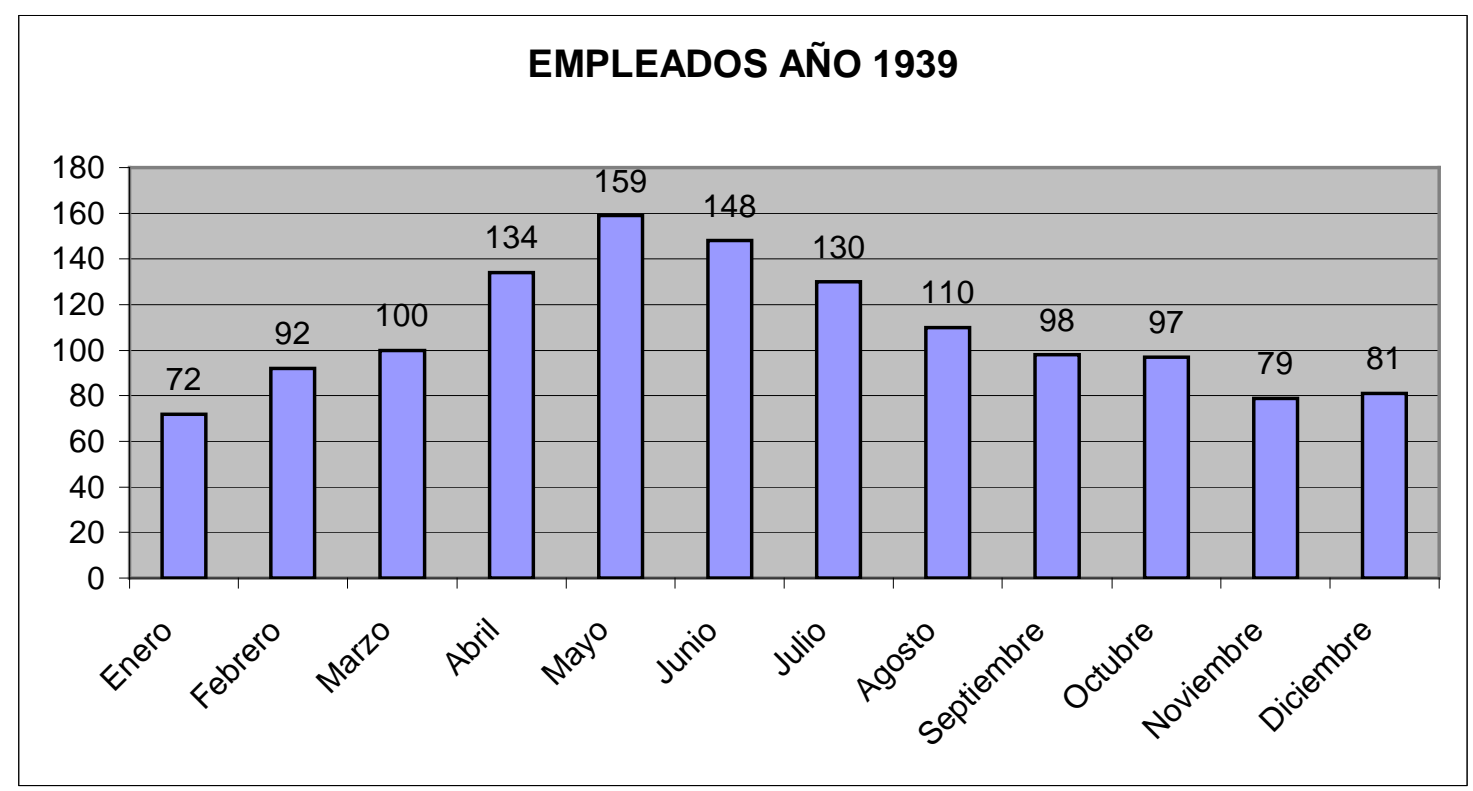

Fig. 2.2. Trabajadores en la Delegación en el año 1939

FUENTES. CDMH. AGGCE. DNSD. Administración. Expedientes. Diez cajas, de la Caja ADMON 001-020 a la Caja ADMON 371-430. Cuadro de elaboración propia.

Más concretamente, la Delegación contó con el mayor número de personal empleado en los meses que van desde el final de la Guerra Civil hasta el final de la primavera, de abril a junio de 1939. Ello se debió a la caída, consecutivamente, de las últimas grandes ciudades: Madrid, el 28 de marzo; Valencia, el 29 de marzo; y, finalmente, Alicante, la tarde del 30 de marzo de 1939. 
Por otra parte, en el gráfico siguiente, se expone el número de personas que trabajaron en la Delegación en función del tiempo de duración de la relación laboral con la misma. Más de 20 años, sólo llegaron a trabajar 14 personas, frente a las 121 que trabajaron entre uno y seis meses en la Delegación.

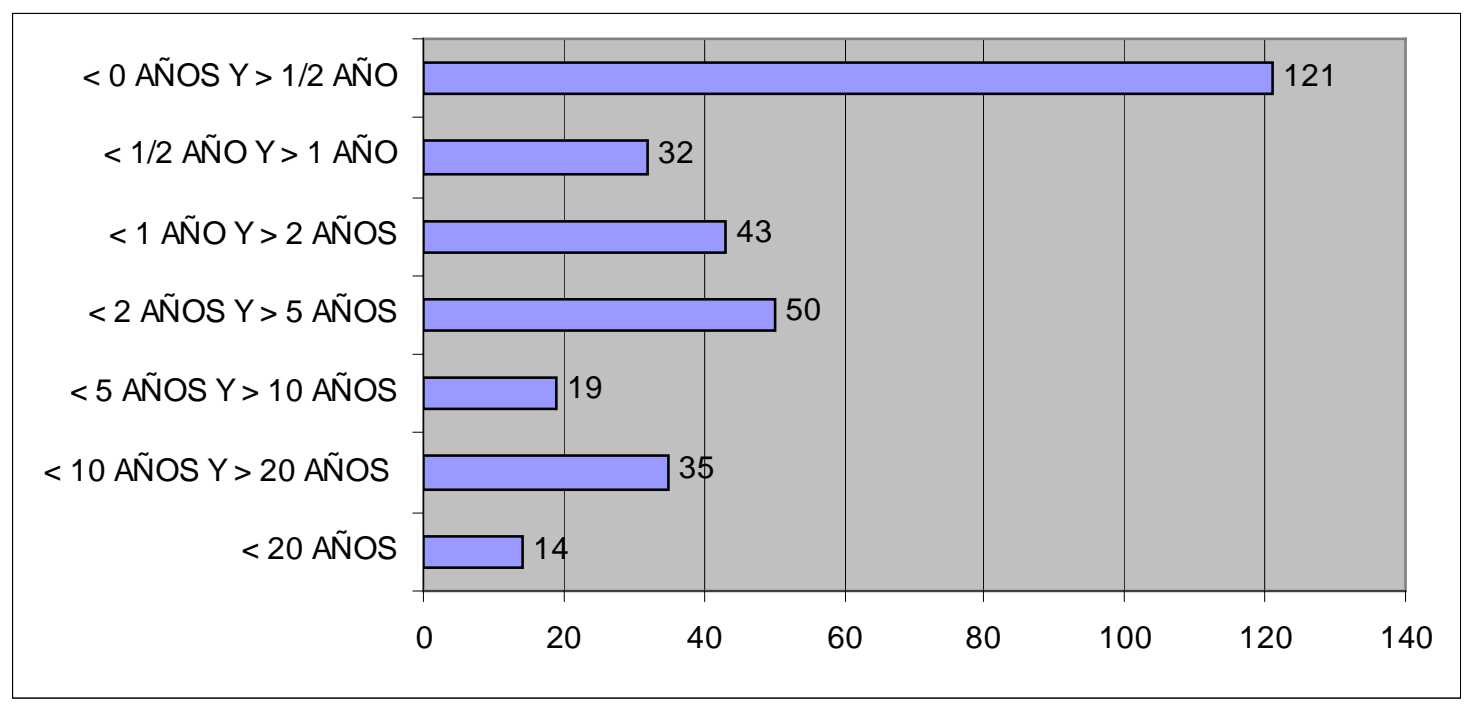

Fig. 2.3. Grado de temporalidad de la relación laboral

FUENTES. CDMH. AGGCE. DNSD. Administración. Expedientes. Diez cajas, de la Caja ADMON 001-020 a la Caja ADMON 371-430. Cuadro de elaboración propia.

El grado de temporalidad en la Delegación fue muy elevado. Una gran mayoría del personal empleado no llegó a estar más de medio año trabajando en la Delegación. Los motivos de la cancelación de los contratos fueron:

- Abandono de las obligaciones sin causa justificada. Los trabajadores dejaron de acudir a trabajar a la Delegación sin causa justificada.

- Finalización del servicio militar. Muchos de los trabajadores de la Delegación trabajaron en la misma mientras realizaron el servicio militar, antes de ser licenciados.

- Realización de estudios. Los trabajadores que simultaneaban el trabajo en la Delegación con sus estudios, abandonaron la misma, para centrarse en sus estudios y finalizar, en su caso, los mismos.

- Mejora en el empleo. Hay otros que encontraron empleos que consideraron mejores, como volver para ponerse al frente de la empresa familiar, y más seguros, tras superar una oposición, dentro de la Administración, siendo destinados, según el caso, a la 
seguridad social, el cuerpo de correos, la policía, el ejército, etc., por lo que todos ellos abandonaron su puesto de trabajo en la Delegación.

\subsection{CUALIFICACIÓN}

La cualificación del personal que trabajó en la Delegación se ha categorizado según su nivel de estudios. Se expone en la siguiente tabla:

\begin{tabular}{|l|c|}
\hline \multicolumn{1}{|c|}{ FORMACIÓN } & $\begin{array}{c}\text { NUMERO DE } \\
\text { PERSONAS }\end{array}$ \\
\hline ESTUDIOS CASTRENSES & 45 \\
\hline ESTUDIOS ECLESIÁSTICOS & 13 \\
\hline ESTUDIOS PRIMARIOS & 44 \\
\hline ESTUDIOS SECUNDARIOS & 42 \\
\hline ESTUDIOS MEDIOS & 20 \\
\hline ESTUDIOS SUPERIORES & 61 \\
\hline NO CONSTA & 182 \\
\hline \multicolumn{2}{|c|}{ TOTAL } \\
\hline
\end{tabular}

Tabla 2.4. Formación del personal de la Delegación

FUENTES. CDMH. AGGCE. DNSD. Administración. Expedientes. Diez cajas, de la Caja ADMON 001-020 a la Caja ADMON 371-430. Tabla de elaboración propia.

Las categorías empleadas nos las han proporcionado las propias fuentes documentales consultadas, los expedientes del personal que trabajó en la Delegación, contenidos en las diez cajas de la serie ADMON. Dichas categorías son las siguientes y se deben entender de la forma que se explicitan:

$1^{\circ}$. Estudios castrenses: enseñanzas relacionadas con la formación en la profesión militar.

$2^{\circ}$. Estudios eclesiásticos: enseñanzas relacionadas con la formación del clero, en particular, del clero regular de las órdenes religiosas.

$3^{\circ}$. Estudios primarios: primera etapa del sistema educativo, en la que se enseña a leer, escribir, nociones de cálculo y cultura general.

$4^{\circ}$. Estudios secundarios: enseñanza intermedia entre la primaria y la superior, en cuyos últimos cursos se incluye el bachillerato. 
$5^{\circ}$. Estudios medios: títulos académicos que capacitaban para diversas profesiones y que se obtenían al acabar una carrera universitaria de tres años.

$6^{\circ}$. Estudios superiores: enseñanzas que comprenden los estudios que requiere cada profesión, como, por ejemplo, derecho o medicina.

Los estudios superiores que poseían los trabajadores de la Delegación se desarrollan en la siguiente tabla:

\begin{tabular}{|l|c|}
\hline \multicolumn{1}{|c|}{ TIPOS DE ESTUDIOS SUPERIORES } & $\begin{array}{c}\text { NUMERO DE } \\
\text { PERSONAS }\end{array}$ \\
\hline CIENCIAS EXACTAS & 2 \\
\hline CIENCIAS QUÍMICAS & 2 \\
\hline DERECHO & 45 \\
\hline FARMACIA & 1 \\
\hline FILOSOFIA Y LETRAS & 6 \\
\hline HUMANIDADES & 1 \\
\hline MEDICINA & 4 \\
\hline \multicolumn{2}{r|}{ TOTAL } \\
\hline
\end{tabular}

Tabla 2.5. Tipos de estudios superiores realizados por el personal de la Delegación

FuENTES. CDMH. AGGCE. DNSD. Administración. Expedientes. Diez cajas, de la Caja ADMON 001-020 a la Caja ADMÓN. 371-430. Tabla de elaboración propia.

Cabe destacar que, entre los trabajadores que tenían estudios superiores, la gran mayoría había cursado estudios jurídicos. El personal que trabajó, desde su creación, en la Delegación del Estado para Recuperación de Documentos, era un personal que no tenía formación archivística alguna. El personal de la Delegación adquirió, a pesar de su temporalidad, a través de una utilización de técnicas eminentemente prácticas, de manera autodidacta, un cierto nivel de conocimiento archivístico y, sobre todo, tuvo claro, desde el principio, la finalidad, en este caso, de la archivística: servir información a la Administración General del Estado, en general, y a los Tribunales Especiales de Justicia, a la Administración de Justicia, en particular, con fines represivos. 


\subsection{IDEOLOGÍA}

La ideología política de los trabajadores de la Delegación era mayoritariamente, el carlismo, seguida por la ideología falangista:

\begin{tabular}{|l|c|}
\hline \multicolumn{1}{|c|}{ IDEOLOGÍA POLÍTICA } & TRABAJADORES \\
\hline CARLISMO & 89 \\
\hline FALANGISMO & 74 \\
\hline CONSERVADURISMO & 3 \\
\hline SIN IDEOLOGÍA DEFINIDA & 241 \\
\hline
\end{tabular}

Tabla 2.6. Ideología política del personal de la Delegación

FuENTES. CDMH. AGGCE. DNSD. Administración. Expedientes. Diez cajas, de la Caja ADMON 001-020 a la Caja ADMON 371-430. Tabla de elaboración propia.

Las categorías empleadas nos las han proporcionado las propias fuentes documentales consultadas, los expedientes del personal que trabajó en la Delegación, contenidos en las diez cajas de la serie ADMON. Dichas categorías son las siguientes y se deben entender de la forma que se explicitan:

$1^{\circ}$. Carlismo: doctrina política del movimiento que se originó por las pretensiones del infante Carlos de Borbón de suceder a Fernando VII contra la entronización de Isabel II, y que defendía el absolutismo y propugnaba reformas dentro de una continuidad tradicionalista ${ }^{51}$.

$2^{\circ}$. Falangismo: movimiento político español impulsado por la Falange, partido cuya ideología se inspiró en el fascismo italiano y sirvió de base del régimen franquista $^{52}$.

$3^{\circ}$. Conservadurismo: doctrina política de los partidos conservadores ${ }^{53}$.

\footnotetext{
${ }^{51}$ BULlón DE MENDOZA, Alfonso., La primera guerra carlista. Madrid, Universidad Complutense, 2001.

52 RODRÍGUEZ JiMÉNEZ, José Luis., Historia de la Falange Española de las JONS. Madrid, Alianza Editorial, 2000.

53 Sobre el conservadurismo español, véase la obra clásica de SECO SERRANO, Carlos., Historia del Conservadurismo español. Madrid, Temas de Hoy, 2000; y, el artículo de Álvarez JunCO, José., "El conservadurismo español, entre religión y nación", en CASTELLS ARTECHE, Luis (coord.)., Del territorio a la nación: identidades territoriales y construcción nacional. Alicante, Biblioteca Nueva, 2016, pp. 3963. Para las ideologías surgidas en el primer tercio del siglo XX en Europa, el comunismo y el nacionalsocialismo, véase el estudio clásico de SABINE, George., Historia de la Teoría Política. México, Fondo de Cultura Económica, 1999, pp. 579-663.
} 
$4^{\text {o }}$ Sin ideología definida: la ideología no aparece reflejada en los expedientes del personal de la Delegación, contenidos en las diez cajas de la serie ADMON.

Como consecuencia lógica, una gran parte de los trabajadores de la Delegación habían militado, antes de la Guerra Civil, en los partidos políticos Comunión Tradicionalista y Falange Española (los denominados “camisas viejas"), y, después de la unificación de ambos partidos, militaron en Falange Española Tradicionalista de las JONS:

\begin{tabular}{|l|c|}
\hline \multicolumn{1}{|c|}{ PARTIDO POLÍTICO } & TRABAJADORES \\
\hline FALANGE ESPAÑOLA & 15 \\
\hline COMUNIÓN TRADICIONALISTA & 13 \\
\hline CEDA & 1 \\
\hline FET DE LAS JONS & 59 \\
\hline SIN FILIACIÓN POLÍTICA & 319 \\
\hline
\end{tabular}

Tabla 2.7. Partidos políticos en los que militaron los trabajadores de la Delegación

FuENTES. CDMH. AGGCE. DNSD. Administración. Expedientes. Diez cajas, de la Caja ADMON 001-020 a la Caja ADMÓN. 371-430. Tabla de elaboración propia.

Las categorías empleadas nos las han proporcionado las propias fuentes documentales consultadas. Dichas categorías son las siguientes y se deben entender de la forma que se explicitan:

$1^{\circ}$. Falange Española: partido político, fundado el 29 de octubre de 1933, por José Antonio Primo de Rivera, desaparecido, tras el Decreto de Unificación, de 19 de abril de 1937. Quince trabajadores de la Delegación, "camisas viejas", no aceptaron la Unificación.

$2^{\circ}$. Comunión Tradicionalista: partido político, fundado en la década de los años 30 del siglo XX, durante la II República. Trece trabajadores de la Delegación, afiliados a Comunión Tradicionalista, no aceptaron la Unificación.

$3^{\circ}$. CEDA (Confederación Española de Derechas Autónomas): partido político, creado como una coalición de partidos políticos conservadores y católicos, durante la II República, en 1933. Desapareció en 1937. Uno de los trabajadores de la Delegación, cuando ingresó en el mismo, había militado en la CEDA.

$4^{\circ}$. FET de las JONS: partido único del régimen franquista, creado por el Decreto de Unificación, de 19 de abril de 1937, que unió a los partidos políticos Falange Española y Comunión Tradicionalista. 
$5^{\circ}$. Sin filiación política: parte del personal que no militaba en ningún partido político al ingresar en la Delegación.

\subsection{PROCEDENCIA}

La procedencia de los trabajadores de la Delegación fue la siguiente:

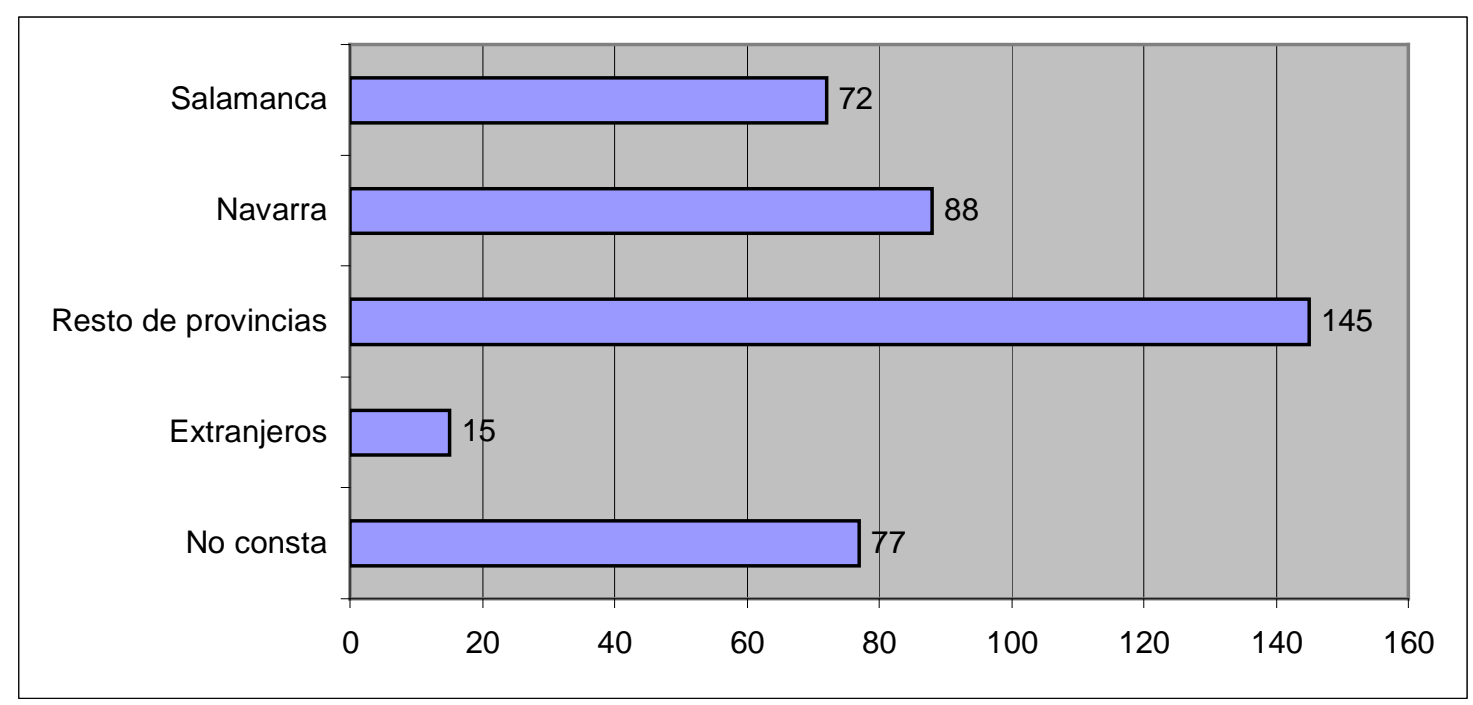

Fig. 2.8. Procedencia del personal de la Delegación

FuENTES. CDMH. AGGCE. DNSD. Administración. Expedientes. Diez cajas, de la Caja ADMON 001-020 a la Caja ADMÓN. 371-430. Cuadro de elaboración propia.

La mayoría de los trabajadores que tuvo la Delegación, de los que se conoce su origen, eran de Navarra y Salamanca.

Los navarros estaban asociados a la figura del director, Marcelino de Ulibarri, y los salmantinos al lugar donde se emplazó la Delegación, Salamanca.

Asimismo, ambos grupos cohabitaron en el Archivo, es decir, fueron los que trabajaron juntos en el Archivo central de Salamanca, frente a los del resto de provincias españolas, que trabajaron en los archivos de la red de archivos dependientes del Archivo central salmantino. 
El Archivo que perdía los papeles. El Archivo de la Guerra Civil según el fondo documental de la DNSD

La procedencia de los trabajadores de la Delegación por provincias es la siguiente:

\begin{tabular}{|c|c|}
\hline $\begin{array}{l}\text { PROVINCIA DE } \\
\text { PROCEDENCIA }\end{array}$ & NÚMERO DE PERSONAS \\
\hline ALICANTE & 12 \\
\hline ALMERÍA & 1 \\
\hline ASTURIAS & 6 \\
\hline ÁVILA & 3 \\
\hline BALEARES & 1 \\
\hline BARCELONA & 11 \\
\hline BURGOS & 1 \\
\hline CÁCERES & 3 \\
\hline CANTABRIA & 11 \\
\hline CASTELLÓN & 9 \\
\hline CÓRDOBA & 1 \\
\hline CORUÑA, LA & 4 \\
\hline CUENCA & 1 \\
\hline GERONA & 1 \\
\hline GRANADA & 1 \\
\hline GUADALAJARA & 4 \\
\hline GUIPÚZCOA & 7 \\
\hline JAÉN & 1 \\
\hline LEÓN & 3 \\
\hline LÉRIDA & 1 \\
\hline LUGO & 1 \\
\hline MADRID & 25 \\
\hline MELILLA & 1 \\
\hline MURCIA & 1 \\
\hline NAVARRA & 88 \\
\hline ORENSE & 1 \\
\hline PALENCIA & 3 \\
\hline RIOJA, LA & 1 \\
\hline SALAMANCA & 72 \\
\hline SEGOVIA & 1 \\
\hline SEVILLA & 2 \\
\hline TARRAGONA & 2 \\
\hline TERUEL & 2 \\
\hline TOLEDO & 1 \\
\hline VALENCIA & 24 \\
\hline VALLADOLID & 4 \\
\hline VIZCAYA & 6 \\
\hline ZAMORA & 2 \\
\hline ZARAGOZA & 4 \\
\hline NO CONSTA & 77 \\
\hline
\end{tabular}

Tabla 2.9. Provincias de procedencia 
También, hubo trabajadores extranjeros en la Delegación, cuya nacionalidad fue la siguiente:

\begin{tabular}{|l|c|}
\hline \multicolumn{1}{|c|}{ PAÍS DE PROCEDENCIA } & $\begin{array}{c}\text { NÚMERO } \\
\text { DE } \\
\text { PERSONAS }\end{array}$ \\
\hline ALEMANIA & 1 \\
\hline CHILE & 1 \\
\hline CUBA & 1 \\
\hline FILIPINAS & 1 \\
\hline ITALIA & 1 \\
\hline MARRUECOS & 1 \\
\hline
\end{tabular}

Tabla 2.10. Países extranjeros de procedencia

De entre ellos, cabe reseñar a Fernand Walter Rummel, nacido el 12 de noviembre de 1908 en Chemnitz (Sajonia, Alemania). Industrial de profesión, ingresó en la Delegación de Madrid, el 7 de abril de 1939. Por dejar de acudir, sin causa justificada, a su trabajo, el 1 de junio de 1939, fue dado de baja de la misma ${ }^{54}$. A Juan González de Andía Irarrazábal y García-Moreno, nacido el 3 de septiembre de 1885 en Santiago de Chile. Era un aristócrata chileno. Trabajó en la Delegación de Madrid del 23 de junio al 21 de septiembre de $1939^{55}$. Y, a Teodoro Manuel Comín Mases, nacido el 13 de junio de 1917 en La Habana (Cuba). El 10 de mayo de 1938, solicitó, por carta, dirigida al Delegado del Estado para Recuperación de Documentos, su ingreso en la Delegación. Como auxiliar de equipo, trabajó en los equipos de recuperación de documentos en los frentes de Aragón, Levante y Cataluña. El 30 de octubre de 1939, causó baja en la Delegación ${ }^{56}$.

54 CDMH. AGGCE. DNSD. Administración. Expedientes. Caja ADMON 206-290. Legajo 12. Expediente 265 .

55 CDMH. AGGCE. DNSD. Administración. Expedientes. Caja ADMON 206-290. Legajo 11. Expediente 208.

${ }^{56}$ CDMH. AGGCE. DNSD. Administración. Expedientes. Caja ADMON 121-205. Legajo 9. Expediente 130. 


\section{SERVICIOS A LOS TRABAJADORES: EL ALOJAMIENTO DEL PERSONAL DE LA DELEGACIÓN}

En un primer momento, y debido al interés que tanto Ayuntamiento como Diputación Provincial de Salamanca mostraron por que los órganos de Gobierno del Estado franquista se mantuvieran en la capital salmantina, el Ayuntamiento se encargó de alojar a todo el personal de la Delegación.

Fue el Ayuntamiento el encargado de buscar y encontrar alojamiento individualizado para cada miembro del personal de la Delegación, entre los vecinos de Salamanca, en sus casas particulares ${ }^{57}$.

Marcelino de Ulibarri quería centralizar el alojamiento del personal, para tener un mayor control sobre el mismo. Por ello, debido al problema del alojamiento del personal de la Delegación, y de la alta temporalidad, pues unos se iban al mes o menos y otros ingresaban, a comienzos de mayo de 1938, Marcelino de Ulibarri se puso en contacto con Inés Luna Terrero. El 31 de mayo, Inés Luna Terrero hizo saber, en una breve carta, a Marcelino de Ulibarri, que cedía, a la Delegación del Estado para Recuperación de Documentos, para alojar al personal de la misma que se estimara oportuno, su inmueble de la calle de San Francisco, ya, en 1938, calle Ramón y Cajal, nº 12 antiguo. Al día siguiente, 1 de junio, Marcelino de Ulibarri enviaba, a Inés Luna Terrero, también una breve carta, para "testimoniarle su generosidad" "58. El personal de la Delegación se alojó en la planta baja y en el ático del inmueble ${ }^{59}$.

\footnotetext{
${ }^{57}$ Así, los trabajadores de la Delegación se hospedaron por toda la ciudad: la calle de Los Ovalle, $\mathrm{n}^{\mathbf{0}} 2$, cerca de la avenida de Portugal y la Estación de Tren; la calle Vista Alegre, $\mathrm{n}^{\circ}$ 7, en el barrio de la Prosperidad, cerca del Noviciado y de la Delegación; la calle Zamora, $n^{\circ} 36$; el paseo de Canalejas, $n^{\circ} 21$; el pasaje de la Caja de Ahorros, $\mathrm{n}^{\circ}$ 7, que une la Plaza Mayor y la calle Espoz y Mina; e incluso el entonces párroco de la Iglesia de Sancti Spíritus, Francisco García, facilitó hospedaje a uno de los trabajadores de la Delegación. Todo ello se puede consultar en CDMH. AGGCE. DNSD. Secretaría. Correspondencia. Caja 073-124. Legajo 6. Expediente 101. Las fuentes no reflejan cómo el Ayuntamiento organizó todo el alojamiento del personal de la Delegación, es decir, cuántos fueron a cada vivienda particular.

${ }^{58}$ CDMH. AGGCE. DNSD. Secretaría General. Expedientes Secretaría. Caja 970. Legajo 30. Expediente 6. Las fuentes no facilitan el número de trabajadores de la Delegación que se alojaron en la planta calle, o entresuelo, y el ático del inmueble cedido por Inés Luna Terreros para tal fin.

59 Inés Luna Terrero, apodada "B.B." (Bagnères-de-Luchon, Francia, 02.07.1885 - Barcelona, 08.02.1953) era hija de Carlos Luna Beovide y de Inés Terrero. Su padre, Carlos Luna Beovide, fue la persona que se encargó de traer la luz eléctrica e iluminar Salamanca, haciendo la primera prueba en el Campo o Parque de San Francisco, además de otros avances técnicos que conoció en Francia, como las
} 
No obstante, y a pesar de obtener el inmueble de Inés Luna Terrero, Marcelino de Ulibarri era consciente del problema que, el alojamiento del personal que trabajaba en la Delegación, seguía ocasionando al Ayuntamiento y las molestias que ocasionaba a los vecinos de la ciudad. Además, Marcelino de Ulibarri era partidario, por motivos de control y de disciplina interna, de tener a todo el personal reunido en un mismo edificio.

El 4 de julio de 1938, Marcelino de Ulibarri comunicaba al Ayuntamiento de Salamanca haber encontrado el edificio adecuado, entre otras características, por sus dimensiones, para dar alojamiento a todo el personal de la Delegación: se trataba del Colegio de San Ambrosio $^{60}$. Según le confesaba Marcelino de Ulibarri al funcionario municipal Dimas Ledesma Martín, “en el Colegio de San Ambrosio, [quitaremos], a este Ayuntamiento, de las molestias que los alojamientos llevan consigo"61. Eso sí, el Colegio de San Ambrosio se encontraba falto del más mínimo y elemental mobiliario necesario, incluyendo la vajilla o cubertería, para que el personal de la Delegación pudiera dormir y desayunar allí. Por ello, Ulibarri rogaba al Ayuntamiento que se encargara de suministrarlo. El mínimo mobiliario necesario consistía en:

$1^{\circ}$. Para dormir: treinta camas; treinta colchones; treinta almohadas; sesenta fundas de almohada; sesenta sábanas cubre-colchón; sesenta sábanas encimeras; y, treinta mantas.

máquinas de segar y otro tipo de abonos. Su madre, Inés Terrero, era una importante terrateniente, que tenía propiedades por toda la provincia de Salamanca. Inés Luna Terrero fue una importante aristócrata, considerada exponente de la mujer modernista española. Aunque viajaba mucho y hablaba siete idiomas, estableció su residencia habitual en la Casa-Palacio de su finca de El Cuartón (Vitigudino), rodeada de jardines y esculturas de mármol, y que contaba con luz eléctrica, piscina y capilla para la celebración de misas de rito oriental. Aficionada a los toros, en su Casa-Palacio, se hospedaron los hermanos Bienvenida, toreros. Murió, en 1953, en Barcelona, a consecuencia de un cáncer de mama. Mantuvo una relación sentimental con el dictador Miguel Primo de Rivera y Obaneja (Jerez de la Frontera, Cádiz, 08.01.1870 - París, 12.03.1930). Sobre la figura de Inés Luna Terrero, véase LloPIS LLOPIS, Salvador., La prócer dama doña Inés Luna Terreros. Sus precedentes y familiares cercanos. Salamanca, Gráficas Cervantes, 2000. Desde febrero de 2009, los fondos del Archivo personal, y familiar, de Inés Luna Terrero, formado por 272 cajas, más un cofre de pergaminos, de los siglos XV al XX, se pueden consultar en el Archivo Histórico Provincial de Salamanca, donde se encuentran depositados. En la actualidad, en el número 15 de la calle Ramón y Cajal, se encuentra el Colegio Mayor Oriental de la Universidad Pontificia de Salamanca, en el que se facilita alojamiento a los estudiantes de postgrado de la citada Universidad salmantina.

${ }^{60}$ CDMH. AGGCE. DNSD. Secretaría. Correspondencia. Caja 073-124. Legajo 6. Expediente 101.

${ }^{61}$ CDMH. AGGCE. DNSD. Secretaría. Correspondencia. Caja 125-200. Legajo 7. Expediente 153. 
$2^{\circ}$. Para el aseo personal: veinte orinales; doce palanganas; doce espejos; doce jarras de agua; sesenta toallas; $y$, veinte perchas.

$3^{\circ}$. Para desayunar: treinta tazones de café; treinta vasos; treinta cucharillas; $y$, dos azucareros.

Además, el edificio necesitaba la instalación del agua corriente y de la luz eléctrica. Era evidente, por las cifras que se facilitan en el mínimo mobiliario necesario, que el Colegio de San Ambrosio podía dar alojamiento a treinta trabajadores de la Delegación $^{62}$.

El 15 de julio de 1938, Marcelio de Ulibarri se dirigía, en calidad de Presidente de la Junta del Patronato del Colegio de San Ambrosio, a Enrique Plá y Deniel, Obispo de Salamanca, solicitándole la utilización del citado edificio, sito en el número 2 de la calle Gibraltar, que se encontraba deshabitado, "para poder servir de alojamiento al personal empleado en el Servicio de Recuperación de Documentos"63. Ocho días después, Enrique Plá y Deniel, Obispo de Salamanca, le contestaba, que, reunida, el 19 de julio, la Junta del Patronato del Colegio de San Ambrosio, ésta había resuelto acordar la utilización del Colegio de San Ambrosio, para poder servir de alojamiento al personal empleado en Recuperación de Documentos ${ }^{64}$.

El 7 de agosto de 1938, Marcelino de Ulibarri comunicaba a Enrique Plá y Deniel, que, el 24 de julio de 1938, se había hecho cargo del Colegio de San Ambrosio ${ }^{65}$.

\footnotetext{
${ }^{62}$ CDMH. AGGCE. DNSD. Secretaría. Correspondencia. Caja 073-124. Legajo 6. Expediente 101; y, Caja 125-200. Legajo 7. Expediente 153.

${ }^{63}$ CDMH. AGGCE. DNSD. Secretaría. Correspondencia. Caja 033-072. Legajo 4. Expediente 72.

${ }^{64}$ CDMH. AGGCE. DNSD. Secretaría. Correspondencia. Caja 033-072. Legajo 4. Expediente 72.

${ }^{65}$ Asimismo, en su misiva, Marcelino de Ulibarri le daba cuenta de las dos obras realizadas en el edificio: la instalación de luz eléctrica, en la parte izquierda del primer piso y en toda la parte habitable del segundo piso, procediéndose a la colocación de veinte bombillas en total (para la instalación de la luz eléctrica en el Colegio de San Ambrosio, Felipe Rodríguez, Comandante de Ingenieros, empleó 200 metros de cable); y la instalación del agua corriente, gracias a dos grifos de agua. Además, Ulibarri le comunicaba, también, al Obispo de Salamanca, no devolver los objetos de culto, que se encontraban en la capilla del Colegio de San Ambrosio, ya que había resuelto celebrar misa diaria, a primera hora de la mañana, a la que asistiría todo el personal alojado en el Colegio. CDMH. AGGCE. DNSD. Secretaría. Correspondencia. Caja 033-072. Legajo 4. Expediente 72.
} 


\section{EL PERFIL DEL ARCHIVERO QUE TRABAJÓ EN LA DELEGACIÓN}

El perfil del archivero que trabajó en la Delegación, a partir del año 1938, en Salamanca, como se describe en el capítulo, apoyándonos en los estudios estadísticos que se aportan, es el de una persona:

I. Cualificada, puesto que, aunque pudiera haberse dedicado a otra profesión con anterioridad, tenía estudios superiores o los estaba realizando en ese momento, en concreto, con formación jurídica, licenciado o estudiante de Derecho.

II. No llegaba a ejercer la profesión de archivero más de medio año, por lo que el grado de temporalidad, en la Delegación, era muy elevado. El trabajo en la Delegación, para estas personas, fue temporal, ocasional, debido, en muchos casos, a la coyuntura histórica de la propia Guerra Civil y a la dureza existencial de la posguerra, y, por tanto, cuando les surgió una oportunidad laboral mejor, no dudaron en abandonar la Delegación.

III. Naturales, mayoritariamente, de las provincias de Navarra y de Salamanca.

IV. De orientación política carlista, el natural de Navarra, o afiliado a Falange Española Tradicionalista y de las Juntas de Ofensiva Nacional Sindicalista (FET de las JONS), el natural de la provincia de Salamanca o procedente del resto de España. 


\section{CAPÍTULO 3}

La sede de la Delegación. El edificio de San Estanislao de Kostka 
El objetivo del capítulo tercero es explicar el porqué la Delegación del Estado para Recuperación de Documentos se instaló en el edificio del Noviciado de San Estanislao de Kostka.

Para ello, el capítulo se estructura en dos apartados. El primero está dedicado a conocer la historia del edificio, los usos que tenía el edificio cuando la Delegación se emplazó en el mismo y las condiciones en las que la Delegación se instaló en el edificio. El segundo apartado de este capítulo trata de las instalaciones del edificio en relación con la conservación de los documentos custodiados en la Delegación. Finalmente, en un tercer apartado, se reúnen las conclusiones a las que se ha llegado en el capítulo.

La Ley 16/1985, de 25 de junio, del Patrimonio Histórico Español, en su artículo 59.1., afirma que un archivo es una institución "donde [...] se conservan [...] conjuntos orgánicos de documentos”. Esta acepción de archivo, como lugar de conservación de los documentos, constituye su significado más antiguo. Según Elio LODOLINI, "el más antiguo significado de la palabra archivo se refiere al lugar en el que se conservan los documentos"66. Esta acepción, consecuencia de la definición dada por los juristas de la antigua Roma a los archivos, permaneció vigente durante la Edad Media y la Edad Moderna. No obstante, ha llegado hasta nuestros días, siendo este sentido de archivo, a la vez, el más antiguo y el menos usado. Por ello, aparece como la segunda acepción del Diccionario de la Lengua Española de la Real Academia Española (Madrid, EspasaCalpe, 2016, 23ª edición), en la que se define archivo como un "lugar donde se conservan $[\ldots .$.$] uno o varios conjuntos ordenados de documentos".$

Todo archivo es, por tanto, un lugar físico, un edificio o conjunto de edificios, donde se reúnen documentos, y sus instalaciones están determinadas por las finalidades del

\footnotetext{
${ }^{66}$ LODOLINI, Elio., Archivística. Principios y problemas. Madrid, ANABAD, 1993, p. 64.
} 
servicio que éste presta. Y todo archivo, sea éste más grande o más pequeño en función del volumen de documentos que alberga, o sea tenido por más o menos importante, suele contar con tres elementos que le son esenciales: depósitos, locales de clasificación y sala de consulta o de lectura.

El Archivo se identifica con el Colegio de San Ambrosio, su actual sede, pero al principio no fue así.

En un principio, el edificio elegido, por las autoridades políticas de la época, para ser sede de la Delegación del Estado para Recuperación de Documentos fue el Noviciado de San Estanislao de Kostka. La Delegación fue instalado en un edificio de carácter histórico. Como suele ocurrir con este tipo de edificios de carácter histórico, éste había sido construido para otro fin, bastante alejado del de acoger un archivo, la preparación de novicios jesuitas.

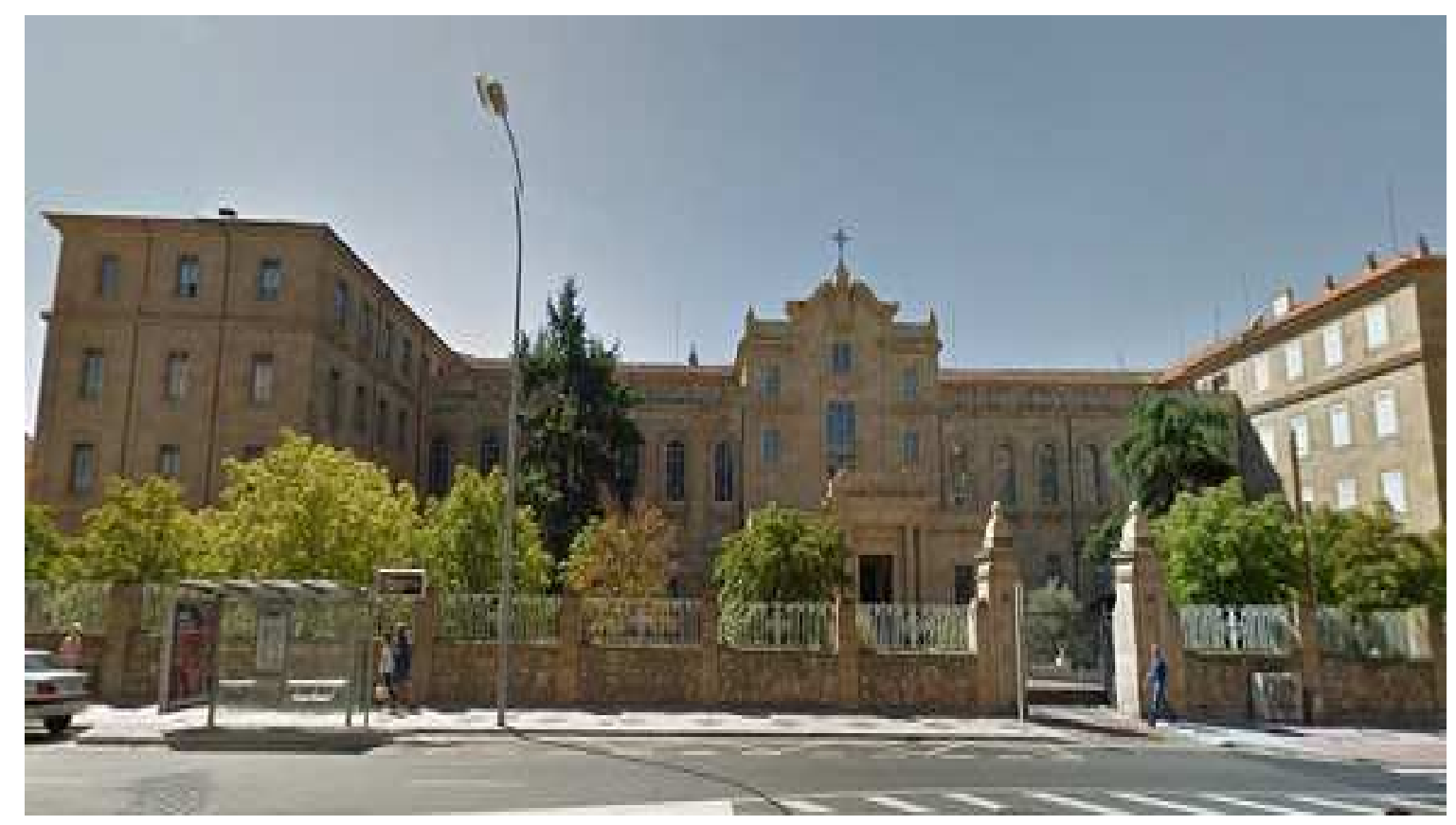

Fig. 3.1. Delegación del Estado para Recuperación de Documentos o Archivo central de Salamanca. Edificio de San Estanislado de Kostka. Paseo de San Antonio, s/n 


\section{EL EDIFICIO: EL NOVICIADO DE SAN ESTANISLAO DE KOSTKA}

\subsection{LA CONSTRUCCIÓN DEL EDIFICIO}

El edificio del Noviciado de San Estanislao de Kostka comenzó a construirse el 28 de mayo de 1922. El edificio fue proyectado por el arquitecto José Yarnoz Larrosa ${ }^{67}$, que, junto al hermano jesuita Pedro Eguíluz, fue el encargado de dirigir las obras de construcción del edificio. Dichas obras de construcción del Noviciado se prolongaron, durante cuatro años y un mes, de mayo de 1922 a julio de 1926. El edificio fue inaugurado el 27 de agosto de 1926, para una comunidad religiosa formada por 160 jesuitas, y abierto al público el 10 de octubre de 1926.

Se trata de un edificio de una estructura sólida, construido empleando tres tipos distintos de piedra: para la base del edificio, se empleó piedra granítica de Villavieja de Yeltes; para la mampostería, se utilizó piedra extraída de una cantera de Carbajosa, cantera que estaba ubicada junto a la carretera de Alba de Tormes; y, finalmente, para la fachada, se empleó la siempre aparente, elegante y característica piedra de Villamayor. También, en menor medida, para la construcción del edificio, se empleó hormigón armado.

\subsection{LOS USOS DEL EDIFICIO}

Cuando el Archivo de la Delegación del Estado para Recuperación de Documentos fue instalado en el Noviciado de San Estanislao de Kostka, el edificio ya se encontraba ocupado por otros organismos.

En el curso 1933-1934, el edificio fue ocupado por el Instituto de Enseñaza Media, hasta entonces ubicado en los edificios del Patio de Escuelas Menores, impartiéndose,

\footnotetext{
${ }^{67}$ Como arquitecto, José Yarnoz Larrosa (Pamplona, 1884 - Madrid, 1965) fue contratado, en 1916, por el Banco de España para proyectar y construir las oficinas del Banco de España en las capitales de provincia, incluyendo, entre otras, las de Castilla y León, en concreto, las oficinas de Ávila, León, Segovia, Soria y Valladolid, que son de su autoría, además de la ampliación de la sede central del Banco de España, realizada en 1927. Además, realizó la reconstrucción del Castillo Real de Olite (1924), el Pabellón de Navarra en la Exposición Iberoamericana de Sevilla (1929), la ampliación del Palacio de la Diputación Foral de Navarra (1934) y la construcción de la Iglesia de San Miguel de Pamplona (1942).
} 
allí, todos los cursos del Bachillerato. Diez años después, el Instituto de Enseñanza Media sería desalojado del Noviciado a finales del curso 1943-1944, en los meses de julio y agosto de $1944^{68}$.

La escolta del general Franco, formada por requetés navarros, residió en el pabellón oriental del edificio, junto con las milicias de Falange. En este pabellón, residió también el líder falangista Manuel Hedilla. Tras promulgarse el Decreto de Unificación, de falangistas y carlistas, en abril de 1937, las milicias de Falange fueron desalojadas del edificio.

El Ministerio del Aire: Desde 1937 hasta 1939, el pabellón central del edificio fue ocupado por el Ministerio del Aire.

El Parque Militar Móvil, que propició, desde 1937, que la Huerta de los Jesuitas se convirtiera, hasta llegar a la tapia del ferrocarril, en un cementerio de automóviles. En las Navidades de 1939-1940, el Parque Militar Móvil fue desalojado del edificio del Noviciado.

Tras la expulsión de las milicias de Falange del edificio, desde 1937, su espacio, el pabellón oriental del mismo, fue ocupado por el Hospital Militar u Hospital de Sangre, que, también, con su abundante material clínico, ocupó el sótano del Noviciado, Hospital que estuvo allí ubicado hasta octubre de 1939, fecha en la que, tras el Decreto, de 7 de mayo de 1938, de Restauración de la Compañía de Jesús ${ }^{69}$, con el regreso de los jesuitas, fue suprimido.

El 7 de mayo de 1938, fue promulgado el Decreto de Restauración de la Compañía de Jesús en España. Al amparo del mismo, los jesuitas regresaron a Salamanca el 2 de septiembre de 1939 y se les se hizo entrega del edificio del Noviciado de San Estanislao

68 En cumplimiento del artículo 26 de la Constitución Española de 1931, que ya preveía la nacionalización de los bienes de la Iglesia con fines benéficos y docentes; del Decreto, de 23 de enero de 1932, de disolución de la Compañía de Jesús, que afectó a 3.000 jesuitas, y, en concreto, en Salamanca, a 220 jesuitas; y del Decreto, de 29 de abril de 1933, se concedió, al Ministerio de Instrucción Pública, el edificio del Noviciado de la Compañía de Jesús en Salamanca.

${ }^{69}$ Boletín Oficial del Estado, $n^{\circ} 563$, de 7 de mayo de 1938, pp. 7.162-7.163. El Decreto de Restauración de la Compañía de Jesús en España fue impulsado por el carlista Tomás Domínguez Arévalo, Conde de Rodezno, entonces Ministro de Justicia, aunque contó con la oposición de los falangistas del Gobierno franquista, encabezados por Serrano Suñer. 
de Kostka, en concreto, de la parte ocupada, hasta esa fecha, por el Hospital Militar, un espacio de $1.200 \mathrm{~m} 2^{70}$.

\subsection{LA INSTALACIÓN DEL ARCHIVO EN EL EDIFICIO}

El 18 de septiembre de 1937, todo el tercer piso del pabellón occidental, o ala izquierda del edificio, junto al desván, del edificio del Noviciado de San Estanislao de Kostka fue requisado por el Estado Mayor del Cuartel General del Generalísimo y puesto a disposición de Laureano de Armas, Comandante-Jefe de Intendencia del citado Cuartel General. La requisa del tercer piso del pabellón occidental del edificio, que formaba parte del Instituto de Enseñanza Media, fue comunicada a Dimas Ledesma Martín, Ingeniero Jefe responsable del Urbanismo y del Catastro Urbano en el Ayuntamiento de Salamanca, y al Rector de la Universidad de Salamanca, como responsable último del Instituto $^{71}$. La Delegación del Estado para Recuperación de Documentos se instaló en el Noviciado de San Estanislao de Kostka el 23 de septiembre de 1937. Allí, estuvo ubicada once años y medio, desde el 23 de septiembre de 1937 hasta el 19 de marzo de 1948.

La existencia de una biblioteca en el Noviciado, con sus sólidas estanterías, fue determinante para el establecimiento del Archivo en el Noviciado de San Estanislao de Kostka. Las sólidas estanterías fueron un elemento clave para que el edificio fuese elegido para sede del Archivo. En dicha biblioteca, se podía almacenar la documentación, a la par que poder realizar trabajos archivísticos con la misma: clasificación documental, ordenación en legajos y elaboración de fichas.

En concreto, el Archivo ocupó todo el tercer piso del pabellón occidental o ala izquierda del edificio, donde se encontraba ubicada la biblioteca, y el desván:

\footnotetext{
${ }^{70}$ CDMH. AGGCE. DNSD. Secretaría General. Expedientes Secretaría. Caja 970. Legajo 30. Expediente 3.

${ }^{71}$ CDMH. AGGCE. DNSD. Secretaría General. Expedientes Secretaría. Caja 970. Legajo 30. Expediente 3.
} 
1. Todo el tercer piso del pabellón occidental, o ala izquierda, del edificio tenía una extensión de $744 \mathrm{~m} 2$ y su pasillo unía todas las dependencias del mismo, destinadas a almacenar la documentación requisada.

2. La biblioteca del Noviciado. La biblioteca era un local, de aproximadamente $342 \mathrm{~m} 2$, que recordaba a las grandes bibliotecas del Barroco. Constaba de un patio central, dos escaleras metálicas de caracol en los extremos y estaba culminada por un lucernario o claraboya. Y, lo que es más importante, contaba con unas más que sólidas y plúmbeas estanterías de hierro.

Dichas estanterías, instaladas en la biblioteca, de hierro forjado y con unos plúteos o estantes de desproporcionadas dimensiones, estaban ensambladas al resto del edificio, por lo que podían ser consideradas como parte de la estructura del edificio. De hecho, la estructura del edificio, en concreto, la planta de debajo de la biblioteca soportaba el excesivo peso de la estructura férrea de las estanterías, junto al de sus fondos, puesto que tenía una capacidad para almacenar en torno a 50.000 volúmenes. De hecho, fue ese excesivo peso de las estanterías de la biblioteca el que obligó, al arquitecto José Yarnoz Larrosa, que proyectó y construyó todo el edificio, a colocar dos hileras de columnas de refuerzo, además de gruesas vigas, en la estancia de la planta inferior a la biblioteca ${ }^{72}$. Estas sólidas e incombustibles estanterías cumplían con las características inherentes a toda estantería de la época; y, dada su inocuidad y dimensiones, podían resistir 750 $\mathrm{kg} / \mathrm{m} 2$ de documentación.

La biblioteca del Noviciado, gracias a sus estanterías, fue utilizada como depósito de la documentación incautada por los equipos de recuperación de documentos de la Delegación. Además, la sala adjunta a la biblioteca fue utilizada como sala de clasificación documental ${ }^{73}$.

\footnotetext{
${ }^{72}$ Esto no difiere en exceso de los depósitos de los Archivos, construidos en los años 60 y 70 del siglo $\mathrm{XX}$, cuya estructura se formaba a base de pilares y vigas metálicas, que soportaban, al mismo tiempo y directamente, el peso de las estanterías.

${ }^{73}$ CDMH. AGGCE. DNSD. Secretaría General. Expedientes Secretaría. Caja 970. Legajo 30. Expediente 3.
} 
3. Finalmente, el desván del Noviciado, de $744 \mathrm{~m} 2$, sin ninguna clase de muebles o efectos existentes en los mismos, destinado también a almacenar la documentación requisada.

En total, el Archivo ocupó 1.914’96 m2 (a las tres estancias aludidas, hay que añadir parte de una galería, convertida en sala de trabajo, de 84’96 m2).

Casi once años después de su instalación en el edificio del Noviciado de San Estanislao de Kostka, el Archivo de la Delegación lo abandonó a partir de marzo de 1948, siendo trasladado a la que sería su sede hasta la actualidad: el Colegio de San Ambrosio, sede del Archivo General de la Guerra Civil Española del Centro Documental de la Memoria Histórica. El motivo del traslado del Archivo, del edificio del Noviciado de San Estanislao de Kostka al Colegio de San Ambrosio, fue la devolución de la parte del edificio ocupada por el Archivo a los jesuitas por el Gobierno de la época.

\subsection{VENTAJAS QUE PRESENTABA EL EDIFICIO PARA LA INSTALACIÓN DEL ARCHIVO}

El edificio del Noviciado de San Estanislao de Kostka estaba ubicado en el antiguo Camino de San Antonio próximo a la antigua muralla.

Directamente comunicado con la estación de tren, por el Paseo de Canalejas y el Camino de la Estación, la documentación, llegada a la estación de tren de Salamanca y enviada en vagones de los transportes militares, podía ser, desde allí, fácilmente recogida y trasladada a la Delegación.

La Delegación del Estado para Recuperación de Documentos se instaló en el entonces extrarradio de la ciudad de Salamanca, en un emplazamiento suburbano, que, a Marcelino de Ulibarri, por motivos de seguridad, le parecía "sito en un lugar un tanto desplazado del casco de la ciudad"74. En general, el emplazamiento del Archivo, alejado y aislado de la ciudad, le proporcionó, al mismo, la discreción, el secretismo y la

${ }^{74}$ CDMH. AGGCE. DNSD. Secretaría General. Expedientes Secretaría. Caja 330-348. Legajo 23. Expediente 330 . 
seguridad, que se requería para trabajar en el mismo, en periodo de guerra, y que, a Marcelino de Ulibarri, tanto obsesionaba. Durante todo el periodo de tiempo en el que la Delegación del Estado para Recuperación de Documentos, y su Archivo, estuvo instalado en el Noviciado de San Estanislao de Kostka, y aunque tuviera que compartir espacio con otros cinco organismos oficiales e instituciones, el personal que trabajó en el Archivo de la Delegación jamás perdió la discreción, ligada al propio trabajador pero también al emplazamiento del mismo, lo cual permitió que el Archivo fuera considerado, ya desde sus inicios y por sus contemporáneos ajenos a él, como secreto, sin que se supiera muy bien qué ocurría y qué tipo de trabajos se realizaban en aquel tercer piso, del pabellón occidental del edificio del Noviciado.

La tercera planta del pabellón occidental del Noviciado tenía su acceso cerrado con dos grandes puertas de hierro y una señal de prohibido el paso, que recordaba, al resto de las personas que hacían uso del edificio por diversos motivos, estudiantes, médicos, militares y enfermos, que, en ningún modo, se podía acceder a tales dependencias. Se trataba, en definitiva, de un depósito cerrado, de unas dependencias herméticamente selladas, que se creían dependientes de los militares, en última instancia, del Ministerio del Ejército.

\section{LA PROBLEMÁTICA DE LAS INSTALACIONES}

\subsection{EL SISTEMA DE DESAGÜE}

En abril de 1938, a consecuencia de una obstrucción de las tuberías de desagüe de las duchas instaladas en el cuarto piso del edificio, pertenecientes a los alféreces del Ministerio del Aire y a los alféreces del Parque Militar Móvil, comenzó a filtrarse agua al piso tercero, donde estaba ubicado el Archivo de la Delegación, y el despacho del Director del mismo, Marcelino de Ulibarri ${ }^{75}$. Dos meses más tarde, en junio de 1938, la humedad en el techo del Archivo, que era un cielo raso, era tan grande que éste corría el riesgo de desprenderse. Para evitarlo, se puso, urgentemente, en conocimiento del

\footnotetext{
${ }^{75}$ CDMH. AGGCE. DNSD. Secretaría. Correspondencia. Caja 125-200. Legajo 8. Expediente 177.
} 
Teniente Coronel-Jefe de Infraestructura de la Jefatura del Aire o Ministerio del Aire, por parte de Marcelino de Ulibarri $^{76}$.

\subsection{LA INSTALACIÓN ELÉCTRICA}

El edificio del Noviciado de San Estanislao de Kostka disfrutó de una línea de corriente eléctrica trifásica, tendida por la Compañía "La Eléctrica Salmantina, S.A.", desde el año 1926, año de finalización de las obras de construcción del citado edificio ${ }^{77}$.

En septiembre de 1939, Marcelino de Ulibarri comunicó, al Jefe de la Comandancia de Ingenieros de Salamanca, la necesidad de realizar la instalación eléctrica de la tercera planta del pabellón occidental del edificio del Noviciado de los Padres Jesuitas, donde se encontraban ubicadas las salas del Archivo de la Delegación ${ }^{78}$.

En el año 1944, se instaló una dínamo, para la producción de la energía eléctrica que se consumía en el edificio, ya que eran años de restricciones, y la poca electricidad que se producía se reservaba para las fábricas. Y, hasta que el Instituto de Enseñanza Media estuvo instalado allí, se estudió utilizando quinqués, o lámparas de mesa alimentadas de petróleo, y velas, con el peligro de incendio que ello conllevaba. En noviembre de 1946, se realizaron obras de reparación en el tendido de la línea eléctrica que suministraba electricidad al Archivo de la Delegación, y se practicó una derivación en el tendido de la citada línea eléctrica, todo ello llevado a cabo por la "La Eléctrica, S.A."79.

\footnotetext{
${ }^{76}$ CDMH. AGGCE. DNSD. Secretaría. Correspondencia. Caja 125-200. Legajo 8. Expediente 177.

${ }^{77}$ CDMH. AGGCE. DNSD. Secretaría. Correspondencia. Caja 125-200. Legajo 8. Expediente 169.

${ }^{78}$ CDMH. AGGCE. DNSD. Secretaría. Correspondencia. Caja 125-200. Legajo 8. Expediente 169.

${ }^{79}$ CDMH. AGGCE. DNSD. Secretaría General. Expedientes Secretaría. Caja 970. Legajo 30. Expediente 970.
} 


\subsection{EL SISTEMA DE CALEFACCIÓN}

La elección de un sistema de calefacción depende de las condiciones climáticas de cada zona geográfica donde se ubica cada archivo. Es necesario hacer un uso adecuado y racional de la calefacción, para que la temperatura sea constante a lo largo de todo el día, de todo el año, fijándola en torno a unos $18-20^{\circ} \mathrm{C}$ y evitando siempre los cambios bruscos de temperatura, tan nocivos para la documentación ${ }^{80}$.

En la Delegación del Estado para Recuperación de Documentos y en el edificio del Noviciado de San Estanislao de Kostka en general, se gastaba mucho en calefacción, no sólo por el rigor del invierno salmantino de la época, sino porque el edificio tenía, y tiene, unos techos excesivamente altos, por lo que costaba mucho calentarlo, lo cual resultaba muy pernicioso para los documentos, sometidos a fuertes tensiones de contracción y dilatación. La calefacción afectaba a la totalidad del edificio, no sólo a los depósitos documentales.

Unos problemas de pago con el proveedor de leña y carbón a la Delegación, Miguel Gómez Valle, que tenía su almacén de carbones minerales y vegetales y de leña en la calle Rodríguez Fabrés, indujeron a Marcelino de Ulibarri y Eguilaz, como director de la Delegación, a que, en diciembre de 1938, éste se decantase por la instalación de un sistema de calefacción eléctrico en el Archivo, ubicado en el tercer piso del pabellón occidental del edificio, que mitigase "las inclemencias del tiempo [...] y que era necesario al fin indicado" ${ }^{\prime}$. Para ello, Marcelino de Ulibarri se puso en contacto con Felipe Rodríguez, Comandante-Jefe de Ingenieros de Salamanca ${ }^{82}$.

\footnotetext{
${ }^{80}$ Bello URGellès, Carmen.; Borrell Crehuet, Ángels., El patrimonio bibliográfico y documental. Gijón, Trea, 2001, p. 323.

${ }^{81}$ CDMH. AGGCE. DNSD. Secretaría. Correspondencia. Caja 125-200. Legajo 8. Expediente 169.

${ }^{82}$ En las obras de instalación del sistema de calefacción eléctrico, iniciadas en diciembre de 1938, se emplearon 190 metros de cable de cobre cubierto; 140 metros de hilo de cobre aislado; 12 enchufes completos bipolares de 15 amperios; 12 cortacircuitos unipolares de 15 amperios y 3 cortacircuitos de 25 amperios; y, 200 aisladores apropiados para los cables de cobre, necesarios para la seguridad del sistema de calefacción eléctrico en su contacto con el aire, además de otros materiales, en CDMH. AGGCE. DNSD. Secretaría. Correspondencia. Caja 125-200. Legajo 8. Expediente 169.
} 
La instalación de la caldera de calefacción, aunque ya fuese eléctrica, en el piso tercero, donde se encontraba la documentación fue poco acertada: las calderas de calefacción deben instalarse en lugares aislados, para evitar daños en los depósitos documentales, por fugas o recalentamientos, e incluso incendios ${ }^{83}$.

El sistema de calefacción se instala para conseguir unas mejores condiciones laborales para los trabajadores aunque ello fuera contraproducente para la conservación de los documentos.

\subsection{MEDIDAS DE SEGURIDAD}

\subsubsection{SISTEMA ANTIINCENDIO}

A Marcelino de Ulibarri, como máximo responsable de la Delegación del Estado para Recuperación de Documentos, siempre le obsesionó la idea de que "su" Archivo, tan importante para la seguridad del Estado, sufriera algún acto de sabotaje, en forma de incendio provocado. De ahí, que, desde un primer momento, se tomasen medidas preventivas contra el fuego ${ }^{84}$.

El fuego es un potencial enemigo y siempre un peligro para los materiales de archivo.

La Delegación contaba, como medida antiincendios, con extintores portátiles.

El 5 de abril de 1938, la Delegación recibía tres extintores de incendios del Cuartel General del Generalísimo ${ }^{85}$; y, siete meses después, el 2 de octubre de 1938, la Delegación recibió otros siete extintores más, procedentes del citado Cuartel General del Generalísimo ${ }^{86}$. También, el Archivo de la Delegación requisó, al comienzo de la Guerra Civil, dos extintores del Teatro Moderno ${ }^{87}$.

\footnotetext{
${ }^{83}$ Pescador Del Hoyo, María del Carmen., El Archivo. Instalación y Conservación. Madrid, Ediciones Norma, 1988, p. 136.

${ }^{84}$ CDMH. AGGCE. DNSD. Secretaría. Correspondencia. Caja 125-200. Legajo 8. Expediente 198.

${ }^{85}$ CDMH. AGGCE. DNSD. Secretaría. Correspondencia. Caja 125-200. Legajo 8. Expediente 198.

${ }^{86}$ CDMH. AGGCE. DNSD. Secretaría. Correspondencia. Caja 125-200. Legajo 8. Expediente 198.

${ }^{87}$ CDMH. AGGCE. DNSD. Secretaría. Correspondencia. Caja 125-200. Legajo 8. Expediente 198. El Teatro Moderno, inaugurado en 1909 y ubicado en la Cuesta del Carmen, fue derribado en 1965.
} 


\subsubsection{EL SISTEMA DE VIGILANCIA}

La vigilancia en la Delegación se centraba en detectar la presencia de intrusos y en evitar la sustracción de documentos del mismo.

La vigilancia era ejercida por una pareja de guardias, en turno alterno, de día y de noche, aunque el Archivo pasase desapercibido para la inmensa mayoría de las personas que desfilaban por el edificio ${ }^{88}$.

Al tener que compartir la Delegación, el edificio del Noviciado de San Estanislao de Kotska, donde se encontraba instalado, con el Instituto de Enseñanza Media y el Hospital Militar, "[la] concurrencia de público heterogéneo [exigía] y, a la vez, [dificultaba] una vigilancia eficaz" ${ }^{\prime \prime 9}$.

El problema de seguridad para Marcelino de Ulibarri era mayor, ya que temía que el Archivo fuera descubierto por el enemigo en la contienda bélica que se estaba librando.

El Archivo fue descubierto por el enemigo. Su descubrimiento se hizo publico, en un boletín de noticias, del día 7 de diciembre de 1938, boletín que llegó a poder de Marcelino de Ulibarri ${ }^{90}$. En dicho boletín, se recogía la noticia de que un soldado del bando sublevado, que había sido hecho prisionero, durante la contienda, por el bando republicano, había facilitado toda la información sobre el contenido documental y la ubicación de la Delegación en Salamanca. En la noticia, según Ulibarri, se hablaba de los fondos documentales del Archivo con una precisión asombrosa, fondos formados

\footnotetext{
${ }^{88}$ CDMH. AGGCE. DNSD. Secretaría General. Expedientes Secretaría. Caja 330-348. Legajo 23. Expediente 330. A Marcelino de Ulibarri, le preocupaba, también, lo fácil que resultaría "lanzar impunemente botellas incendiarias dentro del Archivo, bien desde las terrazas superiores o por las ventanas laterales del Hospital", en CDMH. AGGCE. DNSD. Secretaría General. Expedientes Secretaría. Caja 330-348. Legajo 23. Expediente 330.

89 CDMH. AGGCE. DNSD. Secretaría General. Expedientes Secretaría. Caja 330-348. Legajo 23. Expediente 330 .

90 CDMH. AGGCE. DNSD. Secretaría General. Expedientes Secretaría. Caja 330-348. Legajo 23. Expediente 330. Se desconoce el contenido del boletín, al que la fuente alude, pero no reproduce el texto del citado boletín en su integridad.
} 
por "dos millones de fichas delatoras de actividades delictivas, de otros tantos individuos [republicanos], y la correspondiente documentación probatoria"91.

Marcelino de Ulibarri se muestra hondamente preocupado ante estas informaciones, que ponían al Archivo de la represión y la depuración administrativa, al descubierto. La situación era muy peligrosa, pues conllevaba el riesgo de una posible destrucción del Archivo, lo cual sería también consecuencia, según interpreta el propio Marcelino de Ulibarri, "de una imperdonable imprevisión por [su parte]"92. Marcelino de Ulibarri afirmaba que

la desaparición de este arsenal de documentos supondría, para España, una pérdida irreparable, por la imposibilidad de rehacerlo, y un grave mal, por la impunidad en que quedarían muchos criminales ${ }^{93}$.

Inmediatamente, Marcelino de Ulibarri informaba de la situación, a través de Francisco Franco Salgado-Araujo, Secretario del Jefe del Estado, al general Francisco Franco, en una carta-informe, fechada a 13 de diciembre de 1938.

En dicha carta-informe, Marcelino de Ulibarri proponía dos soluciones para el problema de seguridad que sufría la Delegación:

$1^{a}$. El traslado de la Delegación a otra ciudad, instalándola en un edificio propio y adecuado, lo que muestra que, para Ulibarri, la elección del edificio de San Estanislao de Kostka no le parecía adecuada.

2a. El traslado de la Delegación al edificio, número 4, de la Plaza de los Bandos de Salamanca, que Marcelino de Ulibarri consideraba un edificio "mejor acondicionado para una eficaz vigilancia"94, lo que demuestra las carencias de vigilancia que sufría la Delegación ${ }^{95}$.

${ }^{91}$ CDMH. AGGCE. DNSD. Secretaría General. Expedientes Secretaría. Caja 330-348. Legajo 23. Expediente 330.

${ }^{92}$ CDMH. AGGCE. DNSD. Secretaría General. Expedientes Secretaría. Caja 330-348. Legajo 23. Expediente 330.

${ }^{93}$ CDMH. AGGCE. DNSD. Secretaría General. Expedientes Secretaría. Caja 330-348. Legajo 23. Expediente 330.

${ }^{94}$ CDMH. AGGCE. DNSD. Secretaría General. Expedientes Secretaría. Caja 330-348. Legajo 23. Expediente 330. 
La carta-informe fue contestada, insistiéndose en:

$1^{\text {a }}$. Indicar cuántos guardias necesitaba.

$2^{\mathrm{a}}$. El trámite para el cambio del edificio, recordándole que tal resolución pertenecía " al Sr. Ministro del Interior; [...] mediante una orden del Ministro, Sr. Serrano Suñer" 96 .

Ramón Serrano Suñer no firmó la requerida Orden Ministerial. Setenta y siete años después, el 18 de marzo de 2015, José María Lasalle, Secretario de Estado de Cultura, inauguraba las instalaciones del Archivo General de la Guerra Civil Española del Centro Documental de la Memoria Histórica con sede en el número 4 de la Plaza de los Bandos, en el edificio, muy remodelado, de la antigua Caja de Previsión Social, donde tienen lugar exposiciones temporales, presentaciones de libros y coloquios, además de otras actividades de difusión cultural, del periodo histórico comprendido entre la Guerra Civil y la Transición.

\footnotetext{
${ }^{95}$ Dicho edificio, el número 4 de la Plaza de los Bandos, ubicado entre el edificio de la Telefónica (solar del Palacio de Solís) y la Iglesia del Carmen de los Carmelitas Descalzos, y sobre el solar del antiguo Convento de San Elías, era el edificio de la antigua Caja de Previsión Social, y había sido proyectado y construido, entre 1928 y 1932, bajo la supervisión del arquitecto salmantino José Secall. El edificio, de estructura de hierro y ladrillo, fue construido utilizando buenos materiales: madera de roble americano, para las puertas y las ventanas; cerámica de Manises, para los suelos; y piedra franca de Villamayor, para la fachada principal. En diciembre de 1938, el antiguo edificio de la Caja de Previsión Social estaba ocupado por soldados de infantería italiana del Corpo Truppe Volontaire, donde además se hallaba el Servicio de Postas o de Correos del citado Corpo. En diciembre de 1938, el edificio de la antigua Casa de Previsión Social constaba de las siguientes partes: $1^{\circ}$. Sótanos, bastante bien ventilados, pero reducidos, que podían servir de depósito; $2^{\circ}$. Planta baja, formada por cuatro dependencias: el recibidor, para el portero-guarda de la finca, el despacho del Administrador y otras dos estancias deshabitadas; $3^{\circ}$. Piso primero. Constaba de un salón grande, con dos balcones que daban a la Plaza de los Bandos; cuatro dependencias bastante grandes; seis dependencias pequeñas; dos cocinas; un cuarto de baño completo, para oficiales; y, una capilla, que se encontraba cerrada; $4^{\circ}$. Piso segundo. Constaba de tres habitaciones grandes; siete habitaciones pequeñas; un cuarto de baño; una cocina; y, una pequeña despensa. Además, el edificio contaba con un garaje, cuya puerta de entrada estaba situada en la calle de Santa Teresa, y por el que podía entrar, al patio del edificio, un camión de considerables dimensiones. No obstante, era preceptivo que un arquitecto informara previamente sobre las condiciones de seguridad del edificio, a la hora de soportar el enorme peso documental que había que trasladar allí. Sobre el edificio, número 4, de la Plaza de los Bandos de Salamanca, véase CDMH. AGGCE. DNSD. Secretaría General. Expedientes Secretaría. Caja 330-348. Legajo 23. Expediente 330.
}

96 CDMH. AGGCE. DNSD. Secretaría General. Expedientes Secretaría. Caja 330-348. Legajo 23. Expediente 330. 


\section{CONCLUSIONES}

La instalación de la Delegación en el edificio de San Estanislao de Kostka se debió a las ventajas que presentaba el propio edificio. Dichas ventajas no eran nada desdeñables:

I. Su buen emplazamiento, alejado del casco histórico de la ciudad, por motivos de seguridad y discreción en el trabajo archivístico.

II. Su buena comunicación con la estación de ferrocarril, a donde llegaba buena parte de la documentación requisada, y, desde donde era trasladada, a través del Paseo de Canalejas y el Paseo de la Estación, al Archivo.

III. Su buen equipamiento, ya que el edificio contaba con una instalación de sólidas estanterías.

Por el contrario, los problemas que presentó el edificio de San Estanislao de Kotska para albergar el Archivo fueron los siguientes:

IV. Tener que compartir el edificio con otros cinco organismos, el Instituto de Enseñanza Media, el Ministerio del Aire, el Parque Militar Móvil, la residencia de la escolta del general Franco y las milicias de Falange, y el Hospital Militar.

V. La conservación documental, manifiestamente mejorable, debido a las precarias instalaciones con las que contaba el edificio: sistema de desaguie, instalación eléctrica, sistema de calefacción, sistema antiincendios y sistema de vigilancia. 
CAPÍTULO 4

La metodología archivística de la Delegación 
El Archivo que perdía los papeles. El Archivo de la Guerra Civil según el fondo documental de la DNSD 
Este capítulo está dedicado a la metodología que se aplicó a la documentación incautada, en las distintas fases por las que pasó la misma, desde su requisición hasta el trabajo con fichas, en las que plasmar la información contenida en los documentos, que dio lugar al Fichero General de la Delegación.

El objetivo de este capítulo es, por tanto, explicar la metodología que fue aplicada en cada una de esas fases:

- La metodología de la requisición, es decir, la metodología aplicada en el momento de la requisición de los documentos, puesta en práctica por los equipos de recuperación de documentos, que actuaron de manera coordinada, incidiéndose, particularmente, en la metodología específica de las inspecciones.

- La metodología de los envíos, empleada para el envío de la documentación a la Delegación.

- La metodología archivística, utilizada para la clasificación, la instalación y el tratamiento de la documentación.

Por ello, el capítulo se estructura en diez apartados, los siete primeros dedicados a la requisición de documentos, el transporte de la documentación y los equipos de recuperación de documentos; y, la clasificación documental, la instalación y el tratamiento de la documentación en el Archivo central de Salamanca. El octavo apartado está dedicado a la Delegación y su relación con los otros archivos del sistema archivístico español de la época. En el noveno aparatado, se hace un balance de los trabajos realizados por la Delegación a fecha de agosto de 1938. Y, finalmente, en el décimo apartado del capítulo se presentan las conclusiones. 


\section{LA REQUISICIÓN DE DOCUMENTOS}

Para llevar a cabo la requisición de documentos, primera fase del trabajo archivístico, la organización y la actuación de los equipos de recuperación de documentos se encontraba perfectamente reglada y normativizada. Además, la recuperación de documentos contó, en general y no sin alguna resistencia, con la autorización y estrecha colaboración de las autoridades militares en los frentes, para que ésta pudiese ser ejecutada correctamente, conforme a las aludidas actuaciones, o acciones, normativizadas.

El 11 de julio de 1938, en una carta enviada a su conocido Juan Rosillo, con el cual Marcelino de Ulibarri mantenía comunicación a causa de los medios de transporte, éste le expresaba su preocupación con respecto al funcionamiento irregular de los equipos de recuperación de documentos, debido a la falta de medios de transporte, coches y camiones $^{97}$.

La existencia de unos buenos medios de transporte, de una buena flota de coches y camiones, al servicio de la Delegación era esencial, para la primera fase del trabajo archivístico encomendado a la Delegación del Estado para Recuperación de Documentos, que consistía en "recoger, en los frentes y en las poblaciones conquistadas, toda la documentación que interese, para ser trasladada al Archivo central de Salamanca"98.

\subsection{METODOLOGÍA DE LAS REQUISICIONES DE DOCUMENTOS. CONSIDERACIONES GENERALES}

En este subapartado, se ha realizado una sistematización de las situaciones en las que se produjeron las incautaciones, determinándose las siguientes categorías:

\footnotetext{
${ }^{97}$ CDMH. AGGCE. DNSD. Secretaría. Correspondencia. Caja 125-200. Legajo 7. Expediente 160.

${ }^{98}$ CDMH. AGGCE. DNSD. Secretaría. Correspondencia. Caja 125-200. Legajo 7. Expediente 160.
} 
$1^{\circ}$. Requisiciones realizadas antes de la formalización de los equipos de recuperación de documentos formados por la Delegación del Estado para Recuperación de Documentos.

La $2^{\text {a }}$ Sección, Información, del Ejército del Sur, al frente del cual se encontraba el general Gonzalo Queipo del Llano realizó requisiciones en Andalucía y Extremadura antes de que los equipos de recuperación de documentos llegasen a la región de Extremadura. La $2^{\text {a }}$ Sección, Información, del Ejército del Sur, operó antes en Extremadura que los equipos de recuperación de documentos de la Delegación.

$2^{\circ}$. Colaboraciones externas en las requisiciones.

Las colaboraciones externas fueron aquellas ayudas de otros órganos con las que contaron los equipos de recuperación de documentos en sus tareas de requisición de documentos.

En la requisición de documentos, colaboraron con los equipos de recuperación de documentos, los siguientes órganos:

- La citada $2^{a}$ Sección, Información, del Estado Mayor del Ejército del Sur, del general Gonzalo Queipo de Llano.

- El Servicio de Información y Policía Militar (SIMP), en el caso de Cartagena.

- El Servicio de Investigación de Falange Española Tradicionalista y de las JONS, en el caso, por ejemplo, de Castellón.

$3^{\circ}$. Requisiciones no realizadas.

En algunos casos, las requisiciones resultaron infructuosas, debido a no llegar a realizarse la requisición de la documentación, con la pérdida de información que ello suponía. Ese fue el caso de las requisiciones realizadas en Tamarite de Litera (Huesca), en las que el Alcalde comunicó, a los equipos de recuperación de documentos, que no quedaba un solo papel. Todos los documentos habían sido quemados el día anterior, 6 de junio de 1938, al entrar las tropas franquistas, en dos enormes hogueras. 
En la requisición efectuada en la provincia de Lérida el día 9 de junio de 1938, ocurrió que, en las localidades de Vilanova de Segriá, Torregrosa, Benavent de Lérida, Portella y Albesa, el equipo de recuperación de documentos, que actuaba en la zona, dio por finalizado sus trabajos en la misma, ya que, aquellas localidades:

- Habían sido cañoneadas brutalmente y estaban destruidas la mayoría de ellas.

- Allí, en estas localidades, se alojaban las tropas de posición, que terminaron por destruir la poca documentación que quedaba.

$4^{\circ}$. Disputas y conflictos en las requisiciones.

El principal motivo de las disputas vino motivado por la posesión de los documentos que se querían requisar.

En las requisiciones realizadas, hubo disputas y conflictos entre órganos y los respectivos encargados de los mismos. Fueron los siguientes:

- El general Gonzalo Queipo de Llano, que tenía el mando supremo sobre la 2a Sección, Información, del Estado Mayor del Ejército del Sur, sobre su Estado Mayor, por la requisición de la documentación en Extremadura.

- El Jefe local de FET y de las JONS en Trujillo, por la documentación incautada en la citada localidad.

- El Delegado de Seguridad de Barcelona y superior al Jefe de la Brigada PolíticoSocial de la Policía de Barcelona, por toda la documentación del Centro Israelita "Agudad Ahim" de la Barcelona.

- El Servicio de Información de Autoría de Guerra, en Lérida, por la documentación requisada en Lérida. Al Estado Mayor del general Juan Yagüe Blanco, estuvieron supeditadas todas las actuaciones llevadas a cabo por los equipos de recuperación de documentos de la Delegación, encargados de incautar documentación en la zona.

$5^{\circ}$. El tiempo transcurrido desde la ocupación de un territorio y el comienzo de las requisiciones para la incautación de documentos. 
Absolutamente imprescindible entrar en las ciudades junto con las tropas, ya que el trabajo [de recuperación de documentos] que no se realiza dentro de los cuatro primeros días, deja de tener eficacia ${ }^{99}$.

Pero no siempre los equipos de recuperación de documentos entraron a la par que el cuerpo de ejército que tomaba la localidad. Los hechos demuestran que las situaciones fueron diversas:

- En Teruel, Gijón, Madrid y Barcelona, los equipos de recuperación de documentos entraron el mismo día que se produjo la ocupación militar.

- En Castellón, los equipos de recuperación de documentos entraron una semana después de que la ciudad hubiese sido tomada.

- Y, en Vinaroz, las tropas franquistas entraron el 15 de abril de 1938 y los equipos de recuperación de documentos llegaron el 11 de mayo de 1938, es decir, veintisiete días después.

$6^{\circ}$. Identificación y permisos para realizar la requisición de documentos.

Los miembros de los equipos de recuperación de documentos debían de estar perfectamente identificados para poder desarrollar sus tareas. Así, por ejemplo, para la incautación realizada en Teruel, en febrero de 1938, se obtuvieron los permisos o salvoconductos, del Estado Mayor del general Fidel Dávila, necesarios para que los equipos pudieran actuar en el frente de guerra.

99 CDMH. AGGCE. DNSD. Secretaría General. Expedientes Secretaría. Caja 330-348. Legajo 23. Expediente 330.2. El subrayado es nuestro. El transcurso del tiempo, el transcurso de los días, hacía más probable y factible la pérdida, intencionada o no, de la documentación y, lo que es más importante, de la información que ésta pudiera contener, por lo que la actuación "eficaz" de los equipos de recuperación de documentos era directamente proporcional a su "velocidad o ritmo de trabajo". Lo fundamental era que los equipos de recuperación lograran lo que se esperaba y deseaba de ellos: la incautación de la mayor cantidad de documentación en el menor periodo de tiempo posible. 


\subsection{UN ASPECTO ESENCIAL EN LA REQUISICIÓN DE DOCUMENTOS: LAS INSPECCIONES}

Los equipos de recuperación de documentos, antes de su partida a los frentes de guerra, recibían instrucciones concretas de cómo se debían realizar las inspecciones. Tales instrucciones eran las siguientes:

1. Tras entrar en el municipio, recién tomado y pacificado, y una vez establecido el archivo, del equipo de recuperación de documentos, en un edificio adecuado, se tenía que proceder, inmediatamente, a la elaboración de una lista con los datos obtenidos sobre organismos oficiales y partidos políticos, en la que se recogiera sus direcciones y números de teléfono. Dicha lista se redactaba con la finalidad, a su vez, de preparar, la noche anterior a la realización de las inspecciones, un "plan de inspecciones", en el que se recogían, para evitar pérdidas de tiempo, todas las inspecciones a realizar al empezar la jornada del día siguiente. En los diferentes listados elaborados y en el citado "plan de inspecciones", aparecían las instituciones, productoras de documentación de interés para la Delegación, y ubicadas en inmuebles que eran objeto de las inspecciones: edificios oficiales republicanos, sede del Gobierno de la República, Ministerios, Consejerías, Ayuntamientos, Juzgados, Cárceles, etc; sedes de partidos políticos y sindicatos, prohibidos por la Ley, de 9 de febrero de 1939, de Responsabilidades Políticas; oficinas del ejército republicano, ocupadas, entre otras, por los Estados Mayores, los distintos cuerpos del ejército republicano y los hospitales militares; edificios oficiales soviéticos (embajada de la Unión Soviética en Madrid y consulados de la Unión Soviética, repartidos por el resto del territorio peninsular, en distintas capitales de provincia); domicilios particulares de dirigentes políticos republicanos; cines, editoriales, periódicos, librerías y asociaciones culturales, de cada municipio, ya se tratase de un pueblo o una capital de provincia, considerados, todos ellos, desafectos o contrarios al régimen franquista ${ }^{100}$.

También, en las instrucciones, comunicadas a los equipos de recuperación de documentos, se les advertía, a éstos, de la importancia de incautar toda la documentación generada por Correos y Telégrafos, y sus clientes, con la finalidad de

${ }^{100}$ CDMH. AGGCE. DNSD. Secretaría General. Expedientes Secretaría. Caja 330-348. Legajo 23. Expediente 330.2. 
controlar la información de la correspondencia de particulares, y toda la documentación producida en las tiendas o casas de fotografía de la época, para, así, poder incautar fotografías de personas asesinadas, de desfiles y manifestaciones, y de pasaportes, milicianos y afiliados a partidos políticos, todas ellas de gran interés para poder identificar, físicamente, a los nombres de las personas que figurasen en el fichero general de la Delegación.

2. Precintar todos los edificios, sedes, locales y domicilios, objeto de las inspecciones, quedando un ayudante, integrante de los equipos de recuperación de documentos, de guardia, en la puerta de aquellos inmuebles, para que, de ellos, no "desapareciese la documentación"101. Los precintos debían colocarse en un lugar bien visible de la entrada. Asimismo, el ayudante del equipo de recuperación de documentos debía efectuar la guardia y la vigilancia del inmueble en su interior, y no debía permitir la entrada, en él, a ninguna persona, salvo a aquellas que estuvieran expresamente autorizadas por la Delegación del Estado para Recuperación de Documentos ${ }^{102}$.

3. Requisición de la documentación, dirigida por los jefes de equipo. Además de la documentación propiamente dicha, se podía "recoger" o incautar material gráfico y de otro tipo, como carteles y banderas, que enriquecen, en la actualidad, los fondos del Archivo General de la Guerra Civil Española del Centro Documental de la Memoria Histórica de Salamanca. En esta fase de la inspección, la más importante para la incautación de documentos, el jefe de equipo debía:

3.1. Examinar y dictaminar el interés de los documentos, y de la información contenida en los mismos, en función de los fines para los que fue creada la Delegación $^{103}$.

101 CDMH. AGGCE. DNSD. Secretaría General. Expedientes Secretaría. Caja 330-348. Legajo 23. Expediente 330.2. De ahí la importancia de que los equipos de recuperación de documentos realizaran su trabajo dentro del plazo fijado de los cuatro primeros días.

102 CDMH. AGGCE. DNSD. Secretaría General. Expedientes Secretaría. Caja 330-348. Legajo 23. Expediente 330.2 .

${ }^{103}$ Dada la ingente cantidad de documentación que fue incautada y trasladada al actual Archivo General de la Guerra Civil Española del Centro Documental de la Memoria Histórica de Salamanca, con la finalidad de elaborar un fichero de personas, sospechosas para el régimen franquista, el conocido como Fichero General, y que no fue utilizada para tal fin, se puede afirmar que el juicio, emitido por los jefes de 
3.2. Vigilar el trabajo desarrollado por todos y cada uno de los ayudantes o componentes del equipo de recuperación de documentos durante la inspección, evitando, por ejemplo, que dos mismos ayudantes registrasen la misma habitación repetidas veces, lo cual constituía una flagrante pérdida de tiempo, o que se "recogiesen" o incautasen documentos que encontrasen por duplicado ${ }^{104}$.

3.3. Inspeccionar o examinar, a posteriori, las estancias y habitaciones de los inmuebles, objeto de las inspecciones, para evitar posibles olvidos de documentación por parte de sus ayudantes ${ }^{105}$.

4. Traslado de la documentación, incautada en las inspecciones, a la oficina, donde se tenía el material de oficina, y su correspondiente depósito. El jefe de equipo era el encargado, también, de trasladar y entregar, personalmente, la documentación al jefe del registro.

4.1. De toda la documentación incautada -y esto es fundamental- se hacía un asiento o anotación en el libro de registro, en la oficina, y, ese momento, el del asiento, era aprovechado para colocar, de manera ordenada, "los documentos en los sacos, haciendo pequeños paquetes" 106 .

4.2. Después, la documentación era trasladada al depósito.

5. Finalmente, y bajo la supervisión tanto del jefe de equipo como del jefe del registro, que casi siempre coincidía en la misma persona, la documentación era trasladada al depósito documental, donde era almacenada y custodiada hasta que se produjera su envío al Archivo central de Salamanca.

equipo, sobre la documentación, mediatizado por la urgencia con la que se trabajaba, no fue siempre acertado y muchas veces fue completamente desatinado cuando no totalmente erróneo.

104 CDMH. AGGCE. DNSD. Secretaría General. Expedientes Secretaría. Caja 330-348. Legajo 23. Expediente 330.2.

105 CDMH. AGGCE. DNSD. Secretaría General. Expedientes Secretaría. Caja 330-348. Legajo 23. Expediente 330.2.

106 CDMH. AGGCE. DNSD. Secretaría General. Expedientes Secretaría. Caja 330-348. Legajo 23. Expediente 330.2. 
Cumpliéndose rigurosamente estas instrucciones, para el caso de las grandes ciudades, como Madrid, Barcelona y Valencia, fue necesario que prácticamente todo el personal de la Delegación, con Marcelino de Ulibarri al frente, se trasladase a cada una de esas ciudades.

\subsubsection{ALGUNAS DISFUNCIONES PRODUCIDAS EN LAS INSPECCIONES}

$1^{\circ}$. Errores en el depósito de la documentación en el almacén para depositar la documentación requisada.

En algún caso, los documentos requisados se depositaron, de manera provisional, en locales que no pertenecían a la red de archivos dependientes del Archivo central de

Salamanca. Éste es el caso, por ejemplo, del Archivo de la Diputación Provincial de Barcelona, donde se depositaron documentos de la Departamento de Agricultura, durante la incautación de documentos de la Generalidad.

$2^{\circ}$. Incumplimiento del procedimiento para las inspecciones.

A comienzos del año 1939, por ejemplo, la documentación requisada por los equipos de recuperación de documentos en Lérida, se custodió en el depósito, habilitado para tal fin, en la Plaza Cervantes de Lérida. De esa documentación se supo que se la llevaron, a pesar de las órdenes terminantes de custodia dadas a un guardia civil retirado, unos soldados, a mediados del mes de febrero de 1939, ignorándose a qué unidad pertenecían y el lugar a dónde la condujeron y en el que fue depositada. Todo ello se puso en conocimiento del general de la $4^{\mathrm{a}}$ Región Militar, para que resolviera el problema que se había planteado, y parece ser, que, finalmente, la documentación fue encontrada y trasladada al Archivo central de Salamanca.

$3^{\circ}$. Entregas de documentación.

En aplicación del artículo tercero del Decreto, de 26 de abril de 1938, del Ministerio del Interior, la Delegación contaba, previa petición o no de la misma, con la colaboración de autoridades, funcionarios, entidades y particulares, para incrementar sus fondos 
documentales, a través de las entregas de documentos que estos hicieran a la misma. Por ejemplo, los municipios de las provincias de Barcelona, Gerona y Tarragona, como entidades, enviaron documentación de interés, sin petición previa de Marcelino de Ulibarri y Eguílaz, al Archivo central de Salamanca.

\subsection{EL TRANSPORTE DE LA DOCUMENTACIÓN}

Toda vez que estuvieran normalizadas las comunicaciones ferroviarias, el transporte del material sin clasificar debía hacerse en envío militar por ferrocarril, acudiendo a Transportes Militares, con las garantías de seguridad necesarias, designando, al efecto, el personal que procediera y que hubiera de acompañar los envíos. También, el material sin clasificar era enviado a través de camiones y coches que transportaban los documentos hasta Salamanca.

Toda la documentación era enviada en sacos, acompañada de una relación, listado o nota de envío, a modo de las actuales relaciones de entrega u hojas de remisión, en las que figuraba el remitente, normalmente, el jefe de equipo de recuperación de documentos, la fecha de la remisión, la localidad desde la que se remitía la documentación y un breve resumen del contenido de cada documento que era enviado, habitualmente no más extenso de una línea.

La documentación, en sacos, era almacenada en la Biblioteca del Noviciado de San Estanislao de Kostka y en el Capítulo Nuevo del Convento de San Esteban, donde los sacos llegaban hasta sus altos techos. De la documentación entregada, también quedaba constancia en los libros de registro de entrega.

Como en el caso de las relaciones, listados o notas de envío, de los libros de registro de entrega tampoco se conservan muchos ejemplares. 


\subsubsection{MEDIOS DE TRANSPORTE}

\subsubsection{POR FERROCARRIL}

Desde los depósitos documentales, donde se almacenaba y custodiaba la documentación requisada por los equipos de recuperación de documentos en las distintas localidades, la documentación era enviada, fundamentalmente, a través del ferrocarril, al Archivo central de Salamanca:

- En junio de 1939, fueron enviados 3.500 sacos, llenos de documentos, desde Barcelona hasta el Archivo de Salamanca, con instrucciones directas de Marcelino de Ulibarri, en las que designaba al personal que debía acompañar el envío, realizado a través del transporte militar por ferrocarril, que garantizaba la seguridad del envío y, por tanto, su llegada a Salamanca.

- El 16 de julio de 1939, el primer gran envío de documentación desde Alicante, fue realizado por ferrocarril: exactamente, en el vagón número K13676 de los transportes militares.

- La documentación requisada en Valencia, por los equipos de recuperación de documentos, fue enviada, a partir del 25 de mayo de 1939, por ferrocarril, hasta Salamanca.

\subsubsection{POR CARRETERA}

Otro medio de transporte, utilizado para unir los diferentes depósitos documentales con el Archivo central de Salamanca, fue la flota de camiones y vehículos que llegó a configurar el Archivo.

Asimismo, en ocasiones, el transporte por carretera de la documentación, en un tramo del recorrido, complementó al del ferrocarril.

Éste es el caso de toda la documentación requisada en Cataluña y Levante, en concreto, para Lérida, Tarragona, Teruel y Castellón. Toda la documentación requisada en esas zonas, fue transportada por carretera hasta Zaragoza. Y, de allí, salía, por ferrocarril, hacia Salamanca, lo que propició que Zaragoza se convirtiera en un punto neurálgico 
para el envío de la documentación a Salamanca, final de etapa para el transporte por carretera al mismo tiempo que nudo ferroviario principal con Salamanca.

\subsubsection{ENLACES DE LA GUARDIA CIVIL}

Otro medio, de menor importancia, utilizado para el envío de la documentación a Salamanca, fue la utilización de los enlaces de que disponía la Guardia Civil en su propio transporte. Un ejemplo de esto, lo constituye el envío de documentación que se realizó, por medio de enlaces de la Guardia Civil, para llevar documentación desde Alicante hasta Salamanca, en el mes de julio de 1942, documentación que había sido incautada a sindicatos y partidos políticos del Frente Popular en Alicante.

Así pues, en conclusión, el envío de documentación requisada, desde los depósitos originarios hasta el Archivo central de Salamanca, fue realizó fundamentalmente por tres vías:

- Por ferrocarril, aprovechándose de los transportes militares.

- Por carretera, empleando una flota de camiones y vehículos para ello.

- Otros medios, esencialmente, los enlaces de la Guardia Civil y el correo postal.

\subsection{LAS ORGANIZACIONES A LAS QUE SE INCAUTÓ LA DOCUMENTACIÓN}

La principal función, o tarea, de los jefes de equipo era dirigir las inspecciones, que fueron realizadas de manera metódica y sistemática, en búsqueda de documentación de interés para la Delegación, en cada uno de los edificios oficiales republicanos, sedes de sindicatos y partidos políticos prohibidos por la Ley, de 9 de febrero de 1939, de Responsabilidades Políticas, oficinas del ejército republicano, edificios oficiales soviéticos, domicilios particulares de dirigentes políticos republicanos, cines, librerías, editoriales, periódicos y asociaciones culturales, de cada municipio, ya se tratase de un 
pueblo o una capital de provincia, considerados, todos ellos, desafectos o contrarios al régimen franquista ${ }^{107}$.

Las organizaciones y entidades a las que los equipos de recuperación de documentos requisaron su documentación por localidades y áreas geográficas -según las fuentes consultadas- fueron las siguientes:

- Bilbao:

- Diputaciones de Álava, Guipúzcoa y Vizcaya.

- Banco de Vizcaya.

- Santander:

- El Juzgado de Arredondo.

- Los Astilleros de Santander.

- Gijón:

- El Tribunal Popular de Gijón.

- Los Juzgados militares asturianos, de Avilés, Infesto, Cangas de Onís y Pravia.

- El Gobierno Militar de Gijón.

- La empresa Ferrocarriles Vasco-Asturianos.

- Cartagena:

- El Tribunal Popular de Cartagena.

- Cádiz:

- Partidos políticos (Unión Republicana, Partido Republicano Radical Demócrata, Partido Socialista Obrero Español y Partido Comunista de España) y sindicatos, asociaciones y sociedades (CNT, UGT, Sociedad de Obreros y Empleados del Puerto de Cádiz, etc).

- El Gobierno Civil de Cádiz.

- Los Ayuntamientos de Los Barrios y de La Línea de la Concepción.

${ }^{107}$ CDMH. AGGCE. DNSD. Secretaría General. Expedientes Secretaría. Caja 330-348. Legajo 23. Expediente 330.2. 
- Aragón:

- El Ayuntamiento, el Gobierno civil, las Delegaciones de Hacienda y Trabajo, la Audiencia Provincial de Justicia, la Comandancia Militar republicana, el Cuartel de la Guardia Civil y el Banco de Aragón, en Teruel.

- Lérida:

- Partidos políticos (Partido Socialista Unificado de Cataluña), sindicatos (CNT, UGT) y sindicatos de agricultores y campesinos.

- Los Ayuntamientos Albesa, Benavent de Lérida, Portella y Torregrosa.

- Castellón:

- Las logias masónicas de Castellón.

- El Consulado de Francia en Castellón.

- El Consejo Levantino Unificado de la Exportación Agrícola (CLUEA).

- Vinaroz:

- Partidos políticos (Izquierda Republicana) y sindicatos (CNT y UGT).

- Extremadura:

- Partidos políticos (Partido Socialista Obrero Español, Partido Comunista de España), sindicatos (CNT, UGT) y colectividades y sindicatos campesinos.

- Los Ayuntamientos de Valle de la Serena y Quintana de la Serena.

- Correos y Telégrafos (correspondencia particular depositada en cada una de las estafetas de Correos de cada localidad donde los equipos de recuperación de documentos realizaron requisiciones).

- Jaén:

- La Prisión de Jaén.

- Los Ayuntamientos de Andujar, Mongón, y Villacarrillo.

Las organizaciones y entidades a las que los equipos de recuperación de documentos requisaron su documentación en las grandes ciudades fueron las siguientes:

- Alicante:

- Sindicatos y partidos políticos del Frente Popular (Izquierda Republicana). 
- Madrid:

- Partidos políticos (Asociación Socialista Madrileña).

- Valencia:

- Las logias masónicas de Valencia.

- El Tribunal Permanente de Valencia.

- El Cuerpo de Carabineros,

Asimismo, los equipos de recuperación de documentos requisaron documentación de los domicilios particulares, tanto en las grandes ciudades (Gijón, Madrid y otras) como en las localidades situadas los frentes de guerra (Aragón y Castellón, principalmente).

\section{EL COORDINADOR DE LAS INCAUTACIONES}

De la coordinación de los equipos de recuperación de documentos, se encargó una figura clave en la creación de la Delegación, el licenciado en Derecho, abogado y oficial del Cuerpo Jurídico Militar, Manuel Martín Sastre, Jefe de los equipos de recuperación de documentos en los frentes o del denominado -así aparece en las fuentes- Servicio de Recuperación de Documentos en los Frentes de la Delegación.

Manuel Martín Sastre era consciente de que, además de contar con la ayuda y colaboración oficial del Ejército, "tan pronto como una población de alguna importancia fuese tomada en el frente, había que trasladarse a ella"108. Él, personalmente, así lo hacía.

A finales de diciembre de 1938, antes de que finalice la batalla del Segre, el 3 de enero de 1939, con la toma de Lérida, coordina, desde Zaragoza, la actuación de los equipos de recuperación de documentos, que llevan por nombre los de los respetivos jefes de equipo: el equipo de Juan Queralt Oliva, que actúa al sur de Lérida capital; el equipo de Juan Fuentes Bertrán, que actúa en Balaguer; y, el equipo de Julio Lasanta Miranda, que actúa en Tremp. Martín Sastre afirma satisfecho, "todo el amplio frente de operaciones

${ }^{108}$ CDMH. AGGCE. DNSD. Secretaría General. Expedientes Secretaría. Caja 001-045. Legajo 1. Expediente 6. 
está cubierto con nuestros equipos, -fijándose, ya, en Castellón de la Plana- como base para ulteriores avances por Levante" 109 .

En la ofensiva de Cataluña, que tuvo lugar de diciembre de 1938 a febrero de 1939, coordina la actuación, entre otros, del equipo de Juan Fuentes Bertrán, en el Prat de Llobregat; del equipo de Juan Queralt Oliva, en Villafranca del Panadés; y, de los equipos de Julio Lasanta Miranda y Prudencio Arza Arbe en Manresa, considerando insuficiente el número de equipos desplazados a la zona, a la provincia de Barcelona ${ }^{110}$.

Y, una semana antes de la caída de Madrid, con todos los equipos de recuperación preparados, Manuel Martín Sastre contactaba con los oficiales del Ejército del Centro,

para saludar a todos los Comandantes militares de los diferentes Cuerpos de Ejército, en gestión que espero sea satisfactoria para el Servicio, y que revela una atención grande, por parte de las Autoridades Militares, para nuestro Servicio ${ }^{111}$.

A primeros de septiembre de 1939, habiéndose ya asentado el trabajo de los equipos de recuperación de documentos en Madrid capital, y quedando el Comandante del Ejército y militar africanista Tomás Owens y Pérez del Pulgar, II Conde del Zenete, al frente de los mismos, y coincidiendo, también, con el primer envío de documentación (cuatro vagones), incautada en Madrid con destino a Salamanca, Marcelino de Ulibarri ordenaba, tan pronto como fuese posible, que Manuel Martín Sastre saliera de Madrid con destino a Barcelona, Valencia y Alicante, ya que "sus servicios en Madrid no [eran] necesarios" $" 112$.

Marcelino de Ulibarri envía a Manuel Martín Sastre a Barcelona, Valencia y Alicante,

al objeto de recoger, en dichas localidades, cuanto pertenezca a este Organismo, tanto documentos como objetos de toda índole, para

\footnotetext{
${ }^{109}$ CDMH. AGGCE. DNSD. Secretaría General. Expedientes Secretaría. Caja 001-045. Legajo 1. Expediente 6.

${ }^{110}$ CDMH. AGGCE. DNSD. Secretaría General. Expedientes Secretaría. Caja 001-045. Legajo 1. Expediente 6. Barcelona fue tomada el 26 de enero de 1939.

${ }^{111}$ CDMH. AGGCE. DNSD. Secretaría General. Expedientes Secretaría. Caja 001-045. Legajo 1. Expediente 6.

112 CDMH. AGGCE. DNSD. Secretaría General. Expedientes Secretaría. Caja 001-045. Legajo 1. Expediente 6.
} 
remitirlos a esta ciudad -reconociéndole, el director de la Delegación, a Manuel Martín Sastre- el conocimiento que tiene de este Organismo, así como de sus Oficinas y del personal encargado de las mismas ${ }^{113}$.

\section{LOS EQUIPOS DE RECUPERACIÓN DE DOCUMENTOS}

Los equipos de recuperación de documentos estaban formados por entre tres y cinco personas, habitualmente por tres, el jefe, el asesor y ayudantes, todos pertenecientes al personal de la Delegación.

Los jefes de equipo eran nombrados directamente por el Delegado del Estado para Recuperación de Documentos, de entre los ayudantes más experimentados, teniendo en cuenta, además, "sus cualidades morales y su capacidad intelectual"114. Los jefes de equipo estaban acreditados, gracias a un justificante documental, expedido por el Delegado del Estado para Recuperación de Documentos, que probaba el cargo que ostentaban, ante cualquier militar de alto grado u otra persona, civil o militar, que se lo pudiera requerir $^{115}$.

El jefe de equipo, contaba con un denominado "asesor", o jefe de equipo suplente, que reemplazaba al jefe de equipo, "en caso de ausencia repentina de éste""116, y se hacía responsable, por tanto, de la correcta realización de las inspecciones.

113 CDMH. AGGCE. DNSD. Secretaría General. Expedientes Secretaría. Caja 001-045. Legajo 1. Expediente 6. Valencia y Alicante fueron tomadas el 30 de marzo de 1939. Barcelona había sido tomada dos meses antes, el 26 de enero de 1939. El 14 de noviembre de 1939, Manuel Martín Sastre fue ascendido al grado de Capitán del Cuerpo Jurídico Militar, por lo que recibió la felicitación de Marcelino de Ulibarri, que, en la misma, le recuerda que "de la tercera estrella, me corresponden, por lo menos, tres de sus puntas", en CDMH. AGGCE. DNSD. Secretaría General. Expedientes Secretaría. Caja 001-045. Legajo 1. Expediente 6. Las tres estrellas indican el grado de capitán. Cada estrella tiene seis puntas. Ulbarri consideraba, pues, que de la mitad, al menos, del ascenso de Martín Sastre, era responsable directo.

114 CDMH. AGGCE. DNSD. Secretaría General. Expedientes Secretaría. Caja 330-348. Legajo 23. Expediente 330.2.

115 Además, dicho justificante documental era el que habilitaba, a los jefes de equipo de recuperación de documentos, para realizar y dirigir su principal función: los registros, ya se tratase de edificios públicos u oficiales como de domicilios particulares.

116 CDMH. AGGCE. DNSD. Secretaría General. Expedientes Secretaría. Caja 330-348. Legajo 23. Expediente 330.2. 


\subsection{REQUISITOS PARA FORMAR PARTE DE LOS EQUIPOS DE RECUPERACIÓN DE DOCUMENTOS}

A tenor de lo expuesto por Marcelino de Ulibarri a Miguel Paredes, de la Audiencia del Ejército de Ocupación, las miembros, que podían formar parte de los equipos de recuperación de documentos y que habrían de intervenir en la requisición de los mismos, deberían reunir no tanto conocimientos archivísticos sino:

- Una honorabilidad demostrada.

- Un entusiasmo máximo por servir a la España franquista.

\subsection{OPERATIVA DE LOS EQUIPOS DE RECUPERACIÓN DE DOCUMENTOS}

Los equipos de recuperación de documentos operaron en los frentes de Aragón, Castellón, Extremadura, Lérida y Vinaroz, y en los grandes núcleos de población, una vez que estos eran tomados por las tropas franquistas.

En Aragón, operaron cuatro equipos de recuperación de documentos, comandados por Manuel Martín Sastre, Juan Fuentes Bertrán, Juan Queralt Oliva y Prudencio Arza Arbe.

En Castellón, actuaron cinco equipos de recuperación de documentos, dirigidos por Juan Fuentes Bertrán, Julio Lasanta Miranda, Prudencio Arza Arbe, Félix Amillano López y Juan Queralt Oliva.

En Extremadura, sólo dos equipos de recuperación de documentos llevaron a cabo los trabajos de requisición de la documentación: los dirigidos por Eduardo Galán Ruiz y Francisco Salinas Quijada.

En Lérida, operaron tres equipos de recuperación de documentos, siendo los respectivos responsables de los mismos Francisco Salinas Quijada, Prudencio Arza Arbe y Félix Amillano López. 
Y, en Vinaroz, trabajaron tres equipos de recuperación de documentos, cuyos jefes eran Juan Queralt Oliva, Juan Fuentes Bertrán y Francisco Salinas Quijada.

\subsection{APORTACIÓN DE AYUDA LOCAL A LOS EQUIPOS DE RECUPERACIÓN DE DOCUMENTOS}

La colaboración de las autoridades locales y otros ciudadanos brindada a los equipos de recuperación de documentos fue siempre importante a la hora de obtener información que les condujera a la obtención de la documentación que se estaba interesado en requisar. Por ejemplo, en Don Benito (Badajoz), Eduardo Galán Ruiz contactó con las autoridades civiles y militares, en concreto, con el Ayuntamiento, para obtener un edificio o local que fuese adecuado para albergar el Archivo de la Delegación en Extremadura, para lo cual fue acompañado, por la localidad, y asesorado por un alguacil del Ayuntamiento.

\section{LA RED DE ARCHIVOS DE LA DELEGACIÓN}

Una vez tomado y recién pacificado el municipio, los equipos de recuperación de documentos debían buscar y encontrar un lugar donde establecerse,

un local conveniente, que [sirviera] de Oficina y depósito [documental], al mismo tiempo, con suficiente capacidad para [dar] cabida a los documentos que de los registros [procediesen] ${ }^{117}$.

El lugar adecuado para la Oficina y el depósito documental, lugar donde custodiar los documentos requisados, no debía ser, en principio, demasiado grande, aunque sus dimensiones estuviesen en función del volumen de la documentación a incautar, y, sobre todo, no debía estar ubicado en un inmueble lujoso, del cual los equipos de

${ }_{117}$ CDMH. AGGCE. DNSD. Secretaría General. Expedientes Secretaría. Caja 330-348. Legajo 23. Expediente 330.2 . 
recuperación y los documentos pudieran ser desalojados, para instalarse, allí, otros organismos oficiales, militares o civiles ${ }^{118}$.

El depósito y su correspondiente Oficina, para la administración del mismo, debía contar con el material necesario para organizar el trabajo de requisición de la documentación (precintos, sacos, cuerda, etc.). Al frente del mismo, se encontraba un jefe, que podía ser el propio jefe de equipo, cuya función, primordial y esencial, era la de encargarse del libro de registro, de la documentación que entraba en el depósito, y un secretario $^{119}$.

Una vez establecido y organizado el depósito y su correspondiente oficina en cada municipio, con la premura y apuro impuestos por las propias circunstancias de la coyuntura bélica, se debía comunicar, al Archivo central de Salamanca, la dirección o domicilio del mismo y su correspondiente número de teléfono, para dar noticia de su establecimiento y del desarrollo de los trabajos, de requisición de documentos, efectuados ${ }^{120}$. Esto dio lugar a la creación, por parte de la Delegación del Estado para Recuperación de Documentos, de una red de $\operatorname{archivos}^{121}$, algunos de los cuales tuvieron una efímera existencia, cuyo Archivo central estuvo ubicado en Salamanca y del cual dependían todos ellos. La existencia de esta red de archivos se limitó, en general y para la mayoría de los archivos que la conformaron, a la duración de la propia Guerra Civil. También, el archivo establecido en cada municipio debía comunicar, a las autoridades militares, su creación, informándoles, asimismo, de su dirección, para que toda la documentación, requisada por las autoridades militares, fuera remitida a estos archivos, para su registro, almacenamiento o depósito, custodia y posterior envío, por transporte terrestre o ferroviario, al Archivo central de Salamanca ${ }^{122}$.

\footnotetext{
${ }^{118}$ CDMH. AGGCE. DNSD. Secretaría General. Expedientes Secretaría. Caja 330-348. Legajo 23. Expediente 330.2.

119 CDMH. AGGCE. DNSD. Secretaría General. Expedientes Secretaría. Caja 330-348. Legajo 23. Expediente 330.2.

${ }^{120}$ CDMH. AGGCE. DNSD. Secretaría General. Expedientes Secretaría. Caja 330-348. Legajo 23. Expediente 330.2.

${ }^{121}$ Se puede hablar con propiedad y exactitud definitoria al emplear el concepto de "red de centros o archivos", dependientes del Archivo central, con sede en Salamanca.
} 
La Delegación del Estado para Recuperación de Documentos dio lugar a una red de archivos y depósitos documentales por todo el territorio peninsular.

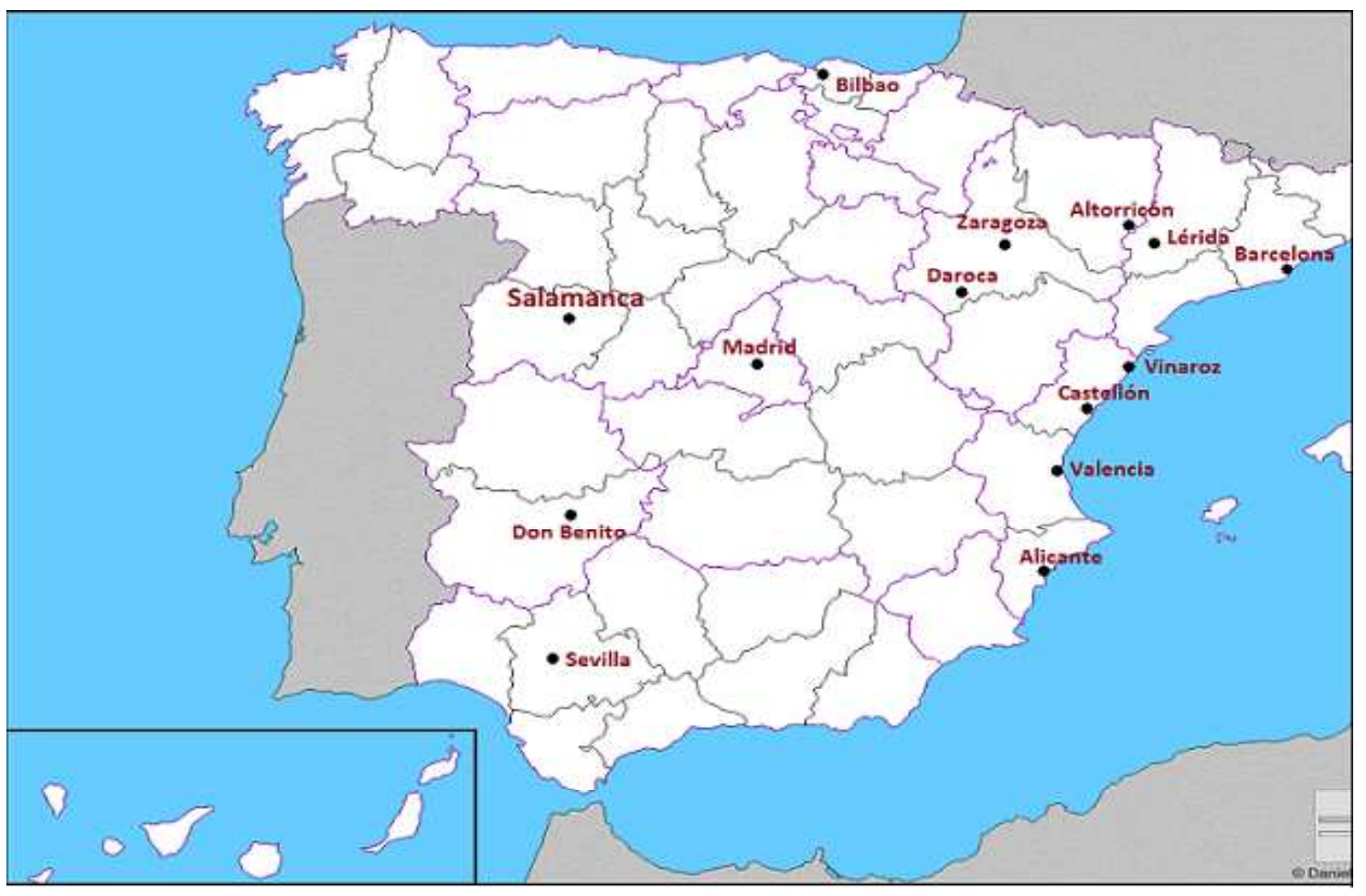

Mapa 4.1. Sedes de la Delegación y depósitos documentales

A continuación, se relacionan los edificios que la Delegación ocupó para conformar la red de archivos y depósitos documentales que formaron parte de la misma.

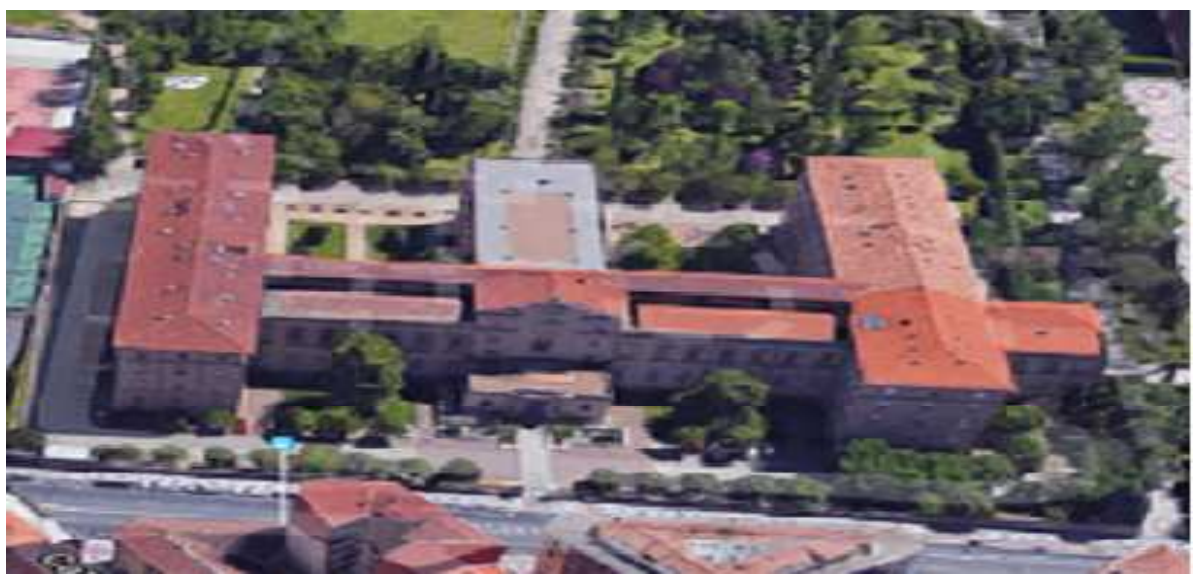

Fig. 4.2. Delegación del Estado para Recuperación de Documentos o Archivo central de Salamanca. Edificio de San Estanislado de Kostka. Paseo de San Antonio, s/n

${ }^{122}$ CDMH. AGGCE. DNSD. Secretaría General. Expedientes Secretaría. Caja 330-348. Legajo 23. Expediente 330.2. 


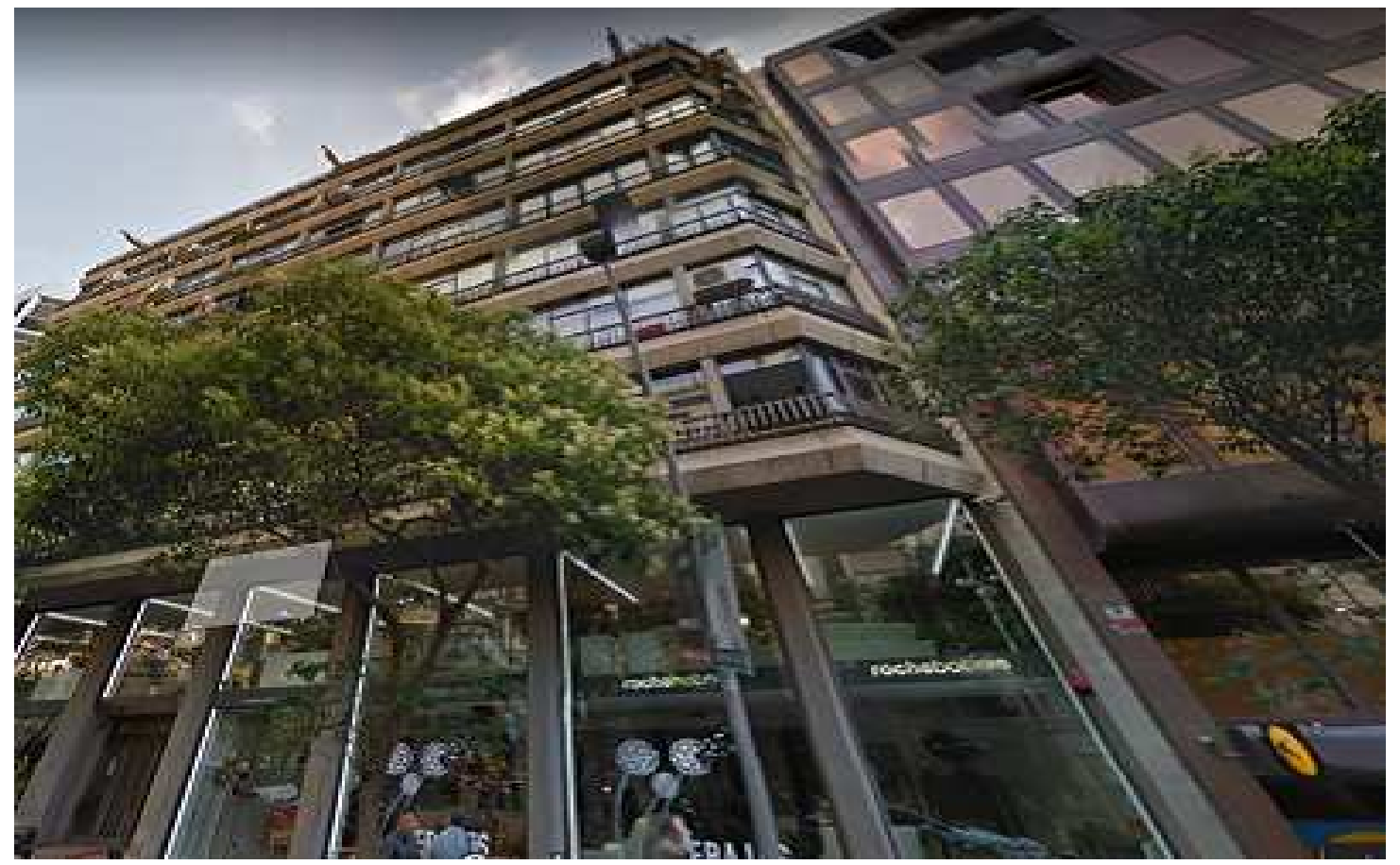

Fig. 4.3. Delegación en Barcelona. Calle Montaner, núm. 264

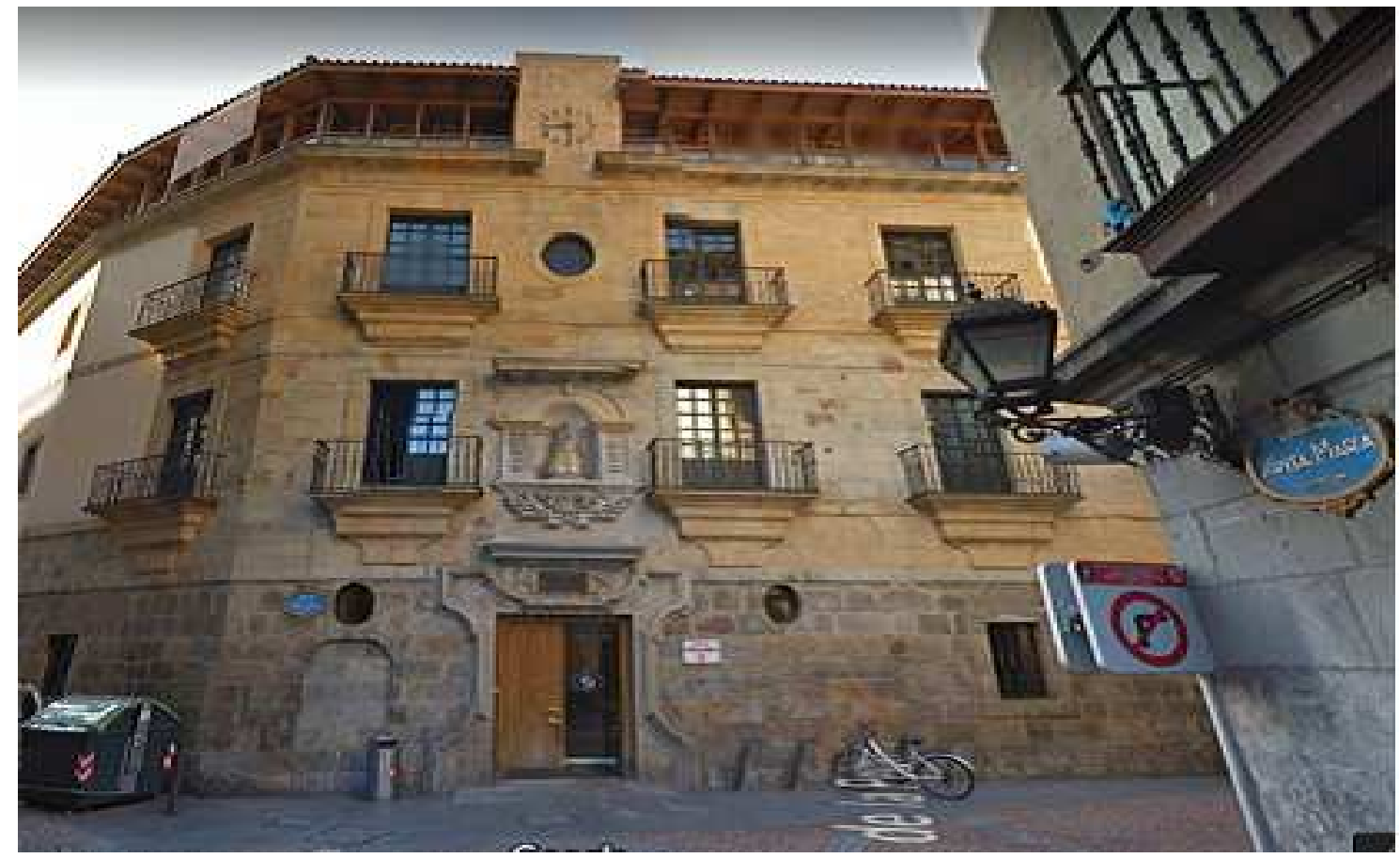

Fig. 4.4. Delegación en Bilbao. Edificio de la Bolsa. Calle Pelota, núm. 10 


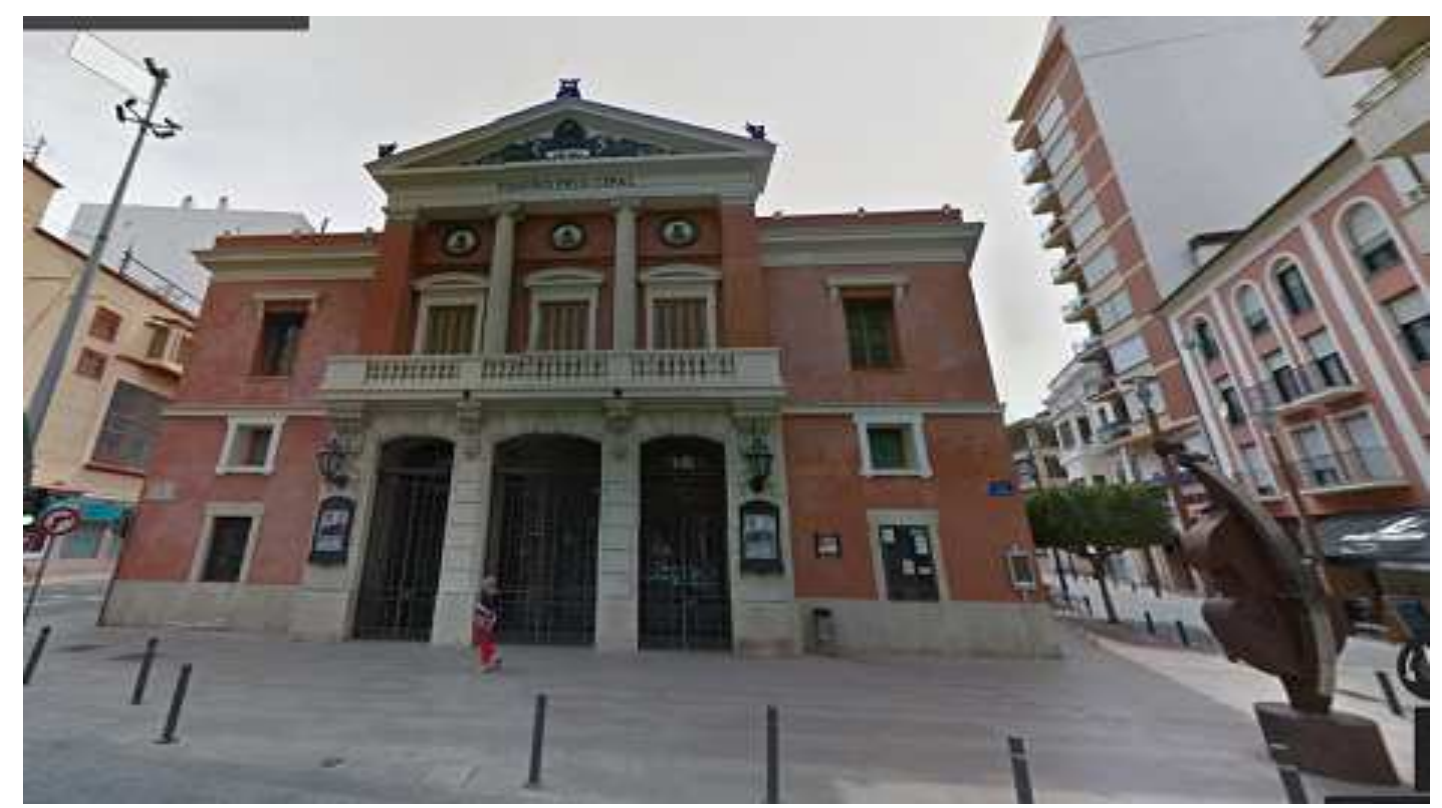

Fig. 4.5. Castellón. Depósito documental.

Plaza de la Paz, núm. 8

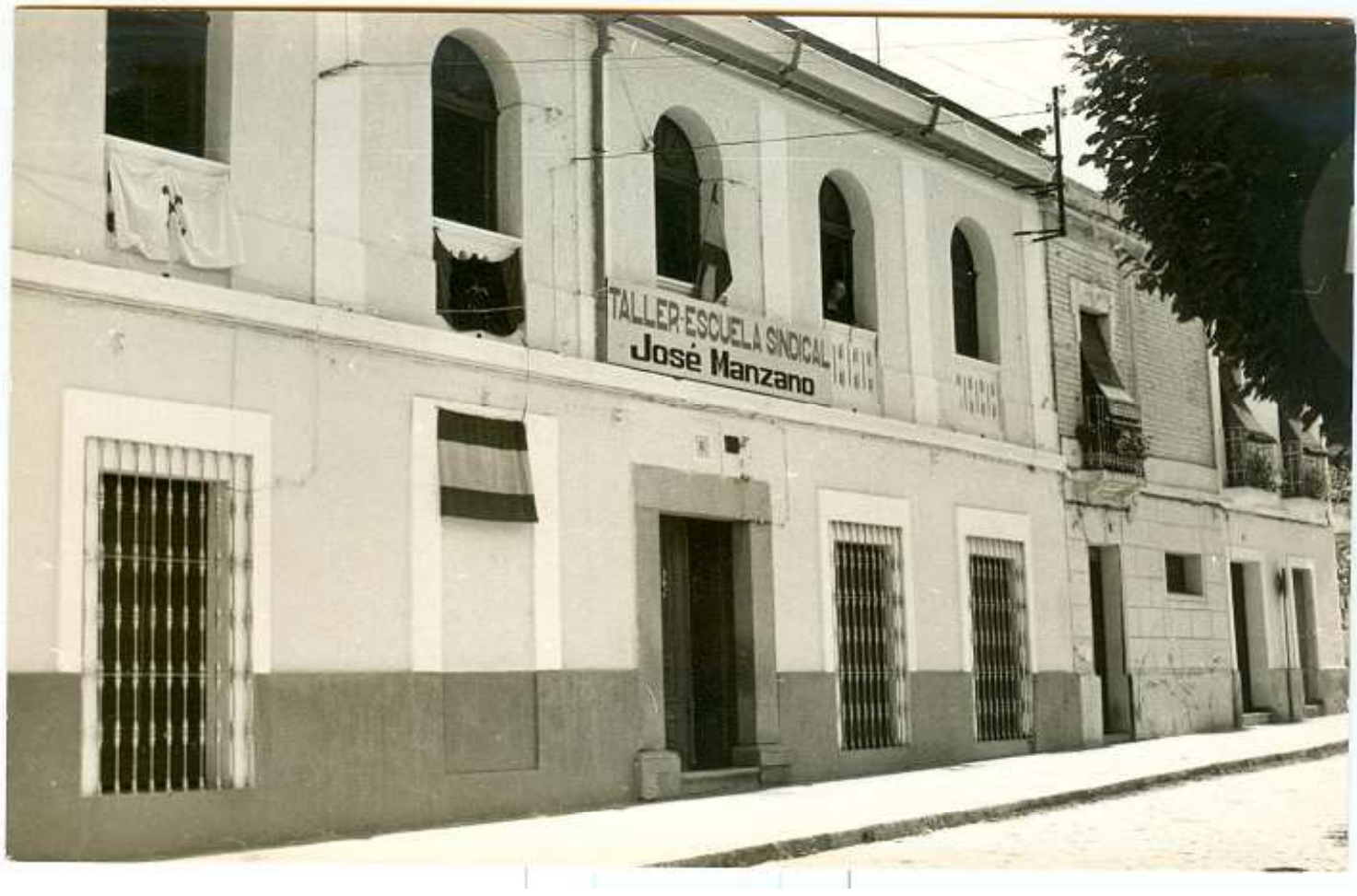

Fig. 4.6. Delegación en Don Benito (Badajoz).

Edificio de la antigua Escuela de Artes y Oficios y de la Escuela Elemental de Trabajo. Calle Torres Isunza, núm. 2 
El Archivo que perdía los papeles. El Archivo de la Guerra Civil según el fondo documental de la DNSD

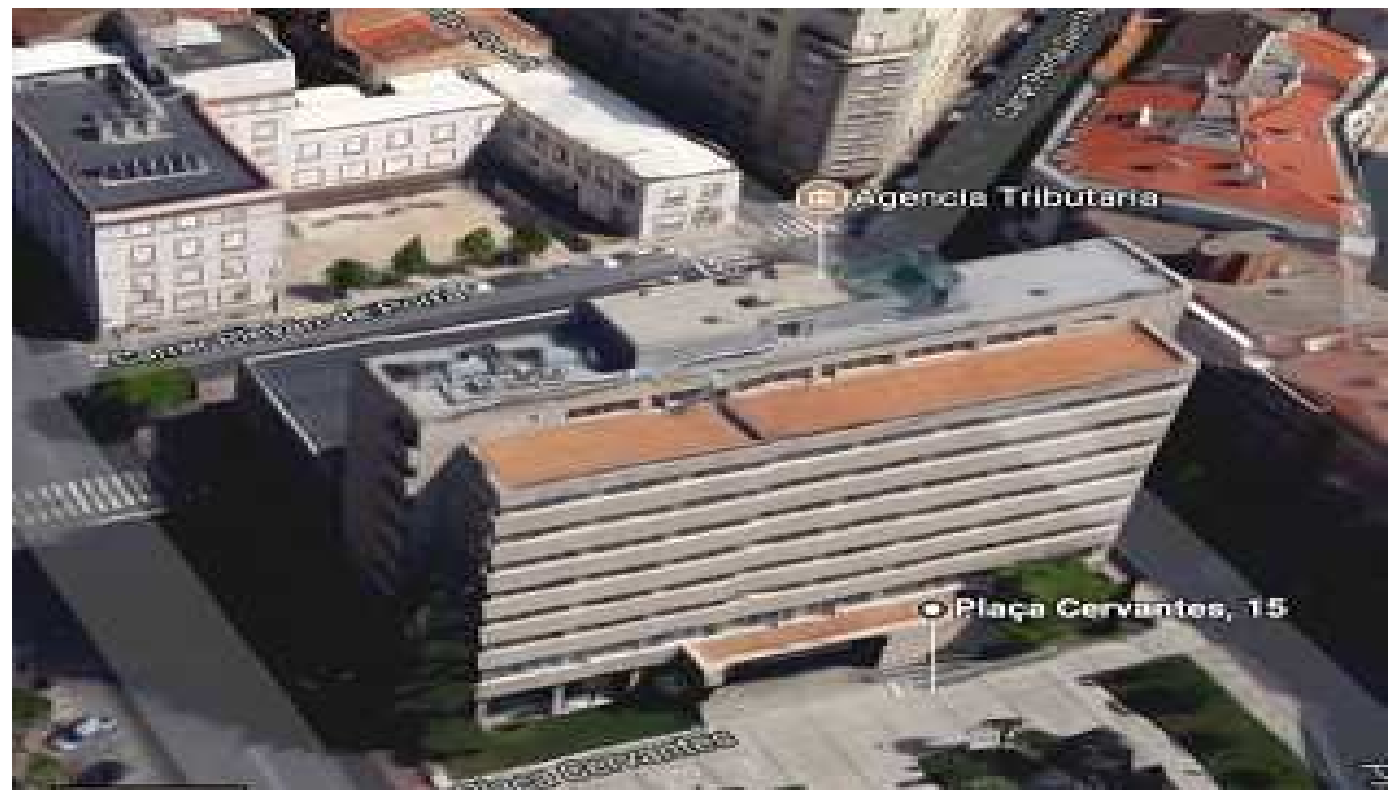

Fig. 4.7. Lérida. Depósito documental.

Plaza de Cervantes, núm. 15.

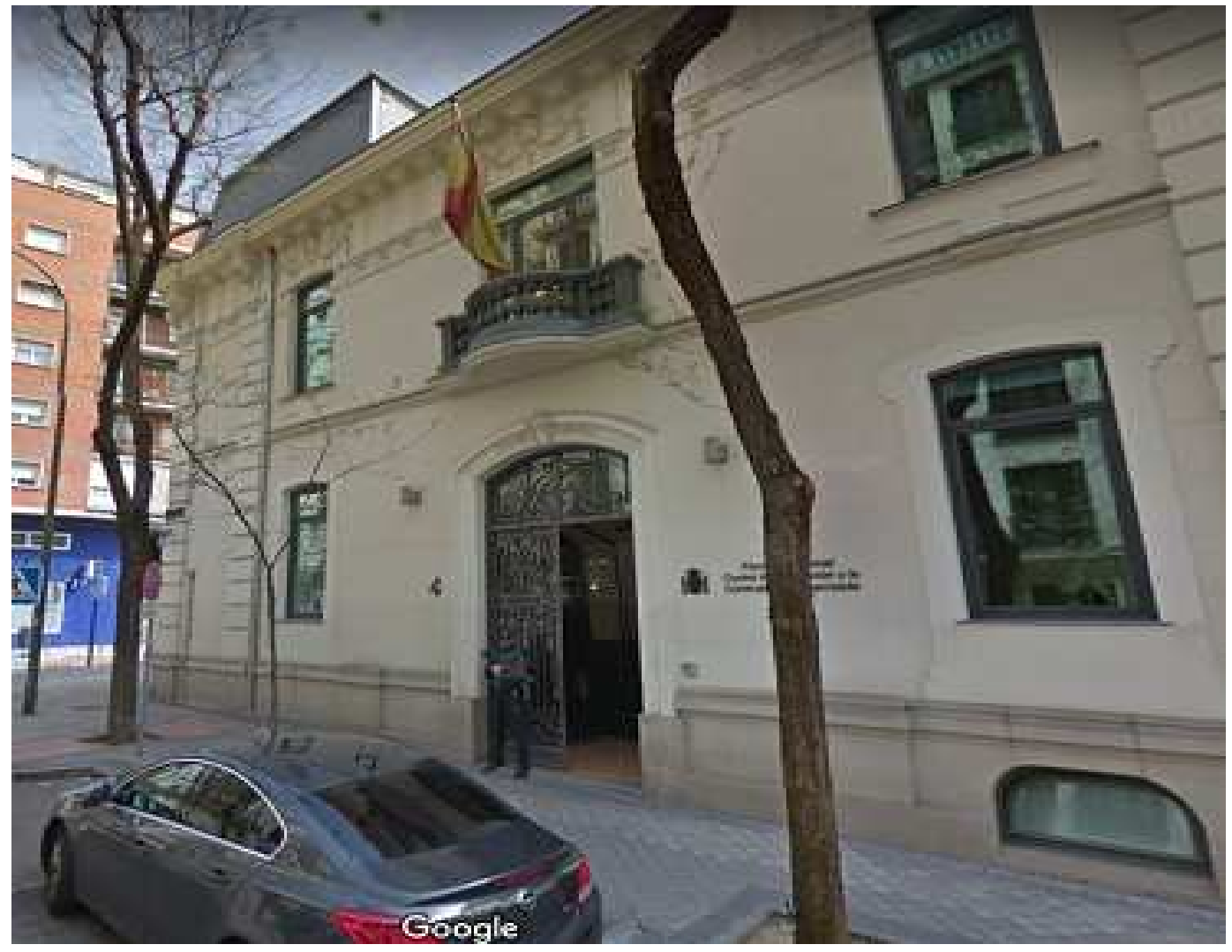

Fig. 4.8. Delegación en Madrid. Calle Manuel Silvela, núm. 4 


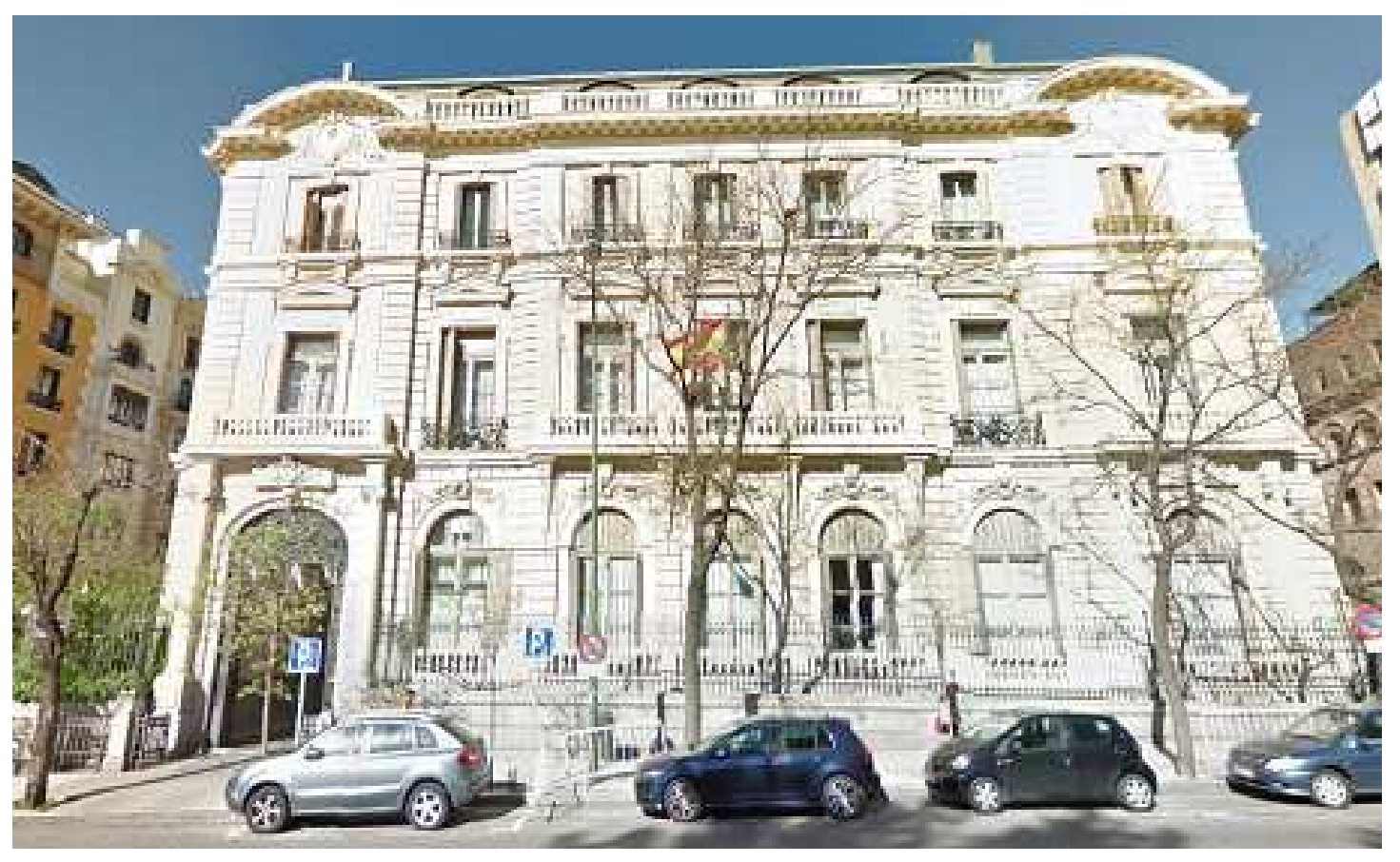

Fig. 4.9. Madrid. Depósito documental. Calle Santa Engracia, núm. 7

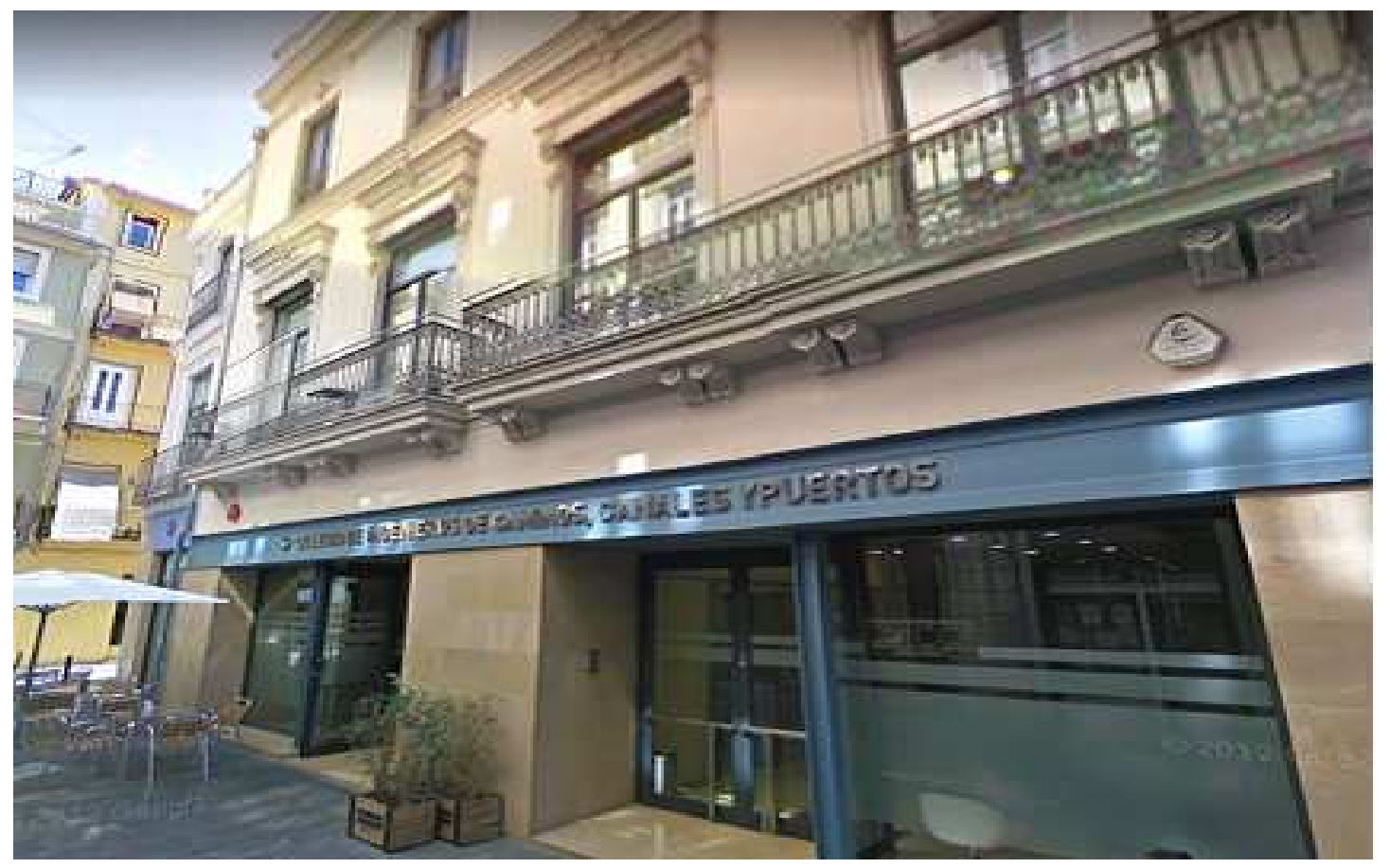

Fig. 4.10. Delegación en Valencia. Calle Luis Vives, núm. 3 


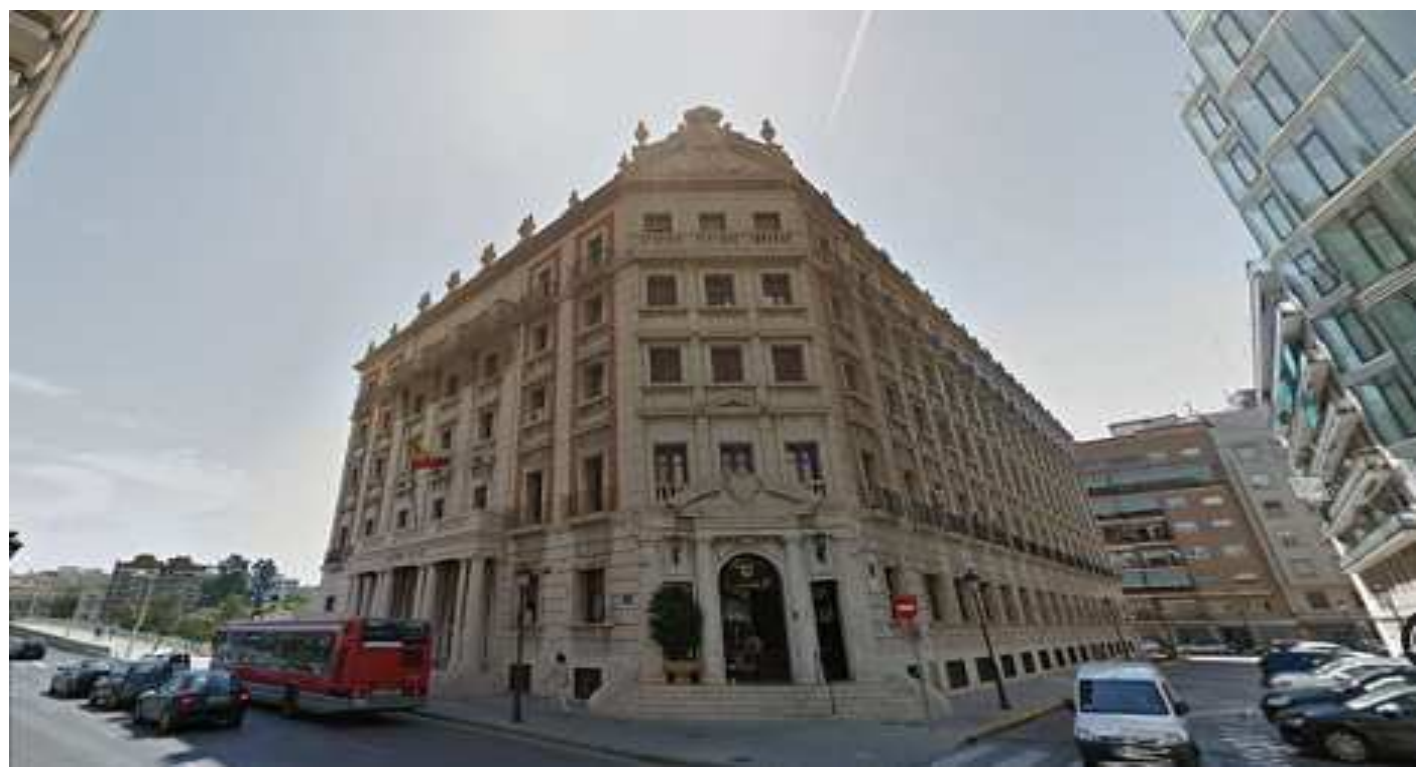

Fig. 4.11. Valencia. Depósito documental. Gobierno militar. Calle del Justicia, núm. 8

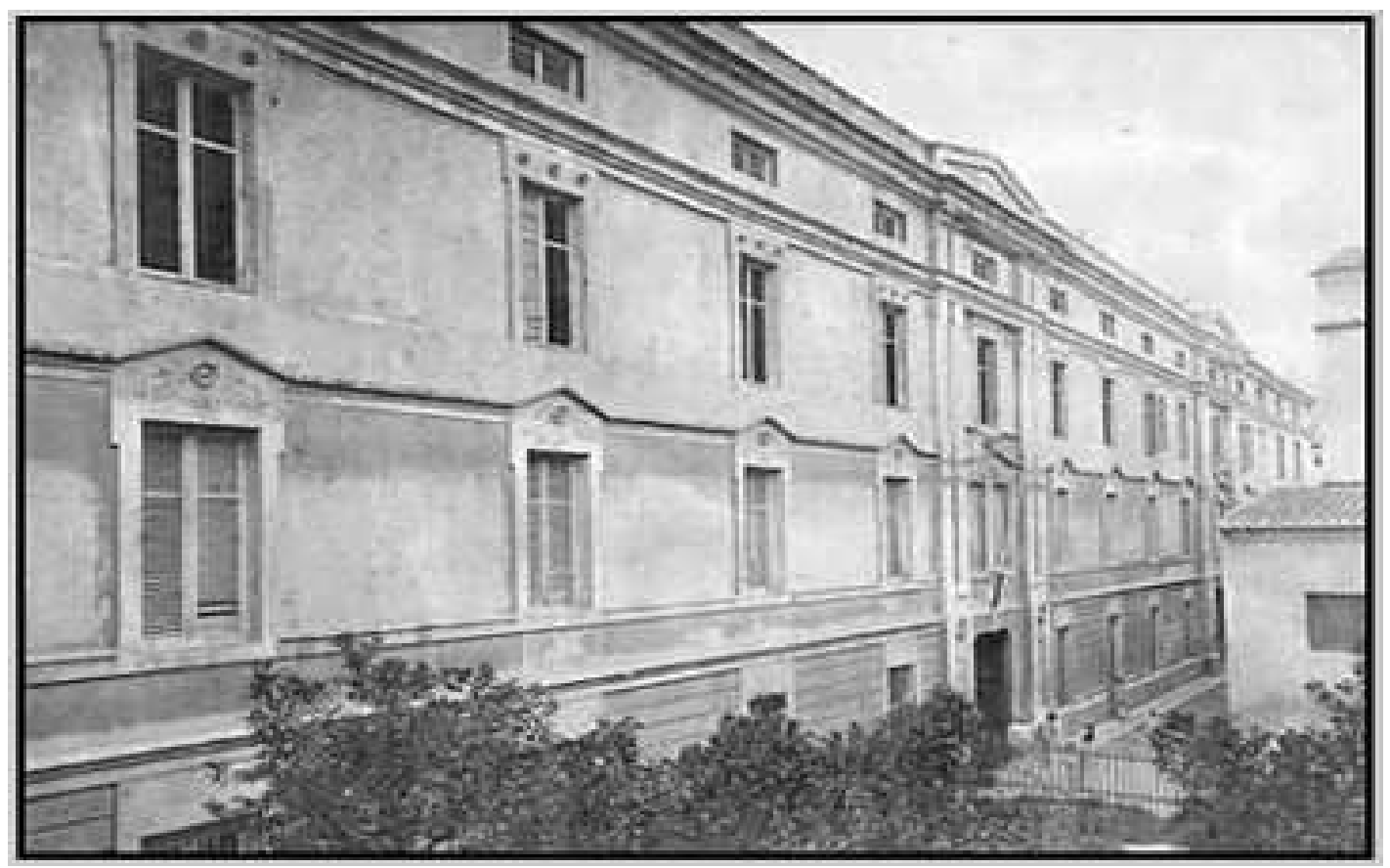

Fig. 4.12. Valencia. Depósito documental. Casa de la Misericordia (edificio derribado en 1949). Antigua plaza de San Miguel, núm. 4 


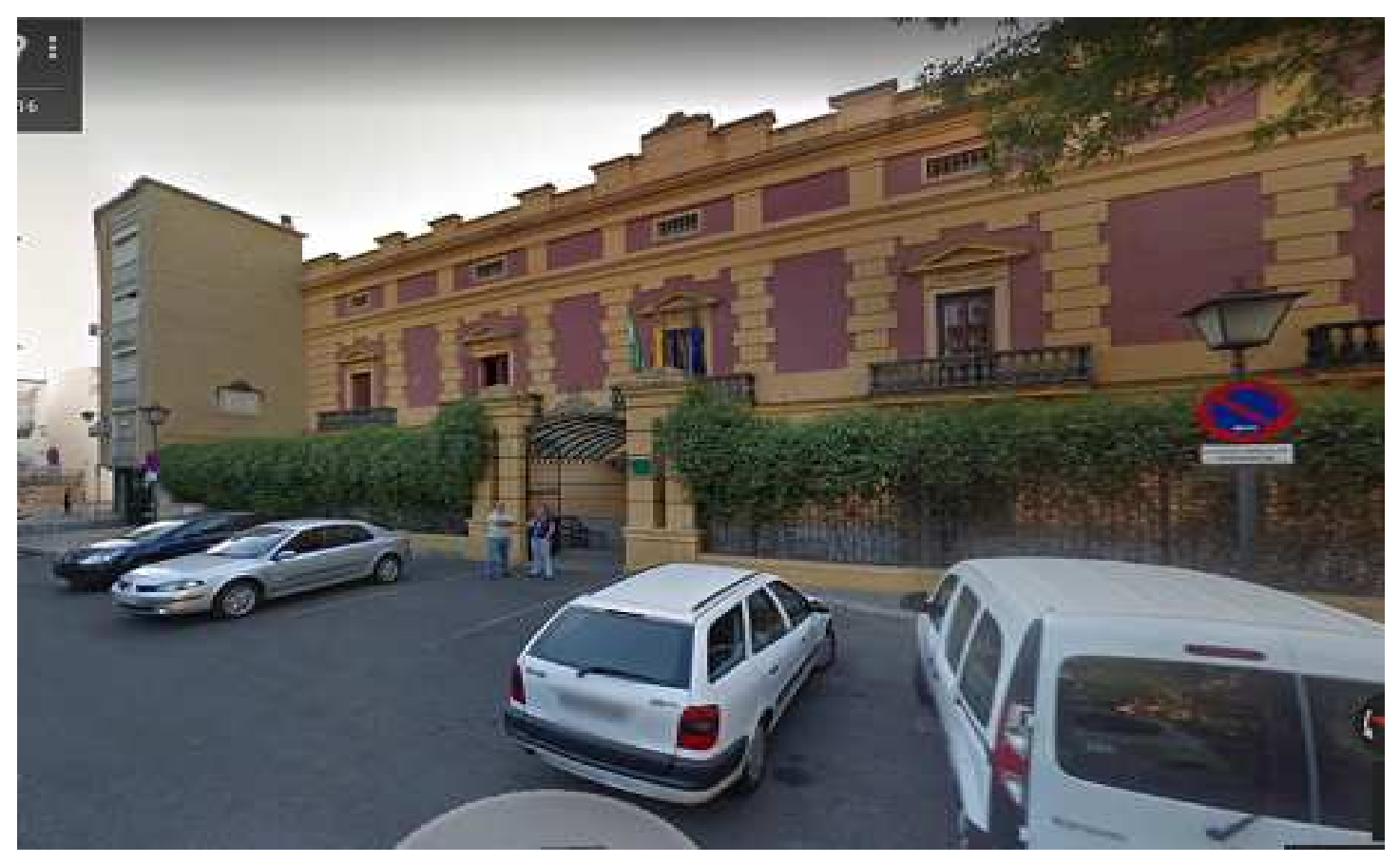

Fig. 4.13. Sevilla. Cuartel General del general Queipo de Llano. Plaza de Gavidia, núm. 2

Al comienzo de la ofensiva oriental, que pondría fin a la Guerra Civil, Manuel Martín Sastre estableció su residencia, y el enlace de todos los equipos de recuperación de documentos, en el Gran Hotel Oriente, ubicado en la calle Coso, números 11-13, de Zaragoza, un establecimiento, cuya fachada de estilo clásico-renacentista del siglo XIX se conserva en la actualidad. De Zaragoza, salieron todas las expediciones, de equipos de recuperación de documentos, camino hacia los frentes de la ofensiva oriental ${ }^{123}$.

${ }^{123}$ CDMH. AGGCE. DNSD. Secretaría General. Expedientes Secretaría. Caja 001-045. Legajo 1. Expediente 6. 


\section{LA CLASIFICACIÓN DOCUMENTAL LLEVADA A CABO EN LA DELEGACIÓN}

La clasificación documental, para el archivero francés Yves Pérotin, implica tres acciones:

$1^{o}$. Une opération purement intellectuelle: le choix d'un cadre de répartition pour les archives d'un pays, d'une collectivité, d'une institution, d'une entreprise, etc., qui comporte un aspect subtantiel (¿sur quoi est fondée la répartition?) et un aspect formel (comment sont designes les groupes, leurs divisions et sudivisions?) représentant l'option pour un système de cotation.

$2^{\circ}$. Une opération à la fois intellectualle et matérielle: la mise en ordre des documents et articles d'une masse limitée d'archives (par example, un versement, un petit fonds, un lot de papiers découverts quelque part).

$3^{o}$. Une opération purement matérielle: le libellé des cotes en fonction des premières opérations et le rangement effectif des articles sur les tabletees des magasins d'archives ${ }^{124}$.

Existen tres sistemas de clasificación:

$1^{o}$. La clasificación funcional. Como su propio nombre indica, las funciones de la entidad que genera o ha generado el fondo de archivo son los elementos tomados en consideración para clasificar los documentos. Siguiendo este criterio, en primer lugar, agruparemos la documentación de acuerdo con las actividades de las que son resultado. Una vez agrupada toda la documentación en series, éstas deben ser reunidas bajo clases más amplias que recojan todas las actividades emparentadas por ser fruto de una función. Por fin, las funciones se agrupan a su vez en las clases más amplias, derivadas en las líneas de acción de la entidad. En el desarrollo de un cuadro de clasificación, las

\footnotetext{
124 "1. Una acción puramente intelectual: la elección de un cuadro de clasificación para los archivos de un país, de una colectividad, de una institución, de una empresa, etc., lo que comporta un aspecto sustantivo (¿en qué se fundamenta la clasificación?) y un aspecto formal (“¿cómo se designan los fondos, sus divisiones y subdivisiones?”), y esto representa la opción para un sistema de valoración; $2^{\circ}$. Una acción intelectual y material al mismo tiempo: la puesta en orden de los documentos de un conjunto limitado de archivos (por ejemplo, un ingreso, un fondo pequeño, un conjunto de documentos descubiertos en cualquier parte); $3^{\circ}$. Una acción puramente material: la redacción de las signaturas / códigos en función de las operaciones previas y la instalación efectiva de los documentos en las baldas de las estanterías de los depósitos", en PÉROTIN, Yves., "Esquisse d'une théorie du classement et de la cotation", en Ministère DES AfFAIRES Culturelles.; AsSOCIATION DES ARCHIVISTES FRANÇAIS., Manuel d'Archivistique. Théorie et practique des Archives publiques en France. París, S.E.V.P.E.N. Imprimiere Nationale, 1970, p. 188.
} 
funciones deberán tomarse en cuenta al establecer clases, series o agrupaciones documentales, de acuerdo con un esquema piramidal o jerarquizado de las mismas.

$2^{\circ}$. La clasificación orgánica. En este sistema, las series se agrupan de acuerdo con las diferentes divisiones administrativas o estructura orgánica de la entidad, reproduciendo sus servicios, secciones, unidades... Decimos las series porque en este caso también los expedientes se agrupan según la actividad de la que son resultado. Sólo a partir de este nivel es posible establecer una clasificación orgánica, la cual se realizará jerárquicamente desde las unidades administrativas básicas hasta las divisiones más amplias.

$3^{\circ}$. Clasificación por materias. Este tipo de clasificación es el resultado del análisis del contenido de los documentos, esto es, de los asuntos o materias sobre los que versan. ${ }^{125}$.

Los sistemas de clasificación documental deben caracterizarse y perseguir la claridad y la precisión, para identificar, con facilidad, a las instituciones productoras de los documentos.

La documentación, en la Delegación, fue clasificada estableciendo agrupaciones documentales por procedencia geográfica de requisición: Alicante (provincia de Alicante), Barcelona (Cataluña), Bilbao (País Vasco), Cádiz (provincia de Cádiz), Cartagena (Tribunal Popular de Cartagena), Castellón (provincia de Castellón), Extremadura (comarca de Don Benito y limítrofes), Gijón (municipio de Gijón y Asturias), Jaén (provincia de Jaén), Lérida (provincia de Lérida), Madrid (Madrid capital), Santander (municipio de Santander y Cantabria), Valencia (provincia de Valencia, capital incluida) y Vinaroz (municipios de las provincias de Lérida, Tarragona, Teruel y Castellón).

Por otra parte, también, a la clasificación de la documentación llegada a la Delegación, exceptuando las agrupaciones de prensa y propaganda que fueron clasificadas por materias, se le aplicaron los criterios de clasificación, aplicados por los militares, para la

${ }^{125}$ CruZ Mundet, José María., Archivística. Gestión de documentos y administración de archivos. Madrid, Alianza Editorial, 2012, pp. 215 y ss. José Ramón CRUZ MUNDET considera obsoleto el sistema de clasificación por materias, y da por descartada su aplicación en la actualidad, aunque se refiera, a él, pues "es independiente del proceso que da lugar a los documentos", es decir, no se corresponde o está en concordancia con los principios de procedencia y orden original, en el Capítulo 10 de la obra de CRUZ MUNDET, José Ramón., Archivística. Gestión de documentos y administración de archivos. Madrid, Alianza Editorial, 2012. 
agrupación documental conocida como PS-Militar o Serie Militar, de la Delegación, criterios de clasificación documental que se exponen a continuación.

En julio de 1939, Eduardo de Fuentes Cervera, entonces Coronel Jefe del recién creado Servicio o Archivo Histórico Militar, ubicado en la calle Mártires de Alcalá, nº 9, de Madrid, remitía a Macelino de Ulibarri y al personal militar bajo su mando, la que denominó Instrucción General con normas para la Clasificación, Ordenación y Remisión de la documentación, propia y enemiga, por las unidades subordinadas y curso correspondiente (de 7 de julio de 1939).

Dicha Instrucción General era una adaptación y, en lo sustancial, casi una copia de la Instrucción, de 23 de junio de 1939, para la constitución del Archivo de Campaña. En ambas Instrucciones, tanto para la documentación del Ejército republicano como para la documentación del Ejército franquista, se optaba por una clasificación, de la documentación, por organismos y unidades, y, dentro de estos, por una subclasificación en divisiones equivalentes a las Secciones del Estado Mayor: Organización, Información, Operaciones y Servicios ${ }^{126}$.

Como señalaba el Coronel Jefe del Servicio Histórico Militar, Eduardo de Fuentes Cervera, en su Instrucción General, remitida a Salamanca, la finalidad y objeto último de la clasificación de la documentación debía ser "la redacción de un estudio históricomilitar de la Campaña del Ejército Nacional”, es decir, para un fin historiográfico, y no tanto archivístico ${ }^{127}$.

Tanto la documentación del Ejército republicano como la documentación del Ejército franquista, que se encontraba depositada en la Delegación de Salamanca, debía ser clasificada y ordenada en expedientes y legajos, entendiendo, en este caso, por expediente "el conjunto de documentos pertenecientes a una Gran Unidad o una Unidad

\footnotetext{
${ }^{126}$ CDMH. AGGCE. DNSD. Secretaría General. Expedientes Secretaria. Caja S.G. 242-243. Legajo 12. Expediente 243.

${ }^{127}$ CDMH. AGGCE. DNSD. Secretaría General. Expedientes Secretaria. Caja S.G. 242-243. Legajo 12. Expediente 243.
} 
inferior, si se desconoce aquella. Y, por legajo, las partes en que se divide un expediente" ${ }^{\prime 28}$.

Cada expediente se dividiría, en su caso, en seis legajos, a saber:

$1^{\text {o. }}$ Organización, legajo en el que se incluiría documentación relativa al personal, asuntos administrativos, justicia, recompensas, y documentación relativa a cambios en la estructura militar dentro de la propia unidad.

$2^{\circ}$. Información, legajo en el que se incluiría documentación relativa a la información periférica o de contacto, boletines informativos, espionaje y propaganda militar.

$3^{\circ}$. Operaciones, legajo en el que se incluiría documentación relativa, como su propio nombre indica, a operaciones, órdenes militares, directivas generales $\mathrm{o}$ particulares, diarios de operaciones, normas de actuación e informes y estudios estratégicos y tácticos.

$4^{\circ}$. Cartografía, legajo que, como su propio nombre indica, incluiría mapas, planos, croquis, fotografías tomadas desde tierra y desde el aire, fotografías en general, etc.

$5^{\circ}$. Varia, legajo en el que se incluiría toda aquella documentación que no tuviera cabida y "encaje" en los legajos anteriores ${ }^{129}$.

En cada expediente y legajo debía figurar, en una carátula, bien visible, por este orden, los siguientes datos:

A. La unidad del Ejército, republicano o franquista, a la que pertenecía la documentación.

B. El lugar de procedencia de la documentación, o el lugar dónde ésta había sido recogida.

${ }^{128}$ CDMH. AGGCE. DNSD. Secretaría General. Expedientes Secretaria. Caja S.G. 242-243. Legajo 12. Expediente 243.

${ }^{129}$ CDMH. AGGCE. DNSD. Secretaría General. Expedientes Secretaria. Caja S.G. 242-243. Legajo 12. Expediente 243. 
C. La fecha de la recogida.

D. La unidad, división o cuerpo de Ejército que la había recogido.

En su caso, y cuando el contenido de los legajos y expedientes así lo exigiera, se indicaría "su carácter de RESERVADO o SECRETO"130. De la documentación que todavía tuviese valor militar vigente, "para el despacho de asuntos militares actuales, [...] se remitirán los originales, conservándose, en el Archivo, copia exacta de ellos"131. En este sentido, se insistía en que la documentación, a enviar al Servicio Histórico Militar, fuese aquella "con valor histórico suficiente para que figure en el Archivo de Campaña"132.

Finalmente, la Instrucción General indicaba cómo debía ser enviada la documentación, desde la Delegación salmantina al Servicio Histórico Militar de Madrid. Para evitar la pérdida de documentos, la documentación no debía ser envidada "en modo alguno, a granel, en cajones o en sacos", algo que, obviamente, no se cumplió ${ }^{133}$.

\footnotetext{
${ }^{130}$ CDMH. AGGCE. DNSD. Secretaría General. Expedientes Secretaria. Caja S.G. 242-243. Legajo 12. Expediente 243.

${ }^{131}$ CDMH. AGGCE. DNSD. Secretaría General. Expedientes Secretaria. Caja S.G. 242-243. Legajo 12. Expediente 243.

${ }^{132}$ CDMH. AGGCE. DNSD. Secretaría General. Expedientes Secretaria. Caja S.G. 242-243. Legajo 12. Expediente 243.

${ }^{133}$ CDMH. AGGCE. DNSD. Secretaría General. Expedientes Secretaria. Caja S.G. 242-243. Legajo 12. Expediente 243. Por otra parte, en cumplimiento de la Instrucción General, al Coronel Jefe del Archivo Histórico Militar, sería enviado un inventario detallado de la documentación que poseyeran y custodiaran las Regiones Militares y los Ejércitos. El Coronel Jefe del Archivo Histórico Militar comunicaría y dispondría su envío. Para la documentación de la Sección Especial de la Delegación, se aplicaron los mismos principios de clasificación que para la documentación de la Sección Político-Social, estudiados más exhaustivamente en esta tesis. Dentro de la Sección Político-Social, sólo a las agrupaciones documentales denominadas Propaganda y Prensa se les aplicó una clasificación temática.
} 


\section{INSTALACIÓN DE LA DOCUMENTACIÓN EN LA DELEGACIÓN. EL INSTRUMENTO CLAVE: EL LEGAJO Y EXPEDIENTE PERSONAL}

La ordenación de la documentación -cuando ésta se produjo- se realizó a través de expedientes personales y legajos diversos, conocidos también pomposamente como varia o más pomposamente aún como miscelánea, "véritable peste de tous les classements"134. En los legajos, se reunía todo lo que concernía a:

- Un persona.

- Una institución.

- Una localidad.

- Etc.

Y, lo que es más importante, a través de una signatura alfanumérica, los legajos y expedientes personales remitían, al mismo tiempo, a los inventarios y a las fichas, fichas personales que dieron lugar a la creación del conocido como Fichero General del Archivo General de la Guerra Civil Española.

\section{FINALIDAD ÚLTIMA: LA CREACIÓN DEL FICHERO GENERAL DE LA DELEGACIÓN}

\subsection{SOBRE LA FICHA}

Según Markus KRAJEWSKI, el inventor de la ficha fue el zoólogo, botánico y bibliógrafo suizo del siglo XVI Johann Conrad GESSNER ${ }^{135}$. Aunque entre sus contemporáneos, Gessner era una autoridad en la descripción científica de animales y vegetales, sus aportaciones a los campos de la bibliología y la bibliografía, no por desconocidas fueron menores, por lo que puede ser considerado como un pionero en la clasificación

\footnotetext{
${ }^{134}$ PÉrotin, Yves., "Esquisse d'une théorie du classement et de la cotation", en MinISTÈre DES AFFAIRES CUltURElles.; AsSOCIATION DES ARCHIVISTES FranÇAIS., Manuel d'Archivistique. Théorie et practique des Archives publiques en France. París, S.E.V.P.E.N. Imprimiere Nationale, 1970, p. 197.

${ }^{135}$ Para realizar sus estudios bibliográficos, Johann Corad GESSNER, sencillamente, procedió a cortar una hoja de papel, generando fichas individuales y dando lugar, así, a un nuevo método de procesamiento de los datos.
} 
bibliográfica $^{136}$. En 1545, publicó su obra Bibliotheca Universalis, un catálogo en latín, griego y hebreo, que recogía el nombre de todos los títulos, junto a sus autores, de todas las obras aparecidas hasta la fecha y de las que había tenido conocimiento: el uso de las fichas que él mismo había ideado, para la realización de tan magna obra, le fue de gran utilidad $^{137}$.

A finales del siglo XVIII, imbuidos por el espíritu racionalizador y sistematizador de la Ilustración, el catálogo de fichas se universalizó y se convirtió en la respuesta eficaz del bibliotecario ante la amenaza de una sobrecarga de información ${ }^{138}$.

La ficha permite el almacenamiento, el procesamiento y la transferencia de datos, y su uso fue habitual en las oficinas y archivos del Occidente europeo hasta el periodo de entreguerras.

La ficha facilitaba una clasificación sencilla de las ideas, ordenaciones diferentes y, lo que es más importante, pronto, sobre todo, a finales del siglo XIX y el primer tercio del siglo XX, su uso se extendió a otras actividades, no sólo las de carácter científico e intelectual, adaptándose, así, a un sinnúmero de trabajos, dando lugar a distintos modelos de fichas según para lo que éstas eran empleadas:

- Fichas estadísticas.

- Fichas contables.

- Fichas empresariales.

- Fichas administrativas.

- Fichas judiciales.

- Fichas policiales.

\footnotetext{
136 Johann Corad GESSNER (Zúrich, 26.03.1516 - 13.12.1565) es uno de los padres de la zoología moderna, gracias a su obra, en cuatro volúmenes, Historia Animalium (1551-1558). Johan Corad Gessner estudió en las Universidades francesas de Estrasburgo, Bourges y Montpellier, donde obtuvo su doctorado en medicina, en 1551, año a partir del cual, la ejerció, trabajando como médico en su localidad natal, Zúrich, lo que no le impidió morir de peste, en 1565. Además, fue profesor de griego en la Academia de Lausana de Berna y profesor de física en el Carolium de Zúrich.

${ }^{137}$ Tres años después, en 1548, publicó su obra Pandectarium sive partitiorum universalium Conradi Gesnari Ligurini Libri XXI, continuación de su Biblioteca Universalis; y, en 1555, publicó su obra Mithridates de differentis linguis, una clasificación de las 130 lenguas conocidas hasta ese momento.

${ }^{138}$ A finales del siglo XVIII, los escritores, intelectuales y philosophes dejaron de emplear, para la realización de sus trabajos científicos y literarios, los cuadernos, que fueron sustituidos por las fichas.
} 
- Fichas archivísticas y bibliográficas ${ }^{139}$.

Estas últimas, las fichas archivísticas, en la Delegación de Salamanca, fueron utilizadas con la finalidad de poder controlar a la población, investigar con fines represivos y, en su caso, depurar administrativamente a los funcionarios por motivos ideológicos.

\subsection{SOBRE LOS FICHEROS ANTROPOMÉTRICOS: EL EJEMPLO DEL FICHERO CENTRAL DEL GABINETE ANTROPOMÉTRICO DE LA PRISIÓN CELULAR DE MADRID}

Diego NaVArro Bonilla, en su obra Morir Matando (Sevilla, Espuela de Plata, 2011) ve en los ficheros de los Gabinetes antropométricos ciertas similitudes con el Fichero General de la Delegación del Estado para Recuperación de Documentos ${ }^{140}$.

Los ficheros antropométricos, que dieron lugar a los ficheros jurídico-policiales decimonónicos, se formaron con el empleo de las denominadas fichas antropométricas, en las que se utilizaba la antropometría, entonces considerada ciencia de las proporciones del cuerpo humano, y la adaptación que de esa "ciencia" realizó el policía francés Alphonse BerTiLlon, en su denominado Sistema de Bertillon (1880), para la identificación de delincuentes comunes y criminales ${ }^{141}$. El sistema, basado en las citadas fichas antropométricas, colocadas adecuadamente, con orden y precisión milimétrica en armarios o ficheros, permitía una búsqueda rápida y una identificación exacta del presunto delincuente.

\footnotetext{
${ }^{139}$ Sobre la historia de la fichas, véase la obra de KRAJEwSKI, Markus., Paper Machines. About Cards \& Catalogs, 1548-1929. Cambridge (Massachusetts), The Massachusetts Institute of Technology Press (MIT Press), 2011.

${ }^{140}$ No en vano, y no es casual, la creación de la Delegación del Estado para Recuperación de Documentos, y el trabajo en su Fichero General, coincide cronológicamente con la creación del Documento Nacional de Identidad (DNI). El primero, el de la Delegación, por Decreto, del 26 de abril de 1938, publicado en el Boletín Oficial del Estado del día siguiente. Casi 20 días antes, el 5 de abril, dentro del Ministerio del Interior, se creó, también, el Servicio de Identificación, que implantó del uso del DNI, para la identificación de las personas. Al respecto, y también sobre los ficheros antropométricos, véase Diego NAVARRO BonILla, op. cit., pp. 294 y 301.

${ }^{141}$ En 1892, apareció el método de identificación mediante huellas dactilares. Alphonse BERTILLON (París, Francia, 1853 - Münsterlingen, Suiza, 1914) era hijo del médico, antropólogo y estadístico francés Louis-Adolphe Bertillon. Su hermano Jacques Bertillon, que siguió los pasos profesionales de su padre, también era médico.
} 
En las fichas antropométricas, además de las fotografías de identificación, frontal y de perfil, que pudieran aparecer en su caso, figuraban los siguientes campos:

- Nombre.

- Pseudónimos.

- Fecha y lugar de nacimiento.

- Filiación.

- Profesión.

- Antecedentes.

- Medidas antropométricas: estatura, longitud del brazo, longitud del busto, anchura y largura de la cabeza, y del pie y del codo izquierdos.

- Rasgos descriptivos o característicos: color del iris del ojo izquierdo, color del cabello, descripción de la nariz y del lóbulo de la oreja.

- $\quad$ Y, señas particulares o cicatrices.

La fichas antropométricas fueron introducidas e implantadas en España mediante Real Decreto, de 10 de septiembre de 1896, dado en San Sebastián y siendo Manuel Aguirre de Tejada, Ministro de Gracia y Justicia en el último gobierno de Antonio Canovas del Castillo, por el cual se crearon los servicios de identificación antropométrica en las cárceles o prisiones provinciales ${ }^{142}$. En la exposición del Real Decreto, se motivaba la implantación del servicio de identificación antropométrica, y sus fichas, en tres razones:

$1^{\mathrm{a}}$. Descubrir al criminal, que solía ocultarse tras un nombre falso.

$2^{a}$. Ganar el tiempo que se perdía, habitualmente, en largas e infructuosas actuaciones de identificación.

$3^{\text {a }}$. Economizar los gastos que ocasionaban los detenidos.

Por el Real Decreto, se creaba, en la Prisión Celular de Madrid, el Gabinete Central antropométrico, con su correspondiente Fichero Central, al que los Gabinetes provinciales, de las prisiones provinciales, tenían la obligación de remitir dos copias de las fichas antropométricas, correspondientes a las personas fichadas. En el Gabinete Central antropométrico de la Prisión Celular de Madrid, el Jefe del Servicio de Identificación, similar al Delegado del Estado para Recuperación de Documentos,

\footnotetext{
${ }^{142}$ Real Decreto, de 10 de septiembre de 1896, por el que se crean, en las cárceles del Reino, el servicio de identificación antropométrica, en Gaceta de Madrid, $n^{\circ}$ 258, del 14 de septiembre de 1896, p. 985.
} 
aunque dependiente de la Dirección General de Prisiones, y no de la Dirección General de Seguridad, estaba encargado, además de dirigir y vigilar todos los trabajos llevados a cabo en el citado Gabinete Central antropométrico, "de suministrar cuantos datos [podían] ser útiles para la persecución y captura de los delincuentes, [así como] de informar a los Tribunales" $" 143$.

Los Gobernadores civiles, para fines policiales; los Tribunales militares; y los Jueces de instrucción, estos últimos con arreglo al artículo 379 de la Ley de Enjuiciamiento criminal, podían solicitar los antecedentes de una persona al Jefe del Servicio de Identificación del Gabinete Central antropométrico ${ }^{144}$.

Las fichas del Archivo de Salamanca contienen los siguientes campos de las fichas antropométricas:

- Nombre.

- Pseudónimos (nombre simbólico, en el caso de los masones).

- Fecha y lugar de nacimiento.

- Filiación (política).

- Profesión.

- Y, antecedentes.

\subsection{LA EXPLOTACIÓN DE LA INFORMACIÓN: EL FICHERO GENERAL DE LA DELEGACIÓN}

En marzo de 1940, el Archivo central de la Delegación de Salamanca se encontraba, en palabras del propio Marcelino de Ulibarri, "en su periodo álgido de obtención de fichas

\footnotetext{
${ }^{143}$ Artículo $6^{\circ}$ del Real Decreto, de 10 de septiembre de 1896, por el que se crean, en las cárceles del Reino, el servicio de identificación antropométrica, en Gaceta de Madrid, $n^{\circ} 258$, del 14 de septiembre de 1896, p. 985. Funciones similares mutatis mutandi a las que tuvo que cumplir Marcelino de Ulibarri y Eguílaz como Delegado del Estado para Recuperación de Documentos.

${ }^{144}$ Artículos $4^{\circ}, 7^{\circ}$ y $12^{\circ}$ del Real Decreto, de 1 de febrero de 1904, por el que se procedió a la división de funciones en el Gabinete o Registro Central, de penados y rebeldes, con la finalidad de que el Registro antropométrico suministre, a los Tribunales de Justicia, cuantos antecedentes le fueran demandados, en Gaceta de Madrid, $n^{o}$ 33, del 2 de febrero de 1904, p. 451. Joaquín Sánchez de Toca y Calvo (Madrid, 24.09.1852 - 13.07.1942) era, por aquel entonces, Ministro de Gracia y Justicia, siendo Antonio Maura, Presidente del Consejo de Ministros.
} 
individuales" 145 , a partir de la documentación que era enviada y los legajos y carpetas a los que remitían. La elaboración de fichas individuales, por estar considerada, en ese momento, la más urgente de todas las actividades a realizar en el Archivo, absorbía a casi todo el personal que trabajaba en el mismo. Además, se estimaba que "el número de fichas que quedaban por realizar era de 800.000 aproximadamente" ${ }^{, 146}$.

Marcelino de Ulibarri era también perfectamente consciente de que había que adaptar el tamaño de los cajones de los ficheros al tamaño de las fichas. Para ello, encargó fabricar ocho ficheros, en los que calculaba guardar ordenadamente 96.000 fichas en cada uno, a la carpintería "Hijo de Genaro García"147, sita en el paseo de Canalejas, número 21, de la capital salmantina ${ }^{148}$.

Los ficheros encargados por Ulibarri debían reunir

las necesarias condiciones de capacidad, solidez, holgura y practicidad. [...] Por su fácil astillamiento, [había que sustituir] el material de pino, que se empleó en el fichero actual [...], por madera de haya ${ }^{149}$.

Además, en los ocho nuevos modelos encargados, con respecto a la estructura del mueble-fichero existente en el Archivo, había que

suprimir los dos pisos superiores de cajones, por inasequibles; $y$, reducir, a dos, la triple división existente en el interior de los cajones, para disminuir el excesivo peso ${ }^{150}$.

\footnotetext{
${ }^{145}$ CDMH. AGGCE. DNSD. Secretaría. Correspondencia. Caja 1380-1481. Legajo 64. Expediente 1477.

${ }^{146}$ CDMH. AGGCE. DNSD. Secretaría. Correspondencia. Caja 1380-1481. Legajo 64. Expediente 1477.

${ }^{147}$ Genaro García padre contaba, desde el año 1931, con una sociedad anónima limitada del mismo nombre dedicada al negocio del cereal, por lo que mantenía relaciones comerciales y tenía delegaciones en Argentina, concretamente, en San Lorenzo, Rosario y Buenos Aires capital.

${ }^{148}$ Hasta esa fecha, el Archivo central de Salamanca sólo contaba con un mueble-fichero, de pino, destinado a la conservación ordenada de las fichas, y dos ficheros más, que habían sido instalados provisionalmente y "recuperados" en Valencia.

${ }^{149}$ CDMH. AGGCE. DNSD. Secretaría. Correspondencia. Caja 1380-1481. Legajo 64. Expediente 1477.

${ }^{150}$ CDMH. AGGCE. DNSD. Secretaría. Correspondencia. Caja 1380-1481. Legajo 64. Expediente 1477.
} 
El 3 de abril de 1940, Marcelino de Ulibarri solicitó un catálogo y presupuesto para la adquisición de treinta y siete ficheros metálicos a la Casa Roneo Unión Cerrajera, S.A., de Mondragón (Guipúzcoa), con una capacidad para guardar ordenadamente en cada uno de ellos 27.000 fichas, es decir, casi un millón de fichas en total (999.000 fichas). Cuatro meses después, el 25 de julio de 1940, el Archivo central de Salamanca, adquirió sólo diez ficheros de los treinta y siete pedidos, y presupuestados en un primer momento, por un coste total de 7.506 pesetas, y en los que se podían ordenar, por tanto, 270.000 fichas $^{151}$.

El envío de los veinte ficheros restantes, Modelo 1109 del Catálogo de Roneo, de 10’00 x 15’00 centímetros, se vio retrasado, ya que la Casa Roneo Unión Cerrajera, S.A. no encontraba, debido a sus dimensiones, el modo de enviarlos a Salamanca, en un único vagón de tren. Finalmente, los archivadores llegaron al Archivo central de Salamanca en octubre de $1940^{152}$.

Los ficheros sirven para guardar ordenadamente las fichas y la información en ellas custodiada. Las fichas se ordenan por orden alfabético según el nombre y apellidos del fichado (criterio onomástico).

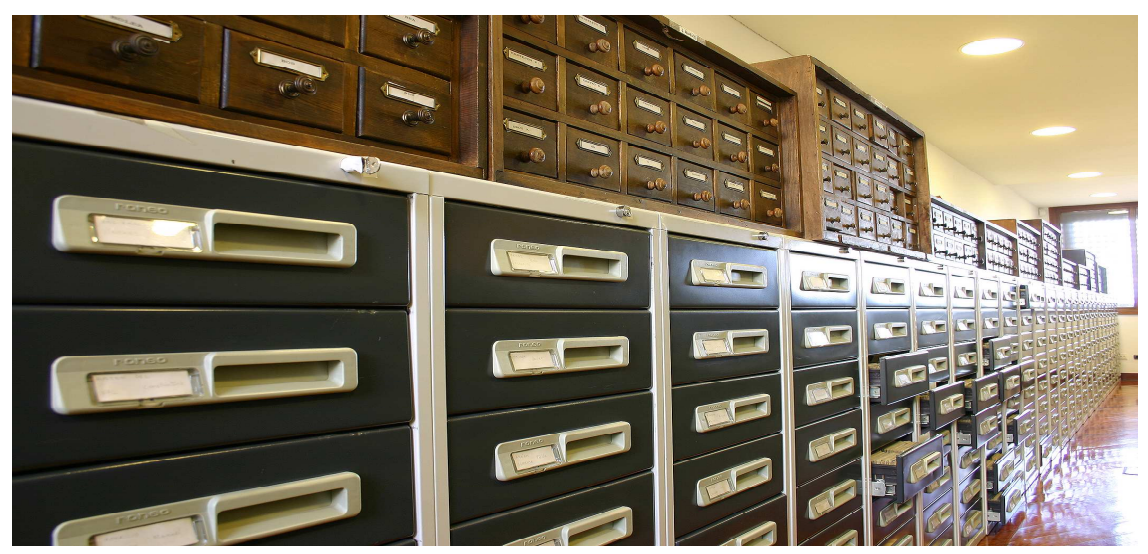

Fig. 4.14. Fichero General. Ficheros de madera y de metal. Autoría de la foto: Manuel Lorenzo González

${ }^{151}$ CDMH. AGGCE. DNSD. Secretaría. Correspondencia. Caja 1380-1481. Legajo 64. Expediente 1477.

${ }^{152}$ CDMH. AGGCE. DNSD. Secretaría. Correspondencia. Caja 1380-1481. Legajo 64. Expediente 1477. De este esta adquisición y envío de ficheros al Archivo central de la Delegación en Salamanca, ficheros fabricados por la Casa Roneo de Mondragón (Guipúzcoa) da noticia el profesor Diego NAVARRO BONILLA, op. cit., pp. 324-325. 
En el presente, dichos ficheros, junto a otros que fueron adquiridos con posterioridad hasta el año 1949, y que conforman el Fichero General, se encuentran en una sala, de acceso restringido ${ }^{153}$, de 60’37 metros cuadrados, destinada al efecto, en el la actual sede, el Colegio de San Ambrosio. Un total de 69 ficheros metálicos, que estuvieron en la sede de la Delegación en el Noviciado de San Estanislao de Kostka, contienen 2.546.644 fichas; y, otros 14 ficheros de madera contienen 155.309 fichas de masones, ficheros que estuvieron custodiados en el Seminario Conciliar.

Antonio GonZÁlez QuintanA, director del Archivo de la Guerra Civil, durante ocho años, de 1986 a 1994, estima que el Fichero General está formado por "más de dos millones de fichas" ${ }^{154}$. Por su parte, Diego NAVARRo BonILla calcula, que el Fichero General del Archivo, o como él lo denomina, la "siniestra casa de las fichas" de Salamanca, está compuesto por "casi dos millones de fichas personales"155, y, por tanto, la "nación fichada", a la que alude en su obra, estaría formada por menos de dos millones de personas ${ }^{156}$. Según el Informe de Propuesta, presentado por el Ministerio de Cultura de España al Registro Internacional de la Memoria del Mundo, para la nominación e inscripción en el mismo del Fichero General del Archivo General de la Guerra Civil Española del Centro Documental de la Memoria Histórica, en diciembre de 2011, el Fichero General está formado por un total de 2.701 .953 fichas ${ }^{157}$.

\footnotetext{
${ }^{153}$ Para su conservación, el Fichero General del Archivo se encuentra completamente digitalizado y a disposición de los usuarios en la Sala de Consulta del Archivo. La digitalización permite visualizar la imagen de la ficha y los datos contenidos en la misma, evitándose, así, en lo posible, el manejo físico de las fichas.

154 GONZÁlez QuiNTANA, Antonio., "Fuentes para el estudio de la represión franquista en el Archivo Histórico Nacional, Sección Guerra Civil”, en Revista Espacio, Tiempo y Forma. Serie V. Historia Contemporánea. Tomo VII. Madrid, Universidad Nacional de Educación a Distancia (UNED), 1994, p. 505.

${ }^{155}$ Navarro Bonilla, Diego., op. cit., pp. 100 y 459.

${ }^{156}$ Hay que tener en cuenta la internacionalización de la Guerra Civil Española como conflicto bélico, y, como consecuencia de la misma, por ejemplo, que los brigadistas internacionales fueran fichados y formen parte del Fichero General.

${ }^{157}$ Nomitation form to the International Memory of the World Register. Madrid. Salamanca, Ministerio de Cultura. Dirección General del Libro, Archivos y Bibliotecas. Subdirección General de Archivos Estatales, 2011, pp. 2-3. Según Diego NAVARRo BONILLA, se calcula que IBM suministró al Tercer Reich alemán un total de 1.500 millones de fichas perforadas anuales, desde 1929 hasta 1945, para controlar desde el horario de los trenes hasta los rasgos físicos de todos sus prisioneros, recluidos en cárceles y en campos de concentración. En 1938, según Diego Navarro Bonilla, "la moderna técnica organizativa policial alemana era admirada por otras policías de todo el mundo". Por su parte, el Ministerio de
} 


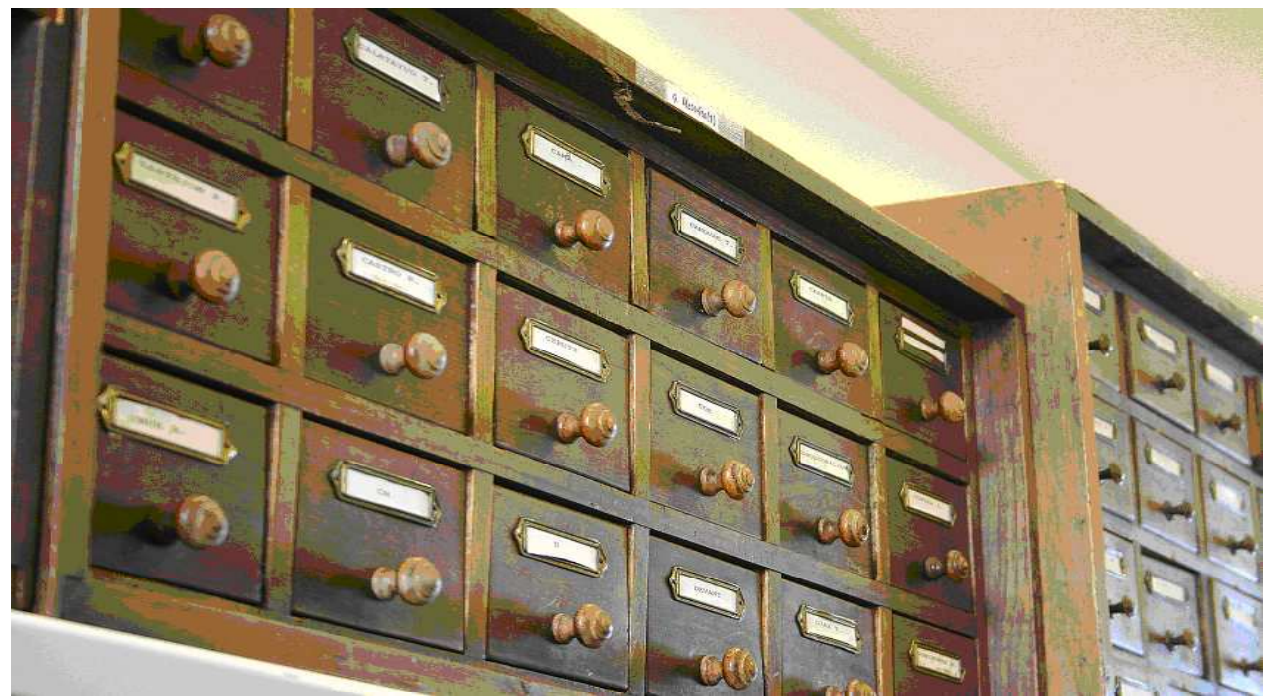

Figura 4.15. Fichero General. Ficheros de madera. Autoría de la foto: Manuel Lorenzo González

El tamaño de las fichas del Fichero General de la Delegación no está normalizado.

Las fichas masónicas, que se guardan por orden alfabético (método onomástico, por apellidos y nombre) en los 14 ficheros destinados a los masones que fueron fichados, tienen unas dimensiones de 5'5 x 10'5 centímetros.

El resto de las fichas, en las que se recogen antecedentes político-sociales, también guardadas en sus respectivos ficheros por orden alfabético, tienen un tamaño de $14 \mathrm{x}$ 10 '5 centímetros.

Se trata de fichas de cartón, de color blanco, grisáceo en alguna, quizá por le paso del tiempo, y marrón claro.

Seguridad del Estado de la República Democrática Alemana, con sede en Berlín, organizó, desde 1950, unos Archivos, a partir del espionaje de sus propios ciudadanos y de la policía secreta (Stasi), que custodiaron fichas relativas a 290.000 personas. Véase NAVARRo BonILlA, Diego., Morir Matando. Sevilla, Espuela de Plata, 2012, pp. 200, 297 y 302-303. En diciembre de 2011, el Fichero General del Archivo de la Guerra Civil Española del Centro Documental de la Memoria Histórica fue propuesto, por el Ministerio de Cultura, para ser inscrito en el Registro Internacional Memoria del Mundo de la UNESCO, en el que ya figuran el Libro del Sindicato de Remensa (1448-1449), el Tratado de Tordesillas (1494), las Capitulaciones de Santa Fé (1492) y los Decretos de León (1188), considerados la cuna del parlamentarismo occidental. El Registro Internacional Memoria del Mundo tiene por objeto promocionar el patrimonio documental de mayor relevancia mundial, así como garantizar su conservación y accesibilidad. Lamentablemente, el Fichero General no fue inscrito en el Registro. 
Las fichas masónicas cuentan con los siguientes campos:

- Nombre.

- Pseudónimo o nombre simbólico (del masón como miembro de la logia, como pseudónimos literarios, por ejemplo).

- Logia (nombre de la logia).

- Población (localidad donde se encontraba la logia).

- Número de legajo y número de expediente, números ambos, a los que remitía la ficha.

Por su parte, en las fichas político-sociales, se suelen reducir los campos a tres:

- Nombre.

- Datos sobre filiación política.

- Y, signatura, mecanografiada o escrita a bolígrafo rojo en la parte superior derecha, que remite la ficha a la serie; carpeta, legajo y / o expediente correspondiente; y, folio, en su caso.

La ficha se convirtió en el instrumento por el que el yo interior fue eliminado siendo suplantado por la externalización oficial de la identidad. Una persona es algo más, mucho más que los datos que, sobre él, figuran en cualquier ficha, fichero o base de datos.

\section{LA DELEGACIÓN Y SU RELACIÓN CON LAS AUTORIDADES ARCHIVÍSTICAS}

El 8 mayo de 1938, Marcelino de Ulibarri escribía una carta al que consideraba su amigo, Gerardo Masa López, director del Archivo General de Simancas y funcionario del Cuerpo Facultativo de Archiveros. Ulibarri había visitado el Archivo General de Simancas hacía pocas fechas. En su carta, le recordaba al entonces director del Archivo General de Simancas, "los ofrecimientos que le había hecho en su última visita", agradeciéndole que le remitiese 
cuantas sugerencias o indicaciones [creyera] pertinentes para la organización y buena marcha del Archivo. [...] $O$-reiterando la idea, antes de despedirse- cuantas observaciones estimase conducentes a un mejor funcionamiento del Archivo ${ }^{158}$.

A través de esta puntual relación epistolar, el director del Archivo General de Simancas conocía de la existencia, había sido creado en abril de 1938, y de la situación en la que se encontraba el Archivo de Salamanca.

Marcelino de Ulibarri, según le explica al Director del Archivo General de Simancas, se encontraba inmerso en la redacción de un Reglamento de funcionamiento interno para el Archivo, en el que se abordaba tanto la recogida y clasificación de los documentos como su custodia y conservación en el Archivo ${ }^{159}$.

En el Archivo, no se ha podido localizar el Reglamento, ya que como, posiblemente, no se completó, quedó en un borrado que fue finalmente desechado y eliminado.

Tres años después, en julio de 1941, Miguel Artigas Ferrando, entonces Director de la Biblioteca Nacional y, desde 1939, primer Director General de Archivos y Bibliotecas, tras una visita a la Delegación, aludía al trabajo archivístico realizado hasta la fecha, con las siguientes palabras:

la clasificación y el estudio de los documentos, a base de la experiencia adquirida, amplía desmesuradamente el Archivo, y su organización es tal que merece mi aprobación ${ }^{160}$.

Miguel Artigas Ferrando se encontraba preocupado, desde su puesto de Director de la Biblioteca Nacional, por el patrimonio bibliográfico español. Ayudado por Vicente Navarro Reverter, del Cuerpo Facultativo de Archiveros y que había sido nombrado

${ }^{158}$ CDMH. AGGCE. DNSD. Secretaría. Correspondencia. Caja 125-200. Legajo 7. Expediente 150.

${ }^{159}$ CDMH. AGGCE. DNSD. Secretaría. Correspondencia. Caja 125-200. Legajo 7. Expediente 150. La Instrucción para el Gobierno del Archivo de Simancas (Madrid, Ministerio de Educación y Cultura, 1998. Estudio preliminar realizado por José Luis RoDRÍGUEZ DE DIEGO) dictada por Felipe II, en 1588, es el primer reglamento de archivos del mundo. En treinta capítulos, se expresan, claramente, las tareas a realizar por un archivero, que, en el siglo XXI, siguen siendo las mismas. Ningún país tiene un documento similar al de la Instrucción filipina. Resulta razonable que Marcelino de Ulibarri recurriera al asesoramiento técnico, archivístico y científico, del entonces Director del Archivo General de Simancas, que, desde 1844, era un archivo histórico y no administrativo, como era la Delegación.

160 CDMH. AGGCE. DNSD. Secretaría General. Expedientes Secretaría. Caja 970. Legajo 30. Expediente 1. 
Jefe de Recuperación Bibliográfica de la Biblioteca Nacional, Miguel Artigas Ferrando comunicó a la Delegación que

los libros no reconocidos por sus antiguos dueños fueran a engrosar las bibliotecas públicas o de organismos que así lo mereciesen ${ }^{161}$.

Se podían, así, enviar libros que se encontraran en la Delegación, fruto de las incautaciones realizadas, a las bibliotecas públicas o a la propia Biblioteca Nacional ${ }^{162}$.

\section{BALANCE DE LOS TRABAJOS DE LA DELEGACIÓN DESDE SU CREACIÓN EN ABRIL DE 1938}

Quince meses después de la creación de la Delegación Nacional de Asuntos Especiales, once meses después de la instalación de la Delegación del Estado para Recuperación de Documentos en el edificio del Noviciado de San Estanislao de Kostka y cuatro meses después de su reconocimiento oficial, en el Boletín Oficial del Estado, en agosto de 1938, Marcelino de Ulibarri elevaba un documento interno de trabajo al Jefe del Estado, Francisco Franco Bahamonde, en el que daba cuenta del estado en el que se encontraban los trabajos que se estaban llevando a cabo en la Delegación ${ }^{163}$.

Ulibarri exponía a Franco los logros alcanzados por la Delegación hasta agosto de 1938:

$1^{\circ}$. Gracias a los equipos de recuperación de documentos, Ulibarri entendía que toda la documentación posible, perteneciente a particulares, autoridades y organismos oficiales republicanos, y hasta la fecha señalada, agosto de 1938, a siete meses del final de la Guerra Civil, había sido completamente "recuperada", es decir, aprehendida o incautada. Indicaba, Ulibarri, con satisfacción, que "las autoridades -con rarísimas y lamentables excepciones- [...] [habían puesto], a [su] disposición, la documentación que

\footnotetext{
${ }^{161}$ CDMH. AGGCE. DNSD. Secretaría. Correspondencia. Caja 1250-1379. Legajo 62. Expediente 1324.

${ }^{162}$ La Dirección General de Archivos y Bibliotecas, de la que Miguel Artigas Ferrando fue nombrado primer Director, había sido creada, por Decreto-Ley, de 25 de agosto de 1939. Casi ochos años después, la Dirección General de Archivos y Bibliotecas, aprobaba el Decreto, de 24 de julio de 1947, relativo al ordenamiento de los Archivos y Bibliotecas, y del Tesoro histórico-documental y bibliográfico español ${ }^{162}$. Por este Decreto, se llevaba a cabo, tras la Guerra Civil, la reorganización del sistema archivístico español, en el que no se contemplaba la inclusión de la Delegación en el mismo.
}

163 CDMH. AGGCE. DNSD. Secretaría General. Expedientes Secretaría. Caja 081-115. Legajo 5. Expediente 97. 
poseían"164. Una de esas lamentables excepciones había sido el Servicio de Investigación e Información de FET de las JONS de Zaragoza, que se había opuesto a entregar "unos cientos de fichas"165. Tampoco se había logrado conseguir la documentación relacionada con la masonería, y sus logias y sectas secretas, en Marruecos, ya que no se había querido molestar al Alto Comisario Español en Marruecos, de abril de 1937 a agosto de 1939, el general Juan Luis Beigbeder, que, seguramente, conocería el lugar donde encontrarla, "por tratarse de tan elevada personalidad",166.

$2^{\circ}$. En la Delegación, existían perfectamente clasificados: 14.930 expedientes individuales; 394 expedientes de logias españolas; 257 expedientes de logias extranjeras; 246 expedientes sobre actividades masónicas; y, 26.148 fichas ${ }^{167}$.

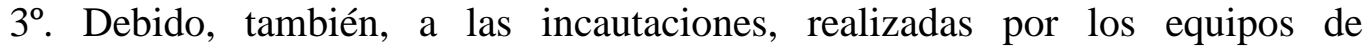
recuperación de documentos, se había podido formar una biblioteca con libros de contenido masónico y teosófico de gran importancia, por el número y la calidad de sus volúmenes $^{168}$.

$4^{\circ}$. Además de reunir y clasificar la documentación indicada, y de confeccionar fichas, gracias a la Delegación, ésta había podido expedir 364 informes a diversas autoridades militares; 336 informes a la Auditoria de Marruecos; 291 informes a diversas Comisiones Depuradoras; 255 informes a la Sección de Justicia del Ministerio de Defensa Nacional; 244 informes a diversas autoridades civiles; 16 informes a diversos Juzgados Militares; 6 informes a otras Auditorias; y numerosos informes

${ }^{164}$ CDMH. AGGCE. DNSD. Secretaría General. Expedientes Secretaría. Caja 081-115. Legajo 5. Expediente 97.

165 CDMH. AGGCE. DNSD. Secretaría General. Expedientes Secretaría. Caja 081-115. Legajo 5. Expediente 97.

${ }^{166}$ CDMH. AGGCE. DNSD. Secretaría General. Expedientes Secretaría. Caja 081-115. Legajo 5. Expediente 97.

167 CDMH. AGGCE. DNSD. Secretaría General. Expedientes Secretaría. Caja 081-115. Legajo 5. Expediente 97.

${ }^{168}$ CDMH. AGGCE. DNSD. Secretaría General. Expedientes Secretaría. Caja 081-115. Legajo 5. Expediente 97. 1.300 de esos libros correspondían a libros de actas y de administración de las logias masónicas. 
dedicados al personal de los Cuerpos de Funcionarios de la Administración Civil del Estado (Cuerpo diplomático, Ingenieros de minas, Correos y Telégrafos, Profesores y Maestros, etc. $)^{169}$.

Finalmente, se indicaba que era posible, ya, que el Estado pudiera editar una historia documentada de la masonería en España; y, la necesidad de instalar un laboratorio fotográfico, y unos archivos metálicos, para preservar la documentación de un posible incendio $^{170}$.

En noviembre de 1939, Marcelino de Ulibarri le confesaba y contestaba a Rafael Barthel, súbdito alemán afincado en la capital de España, que "la cantidad ingente de documentación sin clasificar [...] [excedía] las 700 toneladas"171. Aunque el personal de la Delegación trabajaba con esmero y dedicación absoluta, y “toda la documentación se [iba] clasificando progresivamente" ${ }^{172}$, la Delegación se encontraba desbordada ante tal ingente cantidad de documentación ${ }^{173}$.

\section{CONCLUSIONES}

Las conclusiones a las que se ha llegado en este capítulo son las siguientes:

I. La requisición de documentos, llevada a cabo por los equipos de recuperación de documentos de la Delegación, se encontraba perfectamente reglada y normativizada, incluyendo las inspecciones, aunque las requisiciones sufrieran alguna disfunción sobre el terreno.

\footnotetext{
169 CDMH. AGGCE. DNSD. Secretaría General. Expedientes Secretaría. Caja 081-115. Legajo 5. Expediente 97.

170 CDMH. AGGCE. DNSD. Secretaría General. Expedientes Secretaría. Caja 081-115. Legajo 5. Expediente 97.

${ }^{171}$ CDMH. AGGCE. DNSD. Secretaría. Correspondencia. Caja 352-417. Legajo 28. Expediente 402.

${ }^{172}$ CDMH. AGGCE. DNSD. Secretaría. Correspondencia. Caja 352-417. Legajo 28. Expediente 402.

${ }^{173}$ CDMH. AGGCE. DNSD. Secretaría. Correspondencia. Caja 352-417. Legajo 28. Expediente 402.
} 
II. La documentación requisada fue enviada a la Delegación por medio del ferrocarril, aprovechándose de los transportes militares; por carretera, empleando una flota de camiones y vehículos para ello; y, por correo postal.

III. La actuación de los equipos de recuperación de documentos, y su consecuencia, la requisición documental, dio lugar a la creación de una red de archivos, dependientes de la Delegación o Archivo central de Salamanca.

IV. Con la documentación requisada, se hicieron agrupaciones documentales que fueron clasificadas aplicando el principio de procedencia geográfica. Dentro de cada agrupación documental, se respetaba el orden interno en el que los archivos institucionales o particulares eran enviados a la Delegación, habiendo, así, cierto respeto al principio de procedencia de los fondos. Hubo excepciones, como las agrupaciones documentales de Propaganda y Prensa, que fueron clasificadas por materias.

V. La explotación de la información contenida en la documentación requisada dio lugar al Fichero General, formado por un total de 2.701.953 fichas.

VI. Las autoridades archivísticas siguieron el trabajo archivístico realizado en la Delegación . 


\section{CAPÍtUlO 5}

Las agrupaciones documentales de la Delegación 

fondo documental de la DNSD 
El objetivo de este capítulo es presentar cómo fueron llevadas a cabo las requisiciones de los documentos que acabaron formando los fondos originarios de la Delegación del Estado para Recuperación de Documentos, la sección conocida y denominada PolíticoSocial.

Cada una de las agrupaciones documentales de la sección Político-Social constituyen series, formadas por conjuntos de documentos reunidos y clasificados según su procedencia geográfica. No obstante, puede haber documentación de un mismo productor en las distintas agrupaciones.

Este capítulo se estructura en dos apartados, uno dedicado a las requisiciones realizadas según las áreas geográficas y otro dedicado a la documentación de interés militar, que, una vez en la Delegación, fue transferida al Servicio Histórico Militar. Además, un apartado final se dedica a las conclusiones.

El primer apartado, el dedicado a las requisiciones realizadas según las áreas geográficas es el más extenso y el principal de este capítulo. Se divide en quince subapartados, en los que se sigue el orden alfabético, no la cronología de los frentes de la propia guerra, siendo presentados en el actual cuadro de clasificación del Archivo General de la Guerra Civil Española, estudiándose en cada uno de ellos:

- El personal encargado de realizar las requisiciones.

- La metodología aplicada en las requisiciones.

- La tipología de la documentación requisada.

- El envío de la documentación requisada a la Delegación.

- Y, finalmente, las especificidades que, en cada zona, se plantearon a la hora de realizar las requisiciones. 


\section{LAS REQUISICIONES}

\subsection{LA REQUISICIÓN EN ALICANTE: PS-ALICANTE}

A finales del mes de marzo de 1939, exactamente, la tarde del 30 de marzo de 1939, las tropas franquistas entraron en Alicante. A los pocos días, comenzó a funcionar la Delegación Provincial de Recuperación de Documentos de Alicante.

Pedro Seva Pastor fue el Delegado Provincial de Recuperación de Documentos de Alicante o director de la Delegación de Alicante, y Miguel Alemany Selfa fue el subdirector de la misma. La Delegación en Alicante gozó de cierta autonomía, sobre todo, en la elección del personal, aunque éste estuviera supeditado al Archivo central de Salamanca $^{174}$.

Los equipos de recuperación de documentos fueron coordinados, en Alicante, por Rafael Barberá Albert.

La metodología de las requisiciones se basó en el registro de los organismos oficiales y de los domicilios particulares realizados por el personal de la Delegación en Alicante.

La documentación requisada en Alicante fue la siguiente:

- Documentación de la Administración de Propiedades y Contribución Territorial de Alicante $^{175}$.

- Documentación bastante completa de Izquierda Republicana y referente a los Jefes y Oficiales de Campos de Trabajo republicanos, que se pensaba "remitir, a Salamanca, a la mayor brevedad posible", como le hacía saber, por carta, Miguel Alemany Selfa a Marcelino de Ulibarri y Eguílaz ${ }^{176}$.

\footnotetext{
${ }^{174}$ CDMH. AGGCE. DNSD. Secretaría. Correspondencia. Caja 501-550. Legajo 33. Expediente 546. Las relaciones entre el Jefe de la Delegación del Estado para Recuperación de Documentos en Alicante y el Jefe de Información e Investigación de Falange en Alicante no eran buenas, como tampoco lo eran entre el propio Miguel Alemany y Francisco Mira, dentro de la Delegación en Alicante.

${ }^{175}$ CDMH. AGGCE. DNSD. Secretaría. Correspondencia. Caja 728-795. Legajo 45. Expediente 758.

${ }^{176}$ CDMH. AGGCE. DNSD. Secretaría. Correspondencia. Caja 501-550. Legajo 33. Expediente 546.
} 
- Documentos relativos a sindicatos marxistas y partidos políticos del Frente Popular ${ }^{177}$, y documentación diversa de interés político y social, requisada en junio de 1940.

- Por último, documentación "relativa al Comité de Refugiados [republicanos] de Jumilla (Murcia)" ${ }^{\prime 178}$.

El 17 de julio de 1939, Pedro Seva Pastor, comunicaba, por carta, a Marcelino de Ulibarri y Eguílaz, Delegado del Estado para Recuperación de Documentos, el primer gran envío de documentación de Alicante al Archivo de Salamanca, realizado el día anterior, 16 de julio, por ferrocarril, desde la estación de Alicante: un total de 155 sacos, “de documentación varia y libros, [...] correspondiente a la expedición, no 5.063, perteneciente al vagón $n^{\circ}$ K 13676, de los Transportes Militares"179.

El 6 de abril de 1940, llegaron tres sacos más, con documentación, al Archivo central de Salamanca, procedentes de la Delegación de Alicante $^{180}$. Y, una semana más tarde, el 13 de abril de ese mismo año, el Archivo central de Salamanca recibía una carpeta.

A finales de junio de 1940, el equipo encabezado por Rafael Barberá Albert, incautó documentación en las localidades alicantinas de Onil, Castalla e Ibi, que fue remitida al Archivo de Salamanca ${ }^{181}$.

Pasados casi dos años, a mediados de mayo de 1942, Francisco Mira Reynau, remitía importante documentación al Archivo central de Salamanca "por medio del enlace de la Guardia Civil" 182 .

El último envío de documentación desde la Delegación de Alicante, al Archivo central de Salamanca, del que se tiene constancia, es del 15 de diciembre de 1942, un paquete.

\footnotetext{
${ }^{177}$ CDMH. AGGCE. DNSD. Secretaría. Correspondencia. Caja 501-550. Legajo 33. Expediente 546.

${ }^{178}$ CDMH. AGGCE. DNSD. Secretaría. Correspondencia. Caja 501-550. Legajo 33. Expediente 546.

${ }^{179}$ CDMH. AGGCE. DNSD. Secretaría. Correspondencia. Caja 501-550. Legajo 33. Expediente 546.

${ }^{180}$ CDMH. AGGCE. DNSD. Secretaría. Correspondencia. Caja 501-550. Legajo 33. Expediente 546.

${ }^{181}$ CDMH. AGGCE. DNSD. Secretaría. Correspondencia. Caja 501-550. Legajo 33. Expediente 546.

${ }^{182}$ CDMH. AGGCE. DNSD. Secretaría. Correspondencia. Caja 501-550. Legajo 33. Expediente 546.
} 
Desde la Delegación Provincial de Documentos de Alicante, se remitió documentación procedente de Madrid, al Archivo central de Salamanca, como "la documentación y estadísticas sanitarias del Ejército republicano”, en marzo de $1940^{183}$.

Además, desde mayo de 1940, la Delegación de Alicante trabajaba en su cometido de requisición de documentos, contado con la colaboración de la Policía, los Comisarios de Policía de Alicante, y de Falange ${ }^{184}$.

\subsection{LA FORMACIÓN DE PS-ARAGÓN}

Una semana antes de la llegada del primer equipo de recuperación de documentos, había tenido lugar la batalla de Alfambra, cuyos combates se habían prolongado durante cuatro días, del 5 al 8 de febrero de 1938, y que enfrentó a las tropas del general Enrique Líster con las del general Juan Yagüe.

Durante cuatro días, 18, 19, 20 y 21 de febrero, los equipos de recuperación de documentos estuvieron saliendo, todos esos días, a las siete y media de la mañana desde Daroca hasta Teruel, pero "la caravana se detenía a la vista de la ciudad, a cuatro kilómetros de la misma"185. En Sierra Gorda y el Mansueto estaban teniendo lugar los combates finales que decidirían la batalla de Teruel. Uno de esos días, el 18 de febrero, los equipos de recuperación de documentos sufrieron el ataque de una batería enemiga: no hubo ni muertos ni heridos, pero el vehículo en el que se desplazaban, un coche, marca Ford y matrícula M-30452, sufrió una grave avería.

A las cuatro de la tarde del 22 de febrero de 1938, las tropas franquistas ocuparon la capital del Bajo Aragón, Teruel. Con ellas, entraron los equipos de recuperación de documentos, entre "escombros y ruinas"186.

\footnotetext{
${ }^{183}$ CDMH. AGGCE. DNSD. Secretaría. Correspondencia. Caja 660-692. Legajo 39. Expediente 682.

${ }^{184}$ Sobre la Guerra Civil en Alicante, véase ARÓSTEGUI, Julio., La Guerra en Alicante. Alicante, Instituto Juan Gil-Albert, 1986.

${ }^{185}$ CDMH. AGGCE. DNSD. Administración. Expedientes. Caja 206-290. Legajo 11. Expediente 217. Daroca está a una distancia de poco más de 100 kilómetros de Teruel, y el viaje dura entorno a una hora.

${ }^{186}$ CDMH. AGGCE. DNSD. Administración. Expedientes. Caja 206-290. Legajo 11. Expediente 217.
} 
El 17 de febrero, Manuel Martín Sastre, se había entrevistado en Caminreal (Teruel), con el Estado Mayor del general Fidel Dávila, del que obtuvo los permisos y salvoconductos necesarios para que los equipos de recuperación de documentos pudieran actuar en el frente de guerra, así como víveres de la Intendencia Militar ${ }^{187}$.

A las ocho de la mañana del 15 de febrero de 1938, tres equipos de recuperación de documentos salieron desde Salamanca con destino a la localidad zaragozana de Daroca, a la que llegaron a las ocho y media de la tarde, tras más de doce horas y media de viaje, en el que atravesaron toda la meseta norte, haciendo el trayecto Salamanca-ValladolidBurgo de Osma-Calatayud-Daroca ${ }^{188}$.

Los tres equipos de recuperación de documentos que partieron de Salamanca fueron los encabezados por Manuel Martín Sastre, Juan Fuentes Bertrán y Juan Queralt Oliva.

El día 24 de febrero, para reforzar a los equipos de recuperación de documentos que estaban requisando documentación en la ciudad de Teruel, llegó, procedente de Salamanca, un cuarto equipo, dirigido por Prudencio Arza Arbe.

La metodología de las requisiciones se basó en las expediciones de los equipos de recuperación de documentos. Partiendo de Daroca, el 16 de febrero, se comenzó el registró de los edificios de las localidades de Argente, Visiedo, Perales de Alfambra y la propia localidad de la Alfambra, situada a 25 kilómetros de Teruel capital ${ }^{189}$.

\footnotetext{
${ }^{187}$ CDMH. AGGCE. DNSD. Administración. Expedientes. Caja 206-290. Legajo 11. Expediente 217.

${ }^{188}$ CDMH. AGGCE. DNSD. Administración. Expedientes. Caja 206-290. Legajo 11. Expediente 217.

${ }^{189}$ CDMH. AGGCE. DNSD. Administración. Expedientes. Caja 206-290. Legajo 11. Expediente 217.
} 


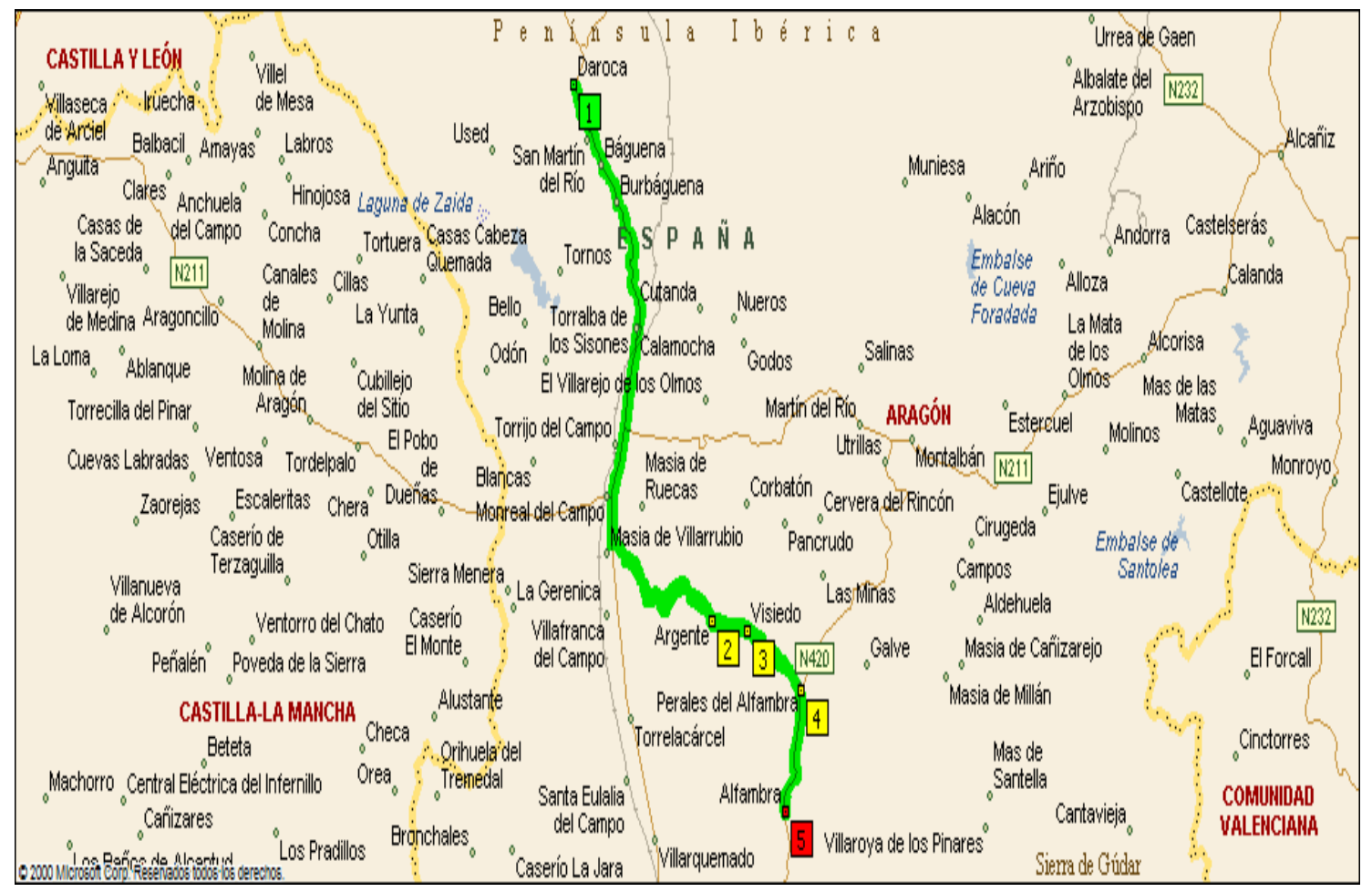

Mapa 5.1. 16.02.1938. Expedición requisitoria.

Itinerario Daroca-Argente-Visiedo-Perales de Alfambra-Alfambra

Aunque el día 22 de febrero fue imposible practicar registro alguno en Teruel, se tomó nota de los edificios susceptibles de un posible registro para el día siguiente. Así fue. A las cinco y media de la mañana del 23 de febrero de 1938, el personal desplazado de la Delegación salmantina salió desde Daroca hasta Teruel.

Asimismo, los equipos de recuperación de documentos comenzaron a practicar registros en poblaciones limítrofes a la capital y en otras localidades de la provincia:

- Los equipos de Fuentes y de Arza registraron la localidad de San Blas, situada a seis kilómetros al oeste de Teruel ${ }^{190}$.

- El equipo de Fuentes continuó la labor, dirigiéndose a Castralvo, localidad situada a nueve kilómetros al sureste de Teruel ${ }^{191}$, donde fueron registrados la Comandancia Militar republicana, el Centro de Transmisiones y el Cuartel de Zapadores.

\footnotetext{
${ }^{190}$ En la actualidad, San Blas es un barrio de Teruel.

${ }^{191}$ Actualmente, Tortajada forma parte del municipio de Teruel.
} 
- El equipo de Queralt se dirigió a Tortajada ${ }^{192}$, Villalba Baja ${ }^{193}$ y Celadas.

- Por su parte, Martín Sastre, con su equipo, realiza registros en las localidades de Cella, Villarquemado y Santa Eulalia del Campo. También, realiza registros en Caminreal y Vivel del Río Martín, perteneciente a la comarca de las Cuencas Mineras.

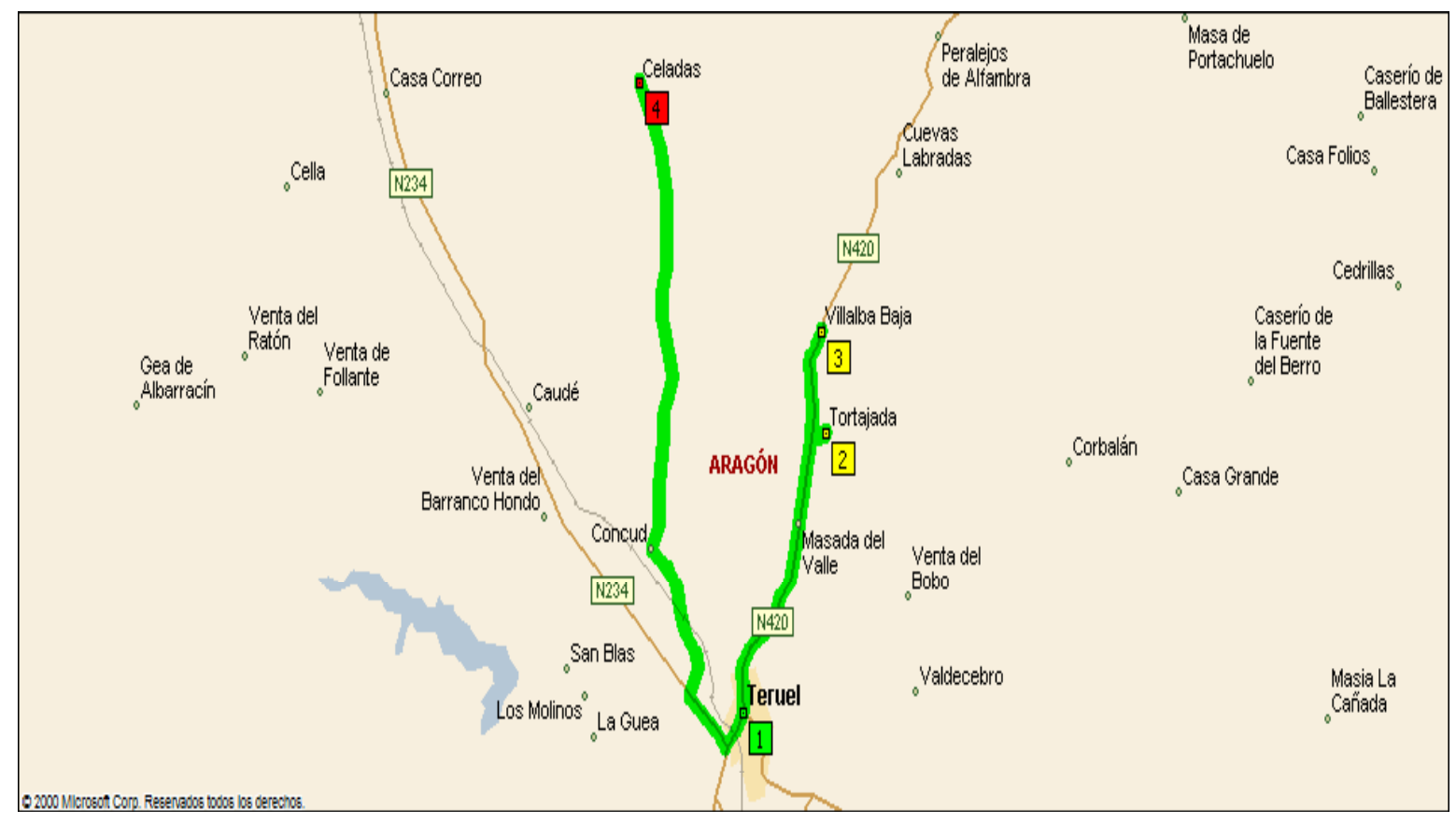

Mapa 5.2. 23, 24 y 25 de febrero de 1938. Expediciones requisitorias Equipo de Queralt. Itinerario Teruel-Tortajada-Villalba Baja-Celadas

\footnotetext{
${ }^{192}$ Actualmente, Castralvo forma parte del municipio de Teruel.

${ }^{193}$ Actualmente, Villalba Baja forma parte del municipio de Teruel.
} 


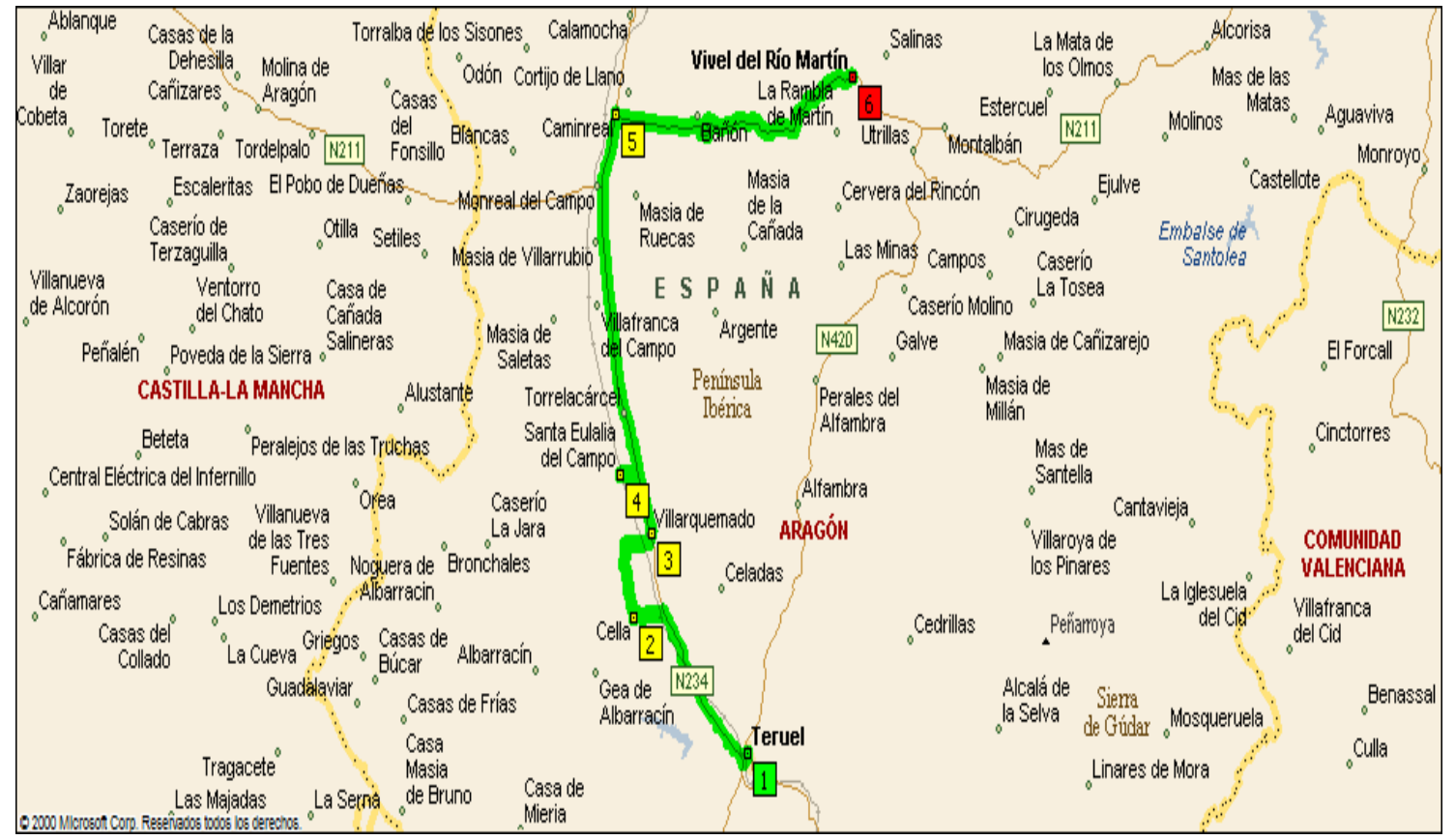

Mapa 5.3. 23, 24 y 25 de febrero de 1938.Expediciones requisitorias.

Equipo de Martín Sastre. Itinerario Teruel-Cella-Villarquemado-Santa Eulalia del Campo-Caminreal-Vivel del Río Martín

El día 23 de febrero de 1938, los tres equipos dirigidos y guiados, respectivamente, por Manuel Martín Sastre, Juan Fuentes Bertrán y Juan Queralt Oliva, procedieron a registrar e incautar la documentación, en Teruel capital, que se localizaba en:

- La Alcaldía.

- $\quad$ El Gobierno Civil.

- Las Delegaciones de Hacienda y Trabajo.

- La Audiencia Provincial de Justicia.

- Correos y Telégrafos.

- El antiguo Cuartel de la Guardia Civil.

- La Caja de Reclutas y la Dirección General de Fortificaciones.

- Una imprenta, que sirvió de centro de propaganda de las Brigadas Internacionales.

- Las oficinas de la $122^{a}$ Brigada de Asalto.

- El Banco de Aragón.

- El primer salón cinematográfico, establecido en 1910, el Cine Parisiana.

- $\quad$ La Ciudad Jardín. 
- Y, los domicilios de los ministros republicanos Vicente Iranzo Enguita y Ramón Feced Gresa, y del doctor José Borrajo Esquiu, primer alcalde de Teruel durante la II República, de abril de 1931 a julio de 1933.

Los registros continuaron los siguientes días, 24 y 25 de febrero. En esos días, incautando documentación de, entre otros inmuebles:

- La Comandancia Militar republicana.

- El Cuartel de los Guardias de Asalto.

- La estación de ferrocarril.

- La plaza de toros.

- $\quad$ Y, diversas entidades bancarias ${ }^{194}$.

En Celadas, se recuperó documentación sobre prisioneros de guerra, que fue remitido al Estado Mayor del general Dávila.

Y, el día 26 de febrero, Marín Sastre recogió los documentos pertenecientes a los Organismos oficiales de los que aún no se habían hecho cargo los militares, previa consulta a la Comandancia militar y a las autoridades locales de Teruel ${ }^{195}$.

Toda la documentación recogida fue enviada desde Teruel, por Daroca, a Zaragoza, y, de allí, por ferrocarril a Salamanca. Marcelino de Ulibarri consiguió establecer en Zaragoza, a partir del 6 de julio de 1938, "una Oficina de etapa, para evitar las distancias tan enormes de los frentes de Levante a Salamanca ${ }^{196}$, y poder traer la documentación, desde allí, por ferrocarril" ${ }^{\prime 197}$.

\footnotetext{
${ }^{194}$ CDMH. AGGCE. DNSD. Administración. Expedientes. Caja 206-290. Legajo 11. Expediente 217.

${ }^{195}$ CDMH. AGGCE. DNSD. Administración. Expedientes. Caja 206-290. Legajo 11. Expediente 217.

${ }^{196}$ La ofensiva de Levante se prolongó durante tres meses, del 23 de abril al 25 de julio de 1938, mientras que la batalla del Ebro duró casi cinco meses, del 25 de julio al 16 de diciembre de 1938.

${ }^{197}$ CDMH. AGGCE. DNSD. Administración. Expedientes. Caja 371-430. Legajo 17. Expediente 414. La denominada, por Ulibarri, "oficina de etapa" se instaló en dos locales de la Auditoría de Guerra de Zaragoza.
} 
Así pues, toda la documentación incautada en esas provincias, donde se desarrolló la ofensiva de Levante y la batalla del Ebro, Castellón, Zaragoza y Tarragona, fue enviada, a Salamanca, a través del ferrocarril, con salida en Zaragoza capital.

En Caminreal, el día 1 de marzo de 1938, Martín Sastre volvió a entrevistarse con el general Fidel Dávila, siendo refrendados los salvoconductos para los equipos de recuperación de documentos, de cara al avance de las tropas y la ofensiva hacia el Levante (Castellón) ${ }^{198}$. Se preparaban, así, de este modo, las futuras e inminentes requisiciones en Vinaroz y Castellón ${ }^{199}$.

\subsection{LA REQUISICIÓN EN CATALUÑA}

\subsubsection{PS-BARCELONA}

El 26 de enero de 1939, las tropas franquistas entraron y ocuparon la ciudad de Barcelona, y, con ella, toda la región catalana desde el río Segre hasta la costa mediterránea.

Tras la toma de la ciudad condal, Marcelino de Ulibarri y Eguílaz, con prácticamente todo el personal del Archivo central en Salamanca, ochenta y una personas en total, se desplazó a Barcelona, formando seis equipos de recuperación de documentos para que estos procedieran a la recuperación e incautación de los mismos. Como director de la Delegación en Barcelona, ubicado en una torre de la calle Montaner, en el número 264, y segundo de Ulibarri en ausencia de éste, fue nombrado Antonio Palau Muñoz.

Todo el meticuloso trabajo de la Delegación en Barcelona, con sus requisiciones documentales, que comenzaron dos días después de la entrada de las tropas franquistas en la ciudad condal, está explicado, no sólo para Barcelona y el Levante, Castellón, Valencia y Alicante, en la obra Els papers de Salamanca de Josep CRUANYES I TOR ${ }^{200}$.

\footnotetext{
${ }^{198}$ CDMH. AGGCE. DNSD. Administración. Expedientes. Caja 206-290. Legajo 11. Expediente 217.

199 Sobre la Guerra Civil en Aragón y la creación de PS-Aragón, véase RoDRíGUEz SIMÓN, Pedro., Vestigios de la Guerra Civil en Aragón. Zaragoza. Diputación General de Aragón, 2011.

200 CRUANYES I TOR, Josep., Els papers de Salamanca. L'espoliació del patrimoni documental de Catalunya, 1936-1939. Barcelona, Edicions 62, 2003.
} 
En este apartado, dedicado a la requisición en Cataluña, se analizan las requisiciones realizadas en toda Cataluña, no sólo en Barcelona, en concreto, los envíos de la documentación, por parte de varios municipios catalanes de las provincias de Barcelona, Gerona y Tarragona al Archivo central en Salamanca, así el cómo ingresó de la documentación de la Generalidad de Cataluña y del Centro Israelita "Agudad Ahim" de Barcelona en el Archivo de Salamanca.

A primeros de junio de 1939, toda la documentación requisada ascendía a "alrededor de $3.500 \operatorname{sacos}^{\text {״201 }}$. Toda esa documentación, más la que se siguió requisando, pasó a formar parte de la agrupación PS-Barcelona del Archivo central en Salamanca.

La documentación requisada fue trasladada, desde Barcelona, al Archivo central en Salamanca, desde el mes de junio al de diciembre de 1939, siguiendo las siguientes instrucciones, para su envío, facilitadas por Marcelino de Ulibarri y Equílaz:

Normalizadas las comunicaciones ferroviarias, el transporte del material sin clasificar debe hacerse en envío militar por ferrocarril, acudiendo a Transportes Militares, con las garantías de seguridad necesarias, designando, al efecto, el personal que proceda y que haya de acompañar el envío, utilizando camiones y coches para el transporte de los documentos ya clasificados ${ }^{202}$.

La documentación que formó la agrupación documental PS-Barcelona del Archivo central de Salamanca no sólo fue aquella que ingresó, en él, tras ser incautada por los equipos de recuperación de documentos que actuaron en la ciudad condal y otros municipios catalanes, sino que, en aplicación del artículo tercero del Decreto, de 26 de abril de 1938, del Ministerio del Interior, la Delegación contó también con la colaboración de autoridades, funcionarios, entidades y particulares, para incrementar sus fondos documentales. Las entidades municipales de las provincias de Barcelona, Gerona y Tarragona, enviaron la documentación de interés de que disponían al Archivo central en Salamanca.

\footnotetext{
${ }^{201}$ CDMH. AGGCE. DNSD. Secretaría. Correspondencia. Caja 551-595. Legajo 35. Expediente 564.

${ }^{202}$ CDMH. AGGCE. DNSD. Secretaría. Correspondencia. Caja 551-595. Legajo 35. Expediente 564.
} 
En los casos en los que los municipios no pudieron enviar documentación alguna a la Delegación salmantina, fue, o bien porque esta documentación había sido destruida por el Ejército republicano en su retirada, o bien porque la documentación de que disponía el municipio era de interés para la administración del mismo, no teniendo relación alguna con la finalidad última de la Delegación. 
Los municipios catalanes que ofrecieron su colaboración y que, en algunos casos, la enviaron, fueron los siguientes:

\begin{tabular}{|c|c|c|}
\hline \multicolumn{3}{|c|}{ PS-Barcelona (provincia de Barcelona) } \\
\hline Localidad & Documentación & Fecha de envío \\
\hline Begas & Particular & 22.03 .1939 \\
\hline Bigas y Riells & Ninguna & \\
\hline Calders & Particular y sanitaria & 10.03 .1939 \\
\hline Castellgalí & Municipal & 03.03 .1939 \\
\hline Catellnou de Bagés & Judicial y municipal & 10.03 .1939 \\
\hline Cornellá de Llobregat & Administrativa y política & 06.03 .1939 \\
\hline Fogás de Tordera & Ninguna & \\
\hline Galla & Judicial y municipal & 07.03 .1939 \\
\hline Granada del Panadés, La & Ninguna & \\
\hline Igualada & Sin datos ${ }^{203}$ & 28.06 .1939 \\
\hline Manlleu & Ninguna & \\
\hline Martorellas & Municipal & 22.08 .1939 \\
\hline Matadepera & Particular y sindical & 08.03 .1939 \\
\hline Mataró & Particular y militar & 14.03 .1939 \\
\hline Molins de Rey & Municipal & 22.08 .1939 \\
\hline Montesquieu & Administrativa & 03.03 .1939 \\
\hline Montmaneu & Municipal & 22.08 .1939 \\
\hline Palleja & Ninguna & \\
\hline Perafita & Ninguna & \\
\hline Pla del Panades & Ninguna & \\
\hline Pontons & Administrativo & 11.03 .1939 \\
\hline Prat de Llusanes & Municipal & 22.08 .1939 \\
\hline Puigdalba & Ninguna & \\
\hline Rocafort y Vilumara & Municipal y parroquial & 01.03 .1939 \\
\hline Sallent & Judicial, municipal y parroquial & 06.03 .1939 \\
\hline San Bartolomé de Grau & Municipal & 22.08 .1939 \\
\hline San Celoni & Municipal & 22.08 .1939 \\
\hline Saln Clemente de Llobregat & Municipal & 22.08 .1939 \\
\hline San Cugat del Vallés & Política, judicial y municipal & 19.06 .1939 \\
\hline San Feliú de Torelló & Política & 03.03 .1939 \\
\hline San Fructuoso de Bages & Ninguna & \\
\hline San Justo Desvern & Ninguna & \\
\hline San Martín Sarroca & Municipal & $22-08.1939$ \\
\hline San Mateo de Bages & Particular, judicial y municipal & 01.04 .1939 \\
\hline San Pedro de Ribas & Municipal & 22.08 .1939 \\
\hline San Pedro de Vilamajor & Ninguna & \\
\hline
\end{tabular}

${ }^{203}$ Treinta y cuatro sacas de documentación. 


\begin{tabular}{|l|l|c|}
\hline \multicolumn{3}{|c|}{ PS-Barcelona (provincia de Barcelona) } \\
\hline \multicolumn{1}{|c|}{ Localidad } & \multicolumn{1}{|c|}{ Documentación } & Fecha de envío \\
\hline San Sadurni de Noya & Municipal & 22.08 .1939 \\
\hline San Saturnino de Osormot & Municipal & 22.08 .1939 \\
\hline San Vicente de Torelló & Judicial, municipal y parroquial & 02.03 .1939 \\
\hline Santa Fe del Panades & Municipal & 22.08 .1939 \\
\hline Sta. María de Navarclés & Ninguna & \\
\hline Sta. María de Marlés & Ninguna & \\
\hline Santa Susana & Ninguna & 22.08 .1939 \\
\hline Senmenat & Municipal & \\
\hline Talamanca & Ninguna & \\
\hline Torrelavit & Ninguna & 29.03 .1939 \\
\hline Vallcebre & Ninguna & 08.03 .1939 \\
\hline Vallirana & Municipal & \\
\hline Vilalleóns & Municipal & \\
\hline
\end{tabular}

Tabla 5.4. Municipios barceloneses que enviaron documentación a la Delegación 


\begin{tabular}{|c|c|c|}
\hline \multicolumn{3}{|c|}{ PS-Barcelona (provincia de Gerona) } \\
\hline Localidad & Documentación & Fecha de envío \\
\hline AMER & Municipal & 22.08 .1939 \\
\hline Aviñonet & Ninguna & \\
\hline Begur & Ninguna & \\
\hline Boadella & Ninguna & \\
\hline Camprodón & Municipal & 22.08 .1939 \\
\hline Darnius & Municipal & 22.08 .1939 \\
\hline Espolla & Ninguna & \\
\hline Jafre & Municipal & 22.08 .1939 \\
\hline La Junquera & Ninguna & \\
\hline Llagostera & Particular y Municipal & 08.03 .1939 \\
\hline Llers & Municipal & 22.08 .1939 \\
\hline Llosas, Las & Municipal & 22.08 .1939 \\
\hline Madremanya & Judicial y municipal & 13.03 .1939 \\
\hline Massanet de la Selva & Municipal & 22.08 .1939 \\
\hline Mayá de Montcal & Particular & 23.03 .1939 \\
\hline Mollet de Perelada & Ninguna & \\
\hline Molló & Ninguna & \\
\hline Palau de Santa Eulalia & Judicial y municipal & 22.03 .1939 \\
\hline Pont de Molins & Municipal & 05.04 .1939 \\
\hline Rabós de Ampurdá & Municipal & 22.08 .1939 \\
\hline Regencós & Municipal & 22.08 .1939 \\
\hline Ripio & Política, judicial y municipal & 14.03 .1939 \\
\hline Riudarenas & Municipal & 22.08 .1939 \\
\hline Riumors & Municipal & 22.08 .1939 \\
\hline San Jaime de Llierca & Militar & 07.04 .1939 \\
\hline San Sadurní & Municipal & 22.08 .1939 \\
\hline Santa Cristina de Aro & Ninguna & \\
\hline Saus (Camallera) & Ninguna & \\
\hline Selva de Mar & Municipal & 22.08 .1939 \\
\hline Taravaus & Ninguna & \\
\hline Terrades & Ninguna & \\
\hline Verges & Ninguna & \\
\hline Vilajuiga & Municipal & 22.08 .1939 \\
\hline Vilamaniscle & Municipal & 22.08 .1939 \\
\hline Vilanant & Ninguna & \\
\hline Vilasacra & Municipal & 31.03 .1939 \\
\hline
\end{tabular}

Tabla 5.5. Municipios gerundenses que enviaron documentación a la Delegación 


\begin{tabular}{|l|l|c|}
\hline \multicolumn{3}{|c|}{ PS-Barcelona (provincia de Tarragona) } \\
\hline \multicolumn{1}{|c|}{ Localidad } & \multicolumn{1}{c|}{ Documentación } & Fecha entrada \\
\hline Altafulla & Municipal & 22.08 .1939 \\
\hline Brafim & Municipal & 22.08 .1939 \\
\hline Conesa & Municipal & 22.08 .1939 \\
\hline Creixell & Municipal & 22.08 .1939 \\
\hline Freginalls & Municipal & 22.08 .1939 \\
\hline Lloa & Municipal & 22.08 .1939 \\
\hline Nulles & Municipal & 22.08 .1939 \\
\hline Reus & Sin datos & \\
\hline Tarragona & Sin datos & \\
\hline
\end{tabular}

Tabla 5.6. Municipios tarraconenses que enviaron documentación a la Delegación

Fuentes. Centro Documental de la Memoria Histórica (CDMH). ARChivo General de la Guerra Civil Española (AGGCE). Delegación Nacional de Servicios Documentales (DNSD). Secretaría. Correspondencia. Caja 501-550. Legajo 33. Expediente 504; Secretaría. Correspondencia. Caja 551-595. Legajo 35. Expediente 564; Secretaría. Correspondencia. Caja 1150-1249. Legajo 59. Expediente 1150; y, Secretaría. Correspondencia. Caja 1150-1249. Legajo 59. Expediente 1151. Cuadros de elaboración propia.

\subsubsection{PS-BARCELONA GENERALIDAD}

Con la autorización del Comandante militar pertinente, comenzaron los registros en la sede de la Generalidad de Cataluña, que se prolongaron durante todo el mes de febrero.

El equipo de recuperación de documentos, encargado de requisar la documentación de la Generalidad de Cataluña, fue el conocido como equipo de Fuentes, formado por el propio Juan Fuentes Bertrán, jefe del mismo, y los auxiliares, Fermín Urriza Muguerza y Ramón Viladrich Capella.

La metodología fue similar a la de las requisiciones practicadas en el resto de organismos oficiales.

Las consejerías registradas fueron: Cultura, Justicia, Finanzas y Economía, Sanidad y Asistencia Social, Agricultura y Defensa.

\footnotetext{
${ }^{204}$ Sesenta kilos de documentación.

${ }^{205}$ Ciento treinta y cinco sacos y ocho paquetes.
} 
La documentación requisada enviada a Salamanca, ingresó en la Delegación en las siguientes fechas:

\begin{tabular}{|c|c|}
\hline \multicolumn{2}{|c|}{ PS-Barcelona Generalidad } \\
\hline Consejerías & Fecha de entrada \\
\hline Cultura & 06.02 .1939 \\
\hline Finanzas y Economía & 13.02 .1939 \\
\hline Sanidad y Asistencia Social & 13.02 .1939 y 14.02 .1939 \\
\hline Agricultura & 14.02 .1939 \\
\hline Defensa & 14.02 .1939 \\
\hline Justicia & 23.02 .1939 \\
\hline
\end{tabular}

Tabla 5.7. Ingreso de la documentación la Generalidad de Cataluña en la Delegación FuENTES. CDMH. AGGCE. DNSD. Secretaría. Correspondencia. Caja 596-659. Legajo 38. Expediente 647; y, Secretaría. Correspondencia. Caja 830-909. Legajo 51. Expediente 875. Cuadro de elaboración propia.

En el caso de la Consejería de Finanzas y Economía, el equipo de recuperación de documentos llegó, a la sede del Departamento, cuando parte de la documentación había sido "recogida, en los primeros días, por el Ministerio de Industria y Comercio, quedando solamente lo que no interesó a ese Ministerio"206. Finalmente, en otros casos, como en la Consejería de Agricultura, los documentos quedaron depositados momentáneamente en el Archivo de la Diputación Provincial de Barcelona ${ }^{207}$, hasta su envío definitivo a Salamanca.

También, por esas mismas fechas, el 8 de febrero de 1939, se remitió, a la Delegación en Salamanca, toda la documentación requisada en el Parlamento de Cataluña, ubicado, entonces, en la calle Parque Ciudadela, y la documentación de José Irla Bosch, que fuera presidente del Parlamento catalán hasta el final de la Guerra Civil.

Toda esta documentación dio lugar a la agrupación documental PS-Barcelona Generalidad del Archivo de Salamanca.

\footnotetext{
${ }^{206}$ CDMH. AGGCE. DNSD. Secretaría. Correspondencia. Caja 596-659. Legajo 38. Expediente 647.

${ }^{207}$ CDMH. AGGCE. DNSD. Secretaría. Correspondencia. Caja 596-659. Legajo 38. Expediente 647.
} 


\subsubsection{CENTRO ISRAELITA “AGUDAD AHIM” DE BARCELONA}

El 8 de febrero de 1939, la Brigada Político-Social de la Policía de Barcelona, dependiente de la Jefatura del Servicio Nacional de Seguridad del Ministerio de la Gobernación, requisó toda la documentación del Centro Israelita "Agudad Ahim" de la ciudad condal $^{208}$.

Inmediatamente enterado de este acontecimiento, Marcelino de Ulibarri solicitó, al Jefe de la Brigada Político-Social de Barcelona, la entrega de la totalidad de la documentación incautada al Centro Israelita de Barcelona ${ }^{209}$.

El 11 de febrero, Ernesto Álvarez, Delegado de Seguridad de Barcelona contestaba que "los documentos que la policía [recogía] son un instrumento de trabajo para la misma, de los que no puede prescindir y [tienen] que quedar en sus archivos" ${ }^{210}$. Sin embargo, el Delegado de Seguridad de Barcelona prometía a Ulibarri que "aquellos otros, que no tuvieran interés para la Policía, [...] le serían remitidos a la Delegación del Estado para Recuperación de Documentos" "211. Concluía, respecto a la documentación del Centro Israelita “Agudad Ahim”, el Delegado de Seguridad de Barcelona, que ésta "está en estudio, por este Organismo, y pudiera acordarse su archivo en nuestras oficinas, su remisión a las que $\mathrm{Vd}$. dirige o su entrega a los interesados a quienes les fueron ocupados, 212 .

El 13 de febrero de 1939, Marcelino de Ulibarri contestaba en los siguientes términos:

a) Le solicitaba que le remitiera un inventario de toda la documentación encontrada en el Centro Israelita, para evitar, así, su pérdida o extravío.

\footnotetext{
${ }^{208}$ CDMH. AGGCE. DNSD. Secretaría. Correspondencia. Caja 830-909. Legajo 51. Expediente 879.

${ }^{209}$ CDMH. AGGCE. DNSD. Secretaría. Correspondencia. Caja 830-909. Legajo 51. Expediente 879.

${ }^{210}$ CDMH. AGGCE. DNSD. Secretaría. Correspondencia. Caja 264-275. Legajo 14. Expediente 272.

${ }^{211}$ CDMH. AGGCE. DNSD. Secretaría. Correspondencia. Caja 264-275. Legajo 14. Expediente 272.

${ }^{212}$ CDMH. AGGCE. DNSD. Secretaría. Correspondencia. Caja 264-275. Legajo 14. Expediente 272.
} 
b) Le proponía que un equipo de recuperación de documentos de la Delegación, con mucha más práctica y celo que el de la policía, se hiciese cargo de la clasificación de la documentación.

c) Por último, le recordaba que, el Archivo de Salamanca era el organismo donde se tenía que centralizar toda la documentación incautada: "los documentos originales, en virtud de las vigentes disposiciones, han de quedar depositadas en este Centro a mi cargo" $" 213$.

Finalmente, se impuso la tesis de la Delegación y los documentos del Centro Israelita “Agudad Ahim” fueron enviados a Salamanca el 13 de febrero de $1939^{214}$.

\subsection{LA FORMACIÓN DE PS-BILBAO}

Las tropas franquistas entraron y ocuparon la ciudad de Bilbao el 19 de junio de 1937.

Tras la toma de Bilbao, Marcelino de Ulibarri y Eguílaz instaló un Archivo para Recuperación de Documentos en el edificio barroco de la Bolsa, o Palacio de John, ubicado en la calle Pelota, ${ }^{\circ} 10$, del casco histórico de Bilbao ${ }^{215}$.

Al igual que en otras grandes localidades o núcleos de población, la metodología de las requisiciones llevadas a cabo en Bilbao se basó en el registro de organismos oficiales y de domicilios particulares.

La documentación requisada en Bilbao fue la siguiente:

- Toda la documentación administrativa, de las tres Diputaciones vascas ${ }^{216}$.

- Toda la documentación del Banco de Vizcaya en Bilbao ${ }^{217}$.

${ }^{213}$ CDMH. AGGCE. DNSD. Secretaría. Correspondencia. Caja 264-275. Legajo 14. Expediente 272.

${ }^{214}$ Sobre la Guerra Civil en Cataluña y sus repercusiones documentales, véase MARTíNEZ REVERTE, Jorge., La caída de Cataluña, Barcelona, Crítica, 2006.

${ }^{215}$ CDMH. AGGGCE. DNSD. Secretaría. Correspondencia. Caja 125-200. Legajo 7. Expediente 154.

${ }^{216}$ CDMH. AGGCE. DNSD. Secretaría. Correspondencia. Caja 1807-1930. Legajo 122. Expediente 1925.

${ }^{217}$ CDMH. AGGCE. DNSD. Secretaría. Correspondencia. Caja 451-500. Legajo 32. Expediente 494. 
- Por otra parte, Marcelino de Ulibarri no pudo hacerse con la documentación producida por el Gobierno vasco, Presidencia y Secretaría, y sus Consejerías, Justicia, Cultura, etc, hasta la toma de Barcelona por las tropas franquistas. Tras diversos registros, realizados a la sucursal del Banco de Vizcaya, ubicada en la calle Diputación, n 314, y en el Paseo de Gracia, $\mathrm{n}^{\circ}$ 60, pisos principal y segundo, donde se encontraba la sede de la denominada "Delegación Vasca", los días del 18 al 23 de febrero de 1939, logró hacerse con ellas. Setenta sacas y cuarenta y dos cajas de madera, con documentación del Gobierno vasco, de mucho más de 70 kilos, fueron enviadas al Archivo central en Salamanca, completándose, así, la agrupación PS-Bilbao del mismo ${ }^{218}$.

\subsection{LA REQUISICIÓN EN CÁDIZ: PS-CÁDIZ}

En la ciudad de Cádiz, triunfó el alzamiento militar del 19 de julio de 1936, con el que dio comienzo la Guerra Civil española.

El personal militar de la $2^{\text {a }}$ Sección, Información, del Estado Mayor del Ejército del Sur del general Gonzalo Queipo de Llano se encargó de realizar la requisición de toda la documentación gaditana.

En el verano de 1938, a mediados del mes de agosto, el día 17, las relaciones entre la Delegación en Don Benito (Extremadura) y el Cuartel General del Ejército del Sur se normalizaron, aceptando éste que la Delegación se hiciese cargo de la requisiciones ${ }^{219}$.

Al final, las relaciones entre Francisco Salinas Quijada, Jefe del Archivo de la Delegación en Don Benito, y el general Gonzalo Queipo de Llano fueron tan buenas, que Salinas reconocía, parte del éxito de los trabajos de los equipos de recuperación de documentos, al propio general:

Los Generales tienen una misión compleja y difícil a seguir. Las preocupaciones de mando, operaciones, abastecimientos de tropa $y$

\footnotetext{
${ }^{218}$ CDMH. AGGCE. DNSD. Secretaría. Correspondencia. Caja 830-909. Legajo 51. Expediente 867. Sobre la Guerra Civil en Bilbao y la actuación paralela entre represión e incautación documental, véase AzConA, José Manuel ., Los desastres de la Guerra Civil Española: la represión en Bilbao, julio de 1936-junio de 1939. Madrid, Dykinson, 2007.

${ }^{219}$ Decreto, de 26 de abril de 1938, del Ministerio del Interior, publicado en el Boletín Oficial del Estado, de 27 de abril de 1938.
} 
gente civil, cartografía y comunicaciones, les restan, avaramente, hasta los más breves minutos de descanso, que pueden disfrutar. $Y$, por ello, en muchas de las ramas y secciones delegan en Jefes, que sirven de enlaces con la especialidad referida: Intendencia, Sanidad, Veterinaria, Farmacia, etc. Pues bien, [...] en nuestro servicio, en el Ejército del Sur no ha habido delegaciones. Ha sido el propio General [...] quien ha querido oír [...] nuestro propósito ${ }^{220}$.

La colaboración entre el Archivo de la Delegación en Don Benito y el Ejército del Sur, entre Salinas y Queipo de Llano fue estrechísima: "estamos en contacto permanente con el Servicio de Información militar del Cuartel General; con el Cuerpo Jurídico del Ejército del Sur; y con el Coronel Jefe de su Estado Mayor"221.

Tal es así, la estrecha colaboración entre Salinas y Queipo de Llano, que Salinas no dudó en afirmar, que "la simpatía y entusiasmo -demostrado por el Cuartel General del Ejército del Sur y Queipo de Llano- hacia el carácter de la Delegación del Estado, y la ponderación valiosa de sus resultados en todo orden, es casi mayor que en el Norte"222.

Francisco Salinas era consciente y conocía que toda la documentación de Andalucía y el sur de España estaba en poder de la $2^{\text {a }}$ Sección, Información, del Estado Mayor del Ejército del Sur de Queipo de Lllano: “toda la documentación habida en la tierra de la región del Sur, desde que se produjo el Alzamiento, obra en Sevilla, en el Cuartel General de Queipo de Llano",223.

La documentación requisada en Cádiz fue la siguiente:

- Documentación de partidos políticos (Partido Republicano Radical Demócrata, Unión Republicana, Partido Socialista Obrero Español y sus Juventudes Socialistas, y Partido Comunista de España).

- Documentación de los sindicatos CNT y UGT.

${ }^{220}$ CDMH. AGGCE. DNSD. Administración. Expedientes. Caja ADMON 371-430. Legajo 17. Expediente 414.

221 CDMH. AGGCE. DNSD. Administración. Expedientes. Caja ADMON 371-430. Legajo 17. Expediente 414.

${ }^{222}$ CDMH. AGGCE. DNSD. Administración. Expedientes. Caja ADMON 371-430. Legajo 17. Expediente 414.

${ }^{223}$ CDMH. AGGCE. DNSD. Administración. Expedientes. Caja ADMON 371-430. Legajo 17. Expediente 414. 
- Documentación de asociaciones y sociedades (Sociedad de Pintores La Decorativa, Sociedad de Teatros y Sociedad Cultura Musical de La Línea de la Concepción; Sociedad de Obreros y Empleados del Puerto de Cádiz; y Sociedad de Espectáculos Taurinos de Cádiz).

- Documentación municipal de los Ayuntamientos de Los Barrios (actas municipales) y de La Línea de la Concepción.

- Documentación procedente del Gobierno Civil de Cádiz 224.

La buena relación existente entre Salinas y Queipo de Llano hizo posible que, a través de PS-Extremadura, la documentación relativa a Cádiz y a Jaén fuese a parar a la Delegación en Salamanca.

En la actualidad, la agrupación documental PS-Cádiz está formada por seis cajas, en las que se contiene documentación de las localidades de Algeciras, Arcos de la Frontera, Los Barrios, Cádiz capital, La Línea de la Concepción, Puerto Real y Tarifa. En esas seis cajas, también hay documentación procedente de Madrid, León y Gijón.

\subsection{LA FORMACIÓN DE PS-CARTAGENA}

El personal encargado de la requisición fue el personal del Servicio de Información y Policía Militar (SIPM) de Cartagena.

La documentación requisada estaba formada por los cuatrocientos diez sumarios instruidos por el Tribunal Popular de Cartagena, además de otros documentos relacionados con el funcionamiento del Tribunal.

El 19 de diciembre de 1939, el Servicio de Información y Policía Militar (SIPM) remitía, en veintiséis paquetes, los citados cuatrocientos diez sumarios y otros documentos relacionados con el Tribunal Popular de Cartagena, a la Delegación del Estado para la Recuperación de Documentos de Salamanca. La documentación llegó a Salamanca e ingresó en la Delegación ese mismo día 19 de diciembre de $1939^{225}$.

\footnotetext{
${ }^{224}$ Véase PS-Cádiz. Cajas 1 a 6.

${ }^{225}$ CDMH. AGGCE. DNSD. Secretaría. Correspondencia. Caja 418-450. Legajo 29. Expediente 432. Con anterioridad, tres meses antes, el 9 septiembre de 1939, el Comandante-Jefe de la Jefatura
} 
Toda la documentación relativa al Tribunal Popular de Cartagena pasó a ser una parte constitutiva, de forma definitiva, de los fondos de la Delegación salmantina, conocida con el nombre de PS-Cartagena, atendiendo a cuantos requerimientos particulares y judiciales de la época, como el Juzgado Militar de Funcionarios de Murcia ${ }^{226}$ o el Fiscal Instructor de la Causa General de Murcia $^{227}$, a los que tuvo que reiterarles que "los sumarios instruidos por el Tribunal Popular de Cartagena no pueden ser remitidos [...], ya que deben archivarse, en esta Delegación, a tenor del Decreto de su creación, de 26 de abril de $1938^{\prime, 228 .}$

El 30 de enero de 1940, Ángel Ruiz de la Lastra, Presidente de la Audiencia Provincial de Murcia, solicitaba, a Marcelino de Ulibarri, el envío de todos los sumarios instruidos por el Tribunal Popular de Cartagena, con la finalidad de "darles la tramitación correspondiente, si no hubiese motivo para su retención",229.

A finales del mes de febrero de 1940, el día 22, Marcelino de Ulibarri contestaba negativamente a las pretensiones del Presidente de la Audiencia de Murcia. La documentación, le dice Marcelino de Ulibarri “encaja dentro de la documentación, cuya custodia y clasificación, compete a este Centro, según Decreto, de 26 de abril de 1938, y, por tanto, este Organismo no puede desprenderse de estos sumarios"230.

Eso sí, Ulibarri le comunicaba su predisposición, y la de la Delegación, a remitirle "cuantos extractos y copias fueren de interés para la Audiencia",231.

Administrativa Militar de la Provincia de Murcia, había remitido, por ferrocarril, a la Delegación, dos cajas, con los legajos e inventario de los mismos, de la Pagaduría Secundaria del Ejército de Tierra Republicado de la provincia de Murcia. Sobre este envío de documentación a la Delegación, véase CDMH. AGGCE. DNSD. Secretaría. Correspondencia. Caja 501-550. Legajo 34. Expediente 537.

${ }^{226}$ CDMH. AGGCE. DNSD. Secretaría. Correspondencia. Caja 1661-1769. Legajo 69. Expediente 1707.

${ }^{227}$ CDMH. AGGCE. DNSD. Secretaría. Correspondencia. Caja 1770-1806. Legajo 71. Expediente 1795.

${ }^{228}$ CDMH. AGGCE. DNSD. Secretaría. Correspondencia. Caja 1770-1806. Legajo 71. Expediente 1795.

${ }^{229}$ CDMH. AGGCE. DNSD. Secretaría. Correspondencia. Caja 501-533. Legajo 33. Expediente 513.

${ }^{230}$ CDMH. AGGCE. DNSD. Secretaría. Correspondencia. Caja 501-533. Legajo 33. Expediente 513.

${ }^{231}$ CDMH. AGGCE. DNSD. Secretaría. Correspondencia. Caja 501-533. Legajo 33. Expediente 513. 


\subsection{LA REQUISICIÓN EN CASTELLÓN: PS-CASTELLÓN}

El 14 de junio de 1938, las tropas franquistas entraron y ocuparon la ciudad de Castellón de la Plana.

A pesar de que Miguel Paredes, de la Auditoría del Ejército de Ocupación, le propuso de manera insistente, a Marcelino de Ulibarri, que la creación y organización de equipos de recuperación de documentos corriera a cargo de la citada Auditoría, para Castellón y toda la zona del Levante, Valencia y Alicante, Ulibarri siguió confiando en los equipos de recuperación creados y formados por él. En una carta, fechada el 8 de abril de 1938, Marcelino de Ulibarri, que no se cerraba a una posible colaboración entre los equipos de recuperación de documentos de la Delegación y el personal de la Auditoría del Ejército de Ocupación, le recordaba a Miguel Paredes que

siendo [...] responsable de este Servicio de tan delicada índole, ha de permitirme le reitere, una vez más, la necesidad de que las personas, que, en él, han de intervenir, reúnan condiciones de máxima honorabilidad, [...] máximo sacrificio y entusiasmo por servir a España, [...] en la medida y fuerzas que España y nuestra delicada misión exigen. [...] Somos, nosotros, los llamados a recoger los frutos de nuestros trabajos y actividades, en los actuales momentos ${ }^{232}$.

También, le comunicaba que ya tenía pensado el nombre y decidida la persona que dirigiría el Archivo de la Delegación en Castellón de la Plana: “posiblemente, destinaré a una persona que viene hace tiempo trabajando a mi lado, para Jefe de todo el Servicio de Castellón",233.

Ulibarri nombró a Manuel Martín Sastre en primera instancia y, cuando éste se ausentó de Castellón, nombró a Francisco Salinas Quijada. El mismo 14 de junio de 1938, fecha de entrada de las tropas franquistas en Castellón de la Plana, Martín Sastre fijó la sede del Archivo de la Delegación en Castellón, en el primer piso del número 8 de la Plaza

\footnotetext{
${ }^{232}$ CDMH. AGGCE. DNSD. Secretaría General. Expedientes Secretaría. Caja S.G. 201-241. Legajo 9. Expediente 216.

${ }^{233}$ CDMH. AGGCE. DNSD. Secretaría General. Expedientes Secretaría. Caja S.G. 201-241. Legajo 9. Expediente 216.
} 
de la Paz, al lado del de la Subdelegación del Gobierno ${ }^{234}$. Dicho Archivo estuvo abierto hasta, al menos, el 25 de noviembre de 1938.

Los equipos de recuperación de documentos, que actuaron por el área de Castellón de la Plana, con el permiso y bajo la supervisión del Estado Mayor del general José Enrique Varela y del Estado Mayor del general Rafael García Valiño, fueron los cinco siguientes:

- El equipo dirigido por Juan Fuentes Bertrán.

- El equipo dirigido por Julio Lasanta Miranda.

- El equipo dirigido por Prudencio Arza Arbe.

- El equipo dirigido por Féliz Amillano López.

- El equipo dirigido por Juan Queralt Oliva.

El 20 de junio de 1938, comenzaron los registros y las incautaciones de documentos en la propia capital, en Castellón de la Plana. Y, el 20 de junio de 1938, se incautó documentación en $\mathrm{Grao}^{235}$. Los equipos de Prudencio Arza, Félix Amillano, Julio Lasanta y Antonio Perurena trabajaron, ya, desde finales de junio, en la incautación de documentos, en las localidades de Grao (actual distrito marítimo de Castellón de la Plana), Villarreal, Nules, Benicasim y Sierra Engarcerán.

\footnotetext{
${ }^{234}$ CDMH. AGGCE. DNSD. Secretaría. Correspondencia. Caja 201-230. Legajo 9. Expediente 205.

${ }^{235}$ CDMH. AGGCE. DNSD. Secretaría. Correspondencia. Caja 288-325. Legajo 24. Expediente 322.
} 


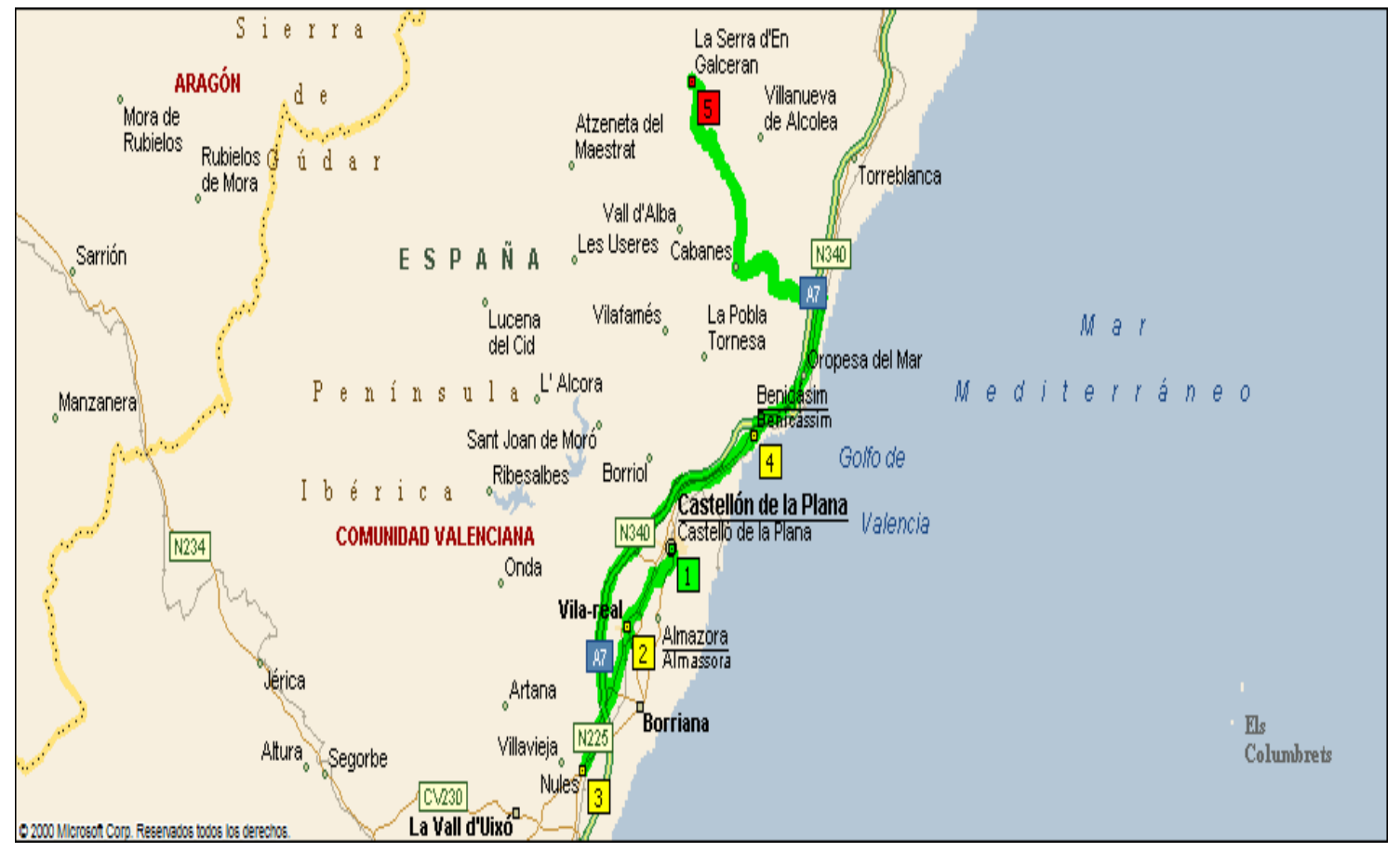

Mapa 5.8. Junio de 1938. Expediciones requisitorias.

Itinerario Castellón-Grao-Villarreal-Nules-Benicasin-Sierra Egarcerán

Transcurrido casi un mes desde la entrada de las tropas franquistas en Castellón de la Plana, el día 15 de julio de 1938:

- El equipo de recuperación de documentos de Juan Fuentes Bertrán, que había salido días antes de Castellón de la Plana, se encontraba en Teruel.

- El equipo de recuperación de documentos de Julio Lasanta Miranda, se encontraba, junto al Estado Mayor del general Rafael García Valiño, en Alcora, a 20 kilómetros al noroeste de Castellón de la Plana.

- Y, el equipo de recuperación de documentos de Prudencio Arza Arbe continuaba incautando documentación, en Castellón de la Plana, de masones y logias masónicas ${ }^{236}$.

El 17 de julio, se seguía incautando documentación masónica en Castellón de la Plana y en la localidad de Torreblanca, población situada, siguiendo la costa, a 37 kilómetros al norte de Castellón de la Plana ${ }^{237}$.

${ }^{236}$ CDMH. AGGCE. DNSD. Administración. Expedientes. Caja ADMON 371-430. Legajo 17. Expediente 414.

237 CDMH. AGGCE. DNSD. Administración. Expedientes. Caja ADMON 371-430. Legajo 17. Expediente 414. 
Dos días después, el 19 de julio, "el trabajo en el frente era escaso, por no decir nulo"238, y los equipos de recuperación de documentos dejaron de actuar.

El 22 de julio, por la mañana, los equipos de Prudencio Arza y Félix Amillano salieron de Castellón de la Plana a Argelita, localidad situada a 40 kilómetros al oeste de la capital.

A los otros pueblos recién tomados, por el Cuerpo del Ejército de Castilla, que operaba en esa zona, como Higueras (a 82 kilómetros al oeste de Castellón de la Planta) y Benafer (a 13 kilómetros al suroeste de Higueras), acudió el equipo de recuperación de documentos de Juan Fuentes.

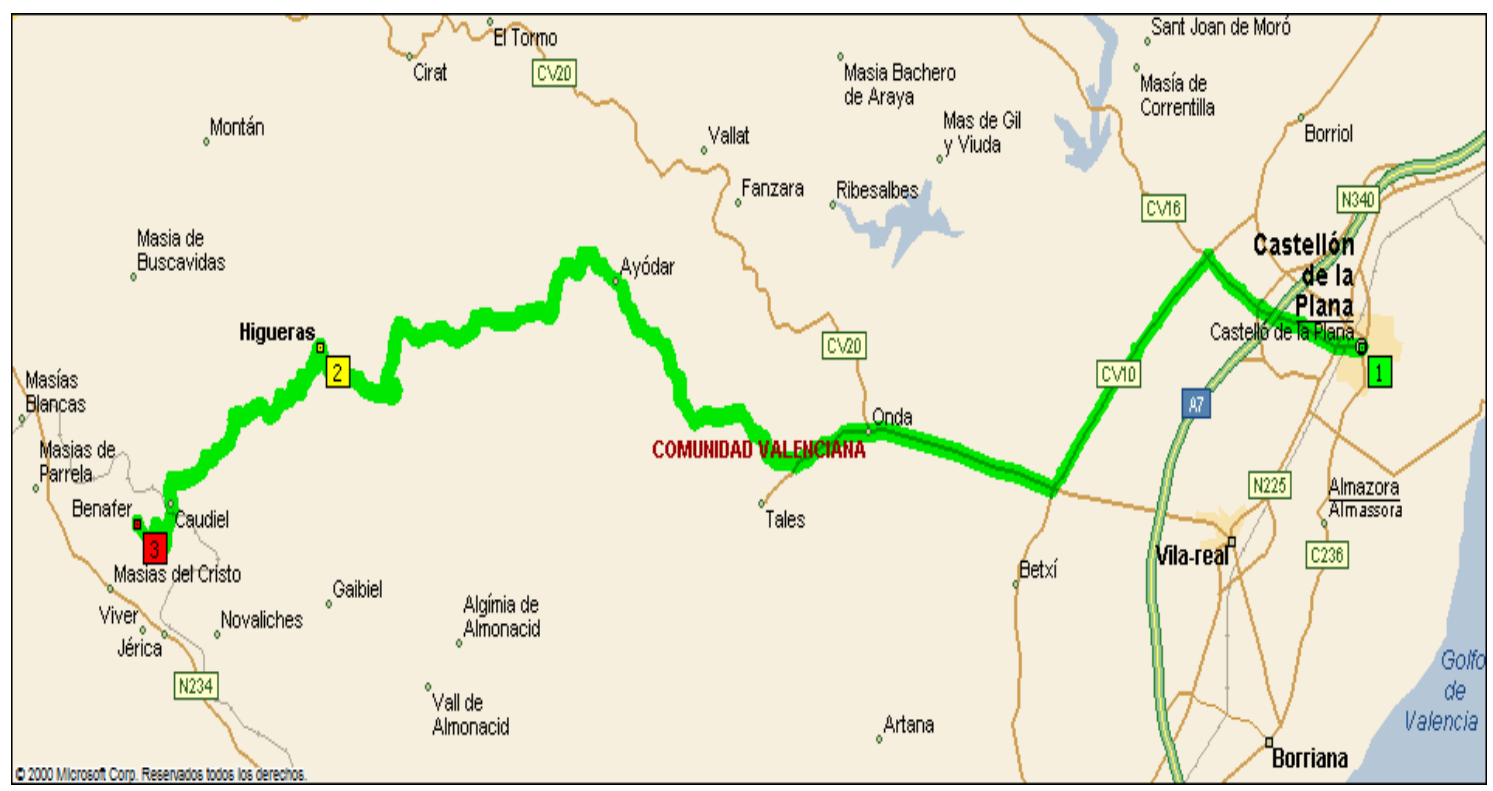

Mapa 5.9. 22.07.1938. Expedición requisitoria.

Equipo de Fuentes. Itinerario Castellón-Higueras-Benafer

Por su parte, el equipo de Juan Queralt se encontraba en Ludiente, a 47 kilómetros al noroeste de Castellón de la Plana.

Como explicaba Francisco Salinas Quijada a Marcelino de Ulibarri: "la labor de frente se lleva al día. [...] Y, ya se está trabajando sobre la futura organización de Valencia, con las listas correspondientes de domicilios a registrar" 239 .

${ }^{238}$ CDMH. AGGCE. DNSD. Administración. Expedientes. Caja ADMON 371-430. Legajo 17. Expediente 414. 
El 24 de julio de 1938, el frente, en el que operaban los generales José Solchaga, Rafael García Valiño y el Cuerpo del Ejército de Galicia, en tierras de Teruel (Rubielos de Mora, Mora de Rubielos, etc.), se encontraba paralizado. Por este motivo, los equipos de Prudencio Arza y Juan Queralt se desplazaron a Ludiente, Zucaina, Fanzara y Vallat, todas localidades de la comarca de Alto Mijares, para continuar con sus trabajos de incautación de documentos ${ }^{240}$.

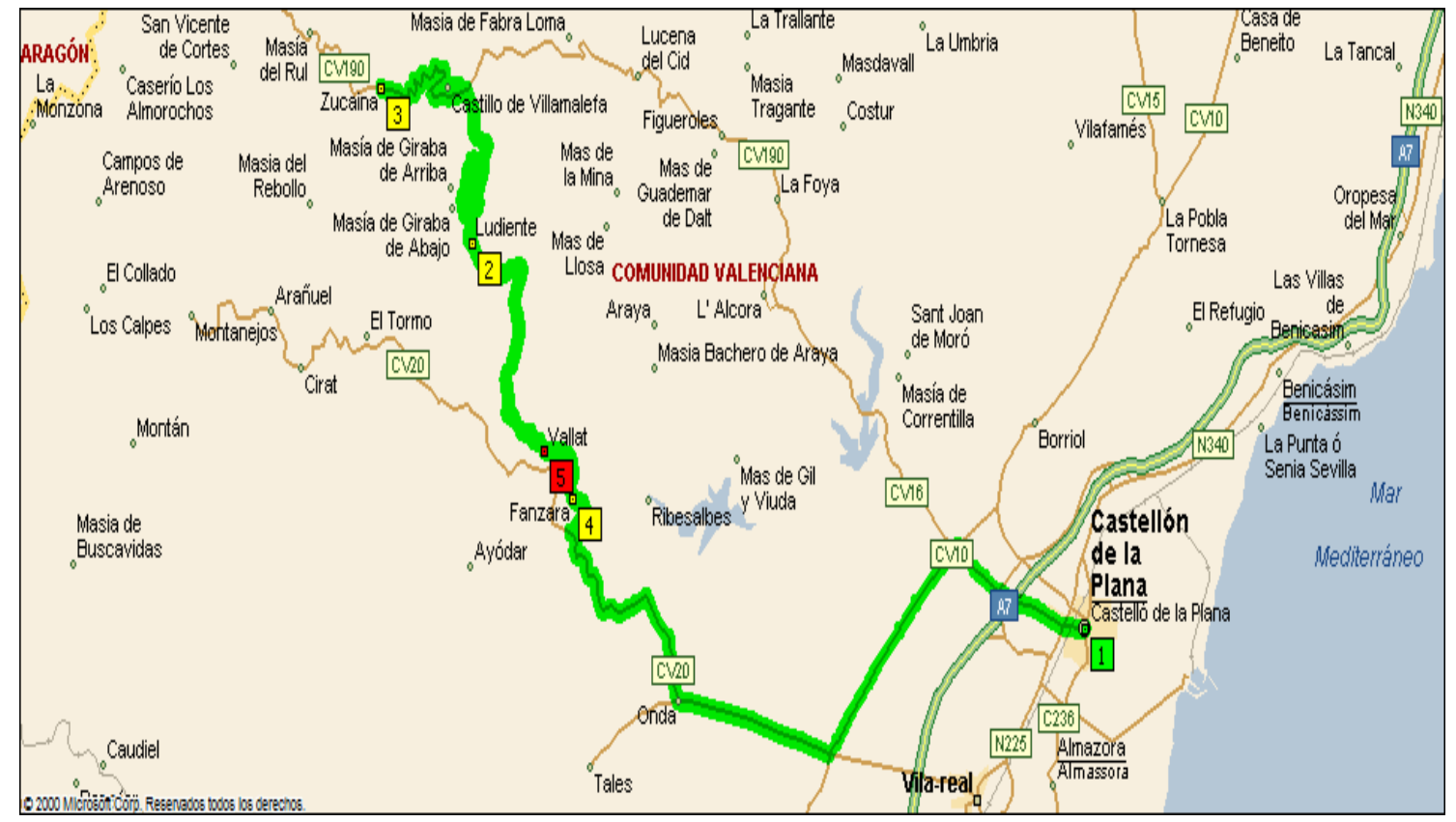

Mapa 5.10. 24.07.1938. Expediciones requisitorias. Itinerario Castellón-Fanzara-Vallat-Ludiente-Zucaina

En Castellón de la Plana capital, se requisó la documentación de:

- Las logias masónicas de la ciudad y de personalidades castellonenses ligadas a la masonería como Amadeo Ribot y Antonia Masip, viuda de Miguel Peña ${ }^{241}$.

- La documentación personal de Fernando Gasset Lacasaña, masón reconocido, tenido por la máxima autoridad de la masonería en Castellón, y que fue Presidente del Tribunal

${ }^{239}$ CDMH. AGGCE. DNSD. Administración. Expedientes. Caja ADMON 371-430. Legajo 17. Expediente 414.

${ }^{240}$ CDMH. AGGCE. DNSD. Administración. Expedientes. Caja ADMON 371-430. Legajo 17. Expediente 414.

${ }^{241}$ CDMH. AGGCE. DNSD. Secretaría General. Expedientes Secretaría. Caja S.G. 001-045. Legajo 1. Expediente 6; Secretaría. Correspondencia. Caja 201-230. Legajo 9. Expediente 212; y, Secretaría. Correspondencia. Caja 288-325. Legajo 24. Expedientes 318, 320 y 324. 
de Garantías Constitucionales, del 20 de diciembre de 1934 al 17 de julio de 1936; y de José Santacreu, Secretario General del PCE en Castellón.

- El Consulado de Francia en Castellón de la Plana ${ }^{242}$.

En la localidad de Grao, se incautó la documentación de Izquierda Republicana y del Partido Comunista de España ${ }^{243}$.

$\mathrm{Y}$, en las expediciones realizadas por los equipos de recuperación de documentos los días 22 y 24 de junio, se requisó toda la documentación de:

- El Consejo Levantino Unificado de la Exportación Agrícola (CLUEA), creado por la CNT y la UGT.

- Los Consejos Locales Unificados de Exportación de Frutos (CLUEF), encargado de la exportación de la naranja, y otros cítricos, durante la Guerra Civil.

El 25 de noviembre de 1938, la mayoría de la documentación incautada en el área geográfica de Castellón de la Plana fue trasladada al Archivo central de Salamanca.

El 9 de octubre, por carta, Marcelino de Ulibarri ordenaba a Manuel Martín Sastre que Francisco Salinas trajera toda la documentación allí existente al Archivo central de Salamanca, un total de "100 paquetes, 53 sacos y 4 cajas de documentación varia, libros, gacetas, propaganda y sellos de correos", que pasaron a formar la agrupación documental PS-Castellón del Archivo ${ }^{244}$.

Manuel Martín Sastre consiguió que el Jefe de Investigación de FET de las JONS de Castellón, en cumplimiento del Decreto, de 26 de abril, del Ministerio del Interior, publicado en el Boletín Oficial del Estado del día siguiente, le entregase toda "la documentación del enemigo que tiene en su poder", haciéndole saber que él y el Archivo de la Delegación en Castellón, ya disponían de "las listas y ficheros de las

\footnotetext{
${ }^{242}$ CDMH. AGGCE. DNSD. Secretaría. Correspondencia. Caja 804-829. Legajo 49. Expediente 825.

${ }^{243}$ CDMH. AGGCE. DNSD. Secretaría. Correspondencia. Caja 288-325. Legajo 24. Expediente 322.

${ }^{244}$ CDMH. AGGCE. DNSD. Secretaría. Correspondencia. Caja 288-325. Legajo 24. Expediente 305.
} 
organizaciones republicanas de Castellón y provincia", incluida la relación de maestros de la provincia de Castellón ${ }^{245}$.

\subsection{LA FORMACIÓN DE PS-EXTREMADURA}

La agrupación documental PS-Extremadura tiene su origen en la conocida como "bolsa de la Serena", territorio fiel a la Republica hasta el verano de 1938. A finales de agosto de 1938, una ofensiva del Ejército republicano consiguió recuperar parte del territorio, estabilizándose el frente a lo largo de la línea del ferrocarril Cabeza del Buey-Castuera y el arroyo de Guadalefra. La batalla de Valsequillo o batalla de Peñarroya, que tuvo lugar entre el 5 de enero y el 4 de febrero de 1939, con la victoria del Ejército franquista, comandado por el general Gonzalo Queipo de Llano, Jefe del Ejército del Sur, puso fin a la ofensiva y la contienda en el frente de Extremadura.

Francisco Salinas Quijada fue el director del Archivo de la Delegación en Don Benito (Badajoz), y Gregorio Rivera Uriz fue el subdirector del Archivo. El Archivo de la Delegación en Don Benito se instaló en la Escuela de Artes y Oficios o antigua Escuela Elemental de Trabajo, actual Instituto de Educación Secundaria Cuatro Caminos, ubicada en la calle Torres Isunza de la localidad pacense.

Eduardo Galán Ruiz fue el máximo responsable o jefe del equipo de recuperación de documentos que actuó en esta zona, formado por los auxiliares Carlos Lauri Fabello y Francisco Aizcorbe Iriarte ${ }^{246}$, donde también actuó el equipo de recuperación de documentos encabezado por Francisco Aizcorbe, y el propio Francisco Salinas Quijada, con su equipo. El equipo de recuperación de Francisco Salinas Quijada estaba formado por Prudencio Arza Arbe, Félix Amillano López y Marcos Huarte Vicente. Gregorio Rivera Uriz -como se ha indicado- permaneció al frente del Archivo de Don Benito, custodiando los documentos, en ausencia de Francisco Salinas.

\footnotetext{
${ }^{245}$ CDMH. AGGCE. DNSD. Secretaría. Correspondencia. Caja 201-230. Legajo 9. Expediente 208; y, Secretaría. Correspondencia. Caja 288-325. Legajo 24. Expediente 305.

${ }^{246}$ CDMH. AGGCE. DNSD. Administración. Expedientes. Caja ADMON 206-290. Legajo 11. Expediente 209.
} 
El día 30 de julio, Francisco Salinas Quijada, habiendo ya sido instalado el Archivo en Don Benito, mandó, desde allí, a Eduardo Galán a Trujillo y a Francisco Aizcorbe a Villanueva de la Serena, Medellín y La Haba, en búsqueda de información y de documentación que incautar.

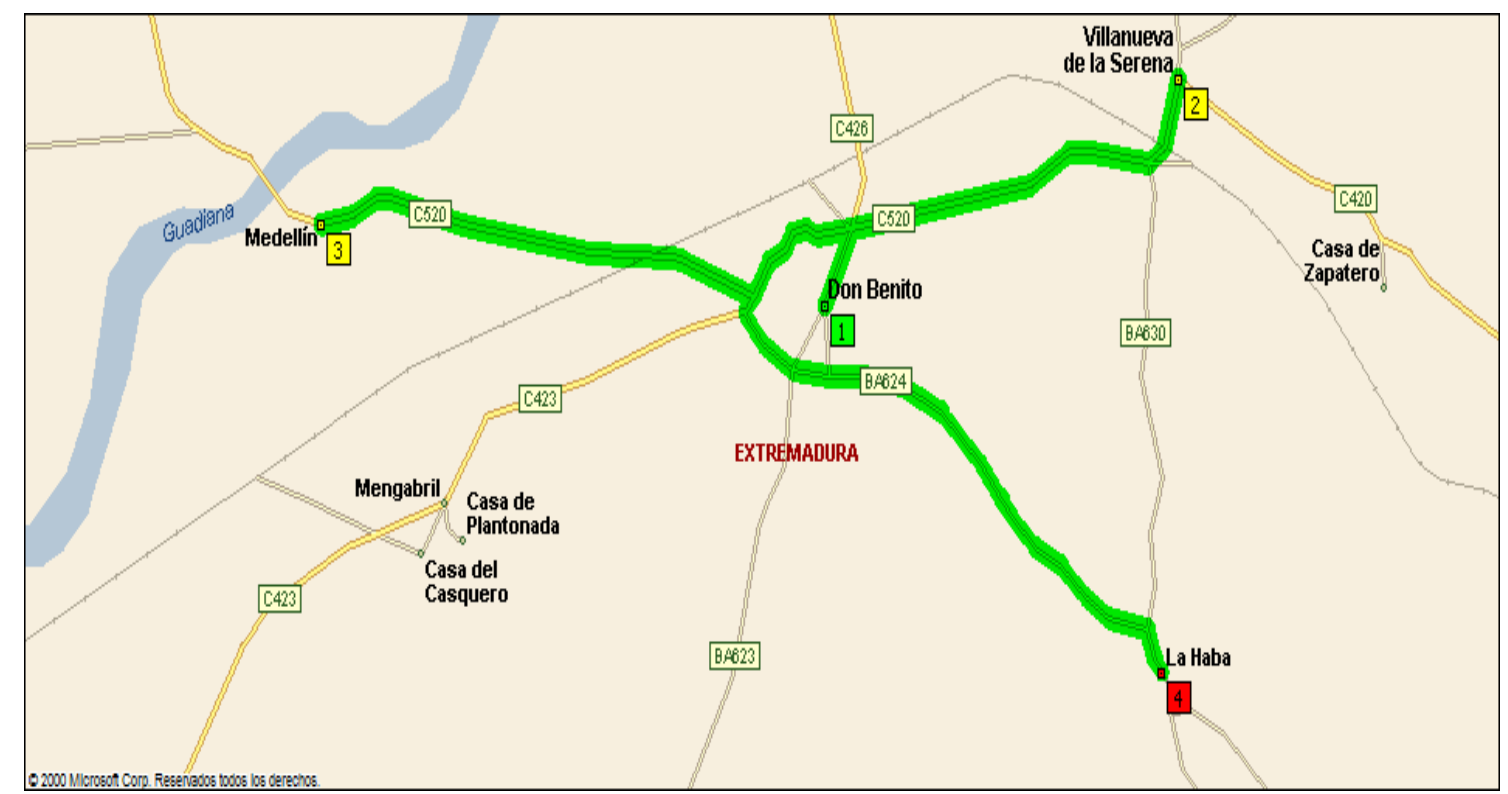

Mapa 5.11. 30.07.1938. Expedición requisitoria. Equipo de Aizcorbe. Itinerario Don Benito-Villanueva de la Serena-Medellín-La Haba

El día 1 de agosto de 1938, Francisco Salinas volvió a salir para el frente. A las tres de la tarde, llegó a Castuera, la localidad más a la vanguardia en la línea del frente de guerra.

El mismo día 1 de agosto de 1938, el equipo de Galán, por su parte, siguió registrando e incautando documentación en Don Benito y Villanueva de la Serena.

Por decisión de Francisco Salinas, Eduardo Galán partió para Trujillo, para distribuirse, geográficamente, las áreas de actuación de sus respectivos equipos de recuperación de documentos: que "Galán atienda la parte norte de la bolsa, mientras yo atiendo la del sur", afirmaba Salinas ${ }^{247}$.

${ }^{247}$ CDMH. AGGCE. DNSD. Administración. Expedientes. Caja ADMON 371-430. Legajo 17. Expediente 414. 
En once días, se realizaron, por los equipos de recuperación de documentos, dirigidos por Francisco Salinas y Eduardo Galán, un total de 106 registros, en las siguientes 22 localidades, Don Benito, Manchita, Mengabril, Medellín, Villanueva de la Serena, La Haba, Magacela, La Coronada, Orellana La Vieja, Acedera, Navalvillar de Pela, Orellana de la Sierra, Campanario, La Guarda, Quintana de la Serena, Valle de la Serena, Malpartida de la Serena, Castuera, Banquerencia de la Serena, Monterrubio de la Serena, Esparragosa de la Serena y Zaralema de la Serena ${ }^{248}$.

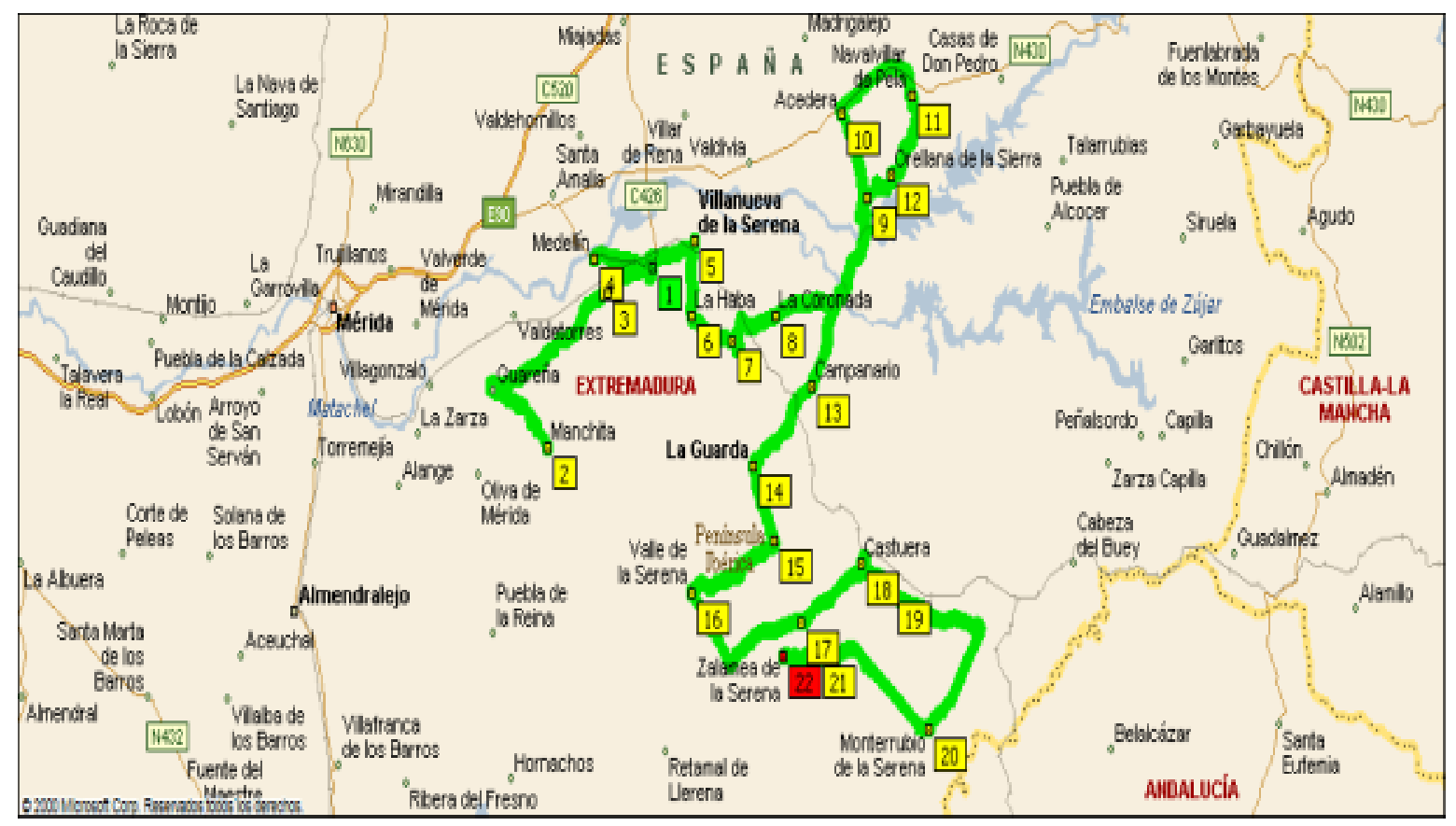

Mapa 5.12. Del 28.07.1938 al 07.08.1938. Expediciones requisitorias. Localidades pacenses donde fueron realizados registros

\footnotetext{
${ }^{248}$ CDMH. AGGCE. DNSD. Secretaría. Correspondencia. Caja 288-325. Legajo 24. Expediente 306.
} 
Como consecuencia de las expediciones y los registros realizados, el día 7 de agosto de 1938, los equipos de recuperación de documentos, dirigidos por Francisco Salinas y Eduardo Galán, habían registrado 22 localidades pacenses y se habían incautado de 106 sacos de documentación, de la siguiente forma:

\begin{tabular}{|l|l|c|}
\hline $\mathrm{N}^{\circ}$ & \multicolumn{1}{|c|}{ Localidad } & $\mathrm{N}^{\circ}$ de Sacos \\
\hline 1 & Acedera & - \\
\hline 2 & Benquerencia de la Serena & - \\
\hline 3 & Campanario & 10 \\
\hline 4 & Castuera & 5 \\
\hline 5 & Coronada, La & 47 \\
\hline 6 & Don Benito & 2 \\
\hline 7 & Esparragosa de la Serena & - \\
\hline 8 & La Guarda (pedanía) & 3 \\
\hline 9 & La Haba & - \\
\hline 10 & Magacela & 8 \\
\hline 11 & Malpartida de la Serena & - \\
\hline 12 & Manchita & - \\
\hline 13 & Medellín & 1 \\
\hline 14 & Mengabril & - \\
\hline 15 & Monterrubio de la Serena & 1 \\
\hline 16 & Navalvillar de Pela & 1 \\
\hline 17 & Orellana de la Sierra & 1 \\
\hline 18 & Orellana la Vieja & 4 \\
\hline 19 & Quintana de la Serena & 7 \\
\hline 20 & Valle de la Serena & 15 \\
\hline 21 & Villanueva de la Serena & 1 \\
\hline 22 & Zalamea de la Serena & \\
\hline
\end{tabular}

Tabla 5.13. Documentación requisada en los municipios de la provincia de Badajoz El día, 17 de agosto, el equipo de recuperación de documentos de Francisco Salinas se desplazó a la localidad de Cabeza del Buey, donde incautó abundante documentación.

El 19 de agosto, los equipos de recuperación de documentos se desplazaron y registraron las pedanías de Helechal y La Nava, "dos pueblecitos situados a derecha e izquierda de la carretera que enlaza Castuera con Cabeza del Buey"249. En Helechal,

249 CDMH. AGGCE. DNSD. Administración. Expedientes. Caja ADMON 371-430. Legajo 17. Expediente 414. Una distancia de 32 kilómetros separa ambas localidades. 
había muy poca documentación y muy pobre en su contenido, y, en La Nava, "ni siquiera había una persona que hubiera podido dar noticia e información"250.

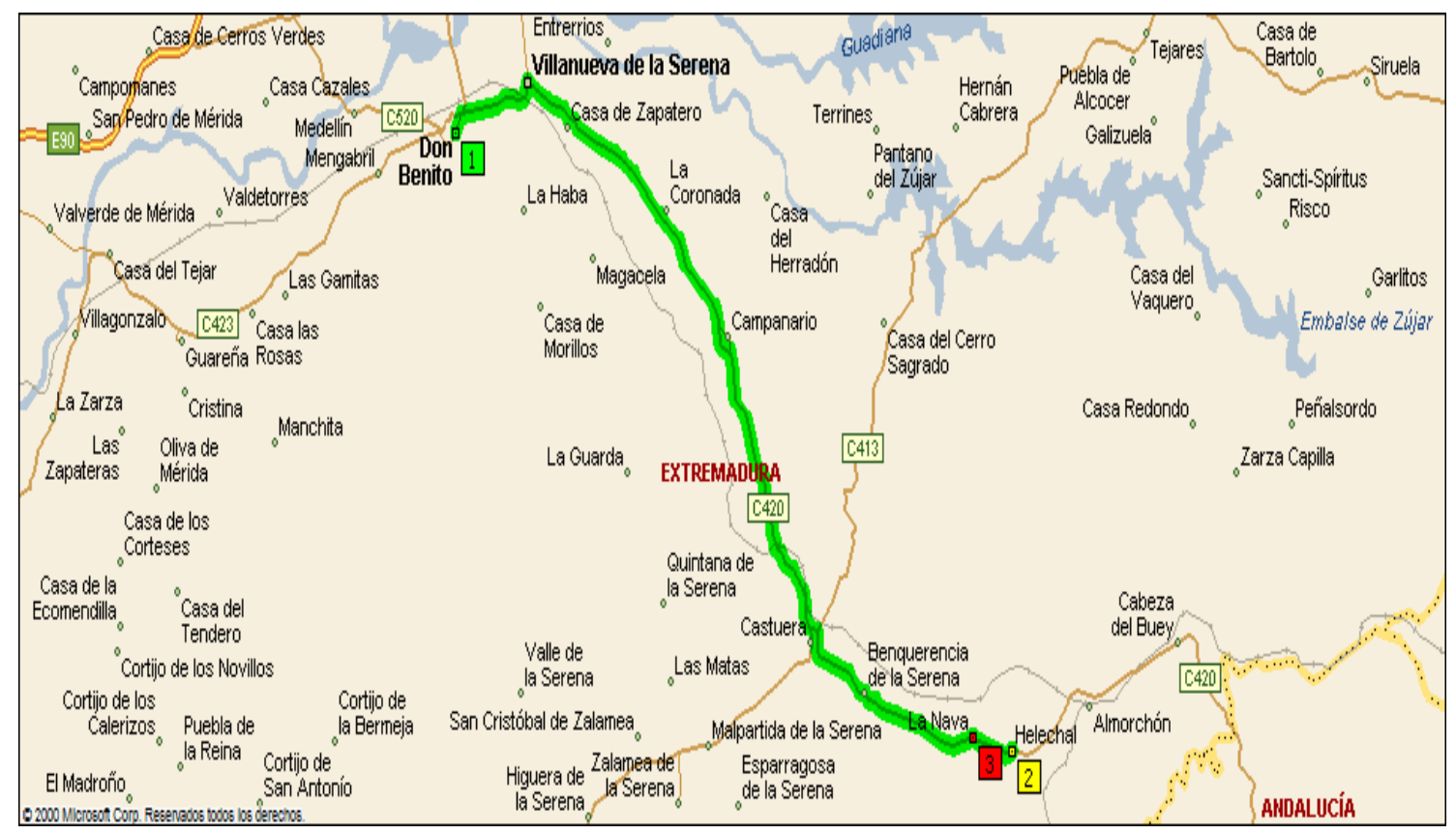

Mapa 5.14. 19.08.1938. Expediciones requisitorias. Itinerario Don Benito-Helechal-La Nava

Al día siguiente, 20 de agosto, los equipos de recuperación de documentos se dirigieron a Belalcázar (Córdoba), Puebla de Alcorcer (Badajoz) y Casas de Don Pedro (Badajoz), que era, según Francisco Salinas, una localidad formada por "media docena de cortijos sin ninguna personalidad política ni atisbo de actividad marxista en su historia"251. La actividad en el frente no cesaba: por eso, Salinas, con su equipo de recuperación de documentos, había llegado hasta la localidad cordobesa de Belalcázar, "último de los pueblos tomados en el último avance" ${ }^{, 52}$.

${ }^{250}$ CDMH. AGGCE. DNSD. Administración. Expedientes. Caja ADMON 371-430. Legajo 17. Expediente 414.

251 CDMH. AGGCE. DNSD. Administración. Expedientes. Caja ADMON 371-430. Legajo 17. Expediente 414. En la actualidad, Cabezas de Don Pedro cuenta con una población de 1.544 habitantes.

252 CDMH. AGGCE. DNSD. Administración. Expedientes. Caja ADMON 371-430. Legajo 17. Expediente 414. 


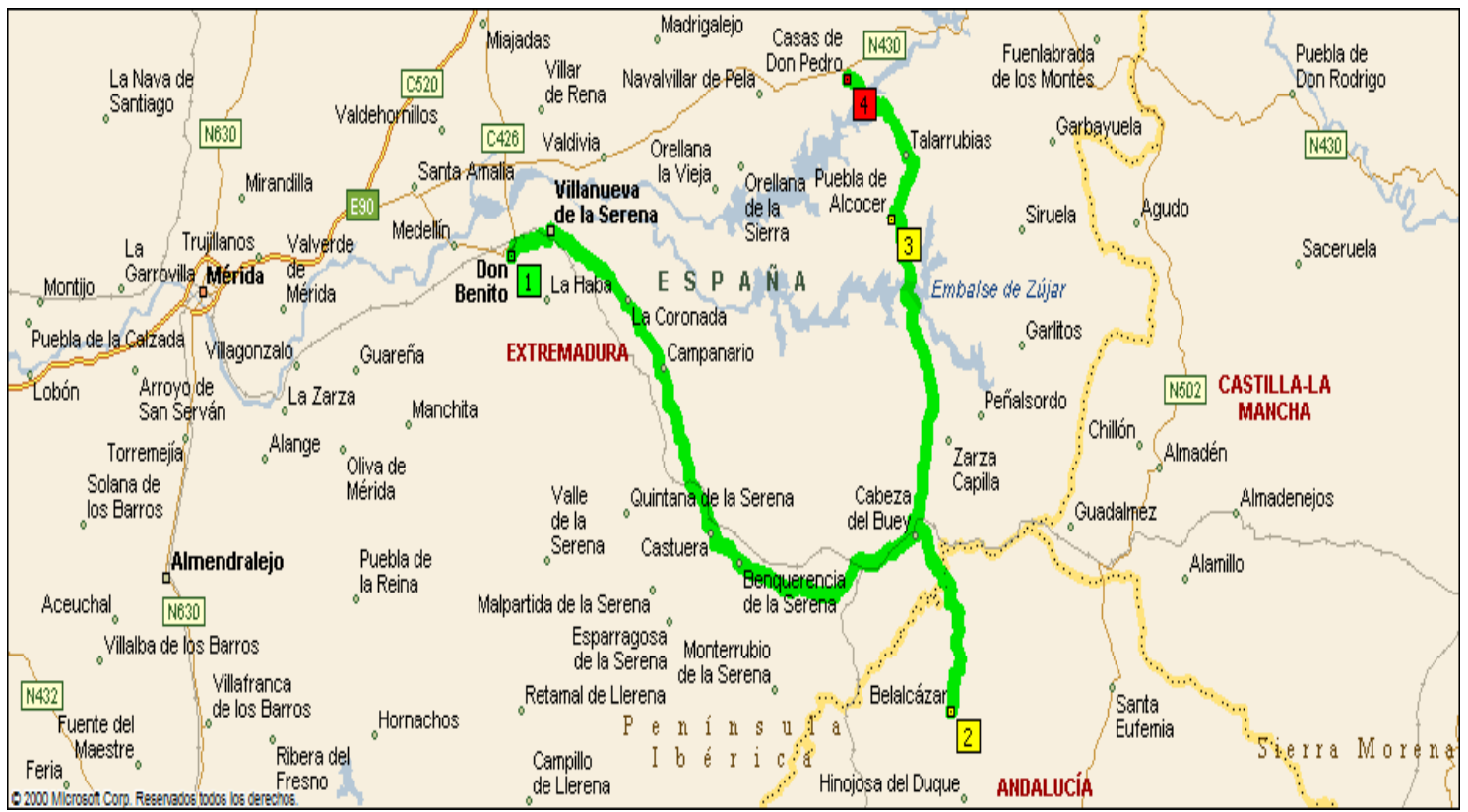

Mapa 5.15. 20.08.1938. Expediciones requisitorias.

Itinerario Don Benito-Belalcázar-Puebla de Alcocer-Casas de Don Pedro

También, el día 21 de agosto, además de continuar con la recuperación de documentos en la localidad de Cabeza de Buey, se trabajó en la recuperación de documentos en la pedanía de Almorchón.

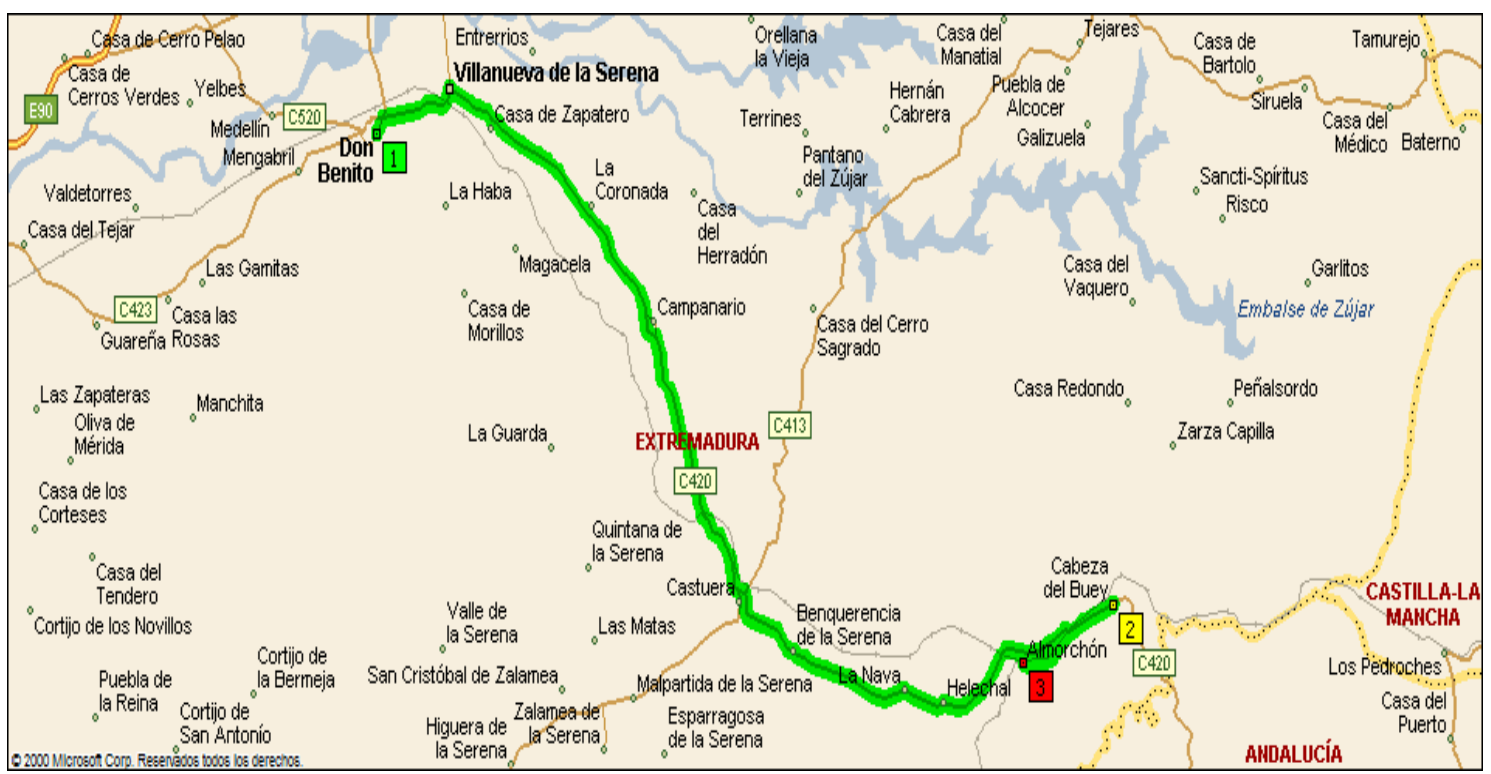

Mapa 5.16. 21.08.1938. Expediciones requisitorias. Itinerario Don Benito-Cabeza de Buey-Almorchón 
En Extremadura, se requisó documentación de:

- El Partido Socialista y de los sindicatos CNT y UGT de Don Benito.

- Las Juventudes Socialistas Unificadas y de la CNT de Villanueva de la Serena.

- El Partido Comunista de España, las Juventudes Libertarias y las Juventudes Socialistas Unificadas de Castuera.

- El Ayuntamiento de Valle de la Serena y del Ayuntamiento de Quintana de la Serena.

- Los sindicatos CNT y UGT de Orellana de la Sierra.

- Las Juventudes Socialistas Unificadas de Esparragosa.

- El Partido Comunista de España de Cabeza de Buey.

- Las Juventudes Socialistas Unificadas de Cabeza de Buey.

- Los sindicatos CNT y UGT de Cabeza de Buey ${ }^{253}$.

- Varios Comités de las localidades de Quintana de la Serena, Navalvillar de Pela y Orellana la Vieja ${ }^{254}$.

- Las colectividades campesinas extremeñas.

- La correspondencia particular, recogida en las estafetas de Correos de cada localidad.

- Fotografías del frente, junto con la propaganda republicana de la localidad de Trujillo, destinadas a la agrupación documental Prensa y Propaganda del Archivo central ${ }^{255}$.

- Y, unas cartas autógrafas de Margarita Nelken y otros dirigentes políticos del Frente Popular $^{256}$.

El día 21 de agosto, se recibieron, en el la Delegación salmantina, los "18 sacos de documentación y dos paquetes", incautados en la localidad de Cabeza del Buey, cuatro días antes ${ }^{257}$.

253 CDMH. AGGCE. DNSD. Administración. Expedientes. Caja ADMON 371-430. Legajo 17. Expediente 414.

${ }^{254}$ CDMH. AGGCE. DNSD. Secretaría. Correspondencia. Caja 288-325. Legajo 24. Expediente 306.

${ }^{255}$ CDMH. AGGCE. DNSD. Secretaría. Correspondencia. Caja 201-230. Legajo 9. Expediente 203.

${ }^{256}$ CDMH. AGGCE. DNSD. Secretaría. Correspondencia. Caja 288-325. Legajo 24. Expediente 306.

257 CDMH. AGGCE. DNSD. Administración. Expedientes. Caja ADMON 371-430. Legajo 17. Expediente 414. 
El día 31 de agosto de 1938, se envió, en sacos, a la Delegación en Salamanca, toda la documentación incautada hasta la fecha en Extremadura, junto con un Informe detallado.

El 12 de septiembre de 1938, por telegrama, Marcelino de Ulibarri ordenaba a Francisco Salinas, y a todo el personal a su cargo, su regreso a Salamanca, "con todo el material que tengáis" 258 .

Pasado el verano de 1938, tres meses después, el 5 de enero de 1939, comenzó la batalla de Valsequillo, que puso fin a la Guerra Civil en el frente de Extremadura. Cinco meses después de acontecida la batalla, el 5 de junio de 1939, el Comandante Jaime Puig, Jefe de la $2^{\text {a }}$ Sección, Información, del Estado Mayor del Ejército del Sur, cumpliendo órdenes del general Gonzalo Queipo de Llano, seguía enviando, por ferrocarril, documentación al Archivo central de Salamanca. En concreto, cuatro sacos de documentación incautadas en Castuera ${ }^{259}$.

Así, procedentes de la $2^{\text {a }}$ Sección, Información, del Estado Mayor del Ejército del Sur, al frente del cual se encontraba el conocido como Virrey de Andalucía, el general Gonzalo Queipo de Llano, también, vía Extremadura, llegarían los documentos que, en la actualidad, componen las agrupaciones documentales PS-Cádiz y PS-Jaén del Archivo salmantino.

El 29 de julio, un día antes de la llegada a Don Benito de Francisco Salinas Quijada, se presentó “un Comandante del Cuartel General del general Queipo de Llano, que quiso retirar y llevarse la correspondencia republicana"260.

La 112 División del general Gonzalo Queipo de Llano se encontraba en Castuera. Francisco Salinas se reunió, los días 14 y 15 de agosto, con el Comandante del Servicio

${ }^{258}$ CDMH. AGGCE. DNSD. Administración. Expedientes. Caja ADMON 371-430. Legajo 17. Expediente 414.

${ }^{259}$ CDMH. AGGCE. DNSD. Secretaría. Correspondencia. Caja 551-595. Legajo 35. Expediente 552.

${ }^{260}$ CDMH. AGGCE. DNSD. Administración. Expedientes. Caja ADMON 206-290. Legajo 11. Expediente 209. 
de Información del Cuartel General de la 112 División del Ejército del Sur, que le comunicó

la prohibición absoluta de recogida de documentación por aquellas personas, o comisiones, que no estuvieran expresamente facultadas por el General Queipo de Llano. A lo que añadió que, en su caso, toda la documentación, antes de mandarla a Salamanca [...], hay que avisar al Estado Mayor del susodicho Cuerpo del Ejército, para que la vea y examine, recoja de ella lo que le pueda interesar y, después, autorice su traslado a dichas Oficinas de Salamanca. Sin tal autorización, no se puede sacar ni un papel $^{261}$.

Finalmente, el Comandante del Servicio de Información del Cuartel General del Ejército del Sur de Gonzalo Queipo de Llano concluyó, al respecto del Archivo central de Salamanca, que

no se sabe, en concreto, las facultades, campo de acción y materia sobre la que se opera, su Servicio, con entera claridad. [...] Y, su papel, con respecto a la justificación del servicio, ante los Cuarteles Generales, es un poco difusa. [...] De hecho, hay muchas autoridades, por encima de mí, que no tienen conocimiento del Servicio. La labor a desarrollar debía ir por conducto jerárquico en forma de orden militar ${ }^{262}$.

El problema se solucionó dos días después, el 17 de agosto, con la presentación oficial del Servicio a los mandos superiores, es decir, con el encuentro entre Francisco Salinas, Jefe de Recuperación de Documentos en Extremadura, y Gonzalo Queipo de Llano, en el Cuartel General de éste, en Villanueva de la Serena. Todo el Estado Mayor de su Cuartel General, incluyendo al propio Queipo de Llano era conocedor del Decreto, del 26 de abril de 1938, del Ministerio del Interior, publicado en el Boletín Oficial del Estado del día siguiente. A partir de ese momento, Queipo de Llano facilitaría el trabajo de los equipos de recuperación ${ }^{263}$.

\footnotetext{
${ }^{261}$ CDMH. AGGCE. DNSD. Administración. Expedientes. Caja ADMON 371-430. Legajo 17. Expediente 414.

${ }^{262}$ CDMH. AGGCE. DNSD. Administración. Expedientes. Caja ADMON 371-430. Legajo 17. Expediente 414.

263 CDMH. AGGCE. DNSD. Administración. Expedientes. Caja ADMON 371-430. Legajo 17. Expediente 414. Sobre la Guerra Civil en Extremadura, véase ChAVES PALACios, Julián., La Guerra Civil en Extremadura: Operaciones militares, 1936-1939. Mérida, Editorial Regional de Extremadura, 1997.
} 


\subsection{LA REQUISICIÓN EN GIJÓN: PS-GIJÓN}

Las tropas franquistas tomaron la ciudad de Gijón el 20 de octubre de 1937. Los equipos de recuperación de documentos acompañaron al Ejército franquista.

Se realizaron más de 97 registros entre Gijón y el resto de las poblaciones asturianas.

En Asturias, y en Gijón, se requisó la documentación de:

- El Gobierno Militar de Gijón ${ }^{264}$.

- La Caja Marxista de Reparaciones de la Hacienda de Asturias y León ${ }^{265}$.

- Los Consejos Obreros de la empresa Ferrocarriles Vasco-Asturianos ${ }^{266}$.

- El Tribunal Popular de Gijón, documentación que constituye el núcleo fundamental de la agrupación documental PS-Gijón. Se trata de la principal documentación incautada ya que, en los Archivos del Tribunal Popular de Gijón, "se custodian muchos de los sumarios y rollos, iniciados o seguidos por dicho Tribunal, por delitos de índole política o común" ${ }^{267}$. También, es importante la documentación de los Juzgados de $1^{\text {a }}$ Instancia e Instrucción y los Juzgados militares asturianos, de Avilés, Infesto, Cangas de Onís, Pravia.

Por otra parte, en la Delegación de Salamanca, no se encontraban "las actuaciones de carácter civil, que se hubieran tramitado por la Audiencia territorial de Gijón, ya que estos documentos no interesan a los fines señalados, a este Organismo, por Decreto, de 26 de abril de $1938^{, 268}$.

\footnotetext{
${ }^{264}$ CDMH. AGGCE. DNSD. Secretaria. Correspondencia. Caja 033-072. Legajo 3. Expediente 49.

${ }^{265}$ CDMH. AGGCE. DNSD. Secretaria. Correspondencia. Caja 231-264. Legajo 12. Expediente 261.

${ }^{266}$ CDMH. AGGCE. DNSD. Secretaria. Correspondencia. Caja 326-352. Legajo 25. Expediente 339.

${ }^{267}$ CDMH. AGGCE. DNSD. Secretaría. Correspondencia. Caja 231-264. Legajo 11. Expediente 239. En este sentido, el fondo PS-Gijón es muy similar al fondo PS-Cartagena.

${ }^{268}$ CDMH. AGGCE. DNSD. Secretaría. Correspondencia. Caja 231-264. Legajo 11. Expediente 239. Sobre la Guerra Civil en Gijón, véase RADCLIFF, Pamela Beth., De la movilización a la Guerra Civil : historia de Gijón, 1900-1937. Barcelona, Debate, 2004.
} 


\subsection{LA FORMACIÓN DE PS-JAÉN}

En Jaén capital y en casi toda la provincia, salvo alguna localidad aislada, fracasó el alzamiento militar del 17 de julio de 1936. El 1 de abril de 1937, por orden del general Queipo de Llano, la ciudad sufrió, sin éxito, un virulento ataque aéreo. A partir de marzo de 1939, comenzaron a caer las localidades de Andujar, Arjona, Bailén, La Carolina, Linares, Marmolejo, Martos y la propia Jaén capital.

Como ya se ha apuntado, gracias a Francisco Salinas Quijada, desde el verano de 1938, las relaciones entre la Delegación salmantina y la $2^{\text {a }}$ Sección, Información, del Estado Mayor del Ejército del Sur eran muy fluidas.

En marzo de 1939, al final de la Guerra Civil, la $2^{\text {a }}$ Sección, Información, del Estado Mayor del Ejército del Sur seguía incautando documentación: "la documentación recogida era enviada, por conducto regular, al Ejército del Sur, a Sevilla. Las Brigadas, a las Divisiones. Éstas, a los Cuerpos de Ejército. Y, estos a aquel"269.

La documentación requisada es, como en otras zonas, de carácter político, relacionada con los partidos políticos y sindicatos republicanos en Jaén. Pero, además, en Jaén, fueron requisados:

- Los expedientes de los presos de la Prisión de Jaén.

- La documentación municipal de los Ayuntamientos de Mongón, Villacarrillo y otras localidades más importantes, como Andujar, de la que se enviaron documentos de

la Guerra Carlista, año 1836; sobre conmemoraciones patrióticas, año 1648; Reales Cédulas y una Real Provisión, años 1792 a 1796, ambos incluidos; Dos relaciones circunstanciales de la Batalla de Masdeu del Rosellón, año 1793; Una carpeta con documentos sobre la Guerra de África, año 1862; Colección de documentos sobre alistamiento de mozos y voluntarios para la guerra con Francia, año 1793; otra sobre las Milicias voluntarias realistas y nacionales, año 1841; $y$, otras sobre Compañías para la fuerza de Cataluña y Portugal; y otras, año $1706^{270}$.

\footnotetext{
269 CDMH. AGGCE. DNSD. Administración. Expedientes. Caja ADMON 371-430. Legajo 17. Expediente 414.

${ }^{270}$ CDMH. AGGCE. DNSD. Secretaría. Correspondencia. Caja 1931-2059. Legajo 123. Expediente 1983.
} 
La $2^{\text {a }}$ Sección, Información, del Estado Mayor del Ejército del Sur, se sometió al Decreto, de 26 de abril de 1938, del Ministerio del Interior, a la Delegación del Estado para Recuperación de Documentos, y envió toda la documentación, por lo menos, la referente a Jaén, a Salamanca.

En julio de 1941, toda la documentación, que acabaría constituyendo la agrupación documental PS-Jaén de la Delegación, se encontraba, ya, en Salamanca ${ }^{271}$. Y en la actualidad, la agrupación documental PS-Jaén está formada por 35 cajas $^{272}$.

\subsection{LA REQUISICIÓN EN LÉRIDA: PS-LÉRIDA}

Las tropas franquistas, comandadas por el general Juan Yagüe Blanco, entraron y ocuparon la ciudad de Lérida el 3 de abril de 1938. Al Estado Mayor del general Yagüe, estuvieron supeditadas todas las actuaciones llevadas a cabo por los equipos de recuperación de documentos de la Delegación, encargados de incautar documentación en la zona.

Francisco Salinas Quijada fue, también, como en Extremadura, el director de la Delegación en Lérida y de los equipos de recuperación que actuaron en la zona. Dichos equipos fueron los encabezados por el propio Francisco Salinas Quijada, Prudencio Arza Arbe y Félix Amillano López. A mediados del mes de junio, en el Cuartel General o Estado Mayor del general Yagüe, que se encontraba en Fraga (Huesca), Francisco Salinas se entrevistó con el Comandante del Servicio de Información de Auditoría de Guerra, para evitar, en lo posible, posibles interferencias en el trabajo de los equipos de recuperación de documentos, quedando el "asunto zanjado",273.

El 7 de junio, el equipo de recuperación de documentos de Francisco Salinas se desplazó, desde Altorricón a:

\footnotetext{
${ }^{271}$ CDMH. AGGCE. DNSD. Secretaría. Correspondencia. Caja 1250-1379. Legajo 62. Expediente 1355.

${ }^{272}$ Sobre la Guerra Civil en Jaén, véase Cово Romero, Francisco., La Guerra Civil y la represión franquista en la provincia de Jaén, 1936-1950. Jaén, Diputación Provincial de Jaén, 1993.

273 CDMH. AGGCE. DNSD. Administración. Expedientes. Caja ADMON 371-430. Legajo 17. Expediente 414.
} 
- Albelda (Huesca), situada a cinco kilómetros al este de Tamarite de Litera. En Albelda, el Secretario del Ayuntamiento le comunicó, a Salinas, que todos los papeles habían sido quemados, y que, "los que quedan, son acuerdos de Ayuntamiento, de exclusiva información local que no interesan" ${ }^{, 274}$.

- Alcarrás, en la provincia de Lérida, a 53 kilómetros al sur de Albelda y a 13 kilómetros al oeste de Lérida capital.

- Alguerri, situada a 41 kilómetros al norte de Alcarrás y a 25 kilómetros al norte de Lérida capital.

- Y, finalmente, a Balaguer, a 15 kilómetros al este de Alguerri.

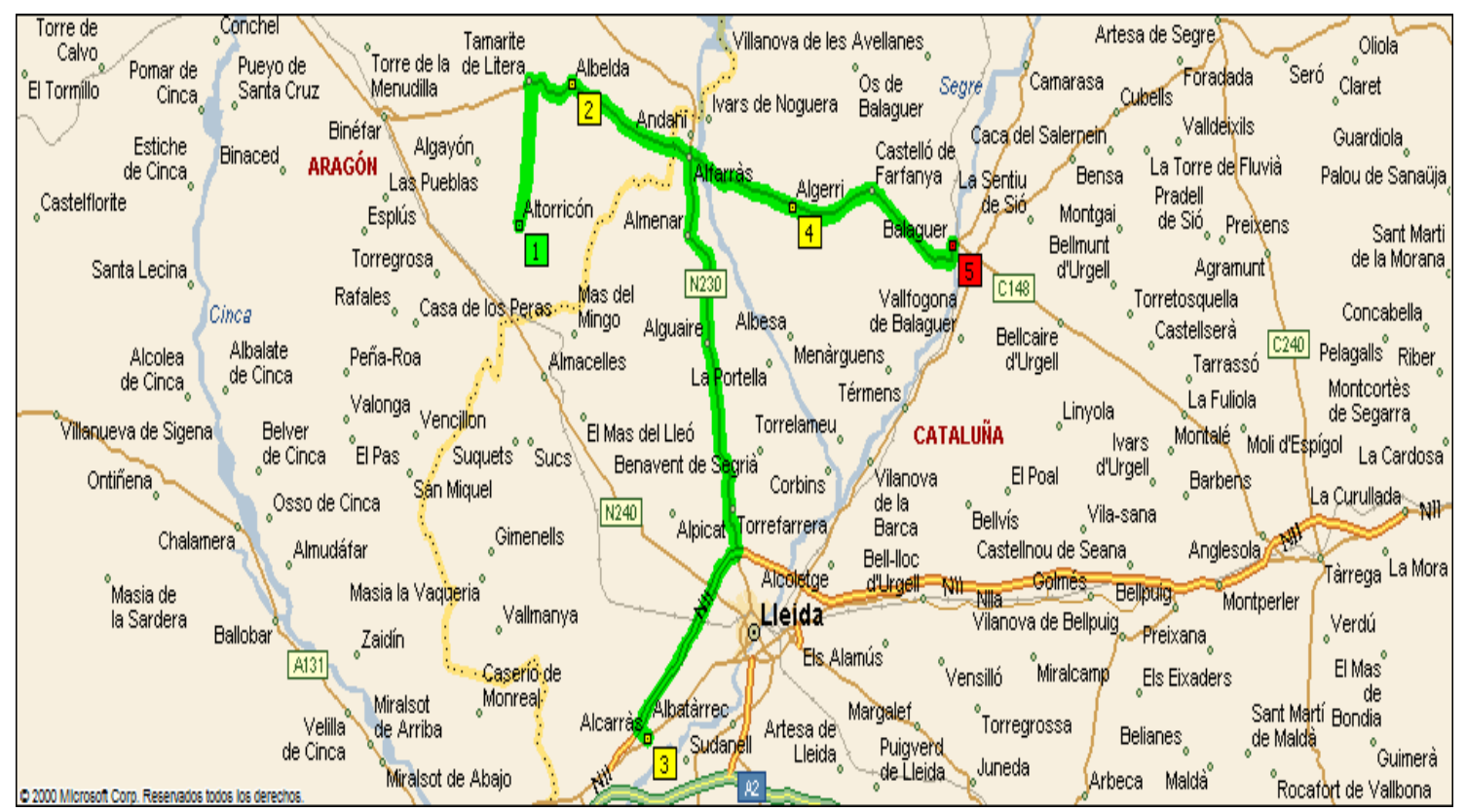

Mapa 5.17. 07.06.1938. Expedición requisitoria. Equipo de Salinas. Itinerario Altorricón-Albelda-Alcarrás-Alguerri-Balaguer

274 CDMH. AGGCE. DNSD. Administración. Expedientes. Caja ADMON 371-430. Legajo 17. Expediente 414. 
El 8 de junio, el equipo de recuperación de documentos de Salinas salió de Altorricón hacia:

- Villanueva de Alpicat (desde el año 1948, denominada solamente Alpicat), en Lérida, recorriendo los 28'8 kilómetros de distancia que separan ambas localidades.

- Torrefarrera, a seis kilómetros de distancia, al este de Alpicat.

- Roselló, situada a cuatro kilómetros al norte de Torrefarrera.

- Alguaire, situada seis kilómetros al norte de Roselló. En Alguaire, toda la documentación había sido destruida ${ }^{275}$.

- Almenar, localidad situada a nueve kilómetros al norte de Alguaire.

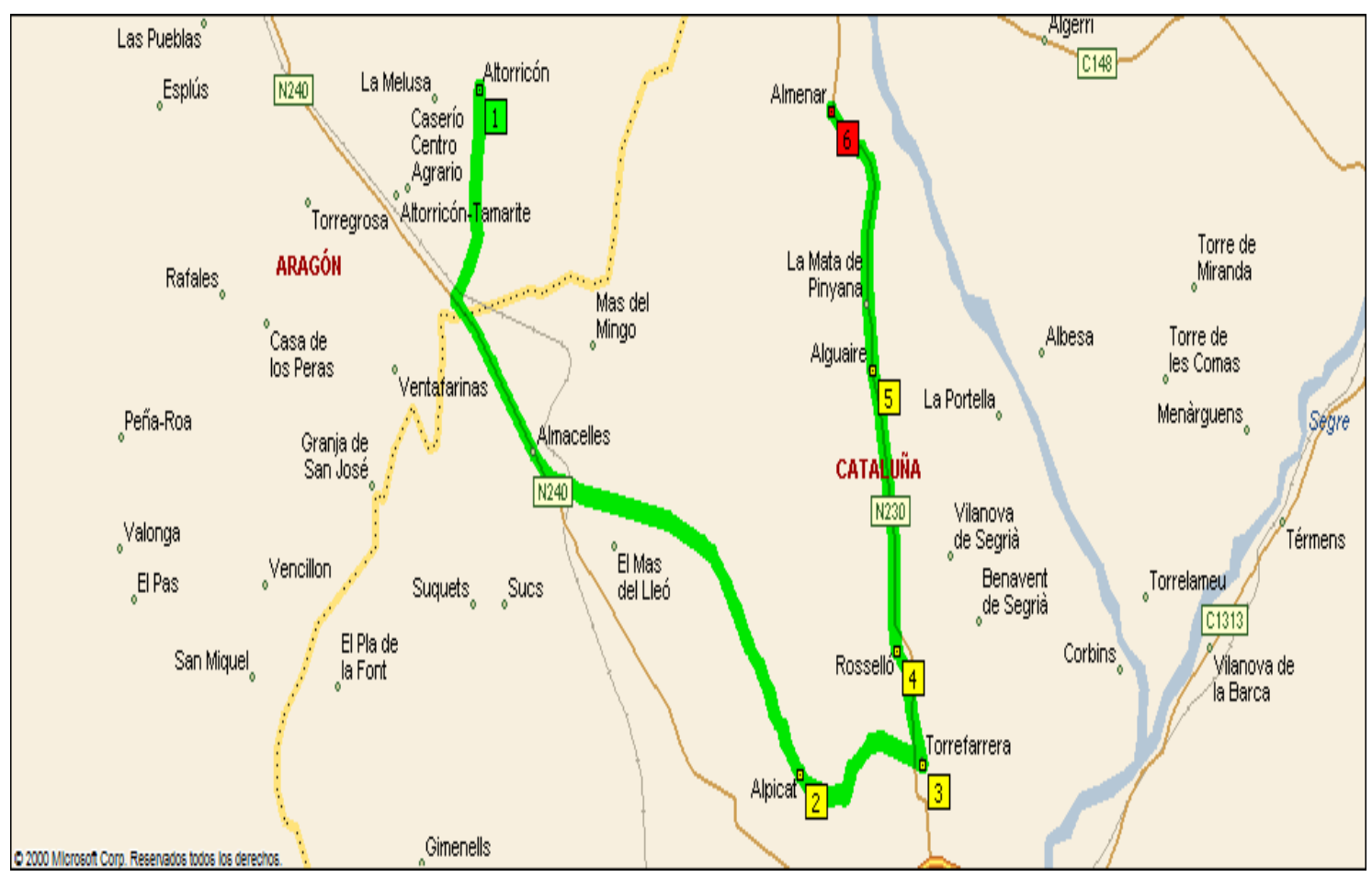

Mapa 5.18. 08.06.1938. Expedición requisitoria. Equipo de Salinas. Itinerario Altorricón-Villanueva de Alpicat -Torrefarrera-Roselló-Alguaire-Almenar

275 CDMH. AGGCE. DNSD. Administración. Expedientes. Caja ADMON 371-430. Legajo 17. Expediente 414. 
El 9 de junio, el equipo de recuperación de documentos de Salinas salió, desde Altorricón hacia:

- Vilanova de Segriá (Lérida), localidad situada a 38 kilómetros al sureste de Altorricón.

- Torregrosa, situada a 30 kilómetros al sureste de Vilanova de Segriá.

- Benavent de Lérida, situada a 28 kilómetros al sureste de Torregrosa.

- De Benavent de Lérida a Portella (distancia de 5’4 kilómetros hacia el norte).

- De Portella a Albesa (distancia de 69 kilómetros hacia el suroeste).

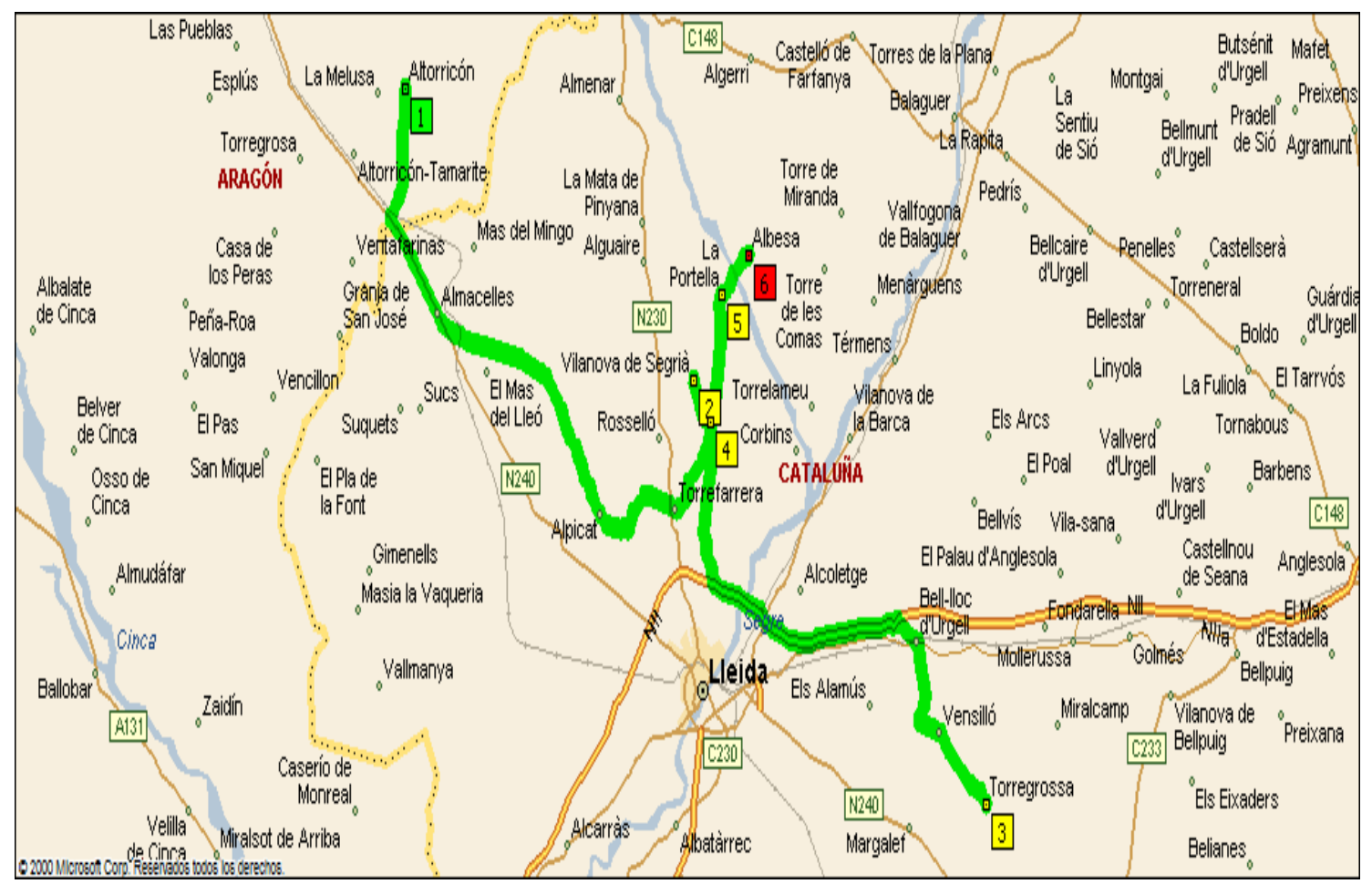

Mapa 5.19. 09.06.1938. Expedición requisitoria. Equipo de Salinas.

Itinerario Altorricón -Vilanova de Segriá-Torregrosa-Benavet-Portella-Albesa

El 13 de junio, continuaron los trabajos del equipo de recuperación de documentos de Francisco Salinas, en las localidades ilerdenses de Os de Balaguer, Avellanes Santa Liña y Ager, localidad, esta última, donde su Alcalde les comunicó que no había quedado "ni un solo documento de los rojos, por haberlos quemado todos al marcharse" $" 276$.

276 CDMH. AGGCE. DNSD. Administración. Expedientes. Caja ADMON 371-430. Legajo 17. Expediente 414. 
Francisco Salinas, por la tarde, llega a Tremp, localidad situada a 87 kilómetros al norte de Lérida capital. Allí, Francisco Salinas se entrevistó, de nuevo, con el Comandante del Estado Mayor del general Yagüe del Servicio de Información de Auditoría de Guerra, que no tenía noticia alguna sobre los equipos de recuperación de documentos de Prudencio Arza Arbe y Félix Amillano López, que estaban operando y trabajando por la zona, y al sur de la capital y de la provincia de Lérida.

Francisco Salinas, con su equipo, decidió regresar a Altorricón, en la comarca de La Litera (Huesca), recorriendo los 92 kilómetros que separan ambas localidades. Francisco Salinas quería recoger la documentación que los equipos de Arza y Amillano hubieran incautado en Lérida, y avisarles de la inminente toma de Castellón de la Plana por las tropas franquistas ${ }^{277}$. Para ello, Francisco Salinas planificó, de nuevo, un viaje a Tremp, para el día 23 de junio ${ }^{278}$.

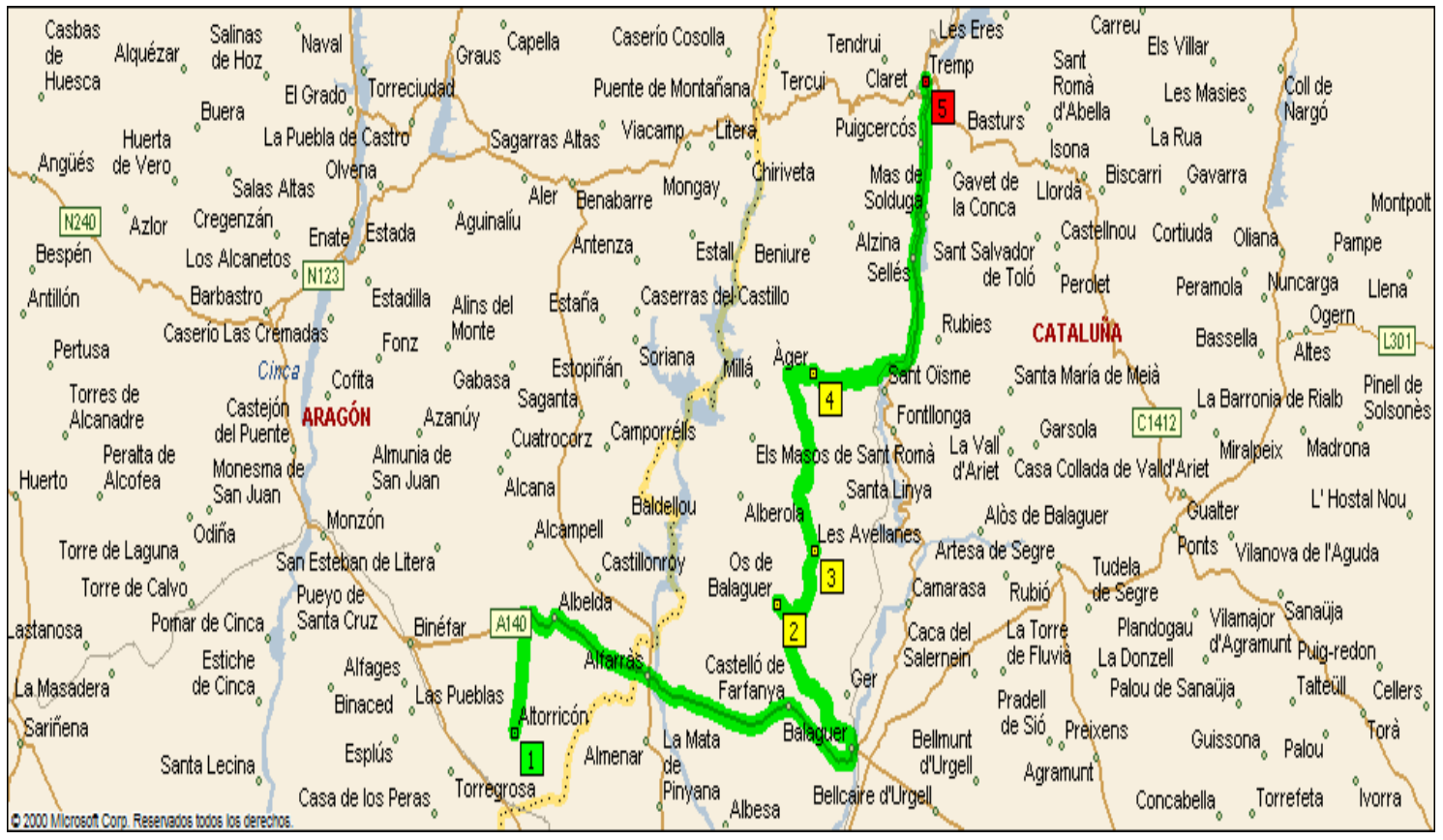

Mapa 5.20. 13.06.1938. Expedición requisitoria. Equipo de Salinas. Itinerario Altorricón-Os de Balaguer-Avellanes-Ager-Tremp

277 CDMH. AGGCE. DNSD. Administración. Expedientes. Caja ADMON 371-430. Legajo 17. Expediente 414.

278 CDMH. AGGCE. DNSD. Administración. Expedientes. Caja ADMON 371-430. Legajo 17. Expediente 414. 

fondo documental de la DNSD >

La documentación requisada en Lérida fue la siguiente:

- Documentación municipal de Albesa, Almenar, Benavent, Portella y Torregrosa ${ }^{279}$.

- Documentación de partidos políticos. Todos los libros del Comité Antifascista y del Partido Socialista Unificado de Cataluña (PSUC) de Roselló ${ }^{280}$.

- Documentación sindical:

- Los carnés y relaciones de Sindicados de campesinos de Alcarrás ${ }^{281}$.

- Todos los libros del Sindicato de Rabasanes de Alguerri ${ }^{282}$.

- La documentación del Sindicato de agricultores local, afecto a la UGT, de la localidad de Vilanova de Segriá ${ }^{283}$.

La documentación incautada, a tenor de las instrucciones dadas por Marcelino de Ulibarri, fue trasladada de forma similar a la documentación que dio lugar a la agrupación documental PS-Barcelona del Archivo central de Salamanca.

La documentación incautada por los equipos de recuperación de documentos, incluida la documentación de Lérida capital, se depositaba en el segundo piso del número 15 de la plaza Cervantes de Lérida. A comienzos del año 1939, con la documentación que allí se custodiaba, ocurrió lo siguiente:

No obstante, las órdenes terminantes de custodia, dadas [...] a un guardia civil retirado -a mediados del mes de febrero de 1939- unos soldados se llevaron la documentación existente, ignorándose a qué Unidad pertenecían y el lugar a dónde la condujeron y en el que fue depositada ${ }^{284}$.

\footnotetext{
${ }^{279}$ CDMH. AGGCE. DNSD. Administración. Expedientes. Caja ADMON 371-430. Legajo 17. Expediente 414.

${ }^{280}$ CDMH. AGGCE. DNSD. Administración. Expedientes. Caja ADMON 371-430. Legajo 17. Expediente 414.

281 CDMH. AGGCE. DNSD. Administración. Expedientes. Caja ADMON 371-430. Legajo 17. Expediente 414.

282 CDMH. AGGCE. DNSD. Administración. Expedientes. Caja ADMON 371-430. Legajo 17. Expediente 414.

${ }^{283}$ CDMH. AGGCE. DNSD. Administración. Expedientes. Caja ADMON 371-430. Legajo 17. Expediente 414.

${ }^{284}$ CDMH. AGGCE. DNSD. Secretaría. Correspondencia. Caja 551-595. Legajo 35. Expediente 564.
} 
Todo ello se puso en conocimiento del General de la $4^{a}$ Región Militar, para que resolviera el problema que se había planteado ${ }^{285}$.

Finalmente, la documentación fue encontrada y trasladada al Archivo central en Salamanca.

La documentación incautada por los equipos de recuperación de documentos comandados por Francisco Salinas Quijada, Prudencio Arza Arbe y Félix Amillano López, durante esos meses de los años 1938 y 1939, en el área geográfica descrita, dio lugar a la agrupación documental denominada PS-Lérida de la Delegación.

\subsection{LA FORMACIÓN DE PS-MADRID}

El 28 de marzo de 1939, las tropas franquistas entraron en Madrid y la ocuparon en los cuatro días siguientes. Durante esos mismos días, entraron, también, en Madrid, los equipos de recuperación de documentos.

Tomás Owens y Pérez del Pulgar, II Conde del Zenete, fue nombrado, por Marcelino de Ulibarri, director del Archivo de la Delegación en Madrid, cargo que ostentó hasta el cierre del mismo, casi durante dos años, de agosto de 1939 a octubre de 1941. El Archivo de la Delegación en Madrid se instaló, el 4 de abril de 1939, en el número cuatro de la céntrica calle Manuel Silvela, donde también se alojó todo el personal allí desplazado. Además, se abrieron unos depósitos documentales, o archivos auxiliares, en el número siete de la calle Santa Engracia, paralela a la calle Manuel Silvela, cuyos depósitos se encontraban a la misma altura del Archivo de la Delegación en Madrid ${ }^{286}$.

Los equipos de recuperación de documentos que actuaron en la capital fueron los encabezados por Francisco Aizcorbe Iriarte, Prudencio Arza Arbe, Cecilio Chapinal

${ }^{285}$ CDMH. AGGCE. DNSD. Secretaría. Correspondencia. Caja 551-595. Legajo 35. Expediente 564.

${ }^{286}$ Miguel Rosillo y Ortiz de Cañabate, I Conde del Rosillo, ofreció el edificio de Compañía de Seguros La Equitativa, más conocido por haber sido la sede central del Banco Español de Crédito (BANESTO), aseguradora de la que era presidente, ubicado en la esquina de la calle Sevilla con la calle Alcalá, para sede del Archivo de la Delegación en Madrid, así como su casa del número 37 de la calle Lista (actual calle Ortega y Gasset) y su casa del número 1 de la calle Padilla, en el barrio de Salamanca, para albergar al personal del Archivo. Finalmente, la oferta fue rechazada por Marcelino de Ulibarri. Se deconoce el por qué fue rechazada esta oferta. Sobre la sede del Archivo de la Delegación en Madrid, véase CDMH. AGGCE. DNSD. Secretaría. Correspondencia. Caja 125-200. Legajo 7. Expedientes 154, 156 y 159. 
García, Andrés Corsino de la Riera Álvarez, Manuel Durán Bravo, Alfredo Ramón Laca Primo, Augusto Nieto Cortés, Manuel Quero y Simón, Rafael Romero Fernández y Jesús Ongay Arbe.

Entre abril y septiembre de 1939, los equipos de recuperación de documentos realizaron más de 1.000 registros por todo Madrid, casi dos registros diarios, que fueron muchos más durante los casi dos años que el Archivo de la Delegación estuvo abierto en Madrid $^{287}$.

Entre la documentación requisada en Madrid, cabe destacar la siguiente:

- Documentación de carácter político y sindical:

- La documentación de la CNT de Madrid.

- La documentación de la Asociación Socialista Madrileña ${ }^{288}$.

- Un legajo con correspondencia e informes de Alejandro Lerroux, entre ellos, el relativo a la preparación de la represión de la Revolución de Asturias de 1934.

- Documentación de carácter administrativo:

- Desde los organismos centrales de la Administración General del Estado, también, se envió, directamente, al Archivo central de la Delegación en Salamanca, documentación de la Administración del Estado del Gobierno republicano, en concreto, documentación del Ministerio de Obras Públicas (correspondencia oficial), el 12 de julio de $1940^{289}$; del Ministerio de Agricultura (expropiación de fincas rústicas), el 26 de mayo de 1941, enviados por ferrocarril ${ }^{290}$; y, del Banco de España ${ }^{291}$.

- Toda la documentación de la Dirección General de Prisiones durante la II República ${ }^{292}$.

\footnotetext{
${ }^{287}$ Sobre la formación de los equipos de recuperación de documentos en Madrid, véase CDMH. AGGCE. DNSD. Secretaría. Correspondencia. Caja 501-550. Legajo 33. Expediente 514.

${ }^{288}$ CDMH. AGGCE. DNSD. Secretaría. Correspondencia. Caja 501-550. Legajo 33. Expediente 514.

${ }^{289}$ CDMH. AGGCE. DNSD. Secretaría. Correspondencia. Caja 201-230. Legajo 10. Expediente 230.

${ }^{290}$ CDMH. AGGCE. DNSD. Secretaría. Correspondencia. Caja 1580-1600. Legajo 68. Expediente 1617.

${ }^{291}$ CDMH. AGGCE. DNSD. Secretaría Correspondencia. Caja 1250-1379. Legajo 62. Expediente. 1332.

${ }^{292}$ CDMH. AGGCE. DNSD. Secretaría. Correspondencia. Caja 501-550. Legajo 33. Expediente 514.
} 
- La documentación de la secretaría política y particular de Ángel Galarza, con correspondencia y asuntos relacionados con la Dirección General de Seguridad ${ }^{293}$.

- Documentación de carácter militar:

- Toda la documentación militar de la Región Militar de Madrid.

- La documentación de las $26^{\mathrm{a}}, 34^{\mathrm{a}}, 40^{\mathrm{a}}$ y $146^{\mathrm{a}}$ Brigadas Mixtas.

- Documentación de carácter periodístico:

- Prensa, ediciones de los principales diarios madrileños, y fotografías.

- La documentación de Unión Radio, entre la que se podía encontrar las conferencias que dictó, por radio, Consuelo Zapala Martínez, en la noche del 03 de julio de 1937, con el tema "Labor a realizar en los Ateneos Libertarios"; la segunda, en la noche de 14 de agosto de 1937, con el tema "Méjico, nación hermana"; y, la tercera, en la noche del 18 septiembre de 1937, con el tema "Sacrifiquémonos por los niños"294.

Del 13 al 18 de septiembre de 1939, ambos inclusive, se produjo el primer gran envío de documentación incautada. En varios viajes diarios y en camiones, llegaron, a Salamanca. Y, la documentación incautada fue enviada, de manera regular, casi diariamente, a Salamanca, durante el bienio 1940-1941 295 .

En octubre de 1941, el Archivo de la Delegación en Madrid fue "liquidado" o cerrado, siendo enviada toda la documentación que en él se custodiaba al Archivo central de Salamanca.

La Delegación y sus equipos de recuperación de documentos se encontraron, como ya había sucedido en otros lugares y frentes de guerra, con otros organismos interesados en incautar la misma documentación, como la Brigada Político-Social de la Dirección General de Seguridad, el Servicio de Información y Policía Militar (SIMP) y la Falange (FET de las JONS), organismos que acabaron entregando la documentación que habían incautado a la Delegación.

${ }^{293}$ CDMH. AGGCE. DNSD. Secretaría. Correspondencia. Caja 501-550. Legajo 33. Expediente 514.

${ }^{294}$ CDMH. AGGCE. DNSD. Secretaría. Correspondencia. Caja 451-500. Legajo 32. Expediente 490. Las colecciones completas de los diarios madrileños El Liberal y El Heraldo de Madrid, cuya publicación finalizó en el año 1939, entre otros periódicos, ya se encontraban, por aquellas fechas, depositados en el Archivo central de Salamanca, en CDMH. AGGCE. DNSD. Secretaría. Correspondencia. Caja 501-550. Legajo 33. Expediente 514.

${ }^{295}$ CDMH. AGGCE. DNSD. Secretaría. Correspondencia. Caja 501-550. Legajo 33. Expediente 514. 
Por otra parte, el 17 de mayo de 1940, la Sección 4ª, Antimarxismo, de la Comisaría General de Información de la Dirección General de Seguridad del Ministerio de la Gobernación entregaba, al Archivo de la Delegación en Madrid, documentación procedente de la Jefatura Provincial de FET de las JONS en Barcelona, que, a su vez, había sido remitida por el Jefe Superior de Policía de Barcelona a la Dirección General de Seguridad ${ }^{296}$.

Además, entre julio y noviembre de 1940, el Archivo de la Delegación en Madrid sirvió de intermediario, y parece ser que lo fue en más de una ocasión, para el envío de documentación procedente del Servicio Histórico Militar, dirigido entonces por el coronel Nicolás Benavides, Jefe del Archivo Histórico Militar de Madrid, al Archivo central en Salamanca ${ }^{297}$.

\subsection{LA REQUISICIÓN EN SANTANDER: PS-SANTANDER}

Las tropas franquistas, a pesar de la resistencia del Comandante militar de Santander, José García Vayas, entraron en la ciudad de Santander el 28 de agosto de 1937.

Los equipos de recuperación de documentos, que acompañaron al Ejército franquista, realizaron 168 registros en la capital cántabra.

Entre la documentación requisada en Santander, cabe destacar la siguiente:

- Toda la documentación de la "Sección de Cultura de Santander", relacionada con el magisterio y los maestros santanderinos ${ }^{298}$.

- Documentación judicial, como, por ejemplo, la del Juzgado de la localidad cántabra de Arredondo ${ }^{299}$.

\footnotetext{
${ }^{296}$ CDMH. AGGCE. DNSD. Secretaría. Correspondencia. Caja 501-550. Legajo 33. Expediente 514.

${ }^{297}$ CDMH. AGGCE. DNSD. Secretaría. Correspondencia. Caja 501-550. Legajo 33. Expediente 514. El 27 de noviembre de 1940, "en el Camión Dodge, matrícula PMM 3684, se mandaba a Salamanca, desde el Archivo de la Delegación en Madrid, 10 sacos de documentación procedentes del Servicio Histórico Militar", en CDMH. AGGCE. DNSD. Secretaría. Correspondencia. Caja 501-550. Legajo 33. Expediente 514. Sobre PS-Madrid, véase ESPINOSA ROMERO, Javier., "La Delegación del Estado para Recuperación de Documentos en Madrid", en AA.VV., Madrid, una ciudad en guerra, 1936-1939. Madrid, Catarata, 2016. pp. 133-158.
}

${ }^{298}$ CDMH. AGGCE. DNSD. Secretaría. Correspondencia. Caja 201-230. Legajo 9. Expediente 215. 
- Toda la documentación de los Astilleros de Santander ${ }^{300}$.

- Además, fue incautada y enviada, al Archivo central de Salamanca, toda la documentación del Tribunal Popular de Euzkadi, compuesta por

la relación de procesados, condenados y absueltos por el citado Tribunal Popular, información sobre militares de la Comandancia Militar de Guipúzcoa e información sobre ejecutados que habían apoyado el alzamiento y la sublevación militar ${ }^{301}$.

A poco más de un mes de la toma de Santander por las tropas franquistas, Jaime Murillo, Comandante-Jefe de los Servicios de Orden y Policía del Ejército de Ocupación en Santander, colaborando con Recuperación de Documentos, envió la primera documentación incautada, desde Santander a Salamanca ${ }^{302}$.

\subsection{LA FORMACIÓN DE PS-VALENCIA}

Las tropas franquistas entraron y ocuparon la ciudad de Valencia el 29 de marzo de 1939.

En los primeros días del mes de abril, Manuel Martín Sastre fue nombrado director del Archivo de la Delegación en Valencia, ubicado en el número tres de la calle Luis Vives $^{303}$. Martín Sastre se alojó en el número seis de la calle Caballeros, situada a siete minutos, por la calle de San Vicente Mártir, del Archivo de la Delegación en Valencia, en casa de su amigo y colaborador Pascual Serrano ${ }^{304}$. Manuel Martín Sastre dirigió los

${ }^{299}$ CDMH. AGGCE. DNSD. Secretaría. Correspondencia. Caja 1931-2059. Legajo 124. Expediente 2012.

${ }^{300}$ CDHM. AGGCE. DNSD. Secretaría. Correspondencia. Caja 1380-1481. Legajo 63. Expediente 1402.

${ }^{301}$ CDMH. AGGCE. DNSD. Secretaría. Correspondencia. Caja 033-072. Legajo 4. Expediente 52. En la actualidad, el Tribunal Popular de Euzkadi es un fondo más dentro la Sección Político-Social del Archivo General de la Guerra Civil Española, como lo es el propio PS-Santander.

${ }^{302}$ Sobre la Guerra Civil en Santander, véase la obra Solla GutiéRREZ, Miguel Ángel., La República sitiada: trece meses de Guerra Civil en Cantabria, julio de 1936-agosto de 1937. Santander, PubliCan, 2010.

${ }^{303}$ CDMH. AGGCE. DNSD. Secretaria. Correspondencia. Caja 596-659. Legajo 37. Expediente 622.

${ }^{304}$ CDMH. AGGCE. DNSD. Secretaría General. Expedientes Secretaría. Caja S.G. 001-045. Legajo 1. Expediente 6. 
equipos de recuperación de documentos, formados y desplazados a la capital levantina, desde Salamanca.

El Archivo de la Delegación en Valencia contó con dos archivos auxiliares, o depósitos de documentos: uno, instalado en la antigua Casa Hospicio de la Misericordia, en el número cuatro de la Plaza de San Miguel; y, otro, en el Gobierno Militar de Valencia, en el número ocho de la calle del Justicia ${ }^{305}$.

El 16 de mayo de 1939, los equipos de recuperación de documentos comenzaron a realizar registros e incautaciones de documentos en las localidades cercanas a Valencia, en concreto, en las localidades de Beniarjó, Bocairente, Domeño, Godella, Navarrés, Oliva, Puebla del Duc, Villanueva de Castellón y Zarra. Y, en Dos Aguas, desde Valencia por Buñol, se incautaron de documentación política y sindical:

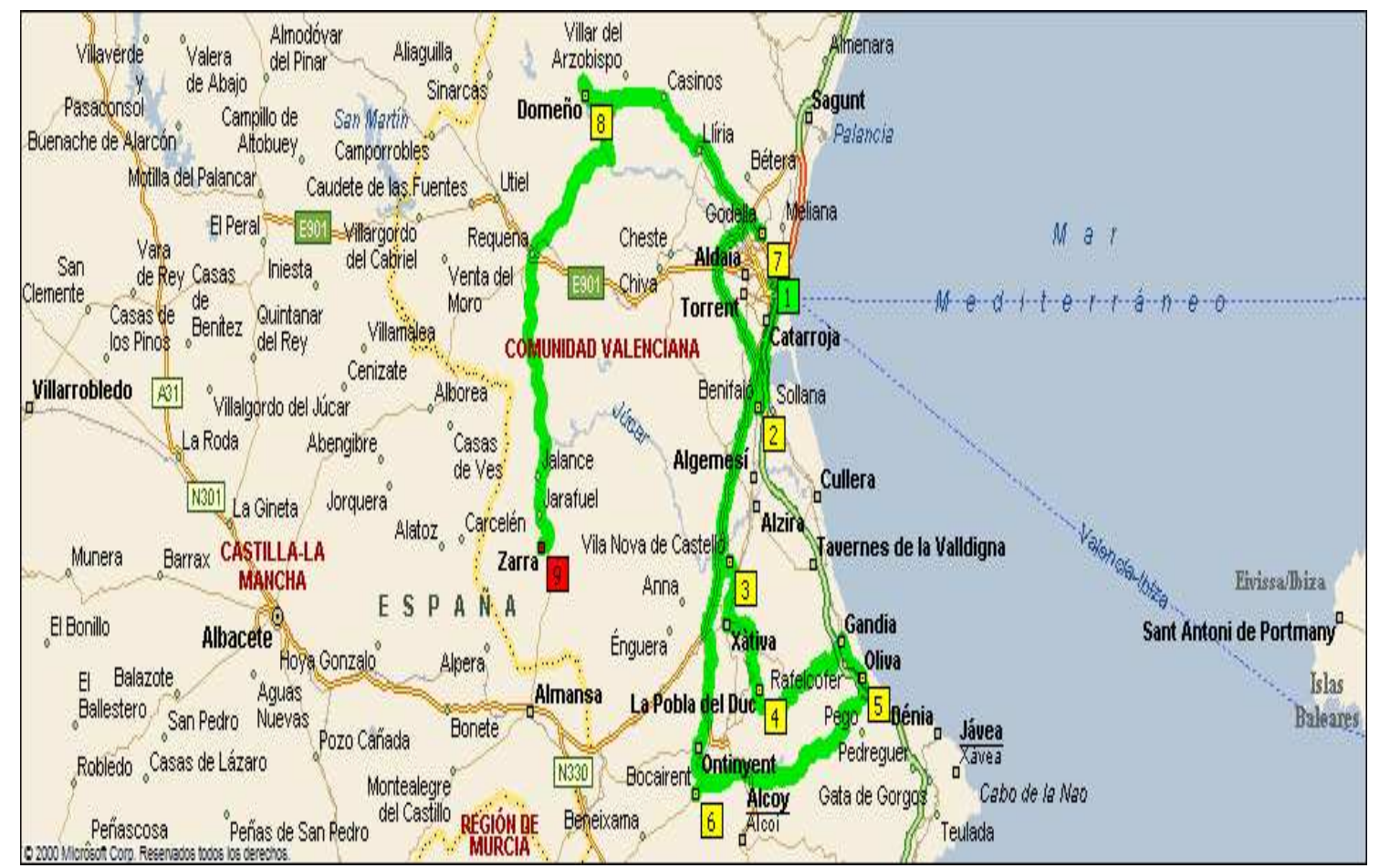

Mapa 5.21. 16.05.1939. Expediciones requisitorias. Itinerario Valencia-BenifayóVillanueva de Castellón-Puebla del Duc-Oliva-Bocairente -Godella-Domeño-Zarra ${ }^{306}$

\footnotetext{
${ }^{305}$ CDMH. AGGCE. DNSD. Secretaría. Correspondencia. Caja 1250-1379. Legajo 62. Expediente 1324; y, Secretaría. Correspondencia. Caja 551-595. Legajo 35. Expediente 556.

${ }^{306}$ CDMH. AGGCE. DNSD. Secretaría General. Expedientes Secretaría. Caja S.G. 001-045. Expediente 6.
} 


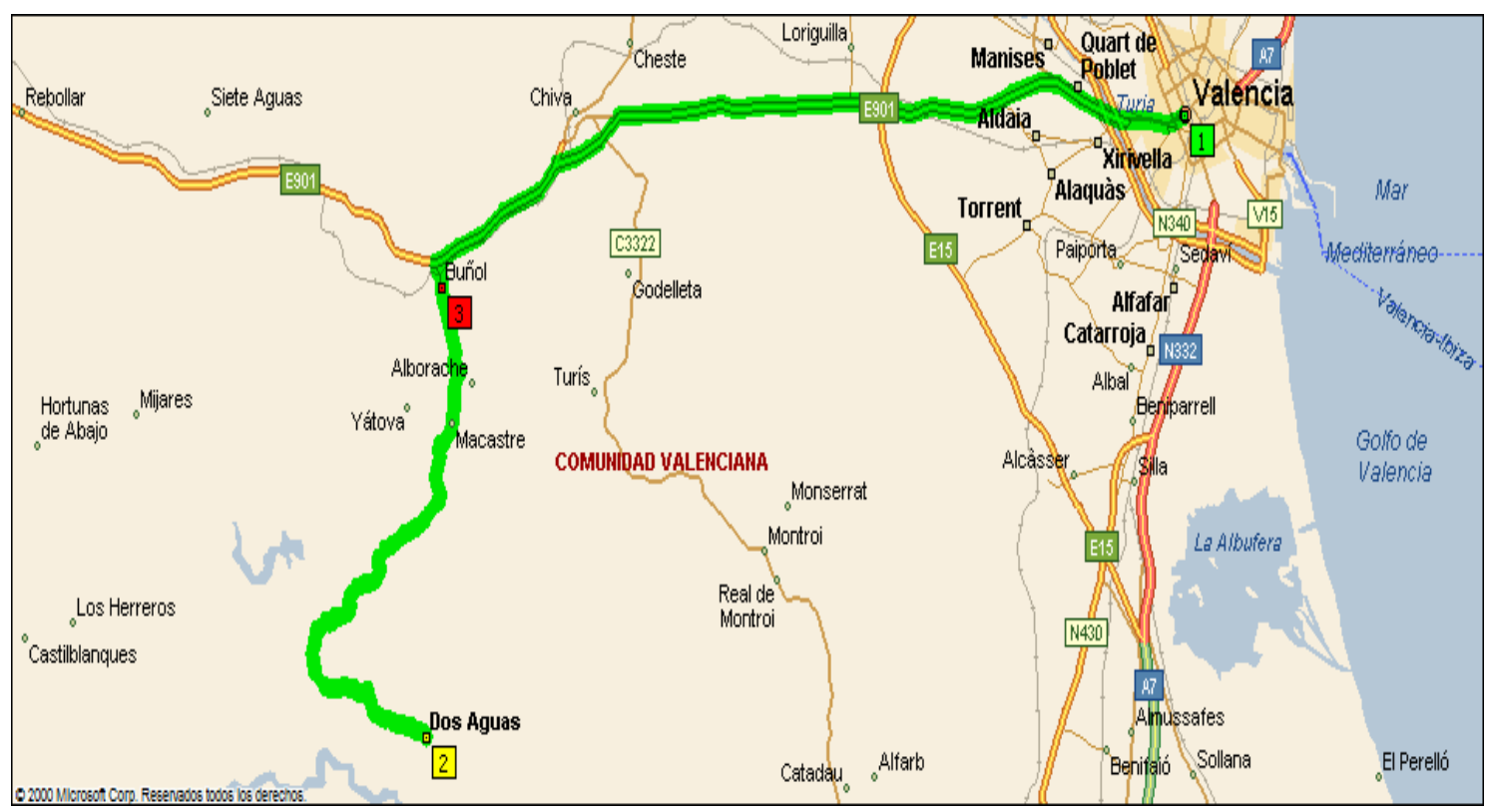

Mapa 5.22. 16.05.1939. Expediciones requisitorias. Itinerario Valencia-Dos Aguas-Buñol

Simultáneamente, continuaron los registros en la ciudad de Valencia. En concreto, en mayo de 1939, se registraron "el número 148 de la calle San Vicente Mártir, el domicilio de Francisco Sebastián Bonafé, la logia Federación Levantina y los bajos de la calle del Conde de Montornés, números 14, 16, 18 y 19״307.

Entre la documentación requisada en Valencia, cabe destacar la siguiente:

- Documentación masónica, en concreto, la incautación de la documentación del político y masón Diego Martínez Barrio, Presidente del Congreso de los Diputados, del 16 de marzo de 1936 al 31 de marzo de 1939, y Presidente de la República en el exilio, del 17 de agosto de 1945 al 1 de enero de $1962^{308}$.

- Documentación de carácter militar y policial, de la 74ª Brigada Mixta y del Cuerpo de Carabineros de Valencia.

- Documentación política, la documentación de Izquierda Republicana y el Partido Socialista Obrero Español de la localidad de Dos Aguas ${ }^{309}$.

\footnotetext{
${ }^{307}$ CDMH. AGGCE. DNSD. Secretaria. Correspondencia. Caja 596-659. Legajo 37. Expediente 622.

${ }^{308}$ CDMH. AGGCE. DNSD. Secretaria. Correspondencia. Caja 596-659. Legajo 37. Expediente 622.

${ }^{309}$ CDMH. AGGCE. DNSD. Secretaría. Correspondencia. Caja 1380-1481. Legajo 63. Expediente 1394.
} 
- Documentación sindical:

. La documentación de la Federación de Trabajadores Campesinos de Valencia.

• Y, la documentación de la UGT y la CNT de la localidad de Dos Aguas ${ }^{310}$.

El día 15 de abril de 1939, se realizó el primer envío de documentación incautada, en Valencia, al Archivo central de Salamanca, un camión cargado de documentación masónica, que, a media tarde, había llegado a Salamanca ${ }^{311}$.

Cinco días más tarde, el 20 de abril, otro camión, cargado con el resto de la documentación masónica, salió para Salamanca ${ }^{312}$.

Marcelino de Ulibarri envió, el 25 de mayo, a Manuel Martín Sastre, "la Guía de los Transportes Militares y un talón resguardo de ferrocarriles"313. La documentación incautada en Valencia se enviaría, a partir de ese momento, por ferrocarril, al Archivo central de Salamanca.

El 18 de agosto, se enviaban, por ferrocarril, a Salamanca, "cuatro cajas, conteniendo toda la documentación depositada en el Archivo del Gobierno Militar de Valencia”, que llegaron en el día ${ }^{314}$.

El volumen de documentación requisada y de trabajo preocupaba a Martín Sastre: "la documentación, existente en Valencia, es más considerable de lo que podíamos pensar" 315 , afirmaba. Pensaba que con ese volumen de documentación se llenarían "tres o cuatro vagones" ${ }^{316}$. Finalmente, Marcelino de Ulibarri -como se ha expuesto- acabaría

\footnotetext{
${ }^{310}$ CDMH. AGGCE. DNSD. Secretaría. Correspondencia. Caja 1380-1481. Legajo 63. Expediente 1394.

${ }^{311}$ CDMH. AGGCE. DNSD. Secretaría General. Expedientes Secretaría. Caja S.G. 001-045. Legajo 1. Expediente 6.

${ }^{312}$ CDMH. AGGCE. DNSD. Secretaría General. Expedientes Secretaría. Caja S.G. 001-045. Expediente 6.

${ }^{313}$ CDMH. AGGCE. DNSD. Secretaría. Correspondencia. Caja 596-659. Legajo 37. Expediente 614.

${ }^{314}$ CDMH. AGGCE. DNSD. Secretaría. Correspondencia. Caja 551-595. Legajo 35. Expediente 556.

${ }^{315}$ CDMH. AGGCE. DNSD. Secretaría General. Expedientes Secretaría. Caja S.G. 001-045. Expediente 6.

${ }^{316}$ CDMH. AGGCE. DNSD. Secretaría General. Expedientes Secretaría. Caja S.G. 001-045. Expediente
} 6. 
atendiendo la petición de Manuel Marín Sastre, y la documentación sería enviada por ferrocarril a Salamanca.

A las once de la noche del 28 de septiembre, salió de la estación de tren de Valencia, con destino a Salamanca, un tren con tres vagones ${ }^{317}$, con más de 200 sacos de documentación incautada, sacos que había entregado, al Archivo de la Delegación en Valencia, el Coronel Jefe de los Servicios de Intendencia de la $3^{\text {a }}$ Región Militar $^{318}$.

El último envío de documentación a Salamanca ${ }^{319}$, fue el realizado, por José María Ibarra y Foljado, el 27 de julio de 1940, fecha en la que el Archivo de la Delegación en Valencia fue cerrado ${ }^{320}$.

Por otra parte, hay que señalar que, a partir del día 6 de junio de 1940, llegó, al Archivo de la Delegación en Madrid, gran parte de toda la documentación del Archivo de la Delegación en Valencia, ya que se estaba procediendo a su "liquidación" o cierre. Estos envíos de documentación, procedentes del Archivo de la Delegación en Valencia, fueron realizados por Pascual Serrano, amigo y colaborador de Manuel Martín Sastre ${ }^{321}$. Entre la documentación enviada a Madrid, destaca la documentación de la 97 ${ }^{\text {a }}$ Brigada Mixta, del Tribunal Permanente de Valencia, del Cuerpo de Seguridad y del Cuerpo de Carabineros, del XVII Cuerpo del Ejército Republicano ${ }^{322}$, y documentación masónica,

los Libros de Actas del primer grado simbólico de la logia Cruz de Hierro; las Actas de la elección de la Diputación, para el Congreso masónico del 1 de octubre de 1890, en Madrid; el Acta de inauguración y constitución de la Logia Puritana II de Valencia; una carpeta de Aurelio Blasco Grajales, con importantes documentos masónicos; varios expedientes de iniciación, del año 1891; un libro con fotografías de la Escuela Sabática de la Iglesia Adventista de Valencia, del año 1929; y

\footnotetext{
${ }^{317}$ Los tres vagones, facilitados por Transportes Militares y la Inspección de Ferrocarriles fueron los siguientes: J 11375; J 17022; y, K 7788),

${ }^{318}$ CDMH. AGGCE. DNSD. Secretaría General. Expedientes Secretaría. Caja S.G. 001-045. Expediente 6.

${ }^{319}$ CDMH. AGGCE. DNSD. Secretaria. Correspondencia. Caja 596-659. Legajo 37. Expediente 622.

${ }^{320}$ CDMH. AGGCE. DNSD. Secretaría. Correspondencia. Caja 1250-1379. Legajo 62. Expediente 1324.

${ }^{321}$ CDMH. AGGCE. DNSD. Secretaría. Correspondencia. Caja 501-550. Legajo 33. Expediente 514.

${ }^{322}$ CDMH. AGGCE. DNSD. Secretaría. Correspondencia. Caja 501-550. Legajo 33. Expediente 514.
} 


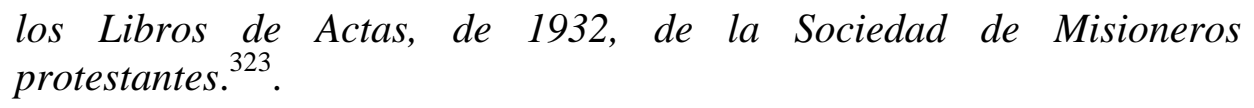

Parece ser que -se desconoce si con el consentimiento de Manuel Martín Sastre-, Pascual Serrano se había puesto un pequeño despacho en la planta baja del Gobierno Civil de Valencia, en el que, por las tardes, seleccionaba documentación masónica, entre ella, la de Aurelio Blasco Grajales, de protestantes, naturistas, etc., además de trabajar en un fichero político-social, con fichas, entre otros, de milicianos republicanos voluntarios, con filiaciones políticas bien definidas y que pudieran, por ello, tener responsabilidades judiciales, fichero que "completaría al magnífico Fichero ya existente" ${ }^{324}$.

\subsection{LA REQUISICIÓN EN VINAROZ: PS-VINAROZ}

Tras la derrota del Ejército republicano en la batalla de Teruel, que tuvo lugar del 15 de diciembre de 1937 al 22 de febrero de 1938, las tropas franquistas avanzaron, por el Maestrazgo hacia Castellón, llegando a Vinaroz el 15 de abril de 1938.

El 11 de mayo de 1938, llegaron, procedentes de la Delegación salmantina, a Vinaroz, los equipos de recuperación de documentos. En la zona, trabajaron tres equipos de recuperación de documentos, al frente de los cuales estuvieron:

· Juan Queralt Oliva.

- Juan Fuentes Bertrán.

· Y, Francisco Salinas Quijada ${ }^{325}$.

El día 18 de mayo, Francisco Salinas Quijada se entrevistó, en el Cuartel General de Antonio Aranda Mata, con dos miembros de su Estado Mayor: el comandante

\footnotetext{
${ }^{323}$ CDMH. AGGCE. DNSD. Secretaría General. Expedientes Secretaría. Caja S.G. 001-045. Legajo 1. Expediente 6.

${ }^{324}$ CDMH. AGGCE. DNSD. Secretaría General. Expedientes Secretaría. Caja S.G. 001-045. Legajo 1. Expediente 6. Sobre Valencia en la Guerra Civil española, véase AZNAR SolER, Manuel., Valencia capital de la República. Valencia, Publicaciones de la Universidad, 2007.

325 CDMH. AGGCE. DNSD. Administración. Expedientes. Caja ADMON 371-430. Legajo 17. Expediente 414.
} 
Villalonga y el teniente Lasa, para poder actuar en la zona. La caída de las localidades de Villafranca del Cid y de Castellfort era inminente.

El 20 de mayo de 1938, el equipo de recuperación de documentos de Salinas se puso de camino hacia Villafranca del Cid, situada a 90 kilómetros de distancia al oeste de Vinaroz, pero como Francisco Salinas "no tenía certeza de que estuviera liberado, $[. .$.$] y$ las carreteras no estaban libres para poder circular, [...] desistí el viaje". Además, existía el riesgo real de que se produjera "la visita diaria de los aviones rojos"326.

A las doce de la mañana del día siguiente, 21 de mayo, llegaron noticias de que las señaladas localidades de Villafranca del Cid y de Castellfort habían caído en manos del Ejército franquista. Francisco Salinas ordenó a su equipo de recuperación de documentos que estuviese preparado para viajar al día siguiente.

Mientras los equipos de recuperación de documentos de Juan Queralt Oliva y Juan Fuentes Bertrán marcharon a Castellfort, a pesar del fuerte viento y del mal tiempo, el equipo de recuperación de documentos de Francisco Salinas salió a las nueve de mañana del domingo 22 de mayo desde Vinaroz con destino a Villafranca del Cid.

En Villafranca del Cid, el equipo de recuperación de documentos registró las sedes de:

- El partido Izquierda Republicana.

- Las Juventudes Libertarias.

- Los sindicatos UGT y CNT.

Durante una semana, del 23 al 29 de mayo, los equipos de recuperación de documentos permanecieron en Vinaroz a la espera de noticias del frente, que se encontraba “estabilizado, parado" 327 : sólo el equipo de recuperación de documentos de Queralt se desplazó, siguiendo la línea de la costa, a la cercana Benicarló, a nueve kilómetros al sur de Vinaroz, para continuar con los trabajos de incautación de documentos, muy avanzados ya, pues se habían comenzado el día 21 de mayo.

${ }^{326}$ CDMH. AGGCE. DNSD. Administración. Expedientes. Caja ADMON 371-430. Legajo 17. Expediente 414.

327 CDMH. AGGCE. DNSD. Administración. Expedientes. Caja ADMON 371-430. Legajo 17. Expediente 414. 
Finalmente, el 30 de mayo, llegaron noticias del frente: habían caído las localidades de Ares del Maestre, Benasal y Culla. Esa misma tarde del día 30 de mayo, mientras Francisco Salinas preparaba a su equipo de recuperación de documentos para viajar al día siguiente a las citadas localidades de Ares del Maestre, Benasal y Culla, Juan Fuentes se trasladó a Traiguera, localidad situada a 18 kilómetros al noroeste de Vinaroz, "a traer la documentación que en ese pueblo nos guardaba el Alcalde"328.

Al día siguiente, el equipo de recuperación de documentos de Francisco Salinas salió hacia Ares del Maestre, a 76 kilómetros de Vinaroz; Benasal, a 69 kilómetros de Vinaroz; y, Culla, a 78 kilómetros de Vinaroz. En Ares del Maestre no se pudo entrar ese día, ya que "el camino provisional tenía los puentes rotos" 329 , por lo que el equipo de recuperación de documentos se desplazó a Benasal y a Culla, nueve kilómetros al sur de Benasal.

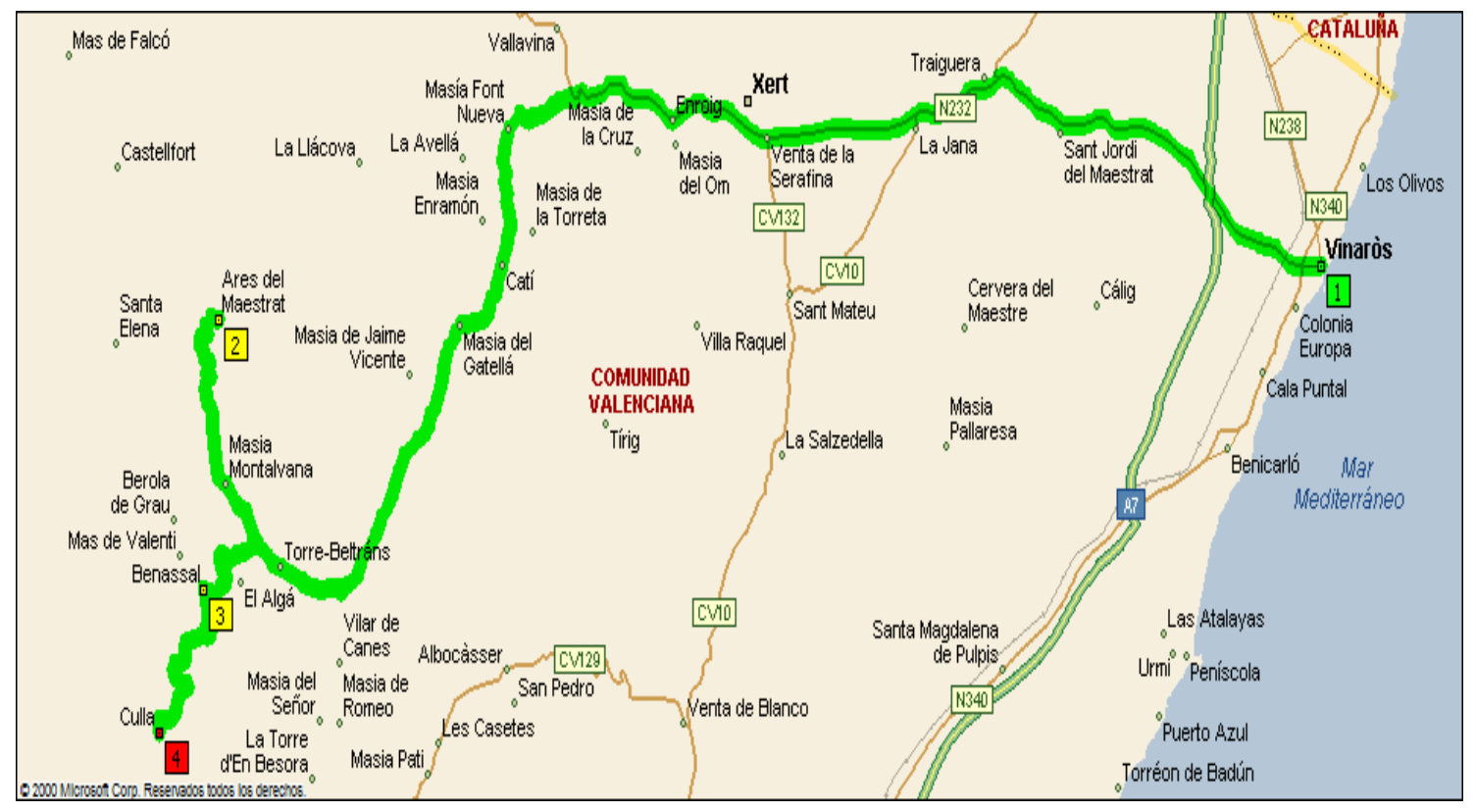

Mapa 5.23. 31.05.1938. Expedición requisitoria. Equipo de Salinas Itinerario Vinaroz-Ares del Mestre-Benasal-Culla

\footnotetext{
328 CDMH. AGGCE. DNSD. Administración. Expedientes. Caja ADMON 371-430. Legajo 17. Expediente 414.

329 CDMH. AGGCE. DNSD. Administración. Expedientes. Caja ADMON 371-430. Legajo 17. Expediente 414.
} 
De esta forma, continuaron desarrollándose los trabajos de recuperación de documentos en la comarca del Bajo Maestrazgo, con capital en Vinaroz, hasta mediados del mes de junio de 1938.

La documentación que fue requisada pertenecía, principalmente, a los sindicatos UGT y CNT, establecidos en las localidades de la $\operatorname{comarca}^{330}$. Y, también, fue requisada toda la documentación municipal de Vinaroz.

Apenas un año después, el alcalde de Vinaroz solicitó la devolución de la documentación municipal al director de la Delegación en Salamanca ${ }^{331}$. Esos documentos ya formaban parte de los fondos de la Delegación.

\section{LA REQUISICIÓN REALIZADA POR LOS MILITARES: PS-MILITAR O SERIE MILITAR}

La agrupación documental PS-Militar, o Serie Militar, es aquella perteneciente a las unidades de los Ejércitos, tanto franquista como republicano, que actuaron en el frente de guerra, y que, tras su incautación, por los servicios de recuperación de documentos, no fue transferida al actual fondo del Servicio Histórico Militar del Archivo General Militar de Madrid ${ }^{332}$.

La Delegación, en Salamanca, transfirió toda la documentación relativa al Estado Mayor Central del Ejército y la documentación relacionada con los expedientes personales de los militares u hojas de servicio, durante los años que duró la Guerra Civil, de 1936 a 1939, al entonces Servicio Histórico Militar. La Delegación transfirió documentación al Servicio Histórico Militar desde febrero del año 1940 hasta junio de $1946^{333}$.

${ }^{330}$ CDMH. AGGCE. DNSD. Administración. Expedientes. Caja ADMON 371-430. Legajo 17. Expediente 414.

${ }^{331}$ CDMH. AGGCE. DNSD. Secretaría. Correspondencia. Caja 1380-1481. Legajo 63. Expediente 1391.

${ }^{332}$ De éste, a su vez, la documentación fue trasladada, en 1993, al Archivo General Militar de Ávila, cuyo núcleo de documentos fundacional procede, por tanto, de los documentos de la Guerra Civil española que formaron parte de esta Serie Militar, o PS-Militar, del Archivo central de Salamanca.

${ }^{333}$ CDMH. AGGCE. DNSD. Secretaría. Correspondencia. Caja 1806. Legajo 73. Expediente 1806. 
En abril de 1940, Jorge Vigón Suero-Díaz, militar, Teniente Coronel de Artillería y futuro Ministro de Obras Públicas de 1957 a 1967, solicitaba, a la Delegación, en Salamanca, la devolución de su Archivo personal. La Delegación le contestaba que

entre la documentación clasificada, bastante numerosa, no figura nada que haga mención al Sr. Vigón, y el resto de ella está sin clasificar en el depósito de San Esteban. No obstante, también le hacían saber, que una pequeña parte de la documentación ya había sido entregada al Servicio Histórico Militar, en Madrid, donde quizá podría encontrarla. ${ }^{334}$.

Efectivamente, así fue: Jorge Vigón localizó parte de su Archivo personal en el Servicio Histórico Militar de Madrid.

El 17 de enero de 1941, ingresó, en la Delegación, la documentación de la Comandancia Militar de Talavera de la Reina (Toledo), a través del Servicio Histórico Militar de Madrid $^{335}$. Dos años y dos meses después, en marzo de 1943, la Delegación transfirió, al Servicio Histórico Militar, toda la documentación de la Comandancia Militar de Figueras (Gerona), producida durante la II República y la Guerra Civil, es decir, de 1931 a $1939^{336}$. La documentación de las Comandancias Militares indicadas corrió caminos inversos. En febrero de ese mismo año de 1941, se enviaron, desde la Delegación, dos camiones llenos de sacos de documentación, al Servicio Histórico Militar $^{337}$.

En octubre de 1943, el Director del Servicio Histórico Militar solicitaba a Marcelino de Ulibarri, que

transfiriera la documentación personal de los Cuerpos de la Policía Armada, Guardia Civil y Carabineros al Juzgado de Inspección General y de la Policía Armada y de Tráfico de la Dirección General de Seguridad, sito en la calle Fernando III el Santo, $n^{\circ} 23$, de Madrid ${ }^{338}$.

\footnotetext{
${ }^{334}$ CDMH. AGGCE. DNSD. Secretaría. Correspondencia. Caja 660-692. Legajo 39. Expediente 674.

${ }^{335}$ CDMH. AGGCE. DNSD. Secretaría. Correspondencia. Caja 1806. Legajo 73. Expediente 1806.

${ }^{336}$ CDMH. AGGCE. DNSD. Secretaría. Correspondencia. Caja 1250-1379. Legajo 62. Expediente 1339.

${ }^{337}$ CDMH. AGGCE. DNSD. Secretaría. Correspondencia. Caja 1806. Legajo 73. Expediente 1806.

${ }^{338}$ CDMH. AGGCE. DNSD. Secretaría. Correspondencia. Caja 1066-1149. Legajo 57. Expediente 1094. En 1945, el Coronel del Estado Mayor, Juan Diego, era el Director accidental del Servicio Histórico
} 
Tanto la Policía Armada como el Cuerpo de Carabineros sufrieron una gran depuración, desde agosto de 1940 hasta abril de 1957.

Procedente de la Delegación en Salamanca, al Servicio Histórico Militar de Madrid, se transfirieron los siguientes fondos documentales, de interés militar: la documentación del Cuerpo del Ejército de Guadarrama ${ }^{339}$; la documentación de los Regimientos de Infantería Was-Ras, $n^{\circ} 1$, León, $n^{\circ} 2$, Covadonga, $n^{\circ} 4$ y Centro de Movilización, $n^{\circ} 1$, republicanos; la documentación de la Pagaduría del Cuartel General del Ejército del Centro y de la Pagaduría Central del Ministerio del Ejército, ubicada en la calle de Alcalá, $\mathrm{n}^{\text {o }}$ 65, de Madrid ${ }^{340}$; la documentación de la Subsecretaría de Marina del Ministerio de Marina de la República, encontrada en un local de la Base Militar de Rosas y de Cadaqués, en Gerona, donde iba a ser instalada la citada Subsecretaría ${ }^{341}$; la documentación sobre Hospitales militares y fichas de hospitalizados; la documentación de maniobras militares y cartografía, correspondiente al Estado Mayor Central del Ministerio de la Guerra ${ }^{342}$; la documentación de las brigadas internacionales $\left(23^{\mathrm{a}}\right.$ Brigada Mixta, 44 ${ }^{\text {a }}$ Brigada Mixta y $110^{\text {a }}$ Brigada Mixta) y los brigadistas internacionales, como la de los belgas Henri Boembeeke Eduard, ${ }^{343}$ Albert Hautem y Lucien Gilson ${ }^{344}$; documentación militar relativa a Portugal, Francia y los Estados Unidos, y hojas de servicios de militares, y de haberes, y sobre deserciones, de ambos bandos, que habían participado en la Guerra Civil ${ }^{345}$; documentación del Partido Unión Republicana $^{346}$; e incluso una carta del periodista y candidato a diputado por la circunscripción electoral de Huelva en las elecciones del 24 de noviembre de 1933,

Militar, en CDMH. AGGCE. DNSD. Secretaría. Correspondencia. Caja 1380-1481. Legajo 63. Expediente 1442.

${ }^{339}$ CDMH. AGGCE. DNSD. Secretaría. Correspondencia. Caja 326-352. Legajo 25. Expediente 333.

${ }^{340}$ CDMH. AGGCE. DNSD. Secretaría. Correspondencia. Caja 728-795. Legajo 45. Expediente 757.

${ }^{341}$ CDMH. AGGCE. DNSD. Secretaría. Correspondencia. Caja 910-990. Legajo 53. Expediente 953.

${ }^{342}$ CDMH. AGGCE. DNSD. Secretaría. Correspondencia. Caja 1806. Legajo 73. Expediente 1806.

${ }^{343}$ CDMH. AGGCE. DNSD. Secretaría. Correspondencia. Caja 910-990. Legajo 53. Expediente 956.

${ }^{344}$ CDMH. AGGCE. DNSD. Secretaría. Correspondencia. Caja 910-990. Legajo 54. Expediente 970. Parece ser que sobre el brigadista internacional Albert Hautem, ambos Archivos disponían de los mismos datos, lo que hace pensar en que quedara copia del expediente del citado brigadista en la Delegación.

${ }^{345}$ CDMH. AGGCE. DNSD. Secretaría. Correspondencia. Caja 1806. Legajo 73. Expediente 1806.

${ }^{346}$ CDMH. AGGCE. DNSD. Secretaría. Correspondencia. Caja 728-795. Legajo 45. Expediente 756. 
dirigida al sargento republicano Luis Cillán, fechada el 3 de noviembre de 1937, por la “interesante información que contenía sobre la Guerra, Franco y el Gobierno Republicano, 347 .

En junio de 1946, terminó la transferencia de documentación de la Delegación salmantina al Servicio Histórico Militar de Madrid. No obstante, casi catorce años después, en mayo de 1960, el Ministerio de Asuntos Exteriores solicitó, a través del Servicio Histórico Militar y la $2^{\text {a }}$ Sección, Información, del Estado Mayor Central del Ejército, "una relación nominal, e información, de los súbditos alemanes que formaron parte de las Brigadas Internacionales, lo cual interesa al Gobierno alemán de Bonn"348.

La colaboración entre la Delegación y el Servicio Histórico Militar llegaba definitivamente, de esta forma, a su fin. Sin embargo, esta colaboración tendría importantes consecuencias para el actual sistema archivístico español ${ }^{349}$.

\section{CONCLUSIONES}

Las conclusiones a las que se ha llegado en este capítulo son las siguientes:

I. Marcelino de Ulibarri y Eguílaz fue el encargado de, entre el personal del Archivo central de Salamanca y como director del mismo, formar los equipos de recuperación de documentos, encargados de realizar las requisiciones. Tanto en los frentes de guerra como en alguna de las grandes capitales conquistadas (Madrid y Valencia), la acción de los equipos de recuperación de documentos fue coordinada por Manuel Martín Sastre. Los equipos de recuperación de documentos estaban formados -como ya se ha

\footnotetext{
${ }^{347}$ CDMH. AGGCE. DNSD. Secretaría. Correspondencia. Caja 501-550. Legajo 33. Expediente 508.

${ }^{348}$ CDMH. AGGCE. DNSD. Secretaría. Correspondencia. Caja 2060-2064. Sin Legajo. Carpeta o Expediente 2064.

${ }^{349}$ En diciembre de 1994, el Archivo General Militar de Ávila, creado por la Instrucción General 1/1993, del Estado Mayor del Ejército, con sede en el Palacio de Polentinos (calle Vallespín, $\mathrm{n}^{\circ}$ 19), declarado Archivo Nacional, por el Real Decreto 2598/1998, de 4 de diciembre, por el que se aprueba el Reglamento de Archivos Militares, y dependiente del Instituto de Historia y Cultura Militar (creado por Orden 220/1997, de 12 de noviembre, del Ministerio de Defensa, publicada en el Boletín Oficial del Estado, $n^{\circ} 278$, de 20 de noviembre de 1997) recibió el primer envió de documentación procedente del Archivo General Militar de Madrid, Cuarta Sección o fondos del Servicio Histórico Militar, documentos de la Guerra Civil española, que, durante el periodo comprendido entre febrero del año 1940 y junio de 1946, fueron enviados por la Delegación salmantina al Servicio Histórico Militar.
} 
explicado- por un jefe, un asesor y ayudantes. El jefe, en la documentación estudiada, daba el nombre al equipo. Los equipos que más requisiciones realizaron fueron los siguientes:

\begin{tabular}{|l|l|l|}
\hline Nombre del equipo (jefe) & \multicolumn{1}{|c|}{$\begin{array}{c}\text { Número de } \\
\text { requisiciones }\end{array}$} & \multicolumn{1}{|c|}{ Áreas geográficas y capitales } \\
\hline Arza & Cuatro & $\begin{array}{l}\text { Aragón, Castellón, Lérida y Madrid } \\
\text { capital. }\end{array}$ \\
\hline Fuentes & Cuatro & $\begin{array}{l}\text { Aragón, Barcelona capital, Castellón } \\
\text { y Vinaroz. }\end{array}$ \\
\hline Queralt & Tres & Aragón Castellón y Vinaroz. \\
\hline Salinas & Tres & Extremadura, Lérida y Vinaroz. \\
\hline
\end{tabular}

Tabla 5.24. Equipos de recuperación de documento y sus áreas de actuación

II. Con la excepción de los casos concretos de las requisiciones realizadas en el Centro Israelita "Agudad Ahim” de Barcelona, en Cádiz, en Cartagena y en Jaén, y por regla general, los equipos de recuperación de documentos se desplazaron, desde Salamanca o desde otros frentes o capitales donde hubieran actuado previamente, a los frentes de guerra recientemente caídos y a las capitales tras ser inmediatamente tomadas:

En el caso de los frentes de guerra, los equipos de recuperación de documentos se desplazaban a los mismos. En una localidad estratégicamente situada, el jefe del primer equipo que llegaba a la zona, fijaba el campamento base para las futuras actuaciones en la zona de los equipos de recuperación de documentos, así como habilitaba uno o varios depósitos de la documentación por requisar. Asimismo, se entrevistaba él, o cada de jefe de equipo, con el general o generales que actuaban militarmente en la zona, para obtener los permisos y salvoconductos necesarios para que cada equipo de recuperación de documentos actuase en la zona. Una vez conseguido todo esto, la metodología propiamente dicha, seguida por los equipos de recuperación de documentos, en las zonas o áreas geográficas correspondientes a los frentes recién caídos, Aragón (Maestrazgo turolense), provincia de Castellón, Extremadura ("bolsa de la Serena", en Badajoz), Asturias, Lérida y Vinaroz (Bajo Maestrazgo castellonense), fueron las expediciones, en las que, a modo de razias, se procedía al registro de las localidades recién tomadas por el Ejército franquita, en busca de un botín en forma de documentación de interés. 
En el caso de las grandes ciudades y capitales de provincia, Madrid, Barcelona, Bilbao, Alicante y Santander, la metodología seguida por los equipos de recuperación de documentos fue la de dedicarse a la inspección sistemática de organismos oficiales y domicilios particulares, desde el primer momento en que las ciudades eran tomadas, ciudades donde también se habilitaron uno o varios locales a modo de depósitos documentales.

III. La documentación que fue requisada. La tipología de la documentación requisada es la siguiente:

- Documentación de carácter administrativo:

- Documentación de la Administración General del Estado durante la segunda República y la Guerra Civil (bando republicano): ministerios, delegaciones del gobierno, gobernadores civiles, Administración de Justicia, Tribunales Populares y Prisiones, Banco de España, Correos y Telégrafos (documentación oficial referente al organismo y correspondencia particular retenida en las estafetas de cada localidad), embajadas, consulados, etc.

Documentación de las diputaciones provinciales.

- Documentación municipal.

- Documentación de carácter político:

- Documentación de partidos políticos: Izquierda Republicana, Unión Republicana, Partido Republicano Radical Demócrata, Partido Socialista Obrero Español (PSOE), Partido Socialista Unificado de Cataluña (PSUC) y Partido Comunista de España (PCE), entre otros.

- Documentación de destacados dirigentes políticos republicanos.

- Documentación de carácter sindical. Documentación de sindicatos y asociaciones, sociedades y consejos obreros y de empleados diversos: Confederación Nacional del Trabajo (CNT), Unión General de Trabajadores (UGT), sindicatos agrarios y colectividades agrarias campesinas, asociaciones de trabajadores portuarios, etc. 
- Documentación de carácter militar y de cuerpos militarizados: Regiones militares, Brigadas Internacionales, Brigadas Mixtas, Guardia Civil, Cuerpo de Carabineros, Guardia de Asalto, etc.

- Documentación masónica, de logias y de personalidades ligadas a la masonería.

- Documentación económica. Documentación bancaria, del Banco de Aragón, del Banco de Vizcaya, etc.

IV. Para el traslado de la documentación al Archivo central de Salamanca, desde los archivos o depósitos documentales creados en localidades, en el frente, o en las grandes ciudades o capitales de provincia, se utilizaron:

- El ferrocarril. Los transportes militares ferroviarios.

- Camiones. Una flotilla de camiones, creada en el propio Archivo central de Salamanca.

- Envíos o correos, directamente, desde el organismo del que se tratase, el Ayuntamiento de un municipio, un ministerio, etc., al Archivo central de Salamanca.

\begin{tabular}{|c|c|c|c|}
\hline Requisiciones & Ferrocarril & Carretera & Otros \\
\hline Alicante & Alicante-Salamanca & & \\
\hline Aragón & Zaragoza-Salamanca & & \\
\hline Cataluña & $\begin{array}{c}\text { Barcelona-Zaragoza- } \\
\text { Salamanca }\end{array}$ & $\begin{array}{l}\text { Barcelona-Zaragoza- } \\
\text { Salamanca }\end{array}$ & $\begin{array}{l}\text { Correos / } \\
\text { Envíos }\end{array}$ \\
\hline Extremadura & $\begin{array}{c}\text { Don Benito-Mérida- } \\
\text { Salamanca }\end{array}$ & $\begin{array}{l}\text { Don Benito-Mérida- } \\
\text { Salamanca }\end{array}$ & \\
\hline Lérida & Lérida-Zaragoza-Salamanca & & \\
\hline Madrid & Madrid-Salamanca & Madrid-Salamanca & $\begin{array}{c}\text { Correos / } \\
\text { Envíos }\end{array}$ \\
\hline Valencia & $\begin{array}{c}\text { Valencia-Cuenca-Madrid- } \\
\text { Salamanca }\end{array}$ & $\begin{array}{l}\text { Valencia-Madrid- } \\
\text { Salamanca }\end{array}$ & \\
\hline
\end{tabular}

Tabla 5.25. Envío de la documentación a la Delegación

V. Finalmente, las especificidades que se produjeron en cada gran ciudad o capital de provincia y área geográfica a la hora de realizar las requisiciones. Estas especificidades tienen que ver, fundamentalmente, con los competidores / colaboradores con los que los equipos de recuperación de documentos del Archivo central de Salamanca se encontraron al realizar las requisiciones. 
Así pues, las instituciones competidoras / colaboradoras con las que el Archivo central de Salamanca y sus equipos de recuperación de documentos se encontraron, a la hora de realizar las requisiciones, fueron los siguientes:

1.- Brigada Político-Social de la Dirección General de Seguridad del Ministerio de la Gobernación.

2.- Sección 4a , Antimarxismo, de la Comisaría General de Información de la Dirección General de Seguridad del Ministerio de la Gobernación.

3.- Servicio de Investigación de Falange Española Tradicionalista y de las JONS.

4.- $2^{a}$ Sección, Información, del Estado Mayor del Ejército del Sur, del general Gonzalo Queipo de Llano.

5.- Servicio de Información y Policía Militar (SIMP).

6.- Servicio Histórico Militar / Archivo Histórico Militar de Madrid. 


\section{CONCLUSIONES GENERALES}


Las conclusiones a las que se ha llegado en esta tesis doctoral son las siguientes:

I. La Oficina de Investigación y Propaganda Anticomunista y la Delegación Nacional de Asuntos Especiales, en un primer momento, y fundamentalmente la Delegación del Estado para Recuperación de Documentos, a partir de abril de 1938, nacidas en tiempo de guerra, fueron creadas para llevar a cabo la requisición de documentos, herramienta imprescindible sin la cual no hubiera podido desarrollarse la represión durante la Guerra Civil y la posguerra, Estos órganos, dedicados a la incautación de documentos pertenecientes al enemigo, nacieron en un contexto político institucional creado para ganar una guerra. La requisición de documentos fue la herramienta mediante la cual se pudo desarrollar la represión durante la Guerra Civil y la posguerra. Para ello, se crearon la Oficina de Investigación y Propaganda Anticomunista, la Delegación Nacional de Asuntos Especiales y, finalmente, la Delegación del Estado para Recuperación de Documentos.

Las funciones de los tres órganos fueron cambiando. En un primer momento, para la Oficina de Investigación y Propaganda Anticomunista, las funciones consistieron en recoger, analizar y catalogar la documentación. Para la Delegación Nacional de Asuntos Especiales, las funciones fueron recuperar, ordenar y clasificar toda la documentación. Finalmente, para la Delegación del Estado para Recuperación de Documentos, las funciones archivísticas a desempeñar fueron la recogida, custodia y clasificación de la documentación.

El enemigo al que requisar la documentación se fue ampliando. En un primer momento, el enemigo fue el comunismo, por que la Oficina de Investigación y Propaganda Anticomunista se dedicó a requisar la documentación de aquellas organizaciones que consideraba comunistas como las logias masónicas, la Liga de los Derechos del 
Hombre, el Socorro Rojo Internacional, los Ateneos libertarios y la Federación de Trabajadores de la Enseñanza. Poco después, la Delegación Nacional de Asuntos Especiales tuvo como objeto específico recuperar la documentación de las logias masónicas, con el objetivo de perseguir y sancionar a los miembros de la masonería. Finalmente, la Delegación del Estado para Recuperación de Documentos tuvo como objetivo la requisición de los documentos de todos los enemigos del Estado franquista, para, también, proceder a su posterior encausamiento.

II. El perfil del archivero que trabajó en la Delegación, a partir del año 1938, en Salamanca, es el de una persona cualificada, puesto que, aunque pudiera haberse dedicado a otra profesión con anterioridad, tenía estudios superiores o los estaba realizando en ese momento, en concreto, con formación jurídica, licenciado o estudiante de Derecho, y que no llegaba a ejercer la profesión de archivero más de medio año, por lo que el grado de temporalidad, en la Delegación, era muy elevado. El trabajo en la Delegación, para estas personas, fue temporal, ocasional, debido, en muchos casos, a la coyuntura histórica de la propia Guerra Civil y a la dureza existencial de la posguerra, y, por tanto, cuando les surgió una oportunidad laboral mejor, no dudaron en abandonar la Delegación. Los trabajadores eran naturales, mayoritariamente, de las provincias de Navarra y de Salamanca, y de orientación política carlista, el natural de Navarra, o afiliado a Falange Española Tradicionalista y de las Juntas de Ofensiva Nacional Sindicalista (FET de las JONS), el natural de la provincia de Salamanca o procedente del resto de España.

III. La sede de la Delegación del Estado para Recuperación de Documentos fue el edificio San Estanislao de Kostka. A pesar de tener que compartir el edificio con otros cinco organismos y con la propia comunidad de religiosos jesuitas propietaria del inmueble recién regresada al mismo, y de las precarias instalaciones del edificio para la conservación documental, la Delegación se instaló allí por las ventajas que presentaba el edificio: su buen emplazamiento, alejado del casco histórico de la ciudad, ante posibles bombardeos aéreos; su buena comunicación con la estación de ferrocarril, por la que fue enviada a la Delegación gran parte de la documentación requisada; y, su buen equipamiento, ya que el edificio contaba con unas sólidas estanterías y unas 
dependencias que permitieron desarrollar el trabajo archivístico a realizar por la Delegación.

IV. La requisición de documentos, llevada a cabo por los equipos de recuperación de documentos de la Delegación, se encontraba perfectamente reglada y normativizada, incluyendo las inspecciones, aunque las requisiciones sufrieran alguna disfunción sobre el terreno.

La documentación requisada fue enviada a la Delegación por medio del ferrocarril, aprovechándose de los transportes militares; por carretera, empleando una flota de camiones y vehículos para ello; y, por correo postal.

La actuación de los equipos de recuperación de documentos, y su consecuencia, la requisición documental, dio lugar a la creación de una red de archivos, dependientes de la Delegación o Archivo central de Salamanca.

Con la documentación requisada, se hicieron agrupaciones documentales que fueron clasificadas aplicando el principio de procedencia geográfica. Dentro de cada agrupación documental, se respetaba el orden interno en el que los archivos institucionales o particulares eran enviados a la Delegación, habiendo, así, cierto respeto al principio de procedencia de los fondos. Hubo excepciones, como las agrupaciones documentales de Propaganda y Prensa, que fueron clasificadas por materias.

La explotación de la información contenida en la documentación requisada dio lugar al Fichero General, formado por un total de 2.701.953 fichas.

Finalmente, hay que destacar que las autoridades archivísticas siguieron el trabajo archivístico realizado en la Delegación.

V. Los equipos de recuperación de documentos de la Delegación, encargados de realizar las requisiciones, actuaron en los frentes de guerra y en las grandes capitales de provincia. 
Marcelino de Ulibarri y Eguílaz fue el encargado de, entre el personal del Archivo central de Salamanca y como director del mismo, formar los equipos de recuperación de documentos, encargados de realizar las requisiciones. Tanto en los frentes de guerra como en alguna de las grandes capitales conquistadas (Madrid y Valencia), la acción de los equipos de recuperación de documentos fue coordinada por Manuel Martín Sastre. Los equipos de recuperación de documentos estaban formados por un jefe, un asesor y ayudantes. El jefe, en la documentación estudiada, daba el nombre al equipo.

Con la excepción de los casos concretos de las requisiciones realizadas en el Centro Israelita “Agudad Ahim” de Barcelona, en Cádiz, en Cartagena y en Jaén, y por regla general, los equipos de recuperación de documentos se desplazaron, desde Salamanca o desde otros frentes o capitales donde hubieran actuado previamente, a los frentes de guerra recientemente caídos y a las capitales tras ser inmediatamente tomadas.

En el caso de los frentes de guerra, los equipos de recuperación de documentos se desplazaban a los mismos. En una localidad estratégicamente situada, el jefe del primer equipo que llegaba a la zona, fijaba el campamento base para las futuras actuaciones en la zona de los equipos de recuperación de documentos, así como habilitaba uno o varios depósitos de la documentación por requisar. Asimismo, se entrevistaba él, o cada de jefe de equipo, con el general o generales que actuaban militarmente en la zona, para obtener los permisos y salvoconductos necesarios para que cada equipo de recuperación de documentos actuase en la zona. Una vez conseguido todo esto, la metodología propiamente dicha, seguida por los equipos de recuperación de documentos, en las zonas o áreas geográficas correspondientes a los frentes recién caídos, Aragón (Maestrazgo turolense), provincia de Castellón, Extremadura ("bolsa de la Serena”, en Badajoz), Asturias, Lérida y Vinaroz (Bajo Maestrazgo castellonense), fueron las expediciones, en las que, a modo de razias, se procedía al registro de las localidades recién tomadas por el Ejército franquita, en busca de un botín en forma de documentación de interés.

En el caso de las grandes ciudades y capitales de provincia, Madrid, Barcelona, Bilbao, Alicante y Santander, la metodología seguida por los equipos de recuperación de documentos fue la de dedicarse a la inspección sistemática de organismos oficiales y 
domicilios particulares, desde el primer momento en que las ciudades eran tomadas, ciudades donde también se habilitaron uno o varios locales a modo de depósitos documentales.

La tipología de la documentación requisada fue de carácter administrativo, político, sindical, militar y de cuerpos militarizados, masónica y económica.

Finalmente, las especificidades que se produjeron en cada gran ciudad o capital de provincia y área geográfica a la hora de realizar las requisiciones. Estas especificidades tienen que ver, fundamentalmente, con los competidores / colaboradores con los que los equipos de recuperación de documentos del Archivo central de Salamanca se encontraron al realizar las requisiciones.

Así pues, las instituciones competidoras / colaboradoras con las que el Archivo central de Salamanca y sus equipos de recuperación de documentos se encontraron, a la hora de realizar las requisiciones, fueron los siguientes:

1.- Brigada Político-Social de la Dirección General de Seguridad del Ministerio de la Gobernación.

2.- Sección $4^{\mathrm{a}}$, Antimarxismo, de la Comisaría General de Información de la Dirección General de Seguridad del Ministerio de la Gobernación.

3.- Servicio de Investigación de Falange Española Tradicionalista y de las JONS.

4.- $2^{\text {a }}$ Sección, Información, del Estado Mayor del Ejército del Sur, del general Gonzalo Queipo de Llano.

5.- Servicio de Información y Policía Militar (SIMP).

6.- Servicio Histórico Militar / Archivo Histórico Militar de Madrid.

Esta tesis no pone fin a las líneas de investigación que quedan abiertas y son múltiples, a modo de ejemplo: la metodología archivística aplicada en la Dirección General de Seguridad bajo la dirección de Mola y su influencia en la metodología archivística seguida en la Delegación 


\section{FUENTES}




\section{FUENTES ARCHIVÍSTICAS}

\section{Archivo General de la Guerra Civil Española (AGGCE) del Centro Documental de la Memoria Histórica de Salamanca (CDMH)}

Delegación Nacional de Servicios Documentales (Fondo). Administración A (Serie). Ocho cajas, de la ADMON - A 1 (1-3) a la ADMON - A 8 (11-13).

Delegación Nacional de Servicios Documentales (Fondo). Administración. Expedientes (Serie). Diez cajas, de la Caja ADMON 001-020 a la Caja ADMON 371-430.

Delegación Nacional de Servicios Documentales (Fondo). Secretaría General. Expedientes Secretaría (Serie). Veintidós cajas, de la Caja S.G. 001-045 a la Caja S.G. 970.

Delegación Nacional de Servicios Documentales (Fondo). Secretaría. Correspondencia (Serie). Sesenta y tres cajas, de la Caja 001-032 a la Caja 2060-2064.

Delegación Nacional de Servicios Documentales (Fondo). Presidencia (Serie). Ciento dos cajas, de la Caja 001-002 a la Caja 118.

Delegación Nacional de Servicios Documentales (Fondo). Sección Político-Social. PSAlicante. Ciento ochenta cajas.

Delegación Nacional de Servicios Documentales (Fondo). Sección Político-Social. PSAragón. Ciento cuarenta y cinco cajas.

Delegación Nacional de Servicios Documentales (Fondo). Sección Político-Social. PSCádiz. Seis cajas.

Delegación Nacional de Servicios Documentales (Fondo). Sección Político-Social. PSCartagena. Sesenta cajas.

Delegación Nacional de Servicios Documentales (Fondo). Sección Político-Social. PSExtremadura. Treinta y nueve cajas.

Delegación Nacional de Servicios Documentales (Fondo). Sección Político-Social. PSJaén. Veintiséis cajas.

Delegación Nacional de Servicios Documentales (Fondo). Sección Político-Social. PSLérida. Sesenta y cinco cajas.

Delegación Nacional de Servicios Documentales (Fondo). Sección Político-Social. PSVinaroz. Trece cajas. 


\section{Archivo del Congreso de los Diputados (ACD)}

Documentación Electoral (Serie)

Expediente relativo al Diputado en Cortes don Ramón Serrano Suñer.

Expediente relativo al Procurador en Cortes don Marcelino de Ulibarri y Eguílaz.

\section{Archivo General de Navarra (AGN)}

Archivo y Museo Provincial. Caja 40246. Carpetas 1, 2 y 3.

\section{FUENTES JURÍDICAS}

\section{Hemeroteca de la Universidad de Salamanca (HUSA)}

\section{Normas legales}

\section{Boletines oficiales}

\section{Gaceta de Madrid}

Real Decreto, de 10 de septiembre de 1896, por el que se crean, en las cárceles del Reino, el servicio de identificación antropométrica, en Gaceta de Madrid, $n^{\circ}$ 258, del 14 de septiembre de 1896.

Real Decreto, de 22 de noviembre de 1901, de aprobación del Reglamento para el régimen y gobierno de los Archivos del Estado, publicado en la Gaceta de Madrid, $n^{o}$ 330, del 26 de noviembre de 1901.

Real Decreto, de 1 de febrero de 1904, por el que se procedió a la división de funciones en el Gabinete o Registro Central, de penados y rebeldes, con la finalidad de que el Registro antropométrico suministre, a los Tribunales de Justicia, cuantos antecedentes le fueran demandados, en Gaceta de Madrid, $n^{\circ}$ 33, del 2 de febrero de 1904.

\section{Boletín Oficial del Estado}

Ley, de 1 de octubre de 1936, estableciendo la Organización administrativa a que ha de ajustarse la nueva estructuración del Estado, en Boletín Oficial del Estado, $n^{o} 1$, del 2 de octubre de 1936. 
Norma general, de 5 de octubre de 1936, para el funcionamiento de la Junta Técnica del Estado, en Boletín Oficial del Estado, $n^{\circ} 2$, del 6 de octubre de 1936.

Instrucciones, de 5 de octubre de 1936, para el desenvolvimiento de los cometidos asignados en el artículo tercero de la Ley, de 1 de octubre de 1936, en Boletín Oficial del Estado, $n^{\circ} 2$, del 6 de octubre de 1936.

Decreto, $\mathrm{n}^{\circ}$ 14, de 4 de octubre de 1936, en Boletín Oficial del Estado, $n^{o} 2$, del 6 de octubre de 1936.

Orden, de 2 de noviembre de 1936, en Boletín Oficial del Estado, $n^{\circ} 21$, del 4 de noviembre de 1936.

Decreto, $\mathrm{n}^{\circ}$ 58, de 5 de noviembre de 1936, en Boletín Oficial del Estado, $n^{\circ} 22$, del 5 de noviembre de 1936.

Reglamento, de 19 de noviembre de 1936, de procedimiento de la Junta Técnica del Estado, en Boletín Oficial del Estado, $n^{\circ} 14$, del 19 de noviembre de 1936.

Decreto, $\mathrm{n}^{\mathrm{o}}$ 255, de 19 de abril de 1937, en Boletín Oficial del Estado, $n^{\circ}$ 182, del 20 de abril de 1937.

Decreto, $\mathrm{n}^{\circ}$ 262, de 22 de abril de 1937, en Boletín Oficial del Estado, $n^{\circ}$ 187, del 25 de abril de 1937.

Ley, de 30 de enero de 1938, de Administración General del Estado, en Boletín Oficial del Estado, $n^{\circ} 467$, del 31 de enero de 1938.

Decreto, del Ministerior del Interior, de 26 de abril de 1938, de creación de la Delegación del Estado para Recuperación de Documentos, en Boletín Oficial del Estado, $n^{\circ} 553$, del 27 de abril de 1938.

Decreto, del Ministerio de Justicia, restableciendo en España la Compañía de Jesús, en Boletín Oficial del Estado, $n^{\circ} 563$, de 7 de mayo de 1938.

Ley, de 9 de febrero de 1939, de Responsabilidades Políticas, publicada en el Boletín Oficial del Estado, $n^{\circ} 44$, de 13 de febrero de 1939.

Ley, de 1 de marzo de 1940, de Represión de la Masonería y el Comunismo, publicada en el Boletín Oficial del Estado, $n^{\circ}$ 62, de 2 de marzo de 1940.

Decreto del Ministerio de Educación Nacional, de 24 de julio de 1947, sobre Ordenamiento de los Archivos y Bibliotecas, y del Tesoro histórico-documental y bibliográfico, publicado en el Boletín Oficial del Estado, $n^{\circ} 229$, del 17 de agosto de 1947. 
Decreto, de 21 de febrero de 1958, de Presidencia de Gobierno, por el que se dispone que la Sección Político-Social de la Delegación Nacional de Servicios Documentales quede integrada en la Dirección General de Seguridad, publicado en el Boletín Oficial del Estado, $n^{\circ} 49$, del 26 de febrero de 1958.

Ley 154/1963, de 2 de diciembre de 1963, sobre la creación del Juzgado y Tribunales de Orden Público, publicada en el Boletín Oficial del Estado, $n^{\circ} 291$, del 5 de diciembre de 1963.

Decreto 248/1964, de 8 de febrero, por el que se dan normas para la liquidación del Tribunal creado poor Ley de 1 de marzo de 1940 y se establece una Comisión para el cumplimiento de la diposición transitoria tercera de la Ley 154/1963, publicado en el Boletín Oficial del Estado, $n^{\circ}$ 36, del 11 de febrero de 1964.

Real Decreto 3025/1976, de 23 de diciembre, complementario del Decreto 670/1976, de 5 de marzo, por el que se regulan pensiones a favor de los españoles que habiendo sufrido mutilaciones a causa de la pasada contienda no estén integrados en el Cuerpo de Caballeros Mutilados de Guerra por la Patria, publicado en el Boletín Oficial del Estado, $n^{\circ}$ 9, del 11 de enero de 1977.

Real Decreto 2761/1977, de 28 de octubre, de Presidencia del Gobierno, por el que se reorganiza la Presidencia del Gobierno, publicado en el Boletín Oficial del Estado, $n^{o}$ 267, del 8 de noviembre de 1977.

Orden, de 7 de mayo de 1979, del Ministerio de Cultura, por la que se dispone se adscriba, al Archivo Histórico Nacional, los fondos documentales de la extinguida Sección de Servicios Documentales, formando, en el mismo, una División independiente, publicada en el Boletín Oficial del Estado, $n^{\circ} 148$, del 21 de junio de 1979.

\section{Repertorios legislativos}

Martínez Alcubilla, Marcelo., Diccionario de la Administración Española, peninsular y ultramarina. Compilación ilustrada de la Novísima Legislación de España en todos los ramos de la Administración pública. Madrid, Administración, 1868-1923. 


\section{FUENTES HEMEROGRÁFICAS}

\section{Hemeroteca de la Universidad de Salamanca (HUSA)}

Publicaciones periódicas

\section{Periódicos}

ABC (edición de Sevilla)

"Disposiciones Oficiales", en diario $A B C$, del 13 de mayo de 1938.

"El día de la victoria en Sevilla", en diario $A B C$, del 2 de abril de 1944.

\section{REFERENCIAS BIBLIOGRÁFICAS}

ÁlVAREZ JunCO, José., "El conservadurismo español, entre religión y nación”, en CASTELlS ARTECHE, Luis (coord.)., Del territorio a la nación: identidades territoriales y construcción nacional. Alicante, Biblioteca Nueva, 2016, pp. 39-63.

Aróstegui, Julio., La Guerra en Alicante. Alicante, Instituto Juan Gil-Albert, 1986.

Ayala, José Antonio., "Revolución, derechos individuales y masonería. Las ligas españolas de derechos del hombre (1913-1936)", en FERRER BENIMELI, José Antonio (coord.)., Masonería, revolución y reacción. Symposium Internacional de Historia de la Masonería Española. Alicante, Diputación Provincial de Alicante. Instituto Alicantino de Cultura Juan Gil-Albert, 1990, pp. 123-143.

AzCona, José Manuel ., Los desastres de la Guerra Civil Española: la represión en Bilbao, julio de 1936-junio de 1939. Madrid, Dykinson, 2007.

Aznar Soler, Manuel., Valencia capital de la República. Valencia, Publicaciones de la Universidad, 2007.

Ballard, Brigid.; Clanchy, John., Cómo se hace un trabajo académico. Guía práctica para estudiantes universitarios. Zaragoza, Prensas Universitarias, 2000.

BARRUSO BARÉS, Pedro., Información, Diplomacia y Espionaje. La Guerra Civil Española en el Sur de Francia, 1936-1940. San Sebastián, Hiria Liburuak, 2008.

Bello Urgellès, Carmen.; Borrell Crehuet, Ángels., El patrimonio bibliográfico y documental. Gijón, Trea, 2001. 
Blanco Escolá, Carlos., Vicente Rojo, el General que humilló a Franco. Barcelona, Planeta, 2003.

BRANCIFORTE, Laura María., "El Socorro Rojo Internacional y su intervención en España", en Congreso La Guerra Civil Española, 1936-1939. Madrid, Sociedad Estatal de Conmemoraciones Culturales, 2006.

Bullón DE MENDOZA, Alfonso., La primera guerra carlista. Madrid, Universidad Complutense, 2001.

Chaves Palacios, Julián., La Guerra Civil en Extremadura: Operaciones militares, 1936-1939. Mérida, Editorial Regional de Extremadura, 1997.

Coвo Romero, Francisco., La Guerra Civil y la represión franquista en la provincia de Jaén, 1936-1950. Jaén, Diputación Provincial de Jaén, 1993.

CRUANyes I TOR, Josep., Els papers de Salamanca. L'espoliació del patrimoni documental de Catalunya, 1938-1939. Barcelona, Edicions 62, 2003.

CRuz Mundet, José Ramón., Archivística. Gestión de documentos y administración de archivos. Madrid, Alianza Editorial, 2012.

DíAZ CARRERA, Carmen., La catalogación de materiales especiales. Gijón, Trea, 2008.

DiReCción DE ARChIVOS EstatAles., Diccionario de Terminología Archivística. Madrid, Ministerio de Cultura, 1993.

DíEZ De los Ríos SAn JuAn, María Teresa, et alii., "La Sección Guerra Civil del Archivo Histórico Nacional (Salamanca)", en AA.VV., La II República española. Ponencias presentadas al Coloquio Internacional sobre la II República española, celebrado en Zaragoza del 7 al 10 de abril de 1981. Barcelona, Universidad de Barcelona, 1983, pp. 23-34.

DíEz DE los Ríos San JuAn, María Teresa., "La Sección Guerra Civil del Archivo Histórico Nacional", en AA.VV., Archivos para la Historia del Movimiento Obrero español. XV Conferencia de la IALHI, celebrada del 25 al 28 de septiembre de 1984 en Madrid. Madrid, Fundación Pablo Iglesias, 1985, pp. 23-34.

DíEz DE los Ríos SAn JuAn, María Teresa., "Estado actual de la Sección Guerra Civil del Archivo Histórico Nacional", en Studia Histórica. Historia Contemporánea, $n^{o} 3$. Salamanca, Universidad de Salamanca, 1985, pp. 129-135.

DíEZ De los Ríos SAN JuAn, María Teresa., Inventari de la documentació de la Generalitat de Catalunya al Archivo Histórico Nacional, Sección Guerra Civil. Barcelona, Generalitat de Catalunya, 1992.

Eco, Umberto., Cómo se hace una tesis doctoral. Técnicas y procedimientos de investigación, estudio y escritura. Barcelona, Gedisa, 1998. 
EsPinOSA Romero, Jesús.; Rodríguez LóPEZ, Sofía., "El Archivo de la Guerra Civil de Salamanca: de la campaña a la transición", en AA.VV., Paseo documental por el Madrid de antaño. Madrid, Universidad Complutense de Madrid, 2015, pp. 131-155.

EsPinOSA ROMERO, Jesús., "La Delegación del Estado para Recuperación de Documentos en Madrid", en AA.VV., Madrid, una ciudad en guerra, 1936-1938. Madrid, Catarata, 2016, pp. 133-158.

Fernández Álvarez, Manuel., Diario de un estudiante en tiempos de la Guerra Civil. Barcelona, Espasa, 2007 (memorias del que fuera trabajador del Archivo de la Delegación, durante su infancia en Oviedo y otros lugares, mucho antes de que llegase a ser Catedrático de Historia Moderna de la Universidad de Salamanca).

Fito MantecA, Francisco Javier., "La documentación anticomunista y el Archivo de Salamanca: el viaje de María de Smeth, el Antikomintern y la Delegación para Recuperación de Documentos", en Archivamos, $n^{o}$ 101. Salamanca, ACAL, 2016, pp. 40-47.

Gallego Domínguez, Olga., Manual de Archivos familiares. Madrid, ANABAD, 1993.

Generelo, Juan José.; Moreno LóPez, Ángeles., Historia de los Archivos y de la Archivística en España. Valladolid, Universidad de Valladolid, 1998.

GonZÁlez QuintanA, Antonio., "Fuentes para el estudio de la represión franquista en el Archivo Histórico Nacional, Sección Guerra Civil", en Espacio, Tiempo y Forma. Serie V. Historia Contemporánea, $n^{o}$ 7. Madrid, Universidad Nacional de Educación a Distancia (UNED), 1994, pp. 479-508.

JARAMILlO GuERREIRA, Miguel Ángel., "Los archivos y la Guerra Civil", en GENERElo, Juan José.; Moreno LóPEZ, Ángeles (coord.)., Historia de los Archivos y de la Archivística en España. Valladolid, Universidad de Valladolid, 1998, pp. 161-174.

MorA, José (coord.)., Represión, Derechos Humanos, Memoria y Archivos. Una perspectiva latinoamericana. Madrid, Ediciones GPS, 2010, pp. 189-227.

Gómez Gómez, Margarita., Fundación y ordenanzas del Archivo General de Indias. Su significación en la política archivística española. Sevilla, Universidad de Sevilla, 1993.

GóMEz GóMEz, Margarita., El sello y registro de Indias. Imagen y representación. Colonia, Böhlau Verlag Köln Weimar Wien, 2008.

HerRero FernándeZ-QuesadA, María Dolores., "La investigación en historia militar de la Edad Moderna y sus fuentes. El Archivo General Militar de Segovia, decano de los Archivos militares españoles", en Cuadernos de Historia Moderna, $n^{o}$ 38. Madrid, Universidad Complutense de Madrid (UCM), 2013, pp. 165-214. 


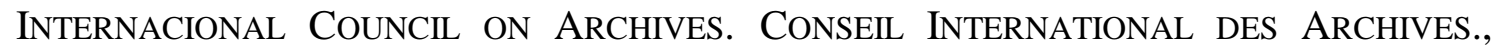
Dictionary of Archival Terminology. Dictionne de terminologie archivistique. English and French, with equivalents in Dutch, German, Italian, Russian and Spanish. New York, London, Paris, München, Peter Walne \& K.G. Saur, 1988.

Krajweski, Markus., Paper Machines. About Cards \& Catalogs, 1548-1929. Cambridge (Massachusetts), The Massachusetts Institute of Technology Press (MIT Press), 2011.

LLOPIS LLOPIS, Salvador., La prócer dama doña Inés Luna Terreros. Sus precedentes y familiares cercanos. Salamanca, Gráficas Cervantes, 2000.

Lodolini, Elio., Archivística. Principios y problemas. Madrid, ANABAD, 1993.

LóPEZ-Brea EsPiAu, Francisco; Soler Fuensanta, José Ramón., Soldados sin rostro. Los servicios de información, espionaje y criptografía en la Guerra Civil española. Barcelona, Inédita Ediciones, 2008.

LUEBBERT, Gregory M., Liberalismo, fascismo o socialdemocracia. Clases sociales y orígenes políticos de los regímenes de la Europa de entreguerras. Zaragoza, Prensas Universitarias de Zaragoza, 1997.

Luis MARTín, Francisco de., La FETE en la Guerra Civil Española, 1936-1939. Barcelona, Ariel, 2002.

MARChamalo, Jesús., Las Bibliotecas perdidas. Sevilla, Editorial Renacimiento, 2008.

MARTín MARTínEZ, Luis P., "Un instrumento de democracia: la Liga Española de los Derechps del Hombre, 1913-1936", en Derechos y libertades. Revista del Instituto Bartolomé de las Casas, $n^{\circ}$ 6. Madrid, Universidad Carlos III, 1998, pp. 377-396.

Martín RodríGuez, José Luis (coord.)., Actas del I Congreso de Historia de Salamanca. Tres Volúmenes. Salamanca, Diputación de Salamanca, 1992.

Martínez Alcubilla, Marcelo., Diccionario de la Administración Española, peninsular y ultramarina. Compilación ilustrada de la Novísima Legislación de España en todos los ramos de la Administración pública. Madrid, Administración, 1868-1923.

Martínez Reverte, Jorge., La caída de Cataluña, Barcelona, Crítica, 2006.

Mateo Marcos, Juan., Servicio de Información en Campaña. Madrid, Ediciones Ejército, 1942.

MAYer, Arno J., La persistencia del Antiguo Régimen. Europa hasta la Gran Guerra. Madrid, Alianza Editorial, 1986.

Mikelarena Peña, Fernando., Sin piedad. Limpieza política en Navarra, 1936. Responsables, colaboradores y ejecutores. Arre (Navarra), Pamiela, 2015. 
MikelarenA PeÑA, Fernando., "Estructura, cadena de mando y ejecutores de la represión de boina roja en Navarra en 1936", en Historia contemporánea, $n^{\circ}$ 53. Lejona (Vizcaya), Universidad del País Vasco, 2016.

Ministère des AfFAires Culturelles.; Association des ARChivistes FranÇAis., Manuel d'Archivistique. Théorie et practique des Archives publiques en France. Paris, S.E.V.P.E.N. Imprimiere Nationale, 1970.

Navarro Bonilla, Diego., Derrotado pero no sorprendido. Reflexiones sobre la información secreta en tiempos de guerra. Madrid, Plaza y Valdés Editores, 2007.

NAVARro Bonilla, Diego., "Explotación y trazabilidad del documento de archivo con fines de inteligencia para la seguridad y la defensa", en Tabula, $n^{\circ} 14$. Salamanca, ACAL, 2011, pp. 33-67.

NAVArro Bonilla, Diego., Morir mantando. Sevilla, Espuela de Plata, 2012.

NAVArro NAVARro, Francisco Javier., "Los Ateneos. Teoría y práctica en el movimiento libertario", en ChAPUT, Marie-Claude.; PÉREZ SERRANO, Julio (coords.)., De l'anarchime aux courants alternatifs XIXe-XXIe siècles. Nanterre, Universidad de París X, 2007, pp. 187-206.

Ollanquindia Aguirre, Ricardo., "La Oficina de Prensa y Propaganda Carlista de Pamplona al comienzo de la Guerra de 1936", en Príncipe de Viana, $n^{\circ}$ 205. Pamplona, Gobierno de Navarra, Institución Príncipe de Viana, 1995, pp. 485-505.

PEÑA, Daniel.; Romo, Juan., Introducción a la Estadística para las Ciencias Sociales. Madrid, McGraw-Hill, 1997.

Pescador Del Hoyo, María del Carmen., El Archivo. Instalación y Conservación. Madrid, Ediciones Norma, 1988.

Ponce AlbercA, Julio., "Los gobernadores civiles en el primer franquismo", en Hispania. Revista Española de Historia, $n^{o}$ 252. Madrid. Consejo Superior de Investigaciones Científicas, 2016.

RADClIFF, Pamela Beth., De la movilización a la Guerra Civil : historia de Gijón, 1900-1937. Barcelona, Debate, 2004.

Real ACAdemia EsPañola., Diccionario de la Lengua Española. Madrid, RAE \& Espasa Calpe, 2014 (23 ${ }^{\text {a }}$ edición).

Riesco Terrero, Ángel., Vocabulario científico-técnico de Paleografía, Diplomática y Ciencias afines. Madrid, Barrezo \& Acedo Ediciones, 2003.

Rivero OrtegA, Ricardo., El Expediente Administrativo. De los Legajos a los Soportes Electrónicos. Cizur Menor (Navarra), Thomson \& aranzadi, 2008. 
Robledo HernándeZ, Ricardo (coord.)., Historia de Salamanca. Tomo V. Siglo XX. Salamanca, Centro de Estudios Salmantinos, 2001.

RodríGUEZ DE DIEGO, José Luis., Instrucción para el gobierno del Archivo de Simancas. Año 1588. Madrid, Ministerio de Cultura, 1998 ( $1^{a}$ edición de 1989).

RodríGUEZ JiMÉNEZ, José Luis., Historia de la Falange Española de las JONS. Madrid, Alianza Editorial, 2000.

Rodríguez Simón, Pedro., Vestigios de la Guerra Civil en Aragón. Zaragoza. Diputación General de Aragón, 2011.

Rodríguez Velasco, Hernán., "Manuel Estrada Manchón”, en García Fernández, Javier (coord.)., Veinticinco Militares de la República. Madrid, Ministerio de Defensa, 2011, pp. 444-462.

RODRÍGUEZ VELASCO, Hernán., Una derrota prevista. El espionaje militar en la Guerra Civil española, 1936-1939. Granada, Comares, 2012.

Romero Tallafigo, Manuel., Historia del documento en la Edad Contemporánea. La comunicación y la representación del poder central de la nación. Carmona (Sevilla), Ediciones S\&C., 2002.

SABINE, George H., Historia de la Teoría Política. México, D.F., Fondo de Cultura Económica, 1976 ( $1^{\text {a }}$ edición de 1945).

SALAS LARRAZÁbal, Ramón., "Los Archivos para la Historia de la Guerra Civil", en AA.VV., Archivos para la Historia del Siglo XX. Madrid, Ministerio de Cultura, Dirección General de Bellas Artes, Archivos y Bibliotecas, 1980, pp. 111-141.

Seco Serrano, Carlos., Historia del Conservadurismo español. Madrid, Temas de Hoy, 2000.

Silva Catela, Ludmila da.; Jelin, Elizabeth., Los Archivos de la Represión. Documentos, memoria y verdad. Madrid, Siglo XXI, 2002.

Solla Gutiérrez, Miguel Ángel., La República sitiada: trece meses de Guerra Civil en Cantabria, julio de 1936-agosto de 1937. Santander, PubliCan, 2010.

THIERS, Adolphe., Historia de la Revolución francesa. Tomo X. San Sebastián, Ignacio Ramón Baroja, 1840.

TuRrión García, María José., "La Biblioteca de la Sección Guerra Civil del Archivo Histórico Nacional (Salamanca)", en Boletín de la ANABAD, $n^{\circ}$ 2. Madrid, ANABAD, 1997, pp. 89-114. 

